\title{
PROCESSO DE CRIAÇÃO DE ESTRATÉGIAS EM PEQUENAS EMPRESAS: \\ ELABORAÇÃO DE UM MAPA ESTRATÉGICO PARA EMPRESAS DE BASE TECNOLÓGICA DO PÓLO DE SÃO CARLOS/SP
}

Tese apresentada à Escola de Engenharia de São Carlos da Universidade de São Paulo para obtenção do título de Doutor em Engenharia de Produção.

Orientador: Prof. Associado Edmundo Escrivão Filho 
AUTORIZO A REPRODUÇÃO E DIVULGAÇÃO TOTAL OU PARCIAL DESTE TRABALHO, POR QUALQUER MEIO CONVENCIONAL OU ELETROONICO, PARA FINS DE ESTUDO E PESQUISA, DESDE QUE CITADA A FONTE.

Ficha catalográfica preparada pela Seçao de Tratamento da Informaçao do Serviço de Bblioteca - EESCUSP

\begin{tabular}{|c|c|}
\hline \multirow[t]{3}{*}{ T316p } & 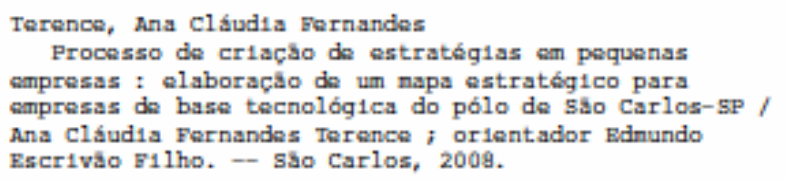 \\
\hline & $\begin{array}{l}\text { Tese (Doutorado-Programa de Pós-Graduaça e farea de } \\
\text { Concentraço em Engenhar1a de Produça) -- Escola de } \\
\text { Engenhar1a de săo Carlos da Un1wersidade de sấ Paulo, } \\
2008 \text {. }\end{array}$ \\
\hline & $\begin{array}{l}\text { 1. Pequena enpresa. 2. Estratég1a. 3. Enpresa de base } \\
\text { tecnológ1ca. 4. Mapa estratég1co. I. Titulo. }\end{array}$ \\
\hline
\end{tabular}




\section{FOLHA DE JULTIANENIO}

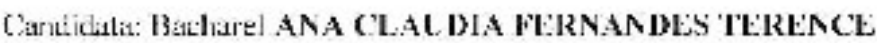

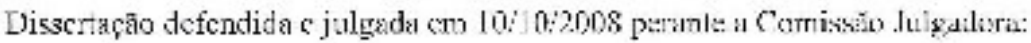

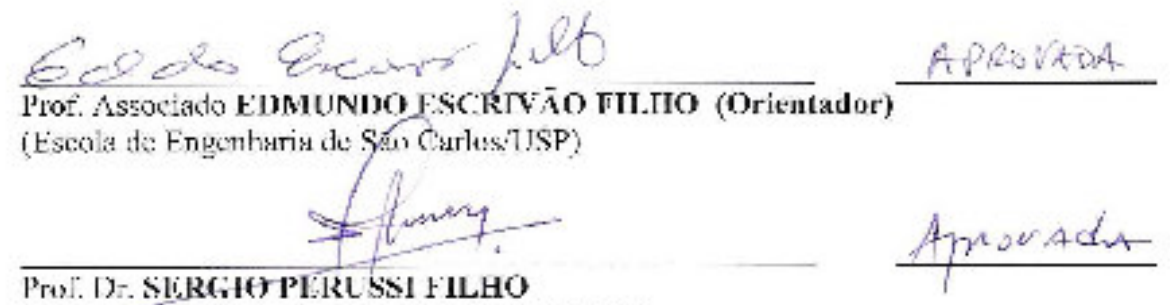

(Centen Tniversitärio Contral Paulistar'CNICTP)

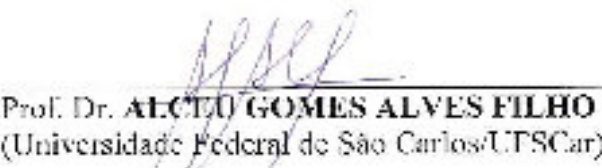

Aprovada

(Universidade Federal de Sà Car'osit:TSCar)

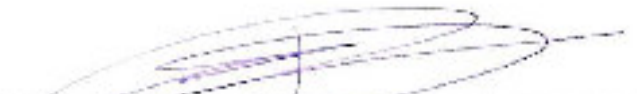

PTÓF ER TAL LO SLRGIO MURA YDA ME VTOONC,

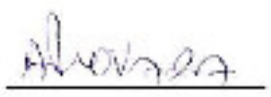

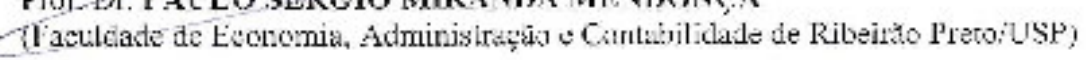

$$
\text { (i) } 202 .
$$

froranta.

Prol: litula: DANTE PIN HEMRO MARTINELLX

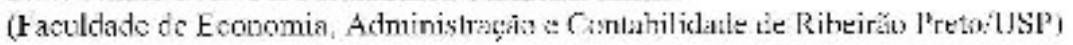

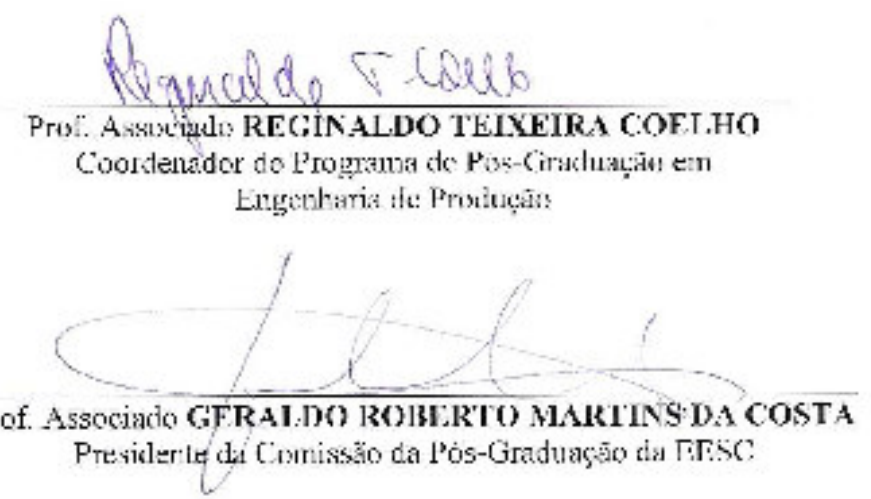





\section{DEDICATÓRIA}

Ao Maurício, ao Pedro e à Ana Luísa, com muito amor. 


\section{AGRADECIMENTOS}

Ao Prof. Dr. Edmundo Escrivão Filho que, com seu conhecimento e sua experiência me orientou com primazia em todas as etapas deste trabalho. Ao mestre que, no decorrer dos anos, se tornou um amigo, agradeço pela dedicação e desmedida compreensão diante das dificuldades enfrentadas para a concretização deste trabalho.

Ao Prof. Dr. Dante Pinheiro Martinelli, pelas valiosas contribuições, sugestões e proposições de reflexão que muito contribuíram para o resultado final desta pesquisa.

Ao Prof. Dr. Paulo Sérgio Miranda Mendonça, pelas contribuições fundamentais à estruturação e resultados da pesquisa.

Ao Prof. Dr. Alceu Gomes Alves Filho, pelo incentivo e pelas sugestões realizadas.

Ao Prof. Dr. Sérgio Perussi Filho, por compartilhar o seu conhecimento e a sua experiência.

Ao Prof. Dr. Antonio Sérgio Ferraudo, pelos ensinamentos de Estatística e pelo auxílio na análise quantitativa dos dados.

Agradeço aos meus familiares. Ao Maurício, pelo apoio, companheirismo e estímulo essenciais. Aos meus pais, Ederaldo e Cida que, mesmo distantes fisicamente, estiveram sempre presentes. Às minhas irmãs, Vânia e Sandra, sempre motivadoras. À Ana Maria e ao Renato, pelo constante estímulo à concretização desta etapa de minha vida acadêmica. À Ana Maria, por todo o cuidado e esmero na revisão ortográfica.

Aos amigos do Departamento de Engenharia de Produção, pelos momentos de descontração, alegria e companheirismo: Giseli, Kristiane, Jair, Aline, Stéfano e Edwin.

Aos amigos do Departamento de Economia Rural da Faculdade de Ciências Agronômicas e Veterinárias da UNESP, que me proporcionaram condições para conciliar as atividades de pesquisa e ensino, especialmente, à Ana Cláudia, Ana Paula, Maria Imaculada, Maria Inês, Maria Madalena, Rosemary e ao Baccarin e Gilberto. 
Aos funcionários do Departamento de Engenharia de Produção, em particular a José Luiz, Silvana, Luis Fernando e Daniel, pelo suporte oferecido para a realização deste trabalho.

Aos professores que gentilmente aceitaram participar das entrevistas, colaborando com seus conhecimentos e experiência: Prof. Dr. Milton Ferreira de Sousa, Prof. Dr. Carlos Aberto Fortulan, Prof. Dr. Sérgio Perussi Filho e Prof. Dr. Sylvio Goulart Rosa.

Aos dirigentes que disponibilizaram o seu precioso e escasso tempo para fornecer informações ao trabalho de campo: Marcos, Djalma, Edimar e Isabel. A vocês um agradecimento especial e desejo de muito sucesso.

Obrigada a todos. 


\section{EPÍGRAFE}

\section{A palavra mágica}

Certa palavra dorme na sombra de um livro raro.

Como desencantá-la?

É a senha da vida a senha do mundo. Vou procurá-la.

Vou procurá-la a vida inteira no mundo todo.

Se tarda o encontro, se não a encontro, não desanimo, procuro sempre.

Procuro sempre, e minha procura ficará sendo a minha palavra. 


\section{RESUMO}

TERENCE, A. C. F. (2008). Processo de criação de estratégias em pequenas empresas: elaboração de um mapa estratégico para empresas de base tecnológica do pólo de São Carlos/SP. 253 p. Tese (Doutorado) - Escola de Engenharia de São Carlos, Universidade de São Paulo, São Carlos, 2008.

O objetivo da pesquisa é elaborar um mapa estratégico que permita compreender o processo de criação de estratégias nas pequenas empresas de base tecnológica, a partir da identificação, descrição e sistematização dos inter-relacionamentos de variáveis que o influenciam. Abordase a criação de estratégias deliberadas e emergentes em um processo único, considerando as especificidades do dirigente-estrategista, do contexto das empresas de base tecnológica e da organização das empresas de pequeno porte. Como procedimento metodológico, optou-se pelo desenvolvimento da pesquisa em duas fases: a primeira, classificada como survey, realizada em trinta e três (33) empresas, com o objetivo de identificar as características gerais do processo de criação de estratégias, e a segunda, um estudo de caso, realizada para descrever e analisar os elementos específicos e formadores do processo de criação de estratégias em três (03) empresas localizadas no pólo de São Carlos/SP. O mapa estratégico destaca os seguintes aspectos: como elementos estruturais, a percepção estratégica, os processos deliberado e emergente, as fases evolutivas, as especificidades de gestão, as condições externas e internas, a formação contínua e a criação quântica da estratégia; como forças de configuração, o posicionamento na representação, a rotação das especificidades, a dinâmica das variáveis, o inter-relacionamento dos processos e a ocorrência de eventos marcantes. A partir da percepção do dirigente, o processo se desenvolve em fases nas quais a influência das especificidades de gestão da pequena empresa manifesta-se em diferentes intensidades, contemplando características emergentes e deliberadas em um processo evolucionário. O mapa estratégico possui a orientação como caráter peculiar e deve ser entendido como uma representação que se aproxima da realidade de um grupo de empresas, não sendo mais abrangente ou complexo que esta.

Palavras-chave: pequena empresa, estratégia, empresa de base tecnológica; mapa estratégico. 


\section{ABSTRACT}

TERENCE, A. C. F. (2008). Creational process of strategies in small business: elaboration of a strategic map for technology-based companies from São Carlos Technopolis, Brazil. 253 p. Tese (Doutorado) - Escola de Engenharia de São Carlos, Universidade de São Paulo, São Carlos, 2008.

The purpose of this research is to elaborate a strategic map that allows the understanding of the strategic process in small technology-based companies, through the systemization, description and identification of the inter-relationships between the variables that influence the process. The creation of deliberate and emerging strategies is approached as an unique process, considering the specificities of the manager, the context of the technology-based companies as well as the organization of a small business. As a methodological procedure, the research was developed in two phases: the first, classified as survey, was accomplished in thirty three (33) companies to identify the general characteristics of the process of strategies, and the second, a case study was accomplished to describe and analyze the specific elements which driven the process of strategies in three (03) companies from the São Carlos Technopolis, Brazil. The strategic map emphasizes the following aspects: as structural elements, the strategic perception, the deliberated and emerging processes, the evolutionary phases, the management specificities, the external and internal conditions, the continuous formation and the quantum creation of the strategy; as configuration forces, the positioning in the representation, the rotation of the specificities, the dynamics of the variables, the interrelationship of the processes and the occurrence of outstanding events. According the manager strategic perception, the process grows in phases where the influence of specificities of the small companies management are shown in different intensities, contemplating emerging and deliberate characteristics in a evolutionary process. The strategic map possesses the orientation as its peculiar character and should be understood as a representation that is closer to the reality of a group of companies, without being more or comprehensive complex than this own reality.

Keywords: small business, strategy, technology-based companies; strategic map. 


\section{LISTA DE FIGURAS}

Figura 1 - Variáveis que influenciam o processo de criação de estratégias em pequenas empresas de base tecnológica.

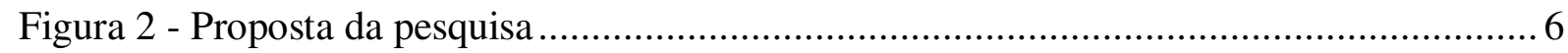

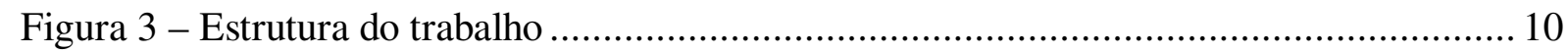

Figura 4 - Estrutura do capítulo estratégia ........................................................................ 11

Figura 5 - Fatores determinantes da competitividade da indústria .................................... 22

Figura 6 - Conceitos-chave estruturantes das escolas do pensamento estratégico .................. 30

Figura 7 - Sistema de Administração Estratégica formado por liderança, organização e ambiente.

Figura 8 - Estrutura do capítulo processo de criação de estratégia....................................... 34

Figura 9 - Linha contínua do processo de criação de estratégias ........................................... 35

Figura 10 - Processo deliberado de criação de estratégias ................................................... 37

Figura 11 - Processo emergente de criação de estratégias .................................................. 40

Figura 12 - Modelo de criação contínua da estratégia .......................................................... 42

Figura 13 - Processo emergente e deliberado: visão de coexistência ..................................... 44

Figura 14 - Processo deliberado e estratégico: visão de coexistência, interação e integração. 45

Figura 15 - Processo de administração estratégica .......................................................... 47

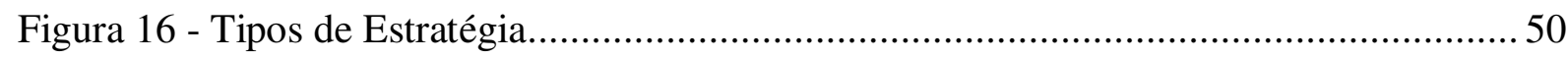

Figura 17 - Eventos determinantes dos modos de criação de estratégias ............................. 58

Figura 18 - Estrutura do capítulo: As pequenas empresas e suas especificidades ..................63

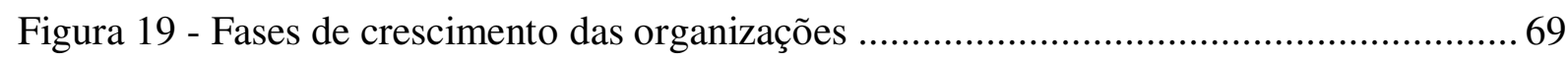

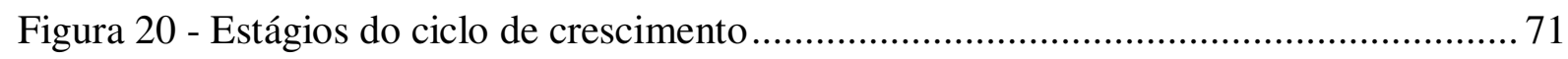

Figura 21 - Ciclo de vida organizacional, competitividade e capacidade de adaptação.......... 73

Figura 22 - Especificidades de gestão da pequena empresa............................................. 75

Figura 23 - Processo de criação de estratégia..................................................................... 84

Figura 24 - Perspectiva do dirigente no processo de criação de estratégias .......................... 85

Figura 25 - O impacto da inserção da tecnologia no ciclo de vida dos produtos .................... 93

Figura 26 - Influência da percepção do dirigente para a definição da política tecnológica e de inovação na empresa de pequeno porte.......................................................... 97

Figura 27 - Estrutura do capítulo trabalho de campo....................................................... 103 
Figura 28 - Ramo de atuação das empresas pesquisadas ............................................. 121

Figura 29 - Ramo de atuação e número de funcionários das empresas pesquisadas ............. 123

Figura 30 - Tempo médio de vida e número de funcionários das empresas ....................... 125

Figura 31 - Tempo de vida e número de funcionários por ramo de atuação........................ 125

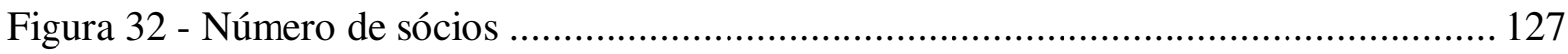

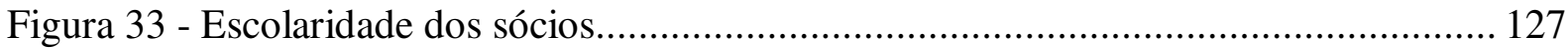

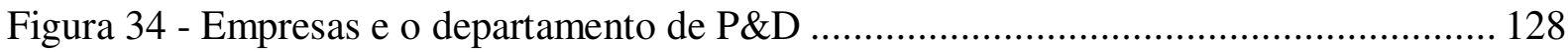

Figura 35 - Influência das variáveis ambientais .............................................................. 134

Figura 36 - Caracterização do dirigente estrategista........................................................ 137

Figura 37 - Características do dirigente estrategista com nível de precisão alto/muito alto.. 138

Figura 38 - Distribuição das empresas e projeção das variáveis determinantes nos dois primeiros componentes principais, CP1 e CP2 …......................................... 141

Figura 39 - Processo de criação de estratégias das EBT - grupo deliberado e emergente .... 142

Figura 40- Processo de criação de estratégias das EBT - grupo emergente, deliberado e misto.

Figura 41 - Processo de criação de estratégias - visão de um conglomerado e de empresas periféricas para CP1 e CP2 ......................................................................... 144

Figura 42 - Processo de criação de estratégias - visão de um conglomerado e de empresas periféricas (CP1 e CP3; CP1 e CP4; CP1 e CP5, CP1 e CP6)........................... 145

Figura 43 - Projeções tridimensionais das empresas e das variáveis determinantes para os três primeiros componentes principais, CP1, CP2 e CP3 ............................ 146

Figura 44 - Fases evolutivas e o processo de criação de estratégias..................................... 206

Figura 45 - Especificidades de gestão de acordo com as fases evolutivas........................... 208

Figura 46 - Especificidades rotacionadas de gestão no processo de criação de estratégia.... 210

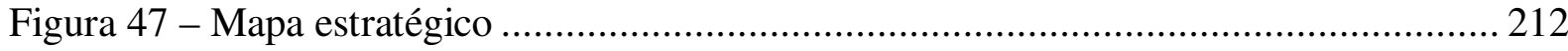




\section{LISTA DE TABELAS}

Tabela 1 - Classificação das empresas segundo o número de funcionários. 65

Tabela 2 - Características gerais das EBT 123

Tabela 3 - Porte das empresas de acordo com o número de funcionários 124

Tabela 4 - Faturamento das empresas, porte e tempo médio de vida 126

Tabela 5 - Empresas com departamento de P\&D. 128

Tabela 6 - Nível de estruturação de P\&D por ramo de atuação 128

Tabela 7 - Nível de estruturação de P\&D 129

Tabela 8 - Motivação para abertura das EBT 130

Tabela 9 - Caracterização do ambiente organizacional 133

Tabela 10 - Influência das variáveis ambientais na criação de estratégias 133

Tabela 11 - Caracterização da organização 135

Tabela 12 - Características das estratégias 139

Tabela 13 - Características do processo de criação de estratégias 140

Tabela 14 - Autovalores e variância dos componentes principais 252

Tabela 15 - Matriz dos componentes principais 252 


\section{LISTA DE QUADROS}

Quadro 1 - Evolução da estratégia nas organizações. 16

Quadro 2 - Elementos-chave na definição de estratégia 19

Quadro 3 - Escolas do pensamento estratégico: processo e características .... 29

Quadro 4 - Estratégia como arte e ciência.

Quadro 5 - Características dos processos deliberado e emergente de criação de estratégias... 43

Quadro 6 - Estruturas, processos e técnicas para a formação contínua de estratégia ..... 44

Quadro 7 - Modelo integrativo de formação de estratégias 56

Quadro 8 - Níveis de sofisticação do planejamento 86

Quadro 9 - Aspectos do processo deliberado e emergente nas pequenas empresas..... 87

Quadro 10 - Características das pesquisas qualitativa e quantitativa 109

Quadro 11 - Aspectos da metodologia da pesquisa

Quadro 12 - Dados gerais das entrevistas realizadas 118

Quadro 13 - Classificação das empresas segundo ramo de atuação e atividade econômica correspondente.

Quadro 14 - Atributos relacionados ao nível de incerteza do ambiente organizacional........ 132

Quadro 15 - Atributos relacionados à organização........................................................ 135

Quadro 16 - Características relacionadas ao perfil do dirigente........................................ 136

Quadro 17 - Variáveis selecionadas para a ACP ........................................................... 140

Quadro 18 - Apresentação geral das empresas investigadas na fase 2 ….......................... 149

Quadro 19 - Fases do processo de criação de estratégias da empresa A ............................ 167

Quadro 20 - Especificidades contextuais de acordo com as fases evolutivas: empresa A .... 169

Quadro 21 - Especificidades de organização de acordo com as fases evolutivas: empresa A.

Quadro 22 - Especificidades do dirigente-estrategista de acordo com as fases evolutivas: empresa A

Quadro 23 - Fases do processo de criação de estratégias da empresa B

Quadro 24 - Especificidades contextuais de acordo com as fases evolutivas: empresa B..... 179

Quadro 25 - Especificidades de organização de acordo com as fases evolutivas: empresa B

Quadro 26 - Especificidades do dirigente-estrategista de acordo com as fases evolutivas: empresa B

Quadro 27 - Fases do processo de criação de estratégias da empresa C.

Quadro 28 - Especificidades contextuais de acordo com as fases evolutivas: empresa C..... 189

Quadro 29 - Especificidades de organização de acordo com as fases evolutivas: empresa C..... 
Quadro 30 - Especificidades do dirigente estrategista de acordo com as fases evolutivas:

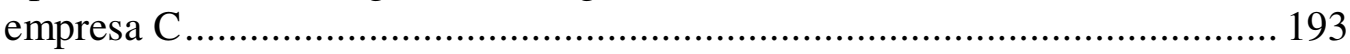

Quadro 31 - Fases do ciclo de vida das pequenas empresas ............................................ 207

Quadro 32 - Influência primária, secundária e terciária das especificidades de gestão de acordo com as fases evolutivas das EBT ..................................................... 209

Quadro 33 - Correlação das variáveis X Componentes Principais ...................................... 251 


\section{LISTA DE ABREVIATURAS E SIGLAS}

ACP - Análise dos Componentes Principais

ANPROTEC - Associação Nacional de Entidades Promotoras de Empreendimentos Inovadores

BCG - Boston Consulting Group

CEDIN - Centro de Indústrias Nascentes de São Carlos

CIESP - Centro das Indústrias do Estado de São Paulo

CP - Componentes Principais

EBT - Empresa de Base Tecnológica

EMBRAPA - Empresa Brasileira de Pesquisa Agropecuária

FAI - Fundação de Apoio Institucional ao Desenvolvimento Científico e Tecnológico

FAPESP - Fundação de Amparo à Pesquisa do Estado de São Paulo

FINEP - Financiadora de Estudos e Projetos

FITEC - Fundo de Incentivo à Pesquisa Técnico-Científica

GEOPE - Grupo de Estudos Organizacionais da Pequena Empresa

IBGE - Instituto Brasileiro de Geografia e Estatística

IPT - Instituto de Pesquisas Tecnológicas do Estado de São Paulo

MIT - Massachussetts Institute of Tecnology

MPE - Micro e Pequena empresa

P\&D - Pesquisa e Desenvolvimento

PARQTEC - Fundação Parque de Alta Tecnologia de São Carlos

PIB - Produto Interno Bruto

PIPE - Programa de Inovação Tecnológica em Pequenas Empresas

PNAD - Pesquisa Nacional por Amostra de Domicílios

RAIS/MTE - Relação Anual de Informações Sociais do Ministério do Trabalho e Emprego

SEBRAE - Serviço Brasileiro de Apoio às Micro e Pequenas Empresas

SENAI-SC - Serviço Nacional de Aprendizagem Industrial de Santa Catarina

SWOT - strengths, weaknesses, opportunities, threats

UFSCAR - Universidade federal de São Carlos

UNESP - Universidade Estadual Paulista Júlio de Mesquita Filho

USP - Universidade de São Paulo 


\section{SUMÁRIO}

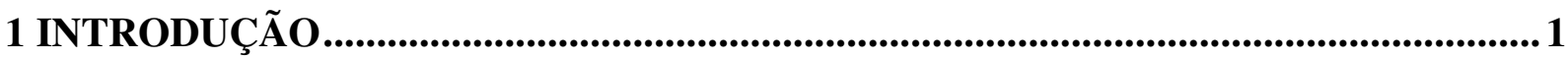

1.1 Caracterização do tema da pesquisa ............................................................................2

1.2 Formulação do problema da pesquisa................................................................................ 4

1.3 Objetivos da pesquisa...................................................................................................5

1.4 Relevância do tema e da pesquisa.........................................................................................

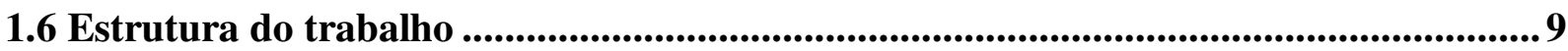

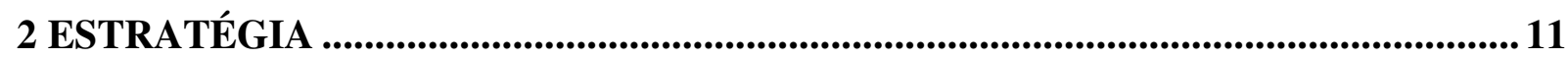

2.1 Estratégia e vantagem competitiva.................................................................................... 12

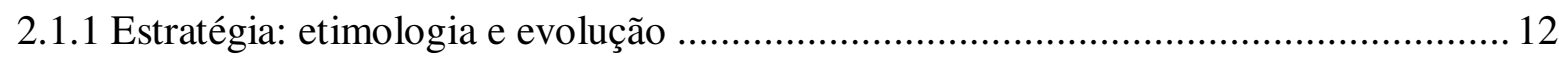

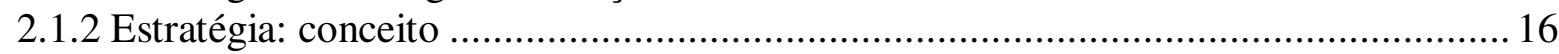

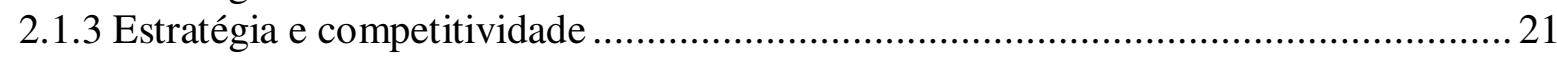

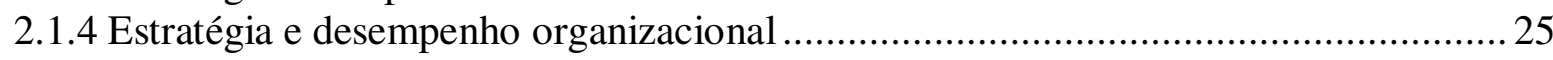

2.2 Como pensar a estratégia nas organizações? ......................................................................26

3 PROCESSO DE CRIAÇÃO DE ESTRATÉGIAS ...........................................................33

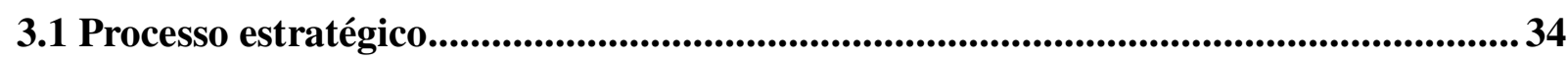

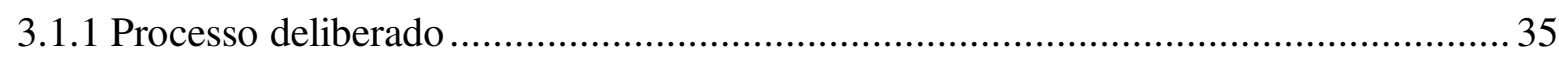

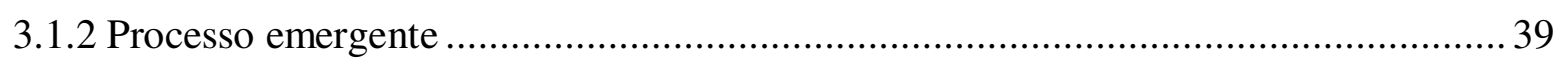

3.1.3 Considerações sobre o processo deliberado e emergente …………………………..... 41

3.2 Modelos do processo de criação de estratégia ..................................................................46

3.2.1 O processo deliberado de criação de estratégias: a visão de Hitt, Ireland e

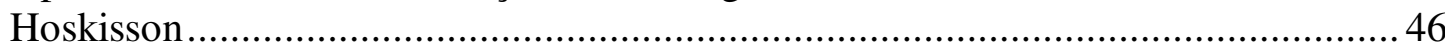

3.2.2 O incrementalismo lógico proposto por Quinn........................................................ 48

3.2.3 O processo de formação de estratégias deliberado e emergente: a visão de

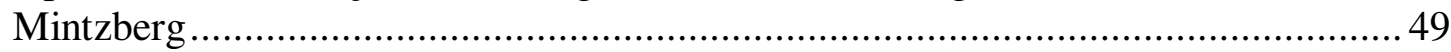

3.2.4 Os processos linear, adaptativo e interpretativo: a visão de Chaffee ...........................51

3.2.5 O modelo de construção de estratégias de Hart ......................................................54

3.2.6 Considerações sobre o processo de criação de estratégias .......................................... 56

$3.4 \mathrm{O}$ papel do estrategista..............................................................................................................59 
4 AS PEQUENAS EMPRESAS E SUAS ESPECIFICIDADES ..................................... 63

4.1 Pequenas empresas: relevância e critério de definição ................................................. 64

4.2 Ciclo de vida das organizações............................................................................... 68

4.3 Especificidades de gestão das pequenas empresas ...................................................... 74

4.3.1 Sobre as especificidades de organização da pequena empresa .............................. 75

4.3.2 Sobre as especificidades do dirigente da pequena empresa...................................... 77

4.3.3 Sobre as especificidades do contexto da pequena empresa ................................... 79

4.4 Processo de criação de estratégia na pequena empresa ................................................ 80

4.5 Empresas de base tecnológica ...............................................................................8 88

4.5.1 Características das empresas e contexto de base tecnológica ....................................91

4.5.2 $\mathrm{O}$ pequeno porte das empresas de base tecnológica........................................... 95

4.5.3 O processo de criação de estratégias das EBT ........................................................ 97

5 TIPOS E MÉTODOS DE PESQUISA ................................................................. 103

5.1 Abordagens de pesquisa: quantitativa e qualitativa ............................................... 104

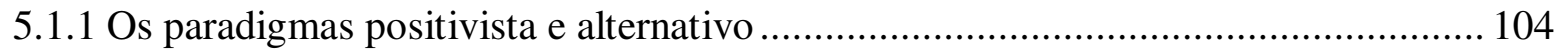

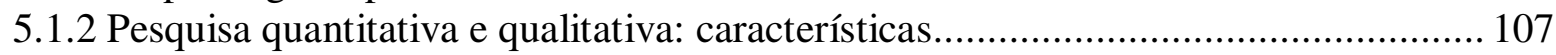

5.2 Métodos da pesquisa ............................................................................................................... 110

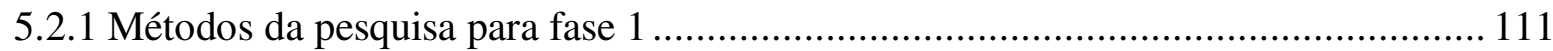

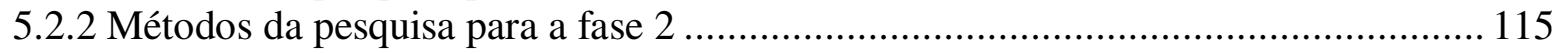

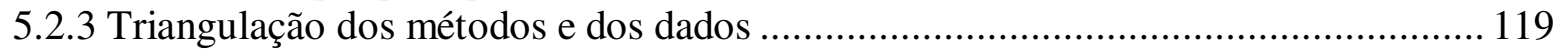

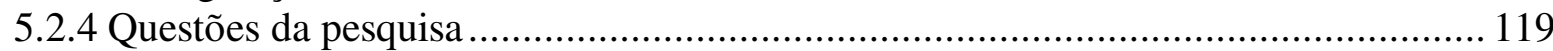

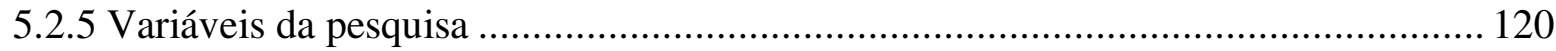

6 APRESENTAÇÃO E ANÁLISE DOS RESULTADOS DA FASE 1 ............................. 121

6.1 Características gerais das empresas de base tecnológica ......................................... 121

6.2 Especificidade da pequena empresa e a criação da estratégia................................. 131

6.2.1 Análise das variáveis de pesquisa: método descritivo........................................ 131

6.2.2 Análise da estrutura das variáveis: análise dos componentes principais.................. 140

7 APRESENTAÇÃO E ANÁLISE DOS RESULTADOS DA FASE 2 ........................... 149

7.1 Caracterização das empresas............................................................................. 149

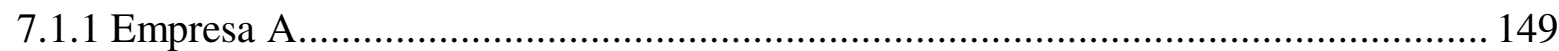

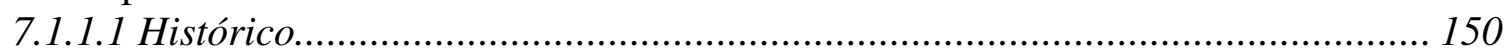

7.1.1.2 Dados gerais: estrutura, produto e mercado ................................................. 152

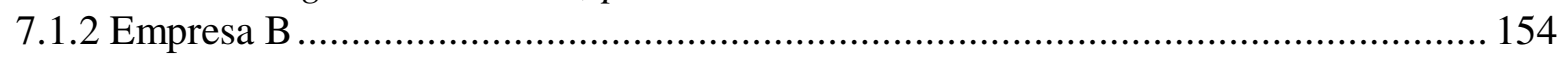

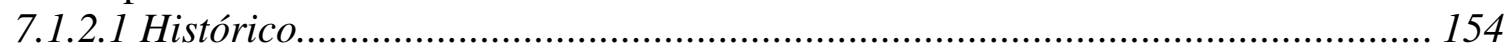

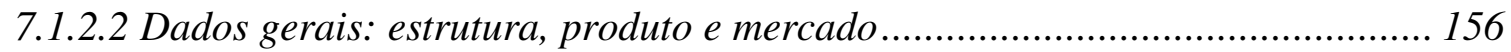

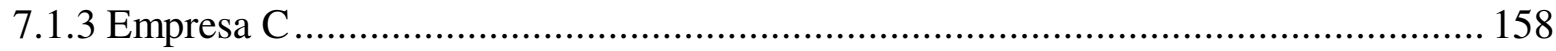

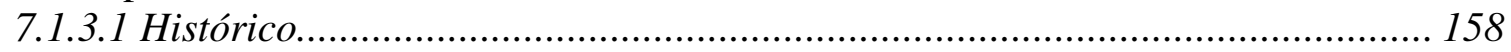

7.1.3.2 Dados gerais: estrutura, produto e mercado ................................................. 161 


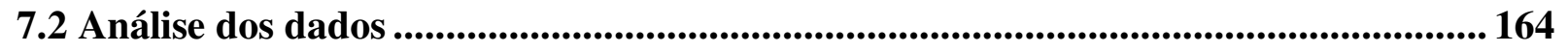

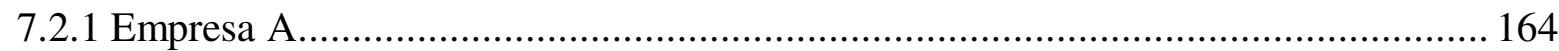

7.2.1.1 Processo de criação de estratégias ................................................................. 164

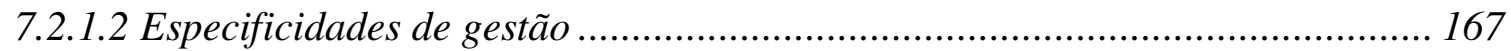

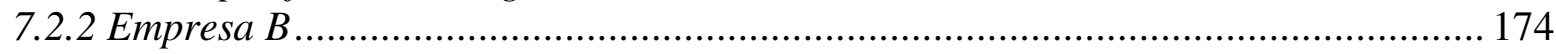

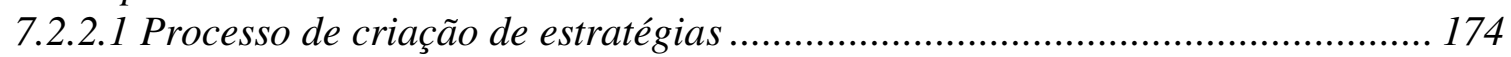

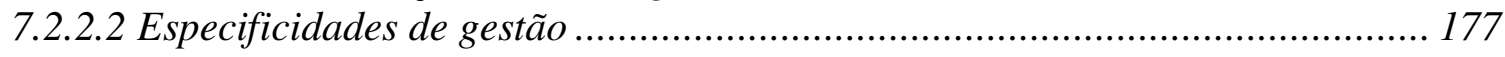

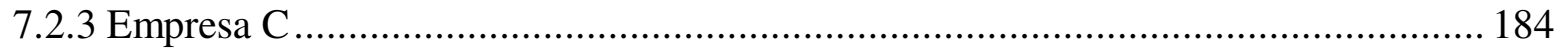

7.2.3.1 Processo de criação de estratégias ................................................................ 184

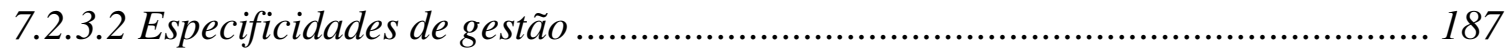

\section{PROCESSO ESTRATÉGICO NA PEQUENA EMPRESA DE BASE}

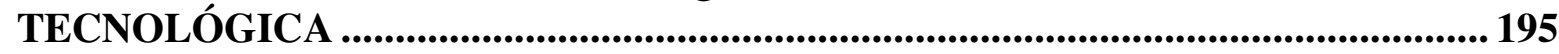

8.1 Interpretação dos resultados....................................................................................... 195

8.1.2 As especificidades de gestão da pequena empresa................................................. 199

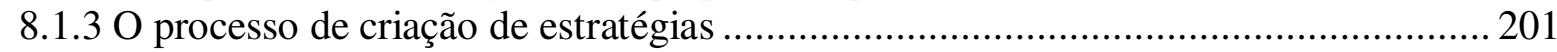

8.2 A criação de estratégias e as fases evolutivas ............................................................... 204

8.3 Proposição do mapa estratégico......................................................................................... 209

9 CONSIDERAÇÕES FINAIS........................................................................................... 213

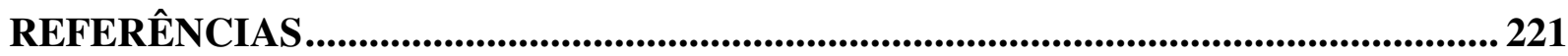

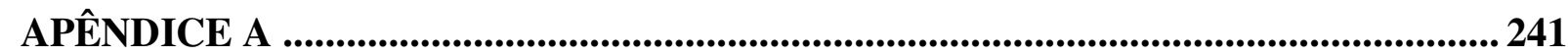

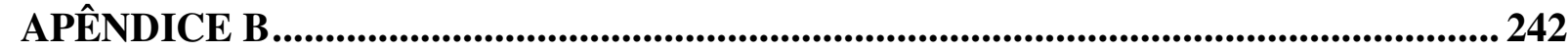

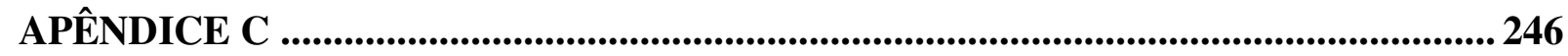

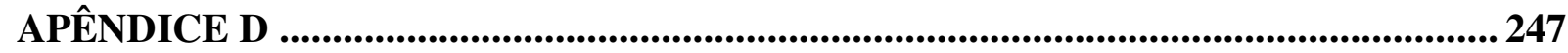

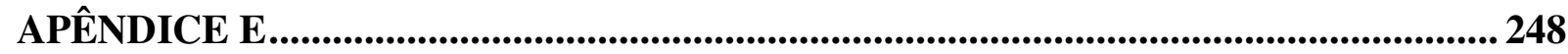

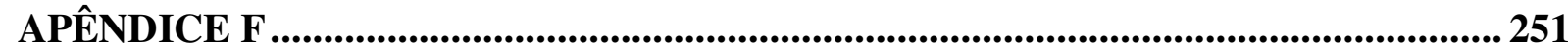




\section{INTRODUÇÃO}

O século XXI traz um novo imperativo para as organizações, uma vez que o ambiente em que estão inseridas passa por constantes, complexas e variadas mudanças, advindas de múltiplos fatores, como: competição acirrada, crescente interdependência econômica de países, globalização dos mercados, fusões, aquisições e alianças no âmbito das empresas e mudanças tecnológicas cada vez mais rápidas. Neste contexto se abre espaço para integração dos negócios, modificações mais velozes nos processos produtivos e desenvolvimento de bens e serviços. Observa-se, ademais, que a competição entre países, assim como entre indústrias e empresas, está em fase de mudança, não se limitando apenas ao campo macroeconômico, mas inserindo-se nas áreas de sociologia, economia e, em particular, de administração das organizações.

As transformações e tendências de ordem social, política, econômica e tecnológica possibilitam entender que a aldeia global não se configura mais uma utopia, já é realidade e representa grande desafio para os profissionais, exigindo que se mantenham atualizados a respeito destes e de outros fatores e efetivamente relacionem suas decisões às mudanças no ambiente. O ritmo, a dimensão e o impacto das mudanças no mundo dos negócios levam os administradores a envidar grandes esforços para acompanhá-las e interpretá-las, tentando compreender sua natureza e as implicações (BARBOSA, 1997, KRAJEWSKI; RITZMAN, 2000; MORAIS, 1999).

Frente a acontecimentos, oportunidades e desafios característicos da sociedade contemporânea, na qual bens, serviços, pessoas, habilidades e idéias se movimentam livremente entre as fronteiras geográficas, preocupar-se com o futuro torna-se uma atitude relevante para as empresas de todo o mundo. Na Teoria das Organizações há quase um consenso quanto a considerar a estratégia como a ferramenta adequada para se trabalhar com estas transformações. Entende-se que o futuro é um elemento fundamental na condução dos negócios e que a estratégia, portanto, deve voltar-se para o futuro, que o seu maior propósito, aliás, é, exatamente, lidar com o futuro, visando criar, por meio do pensar e do agir, um nítido senso de direção para as organizações (ACKOFF 1981; ANSOFF, 1990; BOAVENTURA, FISCHMANN; COSTA, 2005; HITT, IRELAND; HOSKISSON, 2005). 
Em síntese, reitere-se que, na sociedade contemporânea, para enfrentar as constantes mudanças ambientais que interferem na competitividade das empresas, a estratégia é um recurso indispensável, um criada em um processo ou instrumento que permite relacionar a tomada de decisão com as atividades operacionais e cotidianas das organizações, ou seja, o objetivo com a ação (COSTA; ALMEIDA, 2005; GLUCK, KAUFMAN; WALLECK, 1982).

\subsection{CARACTERIZAÇÃO DO TEMA DA PESQUISA}

Não há uma definição de estratégia universalmente aceita (GLUCK, KAUFMAN; WALLECK, 1982; MINTZBERG, 1987a). O postulado de que configura ações que direcionam a empresa em seu ambiente permitiria afirmar que constitui um conjunto de diretrizes para a tomada de decisões organizacionais (MINTZBERG, 1973, 1978; OHMAE, 1982). Minzberg (1987a) empenha-se em sintetizar as diversas abordagens ou correntes do pensamento sobre estratégia em cinco dimensões: plano, padrão, posição, perspectiva e pretexto. Seu intuito é esclarecer os processos por meio dos quais as estratégias se formam e salientar que o conceito de estratégia é complexo e abrange várias correntes.

Existem diversas formas de se criar a estratégia nas organizações. Independentemente da classificação utilizada para definir o processo, pode-se constatar que dois dos seus aspectos se evidenciam: o deliberado, que se baseia em planos lógicos e racionais e se volta para o estabelecimento de objetivos (pró-ativos ou adaptativos), e o emergente, que se fundamenta em flexibilidade, oportunismo, experiências prévias, aprendizado e intuição (GLUCK, KAUFMAN; WALLECK, 1982; HITT, IRELAND; HOSKISSON, 2005; IDENBURG, 1993; MINTZBERG et al., 2006; MINTZBERG, AHLSTRAND; LAMPEL, 2000). É oportuno ainda observar que as características específicas, as necessidades, o estágio de desenvolvimento, as áreas funcionais e os níveis hierárquicos de cada organização exercem influência na adoção do critério que orientará a escolha de suas estratégias e no grau de formalização do processo.

Mintzberg (1978), que denominou "formação de estratégias" o processo de criação de estratégias nas organizações, considera ser preciso levar em conta as diversas situações que definem o tipo de estratégia a ser adotado, pressupondo que situações distintas resultam em estratégias também diferentes, como as explícitas, criadas a partir de um processo formalizado 
de planejamento, e as "não planejadas", que refletem a linha da ação estratégica organizacional cotidiana, o processo emergente.

Entende-se, portanto, como processo estratégico, a forma pela qual são criadas as estratégias, seja este explícito e consciente ou de emersão. Devido às suas características, demanda maior grau de cognição e também grande carga de informações, revelando-se intensivo, complexo e contínuo, uma vez que se realiza em um ambiente dinâmico, no qual um movimento gera um contra-movimento e assim por diante (MINTZBERG, 1978; MINTZBERG et al., 2006).

A ascensão da sociedade globalizada - que tem, como base, a tecnologia e o conhecimento - torna cada vez mais difícil definir estratégias que garantam a sobrevivência das organizações. Assim ocorre porque as variáveis que caracterizam este ambiente competitivo geram incertezas e determinam a obsolescência das metodologias de estabelecimento de estratégias calcadas em análise de tendências. Com a busca de flexibilidade e inovação, a forma tradicional de conceber estratégias não é mais suficiente para lidar com as necessidades das organizações nos dias de hoje (MARCIAL; COSTA, 2001, MARIOTTO, 2003). É oportuno ressaltar que, em época de ocorrência significativa de inovações e mudanças ambientais, a intuição e a criatividade tornam-se determinantes na criação de estratégias que assegurem às empresas um diferencial competitivo.

Ansoff (1991) destaca, porém, que análises racionais e sistemáticas ajudam a identificar alternativas de sucesso que podem substituir o método de tentativa-e-erro, gerando ganho de tempo e redução de custos. Relativamente a esta discussão, Mintzberg (1991) ressalta duas descobertas da literatura sobre gestão estratégica dos últimos anos: (1) a concepção de uma nova estratégia é um processo criativo para o qual não concorre nenhuma técnica formal; (2) a programação de estratégias, em organizações complexas, demanda uma análise formal. Assim sendo, os processos - deliberado e emergente; racional e intuitivo; planejamento e aprendizado - podem se "entrelaçar" na formação de estratégias. A propósito, saliente-se que, no presente trabalho, o esforço investigativo volta-se à compreensão do processo estratégico, levando-se em conta não só o aspecto tradicional, mas também a influência do estrategista (intuição, criatividade e estilo de gestão) e o seu grau de formalização, tendo em vista a criação de estratégias deliberadas e emergentes conjuntamente. 


\subsection{FORMULAÇÃO DO PROBLEMA DA PESQUISA}

Para qualquer empresa, independentemente do seu porte e setor de atuação, a estratégia é uma necessidade. De certa forma, talvez seja mais relevante para as pequenas organizações, que possuem recursos escassos e cuja sobrevivência depende, em grande parte, da noção clara do nicho de mercado em que atuam e das maneiras de se diferenciarem. Tais empresas não precisam adotar um processo oneroso, mas desenvolver estratégias que englobem um sistema de atividades exclusivo (PORTER, 1997). Seus dirigentes e demais membros devem encarar o processo estratégico como um contínuo aprendizado, de modo que, com o passar do tempo, passem a conhecer cada vez mais não só as capacidades, limitações e possibilidades de seu ambiente como o próprio processo.

Em geral, nas pequenas empresas, estabelecem-se estratégias de forma intuitiva, a partir daquilo que o principal executivo, normalmente o proprietário, considera indispensável. Devido às suas características, não se costuma desenvolver um planejamento passo a passo, em longo prazo, utilizando-se a imaginação e a intuição para a tomada de decisões estratégicas (RICHERS, 1988). Por sua vez, as pequenas empresas de base tecnológica caracterizadas pela aplicação intensiva de conhecimento científico a produtos e/ou processos e por sua necessidade de inovar na produção e comercialização de produtos e/ou serviços porque não comportam os custos e as exigências de um planejamento extenso e analítico, tendem a agir de modo reativo, adaptando-se às novas condições oferecidas pelo ambiente e, em alguns casos, realizando julgamentos subjetivos sobre suas condições competitivas (CANCELLIER, 2004).

Frente ao contexto das pequenas empresas de base tecnológica, às peculiaridades organizacionais que apresentam, às limitações do processo de estratégias deliberadas e à necessidade de levar em conta, em sua gestão, tanto as suas características como as do estrategista, pretende-se analisar o processo estratégico desse segmento. Entende-se que tais empresas devem estar preparadas para reconhecer e avaliar as estratégias emergentes e adaptar-se a estas, conforme recomenda Mariotto (2003).

Regnér (2003) observa que o grande desafio, no estudo da estratégia empresarial, é mostrar de que modo elas são criadas, identificando-se as variáveis envolvidas no processo, especialmente nos setores em desenvolvimento, como o de empresas de base tecnológica. Aceitando o desafio, apresenta-se a seguinte questão de pesquisa: 
Como são criadas as estratégias das pequenas empresas de base tecnológica?

\subsection{OBJETIVOS DA PESQUISA}

O objetivo principal desta pesquisa é elaborar um mapa estratégico que ajude a compreender o processo de criação de estratégias nas pequenas empresas de base tecnológica do pólo de São Carlos/SP, a partir da sistematização das variáveis que o influenciam (figura 1): o dirigente estrategista, o contexto das empresas de base tecnológica e as especificidades de organização da empresa de pequeno porte.

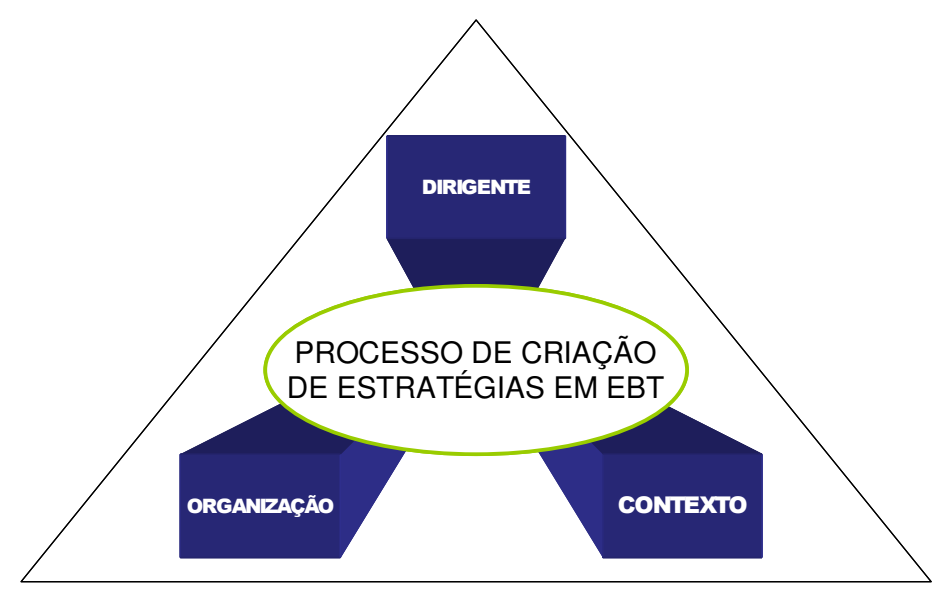

Figura 1 - Variáveis que influenciam o processo de criação de estratégias em pequenas empresas de base tecnológica

De acordo com o exposto no parágrafo anterior, reitera-se que se pretende, com este trabalho, analisar, nas pequenas empresas, o processo de criação de estratégias, considerando o seu grau de formalização e a possibilidade de uma coexistência natural e necessária dos seus aspectos deliberados e emergentes. É importante assinalar que se propõe desenvolver a pesquisa dando ênfase às variáveis que têm influência no processo, em especial o dirigente estrategista, responsável pela concepção de estratégias pretendidas; a organização, referentes à não realização de determinadas estratégias; e o contexto das empresas de base tecnológica, relacionado com a emersão de estratégias, conforme demonstrado na figura 2. 


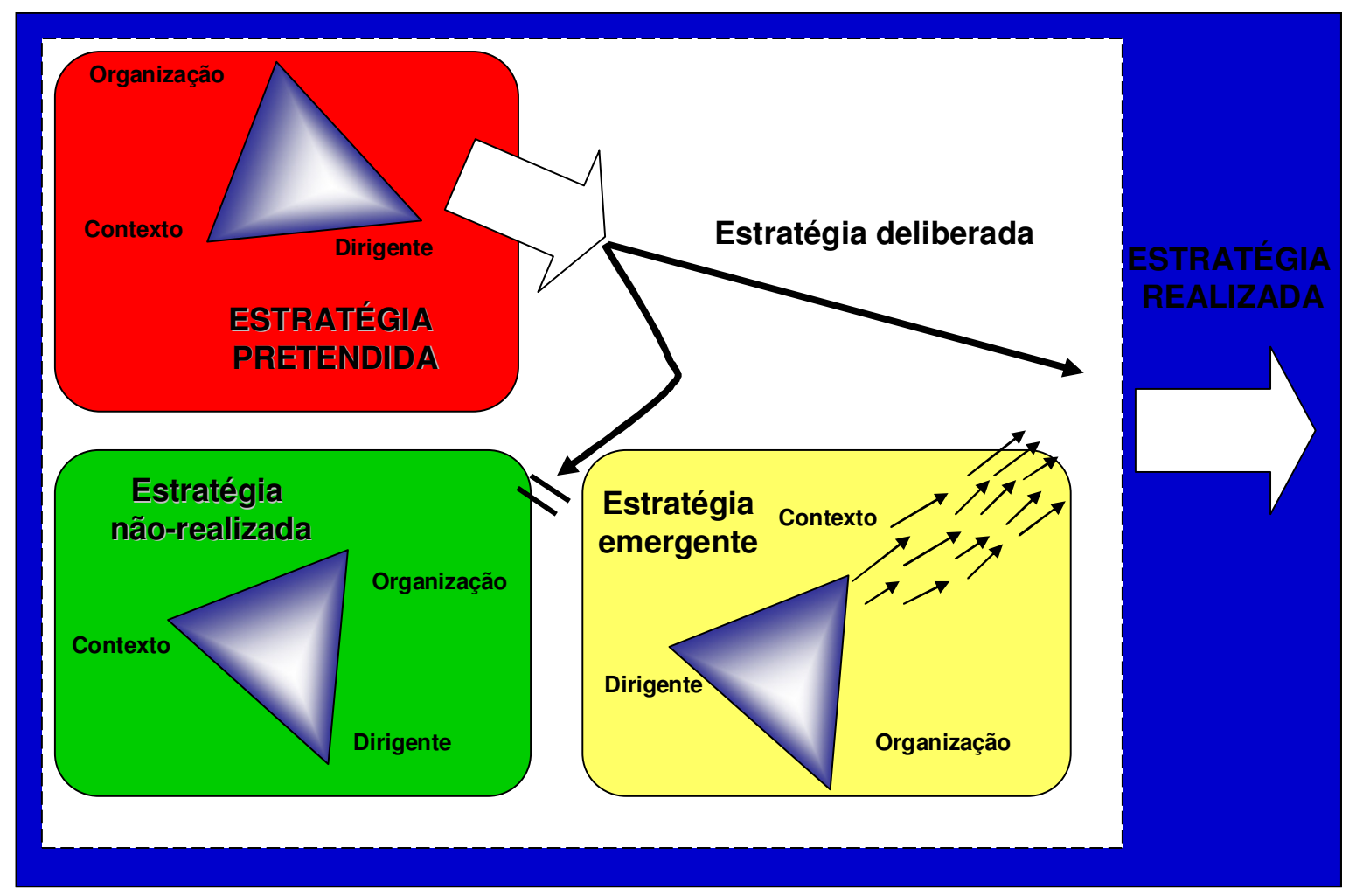

Figura 2 - Proposta da pesquisa

Fonte: adaptado de Mintzberg (1978; 2004)

Mapa é um esquema de representação que permite visualizar os possíveis interrelacionamentos dos aspectos presentes na dinâmica organizacional. Escrivão Filho et al. (2005) destacam e esclarecem que, diferindo do modelo, "o mapa é apenas uma orientação, um esquema de interpretação e, por isso, deve ser usado para entender e traduzir a realidade, que é muito mais complexa do que sua representação" (p. 26). Segundo os autores, os modelos amplamente utilizados na literatura administrativa, por carregarem um viés positivista de objetividade, um status de verdade inquestionável, reduzem a realidade a algo que precisa ser corrigido, e retratam uma relação de causa e efeito no fenômeno complexo que é a organização. Já o mapa, representando o processo administrativo como uma complexa rede de dimensões organizacionais, somente orienta a ação administrativa, mas não substitui a vivência humana.

O conceito de mapa organizacional possibilita que se defina o mapa estratégico como a sistematização e descrição simplificada das variáveis e seus inter-relacionamentos que representa o processo de criação de estratégias nas pequenas empresas de base tecnológica. A partir deste enfoque, mediante experiência interativa com tais empresas, pretende-se identificar os fatores que podem influir na criação de estratégias, tais como: as mudanças do ambiente, as alterações circunstanciais que interferem em suas atividades e decisões, a 
influência do dirigente-estrategista e as potencialidades e/ou limitações impostas pelas características organizacionais. É oportuno salientar que o mapa estratégico apenas se aproxima da realidade, não sendo, portanto, mais abrangente ou mais complexo que esta.

O objetivo específico deste trabalho é analisar, na pequena empresa de base tecnológica, os seguintes aspectos do seu processo estratégico:

- a concepção, em termos de elementos e graus de influência;

- o reconhecimento do processo de emersão da estratégia pelo dirigente;

- a condução centralizada no dirigente;

- a influência das especificidades de organização da pequena empresa;

- a influência do contexto de base tecnológica (variáveis ambientais).

\subsection{RELEVÂNCIA DO TEMA E DA PESQUISA}

Nos últimos anos, muitas pesquisas têm se voltado para o universo das pequenas empresas, contribuindo para uma abordagem adequada de suas características e construção de conhecimento sobre o setor. Aliás, a teoria da pequena empresa está sendo elaborada. Alguns estudos demonstram que as teorias das grandes organizações não se aplicam integralmente às empresas de menor porte, em especial pelo fato de que não explicam ou consideram o comportamento do dirigente (D’AMBOISE; MULDOWNEY, 1988; DANDRIGE, 1979; DAY, 2000). Acredita-se que outros aspectos devam ser levados em conta, pois, embora a literatura relacionada a pequenas empresas tenha começado a se desenvolver nos últimos anos, poucos estudos concentram-se nas suas especificidades de gestão. Entende-se que não devem ser compreendidas como uma "versão diminuída" de grandes organizações, pois não são "pequenas grandes empresas" - grandes empresas em seu processo inicial de crescimento. As pequenas empresas apresentam problemas típicos, ou seja, condições peculiares, que necessitam de uma abordagem teórica específica. (DAY, 2000; LEONE, 1999; SHUMAN; SEEGER,1986; WELSH; WHITE, 1981).

As empresas de base tecnológica (EBT) somam, em sua gestão, problemas e características particulares. Porque atuam em ramos bastante específicos, utilizando tecnologias próprias e ainda não padronizadas, apresentam uma grande variedade de alternativas de projeto e produto (SEBRAE, 2001) que precisa ser considerada. Apesar do interesse dos pesquisadores por estas organizações, tem-se pouco conhecimento acumulado 
sobre suas características, especialmente de gestão. Registra-se uma grande preocupação com o futuro do segmento das EBT, face à concentração de atividades de desenvolvimento tecnológico e intensificação da concorrência no setor. Acrescente-se que as EBT têm dificuldades para obter recursos financeiros e mostram-se deficientes na capacitação gerencial dos empreendedores, problemas que se reforçam mutuamente como obstáculos à sua consolidação.

Em seus diversos aspectos - conceituação, desenvolvimento, processo e implantação temas extensivamente discutidos e pesquisados na literatura administrativa recente, a estratégia fundamenta-se em propósitos coerentes com necessidades, características e desafios das grandes corporações, abrangendo questões próprias de tais empresas, como administração profissional, impessoalidade e racionalidade, entre outras. Apesar de alguns autores afirmarem que as mudanças no ambiente de negócios sugerem o desenvolvimento das pequenas empresas (DAY, 2000), estas apresentam uma série de problemas que resulta, muitas vezes, em alta taxa de mortalidade. Constata-se que as pequenas empresas ainda necessitam de abordagens gerenciais mais eficazes para se tornarem competitivas e que grande parte dos problemas que enfrentam deriva de questões estratégicas - contextuais e de gestão - que, por sua vez, acarretam outros problemas (BORTOLI NETO, 2005). Portanto, a estratégia, no segmento das pequenas empresas, é uma ferramenta simples e poderosa para melhorar sua competitividade e identificar novos negócios (QUEZADA et al., 1999; WOODS; JOYCE, 2003), inclusive no relevante e promissor segmento de empresas de base tecnológica.

Com este estudo, pretende-se colaborar para diminuir a lacuna existente sobre gestão estratégica das pequenas empresas, à medida que se propõe considerar as especificidades do segmento no processo de criação de estratégias. Em outras palavras, por meio da identificação, análise e sistematização das variáveis relevantes neste processo, espera-se chegar a compreender como a empresa de pequeno porte pode ter condições de adotar uma postura pró-ativa de gestão, tornando-se mais competitiva, ágil e adaptativa frente às mudanças e aos acontecimentos de seu ambiente. 


\subsection{ESTRUTURA DO TRABALHO}

Este trabalho está estruturado em nove capítulos. No primeiro, que constitui sua introdução, contextualiza-se o tema abordado e desenvolvem-se os seguintes tópicos: caracterização do tema, formulação do problema de pesquisa, descrição dos objetivos e relevância da pesquisa.

No capítulo 2, com o título Estratégia, primeiramente se apresenta o conceito de estratégia - sua evolução nas organizações, sua interface com a competitividade e o desempenho organizacional - e, a seguir, retratam-se as características das dimensões da estratégia na literatura.

No capítulo 3, denominado Processo de Criação de Estratégias, realizam-se o levantamento e a discussão dos trabalhos desenvolvidos pelos pesquisadores da área a respeito da a criação de estratégias sob as perspectivas deliberada e emergente - processos distintos que, no entanto, se integram, interagem e coexistem.

No capítulo 4, Gestão de Pequenas Empresas, apresentam-se os aspectos específicos de gestão destas organizações, a influência das etapas do ciclo de vida no seu processo de formação de estratégias e as particularidades de tal processo. Trata-se ainda das empresas de base tecnológica - seu contexto e suas características - e, por fim, do processo de criação de estratégias no setor.

No capítulo 5, Tipos e Métodos de Pesquisa, descreve-se a metodologia utilizada na investigação, apresentando-se suas características, as etapas de seu desenvolvimento, as questões de pesquisa, as variáveis identificadas e as considerações sobre a coleta e a análise dos dados.

O capítulo 6, Apresentação e Análise dos Resultados da Fase 1, apresenta a caracterização das empresas investigadas e as especificidades de gestão e do processo de criação de estratégias nas EBT. A seguir, analisa-se o comportamento do grupo de empresas e identificam-se os fatores influentes do dirigente, do contexto e da organização que estão relacionados ao seu processo de criação de estratégias.

O capítulo 7 é denominado Apresentação e Análise dos Resultados da Fase 2. O processo de criação de estratégias é apresentado a partir das fases evolutivas das empresas investigadas, bem como as suas especificidades de gestão.

No capítulo 8, Processo de Criação de Estratégias nas Pequenas Empresas de Base Tecnológica, realiza-se a identificação das características das EBT e a análise de suas 
especificidades de gestão e do seu processo de criação de estratégias. A partir da análise realizada propõe-se o mapa estratégico.

O capítulo 9 contém as Considerações Finais sobre a pesquisa feita, entre as quais se incluem suas limitações e sugestões para trabalhos futuros, relacionados à gestão de pequenas empresas e ao processo de criação de estratégias.

Para visualizar e compreender melhor a pesquisa como um todo e suas partes, elaborou-se uma representação (figura 3), em destaque logo abaixo. Ressalte-se que a etapa epistemológica se apresenta no capítulo 1; nos capítulos 2, 3 e 4 encontram-se os principais referenciais teóricos e, no capítulo 5, registram-se os métodos utilizados para o desenvolvimento da investigação. $\mathrm{O}$ trabalho de campo é representado pela apresentação e análise dos dados das fases 1 e 2, nos capítulos 6 e 7. Por fim, o confronto da teoria com os resultados obtidos, a proposição do mapa e as considerações finais compõem a etapa conclusiva da pesquisa.

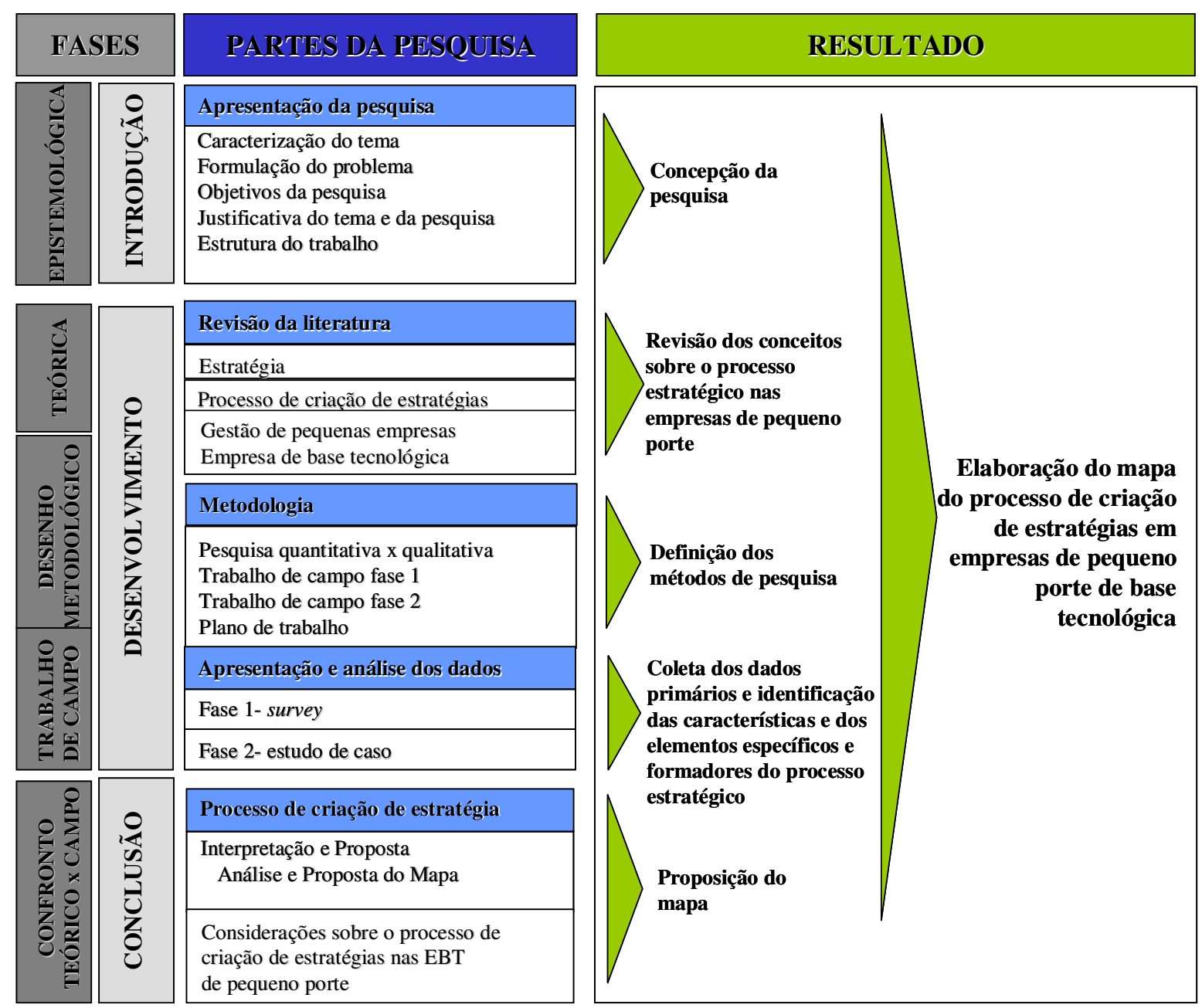

Figura 3 - Estrutura do trabalho 


\section{ESTRATÉGIA}

A estratégia é um fenômeno amplo, complexo e único em toda organização, capaz de moldá-la e transformá-la ou de constituir-se um inibidor ao seu desenvolvimento. Criada pelos dirigentes, é também fruto da dinâmica de interação com agentes internos e externos, envolvidos em circunstâncias econômicas, sociais e históricas específicas (FONSECA; MACHADO-DA-SILVA, 2002; MINTZBERG, 1987b).

Para identificar, nas organizações, as diferentes visões do processo estratégico e as atividades que dele fazem parte, entende-se que é importante e oportuno conceituar estratégia, considerando-a tanto em sua evolução quanto na relação que tem com a competitividade e o desempenho organizacional. Também se faz necessário registrar a reflexão sobre a estratégia nas organizações, a partir de um sistema que integra os conceitos de liderança, organização e ambiente. Assim sendo, estrutura-se este capítulo conforme a figura 4.

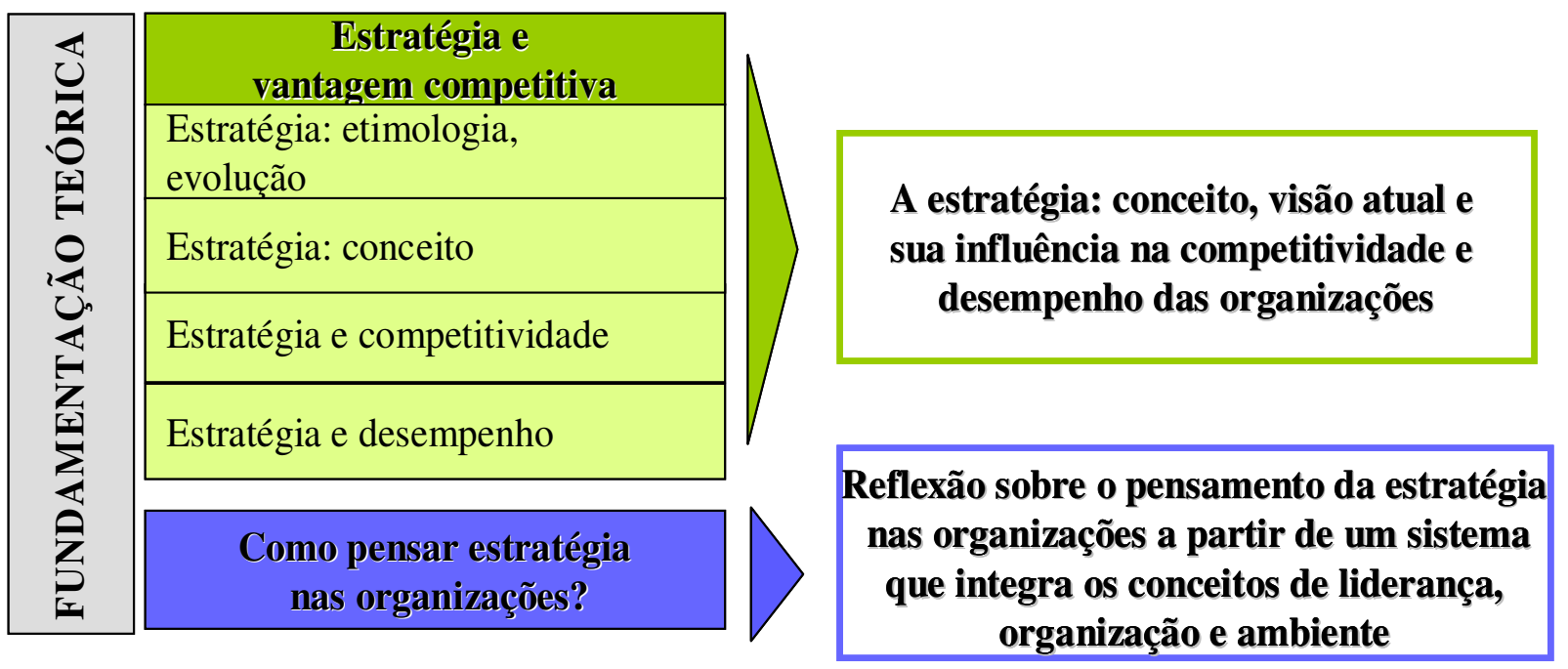

Figura 4 - Estrutura do capítulo estratégia 


\subsection{ESTRATÉGIA E VANTAGEM COMPETITIVA}

A estratégia é um tema que vem conquistando espaço tanto no âmbito acadêmico como no empresarial. Dependendo do contexto, o termo comporta diversos significados, como políticas, objetivos, táticas, metas, programas, entre outros. Aliás, tem sido usado livre e indiscriminadamente, muitas vezes de maneira errônea, nestas áreas, conforme constatam vários autores que abordam a questão (CAMARGOS; DIAS, 2003; CHAFFEE, 1985, MINTZBERG; AHLSTRAND; LAMPEL, 2000; PAULINO et al., 2001). A estratégia, como disciplina administrativa, sob a influência da economia, antropologia, psicologia, sociologia e ciência política, é considerada, na atualidade, um desenvolvimento da Teoria das Organizações. Escrivão Filho (2006, p. 17) registra que "no desenvolvimento histórico da Administração, o estudo da estratégia era uma subárea da Teoria das Organizações", tornando-se, recentemente, uma área específica, ao lado das funcionais, tradicionalmente reconhecidas. Este destaque, que se deve, sobretudo, ao aumento significativo, em volume e importância, de trabalhos acadêmicos e publicações de negócios, sobre o assunto, assim como ao crescente interesse dos executivos pela questão, demonstra a sua relevância nos estudos organizacionais (ESCRIVÃO FILHO, 2006).

\subsubsection{Estratégia: etimologia e evolução}

O significado do termo estratégia, nos estudos organizacionais, fundamenta-se historicamente em conceitos militares. Tem sua origem na Grécia - estima-se que no século IV a.C. - provindo de strategos, que designa a "a arte do general", ou seja, a função do general, no comando do exército, de indicar a direção a ser tomada pelos guerreiros para se atingir a vitória militar. Posteriormente passa a ser usada com o sentido de "a arte da liderança", do general. Esta acepção relaciona um conjunto de conhecimentos necessários ao general que comanda o exército para alcançar seu objetivo. Ademais, a palavra general, que também quer dizer "geral", implica, com esta conotação, que, em algum ponto da história militar, o comandante da ação deixa de atuar na linha de frente, em uma atividade específica, para ter uma visão de conjunto das batalhas. O conhecimento da evolução do significado da palavra estratégia, desde seu remoto étimo, permite concluir que, por toda a Antiguidade até o século XIII, foi entendida como uma forma de vencer o inimigo que comporta estratagemas 
necessários à sua concretização (BETLHEM, 1981; BRACKER, 1980; EVERED, 1983; FERNANDES; BERTON, 2005; SNOW; HAMBRICK, 1980).

Com o crescimento da sociedade e tornando-se os conflitos mais complexos, generais e estadistas passam a estudar, codificar e testar conceitos estratégicos. Surge então um grupo de princípios, expostos por Sun Tzu e Clausewitz. Estrategista chinês, Sun Tzu aborda a estratégia como a forma de obter grandes vitórias. Em seu livro, A Arte da Guerra, o mais antigo tratado sobre a questão, Sun Tzu, precursor das idéias de Clausewitz, destaca que o conhecimento antecipado das estratégias do inimigo conduz o exército e a batalha, levando à conquista de vitórias (SUN TZU, 2004). Clausewitz, general prussiano, considerado o "pai" da estratégia militar moderna, amplia a abrangência da estratégia, limitada até então ao terreno das concepções do planejamento militar na condução das forças, antes e depois da batalha. Clausewitz contribui, definindo três pré-requisitos para vencer o inimigo: (1) avaliação das forças do inimigo, (2) avaliação dos recursos do inimigo e (3) disposição para lutar. As análises propostas abrangem os fatores psicológicos e acidentais da guerra, bem como seu caráter situacional (CLAUSEWITZ, 2003; FERNANDES; BERTON, 2005; QUINN, 2006; TAVARES; AMARAL; GONÇALVES, 2003).

De forma gradativa, portanto, a estratégia extrapola o campo militar, passando a abranger ações de caráter político, econômico, tecnológico e social. No século XX, especificamente após a Segunda Guerra Mundial, os conceitos militares de estratégia são incorporados ao universo das organizações pelos membros da Harvard Business School. Consta que, em 1912, o tema "Política de Negócios" já se destaca, no ensino de Harvard, como um processo normativo e situacional, com o objetivo de desenvolver uma visão ampla dos problemas que enfrentam os executivos das grandes empresas para a integração das áreas funcionais de contabilidade, operações e finanças (FERNANDES; BERTON, 2005; SILVEIRA, 2003; SNOW; GHEMAWAT, 2000; HAMBRICK, 1980).

Como ferramenta administrativa, a estratégia desenvolve-se após a Segunda Guerra Mundial, em virtude da promoção de um cenário de alta produtividade da indústria frente ao grande investimento das empresas em manufatura/marketing e hierarquias gerenciais (PANKAJ, 2000; PAULINO et al. 2001). O conceito de estratégia é introduzido nos métodos de gestão com a finalidade de se estabelecerem ações para competir no mercado, tendo em vista concretizar-se uma situação futura desejada. Passa-se assim a considerar, por um lado, as oportunidades que o ambiente oferece e, por outro, os recursos de que a organização dispõe.

Em 1962, Alfred Dupont Chandler publica a obra "Strategy and Structure", destacando-se como pioneiro ao empregar um conceito descritivo de estratégia. Chandler 
(1990) afirma que as decisões estratégicas influem no desempenho de longo prazo das organizações. Segundo o autor, a estratégia é fruto da competitividade, relaciona-se com a incerteza do ambiente e interfere na configuração da estrutura organizacional. Para ele, diferentes estratégias levam a diferentes formas de organização, porém, por sua vez, a estrutura organizacional influencia profundamente a estratégia. Estes inter-relacionamentos de estratégia e estrutura passam a despertar o interesse de vários autores, pois, em seu estudo Chandler (1990), que identificou relações até então ignoradas, ao concluir que estratégias distintas levam a formas distintas de organização (GALBRAITH; LAWLER III, 1995).

Outra obra influente sobre o tema, publicada, em 1965, com o título de "Corporate Strategy" e escrita por Igor Ansoff, aborda a estratégia, na área administrativa, de forma inovadora. Define-a como um processo de formular e implementar ações cujo objetivo principal é adequar constantemente a organização ao seu ambiente, de maneira a garantir a criação de riquezas para os acionistas e a satisfação dos seus stakeholders $^{l}$ (CAMARGOS; DIAS, 2003; VASCONCELOS, 2001). Desde então, a literatura sobre o assunto, englobando a competitividade das empresas e a preocupação com o ambiente, vem crescendo de forma acentuada.

Nas décadas de 70 e 80, a estratégia empresarial é um tema pesquisado de modo extensivo. Abordam-se principalmente as questões de planejamento e posicionamento estratégicos, como instrumentos administrativos de previsão, coordenação e controle. Aliás, o planejamento estratégico, inicialmente restrito à análise dos pontos fortes e fracos de uma organização, passa a integrar a administração de eventuais mudanças no ambiente organizacional. Reiterando, o planejamento estratégico, conforme concebido de início, esgotase a partir de mudanças e rupturas no ambiente de negócio que, causando imprevisibilidade cada vez maior, impõem uma abordagem mais dinâmica e de integração (BERTERO, 1995; MINTZBERG, 1994).

Apesar das várias contribuições de Ansoff, referentes ao planejamento estratégico e à administração estratégica (ANSOFF, 1976), é a partir da década de 1980 que se consolida a Administração Estratégica como um enfoque que ameniza a separação entre formular e implantar estratégias, existente no planejamento estratégico. Passa-se a entender que a gestão estratégica implica formular, rever e implantar estratégias e que a estratégia empresarial constitui uma perspectiva contínua de gestão, um processo em que se destaca a influência do

\footnotetext{
1 Stakeholders podem ser definidos como todo e qualquer grupo ou indivíduos identificáveis que afetam, desejam afetar ou são afetados pelas ações de uma organização na consecução de seus objetivos, tais como agências do governo, acionistas, clientes, concorrentes, fornecedores, empregados, entre outros (FREEMAN; REED, 1983).
} 
ambiente. Para o autor, a administração estratégica diz respeito à gestão do relacionamento da empresa com o seu ambiente (ANSOFF, 1984). Em outras palavras, a estratégia empresarial passa a ser encarada como um processo que delineia gradualmente o futuro e auxilia a organização para enfrentá-lo por meio de qualificações, recursos e competências adequadas à realidade ambiental a se concretizar (BERTERO, 1995; BERTERO, VASCONCELOS; BINDER, 2003, grifo nosso). É oportuno ressaltar que, nos dias de hoje, tem ampla utilização no mundo dos negócios.

Constata-se que a estratégia empresarial, sujeita a várias formas de abordagem, recebe diferentes significados e diversas denominações, como diretrizes de negócios, planejamento estratégico, pensamento estratégico, diretrizes administrativas e gestão ou administração estratégica (BERTERO, 1995; CAMARGOS; DIAS, 2003). A questão semântica deve-se à evolução do termo, decorrente de rupturas, no ambiente das organizações, geradas por descontinuidades e mudanças. Portanto, a concepção de estratégia passa de um enfoque analítico interno, que visa à coordenação de esforços, a uma perspectiva externa, relacionada ao modo de a empresa atuar no mercado.

$\mathrm{O}$ aspecto interno, dominante até os anos 50, retrata o empenho dos administradores e teóricos da primeira metade do século em conseguir a coordenação de esforços, por meio do estabelecimento de diretrizes administrativas, para uma organização fragmentada ou, ainda, para pessoas que, submetidas à crescente divisão de tarefas e funções, haviam perdido a visão global do sistema produtivo, tornando-se alienadas e desmotivadas. O foco no fator interno visa melhorar a eficiência dos mecanismos de produção, uma vez que ainda não existe um ambiente de hostilidade competitiva e o mercado não é diversificado e complexo, oferecendo oportunidades de crescimento rápido.

$\mathrm{O}$ aspecto externo concentra-se na complexidade do ambiente, ou seja, em sua turbulência e alto grau de competitividade, que influenciam as ações da empresa no mercado. Catalisadas pelos esforços da Segunda Guerra Mundial, surgem as grandes organizações, que demandam uma administração mais complexa e profissional, em um cenário que configura um mercado competitivo e dinâmico, que exige um perfil gerencial empreendedor, respostas mais rápidas e corretas à ação de concorrentes, redefinição do papel social e econômico das empresas e melhor adequação à nova postura assumida pelos consumidores.

Pode-se considerar, portanto, que a estratégia diz respeito à relação da empresa com seu ambiente e suas condições internas. Sob esta perspectiva, a empresa procura definir e operacionalizar ações que maximizem os resultados da interação estabelecida de maneira 
consciente ou intuitiva (CAMARGOS; DIAS, 2003; TERENCE, 2002; VASCONCELOS, 2001).

Conforme se vem expondo, com o decorrer dos anos, o termo estratégia passa a ter, em Administração, um uso comum, utilizado para designar o caminho que a organização deve seguir para alcançar seus objetivos. A estratégia volta-se para o futuro: busca delineá-lo e também prepara a empresa para nele atuar, competindo e obtendo sucesso. O equilíbrio entre forças (externas e internas) é o que garante a longevidade do negócio (BERTERO, 1995; PAULINO et al., 2001; TERENCE, 2002). O quadro abaixo demonstra a evolução do conceito de estratégia utilizado nas organizações até os dias atuais.

\begin{tabular}{|c|c|c|c|}
\hline FOCO & ÉPOCA & CARACTERÍSTICA & DESIGNAÇÃO \\
\hline INTERNO & $\begin{array}{l}\text { Até os } \\
\text { anos } 50\end{array}$ & $\begin{array}{l}\text { Coordenação de esforços por meio do } \\
\text { estabelecimento de diretrizes administrativas } \\
\text { para a melhoria da eficiência dos } \\
\text { mecanismos de produção. }\end{array}$ & $\begin{array}{l}\text { Política de negócios, } \\
\text { diretrizes de negócios ou } \\
\text { diretrizes administrativas. }\end{array}$ \\
\hline \multirow{3}{*}{ EXTERNO } & $\begin{array}{l}\text { Década } \\
\text { de } 60\end{array}$ & Adequação da organização ao ambiente. & $\begin{array}{l}\text { Planejamento, } \\
\text { Estratégia empresarial }\end{array}$ \\
\hline & $\begin{array}{l}\text { Décadas } \\
\text { de } 70 \text { e } \\
80\end{array}$ & $\begin{array}{l}\text { Estratégia como processo } \\
\text { realizado pela alta cúpula, } \\
\text { posicionamento da organização. }\end{array}$ & $\begin{array}{l}\text { Posicionamento, } \\
\text { Planejamento estratégico }\end{array}$ \\
\hline & $\begin{array}{l}\text { Década } \\
\text { de } 90\end{array}$ & $\begin{array}{l}\text { Ações formuladas para dar estabilidade à } \\
\text { organização, por meio do equilíbrio entre } \\
\text { forças - externas e internas. } \\
\text { Estratégia como perspectiva de gestão em } \\
\text { todos os níveis organizacionais. }\end{array}$ & $\begin{array}{l}\text { Pensamento estratégico, } \\
\text { Administração estratégica }\end{array}$ \\
\hline $\begin{array}{l}\text { EXTERNO/ } \\
\text { INTERNO }\end{array}$ & $\begin{array}{l}\text { Década } \\
\text { atual }\end{array}$ & $\begin{array}{l}\text { A estratégia é criada a partir de um processo } \\
\text { que integra aspectos emergentes e } \\
\text { deliberados. }\end{array}$ & $\begin{array}{l}\text { Processo de criação de } \\
\text { estratégias }\end{array}$ \\
\hline
\end{tabular}

Quadro 1 - Evolução da estratégia nas organizações

\subsubsection{Estratégia: conceito}

Nas organizações não há consenso sobre o conceito de estratégia, uma questão relativamente complexa Por sua vez, a literatura aponta inúmeras definições, que focalizam diferentes aspectos (CHAFFEE, 1985; GLUCK; KAUFMAN; WALLECK, 1982). Quinn (2006) propõe uma definição útil, segundo a qual a estratégia é o padrão ou plano que integra 
as principais metas, políticas e sequiências de ações de uma organização em um todo coerente. Sob este enfoque, ajuda a ordenar e alocar os recursos de uma empresa com base em suas competências e deficiências internas relativas, mudanças antecipadas no ambiente e ações dos concorrentes. Para o autor, a estratégia deve conter três elementos: metas, políticas e planos de ação.

Atribuem-se diversos sentidos ao termo estratégia, considerando-se que uma única definição não refletiria com clareza todos os seus aspectos. Mintzberg (1987a), com o intuito de ampliar o conceito, argumenta que a estratégia engloba vários sentidos que podem ser apresentados em cinco definições, que ele denomina 5P: plano (plan), pretexto (ploy), padrão (pattern), posição (position) e perspectiva (perspective). A seguir são desenvolvidas as cinco definições de estratégia, segundo cada sentido destacado pelo autor (MINTZBERG, 1987a; MINTZBERG, AHLSTRAND; LAMPEL, 2000, grifo nosso).

- A estratégia, como plano, refere-se ao estabelecimento de um curso de ação conscientemente pretendido, ou seja, de um conjunto de diretrizes para lidar com uma determinada situação. Caracteriza-se por ser criada antes da ação à qual vai se aplicar, por ser desenvolvida de modo consciente e proposital e, finalmente, por ser estática e focar-se em um plano geral derivado da mente do estrategista.

- A estratégia, como pretexto, configura uma "manobra” específica para superar um opositor ou concorrente. Sob este ponto de vista é intencional - um pretexto para se obter uma vantagem - dinâmica, pretendida e focada em uma ação competitiva particular.

- A estratégia, como padrão, representa o resultado do processo, ou melhor, um padrão que pode ser observado em um conjunto de ações gerenciais que não é necessariamente preconcebido. Com este sentido, apresenta as seguintes características: é realizada, deliberada ou emergente; agrega o que foi planejado e realizado (os planos podem ou não se concretizar) e os padrões de comportamento (que não exigem necessariamente um planejamento prévio); tem, como foco, a ação e o comportamento da empresa.

- A estratégia, como posição, constitui especificamente um meio de localizar a empresa no ambiente em que atua, sendo, portanto, a força mediadora entre a organização e o ambiente. Sob tal ponto de vista enfatiza o contexto.

- A estratégia, como perspectiva, é um conceito compartilhado pelos membros da organização, um ponto de vista refletido em ações ou intenções, pois seu foco é a ação coletiva dos membros da organização, baseada em suas intenções e comportamentos.

Estas definiçõoes, quando aplicadas, ajudam a entender e a administrar os processos pelos quais se formam as estratégias. São conceitos que englobam relações que acrescentam 
elementos importantes à compreensão da estratégia, que não pode ser considerada apenas uma forma de competir, segundo geralmente é tratada na literatura e em seu uso popular. A estratégia, como instrumento de percepção coletiva e de ação, também revela questões fundamentais sobre as organizações (MINTZBERG, 1978, 1987a; SNOW; HAMBRICK, 1980).

Hambrick $(1980,1983)$ enfoca a estratégia como um padrão para o processo de tomada de decisões, que orienta e alinha a empresa relativamente ao que acontece em seu ambiente, definindo políticas e procedimentos. Por ser utilizada em organizações com características distintas, inseridas em contextos diversos, o autor alega que a dificuldade em se atingir um consenso quanto a seu conceito se deve a dois aspectos que a definem - o multidimensional e o situacional. O caráter multidimensional advém do fato de se encarar a estratégia sob distintas e, algumas vezes, conflitantes visões, implícitas na literatura. $\mathrm{O}$ aspecto situacional, por sua vez, diz respeito ao fato de a estratégia variar e depender de alguns fatores: tipo de indústria, estágio do ciclo de vida do produto e nível de inovação do setor. Assim, por se vincular ao ambiente - em constante mudança, acarretando novas circunstâncias ou situações para as organizações - a estratégia configura um processo não programável, não repetitivo e desestruturado.

Nas definições de estratégia apresentadas pelos autores da área, pode-se constatar que, apesar de não haver um consenso, registram-se alguns elementos comuns, como elaboração de um plano, estabelecimento de um curso de ação e de políticas e alocação de recursos para atingir objetivos pré-determinados, visando ao aumento da vantagem competitiva. O quadro 2 apresenta os elementos-chave presentes nas várias definições de estratégia.

- Determinação de objetivos de longo prazo, adoção de cursos de ação e alocação de recursos necessários, para atingir as metas (CHANDLER, 1990).

- Utilização dos diversos recursos - humanos, técnicos e financeiros - que estão à disposição do empresário. Convém ressaltar que a estratégia e os objetivos da organização descrevem, conjuntamente, o seu campo de atuação. Assim considerando, observe-se que, ao adotar uma estratégia, o empresário deve analisar a organização e o seu ambiente, com o intuito de estabelecer quais são os caminhos, os cursos e os programas de ação que precisam ser levados em conta, para que sejam alcançados os objetivos previamente definidos pela empresa (ANSOFF, 1977; 1990).

- Padrão de decisões de uma empresa, conceito segundo o qual a estratégia determina e revela os objetivos, os propósitos e as metas de uma organização e produz as principais políticas e planos para se alcançar o resultado esperado. A estratégia ajuda ainda a definir o 
negócio, o tipo de organização - econômica ou humana - e a natureza de contribuição econômica e não-econômica a ser oferecida aos seus públicos relevantes (ANDREWS, 1987).

- Padrão ou plano que reúne as principais metas, políticas e programas da organização em um todo coeso, que a ajuda a organizar e alocar seus recursos segundo uma postura única e viável, com base em suas competências e deficiências internas relativas, em mudanças antecipadas no ambiente e em movimentos circunstanciais por parte dos opositores (QUINN, 1980; 2006).

- Ações ofensivas ou defensivas para se definir uma posição defensável, a partir da criação de vantagem competitiva no ramo de negócio em que a empresa atua, pelo estabelecimento de uma posição lucrativa e sustentável contra as forças que determinam a competição industrial (PORTER, 1985, 1991, 1996). "É uma solução única que reflete suas circunstâncias particulares" (PORTER, 1991, p. 49).

- Definição de uma base contínua para alinhar as adaptações da empresa com os objetivos concebidos de forma mais ampla (MINTZBERG, 1987a).

- Mudanças ao longo do tempo, que podem ser graduais, incrementais, rápidas ou radicais. Observe-se, portanto, que a resposta da organização a uma mudança ambiental pode ser caracterizada como uma mudança estratégica (SNOW; HAMBRICK, 1980).

\begin{tabular}{|l|l|}
\hline \multicolumn{1}{|c|}{ Autor } & \multicolumn{1}{c|}{ Elementos-chave } \\
\hline Chandler & objetivos de longo prazo, cursos de ação, alocação de recursos \\
\hline Ansoff & $\begin{array}{l}\text { utilização dos recursos empresariais (humanos, técnicos e financeiros), objetivos, } \\
\text { campo de atuação, ambiente, caminhos, cursos, programas de ação }\end{array}$ \\
\hline Andrews & padrão de decisões, objetivos, propósitos, metas, políticas, planos \\
\hline Quinn & $\begin{array}{l}\text { padrão, plano, metas, políticas, programas, alocação de recursos, competências, } \\
\text { deficiências, mudanças no ambiente e movimentos contingentes por parte dos } \\
\text { oponentes }\end{array}$ \\
\hline Porter & ações, vantagem competitiva, ramo de negócio \\
\hline Mintzberg & adaptação da organização, objetivos \\
\hline Snow; Hambrick & mudanças graduais, incrementais, rápidas ou radicais \\
\hline
\end{tabular}

Quadro 2 - Elementos-chave na definição de estratégia 
Hax e Majluf (1988) apresentam uma definição mais ampla de estratégia, que abrange a maioria dos elementos-chave apresentados anteriormente. Para os autores, a estratégia é um padrão de decisões coerente, único e integrativo, que define: o propósito organizacional ao estabelecer objetivos de longo prazo, programas de ação e prioridades para alocação de recursos; seleciona os negócios nos quais a organização atua ou irá atuar; caracteriza o tipo de organização econômica e humana que a empresa é ou pretende ser; apresenta alternativas para se alcançar uma vantagem sustentável, em longo prazo, em cada um dos negócios da empresa, respondendo corretamente às oportunidades e ameaças do seu ambiente e às forças e fraquezas da organização; está presente em todos os níveis hierárquicos da empresa (corporativo, de negócio e funcional) e, por fim, determina a natureza das contribuições que pretende oferecer a seus stakeholders.

Sob tal enfoque, a estratégia não representa apenas o conjunto de ações coordenadas para o alcance de objetivos. Comporta também aquelas que remetem a um contexto, ou seja, a espaço e tempo, as que são condicionadas às características ambientais - as ações de outros agentes e as suas várias interações. A estratégia é, portanto, um instrumento que alinha a organização com o seu ambiente (HITT; IRELAND, 1985; MacCRIMMON, 1993). Pode-se afirmar que as dimensões da estratégia incluem: o estabelecimento do propósito organizacional, a definição do foco competitivo da organização, o direcionamento das ações, a resposta às demandas do ambiente e os aspectos de gestão (HAX; MAJLUF, 1988). Complementando, a estratégia diz respeito tanto à organização como ao ambiente; é complexa, pois, mesmo considerando que as mudanças remetem a novas circunstâncias, sua essência deve permanecer inalterada; afeta a organização como um todo; implica questões de conteúdo e de processo; existe em níveis diferentes na organização e envolve vários aspectos conceituais e analíticos (MINTZBERG; AHLSTRAND; LAMPEL, 2000).

Conforme a abordagem utilizada neste trabalho, a estratégia deve ser entendida como um curso de ação - geral ou específico - voltado para determinadas situações, que visa alinhar a empresa com um objetivo a ser alcançado. Assim, pode ser definida como uma forma de agir consciente e propositalmente concebida antes das ações (intencional e deliberada) ou como padrão estabelecido em uma seqüência de ações (intencional ou não). É, em suma, um conjunto de ações resultante de um processo contínuo de formulação, emersão e realização de estratégias, cuja finalidade é manter ou melhorar o desempenho da organização e aumentar a sua competitividade. 


\subsubsection{Estratégia e competitividade}

O sistema capitalista encontra-se em constante evolução. $\mathrm{O}$ ambiente mutável em que se insere leva as empresas que dele fazem parte a criar novos bens de consumo e métodos de produção e transporte, bem como novas formas de organização da indústria (SCHUMPETER, 1954). Diante das condições que propiciam esta evolução, como a integração dos mercados, a competitividade torna-se cada vez mais relevante. Em um contexto em contínua mudança, a transformação de ameaças em oportunidades de negócio depende de um sistema de coordenação capaz de transmitir informações, estímulos e controles ao longo de toda a cadeia produtiva, com o intuito de viabilizar a estratégia. Como este sistema é definido a partir de um conjunto de estruturas de governança que interligam os segmentos da cadeia produtiva, podese afirmar que a sua eficiência é determinada pelas transações estabelecidas com tais segmentos (FARINA, 1997).

O conceito de competitividade está presente na Administração desde o final do século XIX e vem se tornando cada vez mais popular, tanto quando considerado de maneira isolada como em conjunção com a estratégia, correspondendo, no último caso, à estratégia competitiva. Estratégia e competição estão genericamente vinculadas aos mesmos propósitos: ambas referem-se à manutenção ou conquista de posições e à sobrevivência. Diferem, contudo, em sua natureza - enquanto a competição é natural em todos os seres vivos, a estratégia decorre do uso da inteligência e de recursos (TAVARES; AMARAL; GONÇALVES, 2003; VASCONCELOS; CYRINO, 2000).

A competitividade tem sido interpretada de várias maneiras. Assim sendo, pode ser definida como a capacidade que tem uma empresa de produzir mercadorias com padrões de qualidade específicos, requeridos por mercados determinados, utilizando recursos em níveis iguais ou inferiores aos que prevalecem em indústrias semelhantes no resto do mundo, durante um certo espaço de tempo. No âmbito organizacional, depende, entre outros fatores, de: ambiente social e político economicamente estável, instituições eficientes, sistemas educacionais adequados, políticas industriais que favoreçam, por meio de incentivos, pesquisa $\&$ desenvolvimento $(\mathrm{P} \& \mathrm{D})$, treinamento de mão-de-obra e acesso a crédito (HAGUENAUER, 1989).

Pode-se abordar a questão da competitividade, considerando-a sob enfoque micro e/ou macroeconômico. Sob a perspectiva macroeconômica, diz respeito à capacidade das economias nacionais de apresentar resultados que se relacionam com o comércio internacional, como elevação do nível de vida e do bem-estar social. Sob a ótica 
microeconômica, centra-se na empresa, especificamente na sua capacidade de desenvolver, produzir e vender um determinado produto, em relação aos concorrentes. Neste caso, as empresas elaboram estratégias e tomam decisões que refletirão sobre volume de vendas, participação no mercado ou margens de lucro (CHUDNOVSKY², 1990 apud KUPFER, 1992).

A competitividade depende de se criar e renovar vantagem competitiva mediante um processo que possibilite a cada empresa desenvolver peculiaridades que a distingam das demais, como, por exemplo, custo, qualidade, lead-time e atendimento. Por outro lado, demanda que as organizações estejam aptas a adotar estratégias e impor correções de rumo quando necessário (COUTINHO; FERRAZ, 1995) ou, como observam Child e Smith (1987), sejam permeáveis ao meio ambiente, isto é, percebam as mudanças que este apresenta e as considerem como referencial para o desenvolvimento de suas atividades.

As características particulares do mercado e do ambiente devem nortear a seleção da estratégia. Pode-se, portanto, afirmar que a competitividade está condicionada a fatores por meio dos quais a organização procura se distinguir de seus competidores, fatores estes que podem ser agrupados, conforme três dimensões, em: internos, estruturais (setoriais) e sistêmicos (macroeconômicos), apresentados na figura 5.

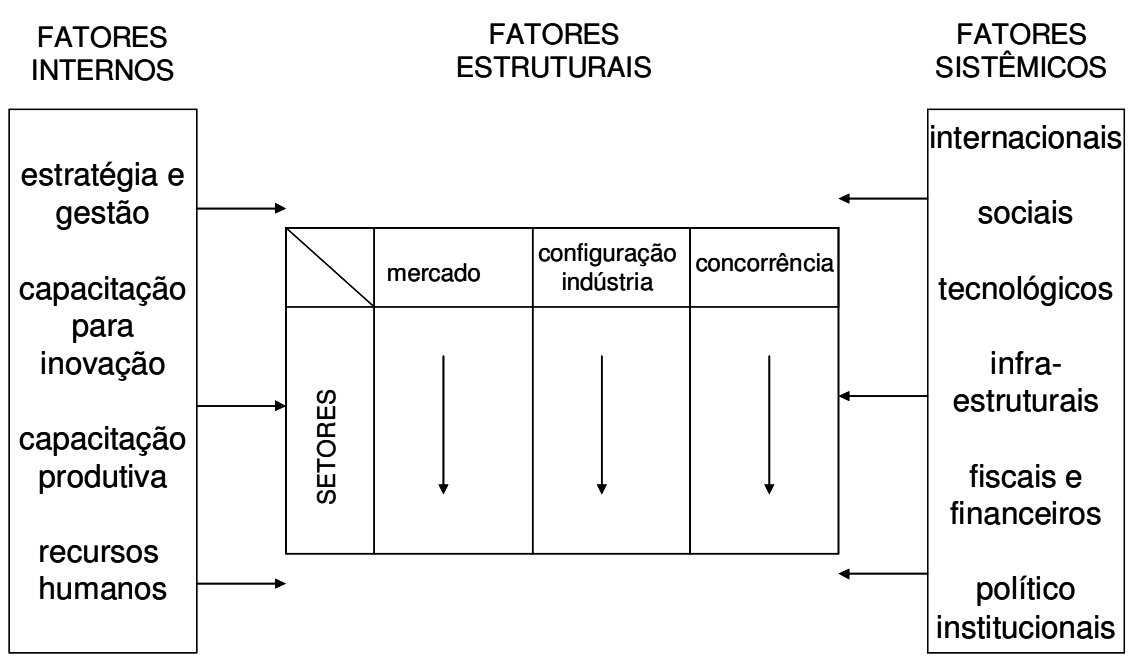

Figura 5 - Fatores determinantes da competitividade da indústria Fonte: Coutinho e Ferraz (1995, p.5)

\footnotetext{
${ }^{2}$ CHUDNOVSKY, D. (1990). La competitividad internacional: principales cuestiones conceptuales y metodologicas. CEIPOS/Montevideo /mimeo/
} 
Os fatores internos, afetos à esfera de decisão, entre outros, são os seguintes: capacidade produtiva e tecnológica, qualidade, produtividade, conhecimento do mercado e serviços pós-vendas. Os fatores estruturais, que caracterizam o ambiente competitivo, estando apenas parcialmente sob o controle da empresa, são as características do mercado consumidor, a configuração da indústria (grau de concentração, escalas operacionais, atributos dos insumos, alianças, grau de verticalização e diversificação setorial, desenvolvimento tecnológico) e a concorrência. Os fatores sistêmicos, que também caracterizam o ambiente competitivo, são de natureza macroeconômica e se classificam em político-institucionais, reguladores, infra-estruturais e sociais (COUTINHO; FERRAZ, 1995).

A competitividade, como se vem expondo, pode se referir ao ambiente ou às nações. Neste estudo, sob o enfoque microeconômico, liga-se à organização, revelando-se como sua capacidade de conceber e implementar estratégias de concorrência, que permitem ampliar ou conservar uma posição sustentável e duradoura no mercado (COUTINHO; FERRAZ, 1995, p.4). Enfatiza-se que a competitividade se relaciona diretamente a duas premissas: o tempo e a incerteza quanto ao futuro. O tempo é fator decisivo no processo de concorrência, à medida que as estratégias competitivas adotadas pelas organizações não rendem frutos de imediato. A incerteza implica a incapacidade de a empresa avaliar com precisão as suas estratégias, aquelas que seus concorrentes adotaram e, por fim, o próprio padrão de concorrência setorial (KUPFER, 1998).

As organizações adotam estratégias competitivas de acordo com a avaliação que fazem do seu desempenho no passado e, principalmente, com base em suas expectativas quanto ao futuro. Em um dado mercado, atuando de forma autônoma e interdependente, sempre tendem a reformular as suas estratégias, em decorrência de variações, entre outros aspectos, do seu estoque de capital, da demanda, dos preços dos fatores de produção, das técnicas, das estratégias das demais competidoras e das expectativas. Assim considerando, a competitividade é função da adequação das estratégias das empresas ao padrão de concorrência vigente no mercado específico. Em cada mercado vigora um dado padrão de concorrência, definido a partir da interação entre estrutura e condutas dominantes no setor. Seriam competitivas as firmas que a cada instante adotassem estratégias de conduta (investimentos, inovação, vendas, compras, financiamento etc.) mais adequadas ao padrão de concorrência setorial (KUPFER, 1992, grifo nosso). 
Se, por um lado, a empresa seleciona estratégias que possibilitam ampliar sua capacitação para atingir alvos pretendidos, por outro, a capacitação acumulada também atua de modo restritivo, uma vez que a empresa só pode adotar estratégias para as quais reúne as competências necessárias. A propósito, deve-se observar que a organização pode não ter condições de adotar estratégias desejadas, por ser este um processo cumulativo que, envolvendo aprendizado, exige tempo para se viabilizar e, em geral, o aporte de recursos adicionais, desproporcionalmente grandes (KUPFER, 1998).

Um dos principais estudos sobre competitividade é de Porter (1985), que ressalta a influência das forças competitivas na elaboração de estratégias. Sua abordagem pressupõe que a atividade organizacional está relacionada com as forças competitivas do seu setor de atuação, como o nível de rivalidade entre os competidores, a ameaça de novos entrantes no mercado, a possibilidade de surgirem produtos que substituam os atuais e o poder de barganha dos compradores e fornecedores. Destaca-se assim que a dinâmica das forças competitivas determina a rentabilidade da empresa e seu posicionamento no setor em que atua, estabelecendo as relações de poder e conflito. Portanto, sob este ponto de vista, considera-se que estas forças influenciam não só o ambiente da organização, mas também a sua competitividade. O enfoque apresentado por Porter (1985, p. 31) relaciona-se com a cadeia de valor que, segundo afirma o autor, "desagrega uma empresa em suas atividades de relevância estratégica para que se possa compreender o comportamento dos custos e as fontes existentes e potenciais de diferenciação". É oportuno observar que a cadeia de valor de uma organização compõe-se de atividades primárias (logística interna, distribuição, marketing e serviços) e de suporte (contabilidade, recursos humanos, administração, compra e desenvolvimento tecnológico) e que a gestão das suas atividades interdependentes torna o produto ou o serviço competitivo (PORTER, 1985).

Basicamente, portanto, relaciona-se o conceito de competitividade com a lucratividade das organizações, considerando aspectos como: posição no mercado, capacidade de formar competências que propiciem produtos e serviços que não podem ser antecipados, qualidade superior e poder de ofertar custos inferiores aos de seus concorrentes (KRUGMAN, 1994; PRAHALAD; HAMEL, 1990).

A literatura apresenta diversos indicadores do nível de competitividade das organizações, como: produtividade, parcela de mercado, qualidade, ganho por ação, medidas sociais e retorno sobre o investimento. Os indicadores de características econômicas, em especial os associados ao lucro, são os mais citados (ZILBER; FISCHMANN, 2002). 
De acordo com Hitt, Ireland e Hoskisson (2005), uma empresa passa a ter vantagem competitiva quando é bem-sucedida na implementação de uma estratégia que gera valor, estratégia esta que outras organizações não conseguem reproduzir ou acreditam que seja muito dispendioso fazê-lo. Destaque-se que, para uma empresa obter retornos superiores à média, precisa saber como explorar a própria vantagem competitiva. Na tentativa de resolver esta questão, os autores apresentam o modelo de organização industrial e o modelo baseado em recursos. Segundo o modelo de organização industrial, o ambiente tem influência dominante sobre as ações estratégicas da empresa e seu desempenho, ou seja, este modelo implica a premissa de que as características externas - do ambiente geral, da indústria e da concorrência - são determinantes ao retorno superior à média. Por outro lado, o modelo baseado em recursos pressupõe que toda organização é um conjunto de recursos e capacidades únicos, que poderão gerar a base para a sua estratégia e vir a ser a principal fonte de seus retornos.

\subsubsection{Estratégia e desempenho organizacional}

A relação entre estratégia e desempenho organizacional tem sido investigada nas principais publicações internacionais desta área de estudos pertinentes à questão, porém, apesar da relevância do tema, é apresentada de forma confusa, contraditória e pouco conclusiva. Geralmente as pesquisas adotam o conceito segundo o qual a estratégia alinha as capacidades da organização com as exigências ambientais, proporcionando à empresa um desempenho superior (JEMISON, 1987; POWEL, 1982).

$\mathrm{O}$ desempenho organizacional varia de acordo com o tipo de empresa e remete à dependência de recursos, como: participação no mercado, vendas, taxa de crescimento e rentabilidade (DAVIES; WALTERS, 2004). Para tais autores, portanto, o desempenho de uma organização depende do seu ambiente e de sua estratégia, destacando-se que esta auxilia na identificação dos ajustes necessários para se chegar a melhores resultados. Pode-se assim afirmar que a relação entre estratégia e desempenho é contingencial, associando-se ao nível de mudança e competitividade do ambiente (ARMSTRONG, 1982; PEARCE; FREEMAN; ROBINSON, 1987).

Para Venkatraman e Ramanujam (1986), o desempenho da organização é multidimensional e pode ser classificado em três níveis: (1) financeiro, referente ao retorno 
sobre ativos, vendas e patrimônio líquido; (2) empresarial, relativo a fatores como participação no mercado, crescimento, diversificação e desenvolvimento do produto e (3) de efetividade organizacional, avaliada pela satisfação dos funcionários, qualidade dos produtos e responsabilidade social.

A relação entre estratégia e desempenho organizacional gera diferentes resultados. Explicitam-se alguns, a seguir, observando-se que a estratégia:

- possibilita o alinhamento da organização com o seu ambiente (ANSOFF, 1990; ARMSTRONG, 1982; JEMISON, 1987; MILLER; CARDINAL, 1994; SNOW; HAMBRICK, 1980);

- proporciona agilidade na tomada de decisões e auxilia na adoção de novos produtos, modelos de gestão ou tecnologias (BAUM; WALLY, 2003; EISENHARDT, 1989);

- resulta em mais vendas e maior rentabilidade, ou seja, melhores resultados financeiros (ANSOFF, 1990; EISENHARDT, 1989);

- favorece a exploração de oportunidades e aquisição de vantagem competitiva, ou seja, permite que as organizações, inseridas em ambientes dinâmicos ou estáveis, explorem as oportunidades antes que desapareçam ou não representem mais vantagem competitiva (BAUM; WALLEY, 2003; HAX; MAJLUF, 1988);

- motiva os stakeholders, viabilizando a identificação de competências, possibilidades de crescimento, melhor utilização de recursos para atingir objetivos previamente definidos (HAX; MAJLUF, 1988; HITT; IRELAND, 1985; SNOW; HAMBRICK, 1980);

- aumenta a probabilidade de sobrevivência e prosperidade das organizações, diante de crises, ameaças constantes ou revoluções (BARNEY, 1986).

\subsection{COMO PENSAR A ESTRATÉGIA NAS ORGANIZAÇÕES?}

Mintzberg e Lampel (1999) classificam dez escolas de pensamento estratégico, que enfatizam diferentes aspectos do processo. Esta classificação foi bem aceita pelas comunidades acadêmica e profissional, devido à sua abrangência, ou seja, por fundamentar a estratégia em várias disciplinas - economia, antropologia, psicologia, sociologia, ciência política, biologia e possivelmente outras. Entre tais escolas, encontram-se três de caráter prescritivo, ou seja, de natureza normativa, que dão maior destaque ao modo de formular estratégias que à forma de concebê-las (do design, do planejamento e do posicionamento) e 
seis descritivas (empreendedora, cognitiva, do aprendizado, do poder, cultural e ambiental), que se concentram no processo de concepção da estratégia. A escola da configuração, inicialmente classificada como descritiva, por constituir uma síntese das anteriores, apresenta aspectos prescritivos e descritivos. (MINTZBERG; LAMPEL, 1999; MINTZBERG, AHLSTRAND; LAMPEL, 2000; VASCONCELOS, 2001; grifo nosso). A seguir realiza-se uma breve descrição das dez escolas do pensamento estratégico que encontram-se sintetizadas no quadro 3.

- Escola do design: enfatiza o caráter conceitual e consciente do processo de formação de estratégia. Este processo se desenvolve a partir da avaliação das forças e fraquezas organizacionais e das oportunidades e ameaças oferecidas pelo ambiente, tendo em vista realizarem-se ajustes necessários (processo deliberado, que não é formalmente analítico nem informalmente intuitivo). Segundo esta abordagem, a estratégia resulta em um projeto e o seu processo de formação é prescritivo.

- Escola do planejamento: considera a formação de estratégias um processo formal, estruturado e numérico. Sob tal ótica, tal processo demanda instrumentos formais e numéricos, decompõe-se em passos distintos, delineados por listas de verificação, e exige o suporte de técnicas. A estratégia, neste caso, resulta em um plano e o seu processo de formação é prescritivo.

- Escola do posicionamento: destaca que a formação de estratégias pressupõe a escolha deliberada de posicionamento competitivo mediante um processo analítico de decisão. Privilegia a análise formal das situações do segmento - estrutura da indústria em que a organização se insere - para se definir uma posição genérica. De acordo com esta perspectiva, a estratégia resulta em uma posição e o seu processo de formação é prescritivo.

- Escola empreendedora: considera a formação de estratégia um processo visionário, que focaliza o papel dos líderes carismáticos e dos empreendedores visionários. Sob este ponto de vista, tanto a formulação quanto a implementação de estratégias são processos informais e intuitivos, isto é, baseados na criatividade, visão e perspectiva do líder da organização. Conforme esta escola, a estratégia configura uma visão e o seu processo de formação é descritivo.

- Escola cognitiva: propõe um processo mental de elaboração e implementação de estratégias. Este processo implica não apenas a interpretação e o processamento de informações, mas também o mapeamento da realidade, com o objetivo de defini-la a partir 
de novos conceitos, considerando inovações radicais. A criação de estratégias pressupõe, portanto, um processo mental descritivo.

- Escola do aprendizado: presume que a estratégia deriva de um processo emergentelexploratório, com ênfase no aprendizado por tentativa e erro. Trata-se de um processo que se revela e evolui como um modo interativo de formulação e implementação de estratégias presente, em toda a organização, na figura do estrategista. Conforme esta abordagem, a estratégia é descritiva.

- Escola do poder: desvenda a presença de um processo de negociação e interesses na elaboração de estratégias. Entende-se assim que a formação de estratégias é influenciada por relações de poder tanto no micro quanto no macrocontexto. No microcontexto, ocorre mediante um processo político que implica barganha, persuasão e confronto nas negociações entre os atores que dividem o poder. No macrocontexto, o poder é utilizado sobre os parceiros e outras redes de relacionamento na negociação de estratégias de interesse coletivo. O processo de formação de estratégia, sob esta perspectiva, é descritivo.

- Escola cultural: revela a inserção humana e social no processo de formar estratégias. Caracterizado como um processo social e integrativo, pressupõe-se que seja influenciado pela cultura da organização. Trata-se de um processo descritivo.

- Escola ambiental: enfatiza o papel determinante do ambiente na formação das estratégias organizacionais, processo este considerado reativo. Postula-se que o ambiente, por meio de comportamentos isomórficos, determina a estratégia da empresa. O processo de formação de estratégias, neste caso, é descritivo.

- Escola da configuração: uma síntese das escolas anteriores, com ênfase no processo contextual de transformação. Esta escola, extensa e integradora, apresenta-se sob dois diferentes aspectos: o descritivo e o prescritivo. (1) O descritivo refere-se à classificação das organizações como agrupamentos coerentes, em termos de suas características e seus comportamentos, e integra as escolas anteriores de acordo com seus aspectos (por exemplo, organizações mecanicistas, em condições de estabilidade relativa, tendem a adotar o planejamento, enquanto o estilo empreendedor se faz presente nas configurações dinâmicas de empresas iniciantes). (2) O prescritivo diz respeito à transformação e prática, à alteração da condição atual da organização. 


\begin{tabular}{|c|c|c|c|}
\hline Categoria & Escolas & Processo & Características \\
\hline \multirow{3}{*}{ Prescritiva } & Design & $\begin{array}{l}\text { Concepção e } \\
\text { adaptação }\end{array}$ & $\begin{array}{l}\text { Processo conceitual, consciente e deliberado. Estratégia } \\
\text { como adequação de forças e fraquezas internas com } \\
\text { ameaças e oportunidades. }\end{array}$ \\
\hline & Planejamento & Formalização & Requer procedimentos formais e estruturados. \\
\hline & Posicionamento & Analítico & Análises formalizadas e escolha deliberada da posição. \\
\hline \multirow{6}{*}{ Descritiva } & Empreendedora & $\begin{array}{l}\text { Visionário } \\
\text { (previsão) }\end{array}$ & Centralizada no líder e em sua visão. \\
\hline & Cognitiva & Mental (criação) & Processo individual informal e intuitivo \\
\hline & Aprendizagem & $\begin{array}{l}\text { Aprendizado } \\
\text { (emergente) }\end{array}$ & $\begin{array}{l}\text { Processo emergente que surge com o aprendizado do } \\
\text { estrategista. }\end{array}$ \\
\hline & Poder & $\begin{array}{l}\text { Político } \\
\text { (negociação) }\end{array}$ & $\begin{array}{l}\text { Interesses coletivos são negociados e desvendados nos } \\
\text { âmbitos macro e micro. }\end{array}$ \\
\hline & Cultural & Coletivo & $\begin{array}{l}\text { Processo social e integrativo influenciado pela cultura da } \\
\text { organização }\end{array}$ \\
\hline & Ambiental & Reativo & As características ambientais definem a estratégia \\
\hline $\begin{array}{l}\text { Prescritiva/ } \\
\text { Descritiva }\end{array}$ & Configuração & $\begin{array}{l}\text { Transformação e } \\
\text { integração }\end{array}$ & $\begin{array}{l}\text { Processo de transformação resultante de uma síntese das } \\
\text { escolas anteriores }\end{array}$ \\
\hline
\end{tabular}

Quadro 3 - Escolas do pensamento estratégico: processo e características

Fonte: elaborado a partir de Mintzberg e Lampel (1999); Mintzberg; Lastran e Lampel (2000)

Em estudo feito com executivos ligados ao processo de formação de estratégias em empresas nacionais e multinacionais, de grande, médio e pequeno porte, destaca-se que nenhuma escola é unanimemente aceita ou sistematicamente rejeitada (VASCONCELOS, 2001). Por outro lado, a interpretação da estratégia como um processo único respalda-se no fato de que algumas escolas se apresentam como estágios ou aspectos do processo de criação de estratégias.

Escrivão Filho (2006), com base na obra "Safári de Estratégias" (MINTTZBERG; AHLSTRAND; LAMPEL, 2000), identifica três níveis de análise nas escolas do pensamento estratégico: (1) abordagem individual e interna à organização, nas escolas do design, empreendedora, cognitiva e do aprendizado, com a possibilidade de fusão das duas últimas; (2) abordagem coletiva e interna à organização, nas escolas do planejamento, cultural, do aprendizado e do poder micro; (3) abordagem externa à organização, nas escolas do posicionamento, ambiental e do poder macro. Estas dimensões ajudam a compreender as escolas em seu conjunto e identificar o comportamento que estudam, ou seja, o indivíduo (a 
partir do conceito de liderança), a organização (a partir da estruturação de recursos e competências) e o ambiente (a partir das oportunidades e forças competitivas), conforme o demonstra a figura 6.

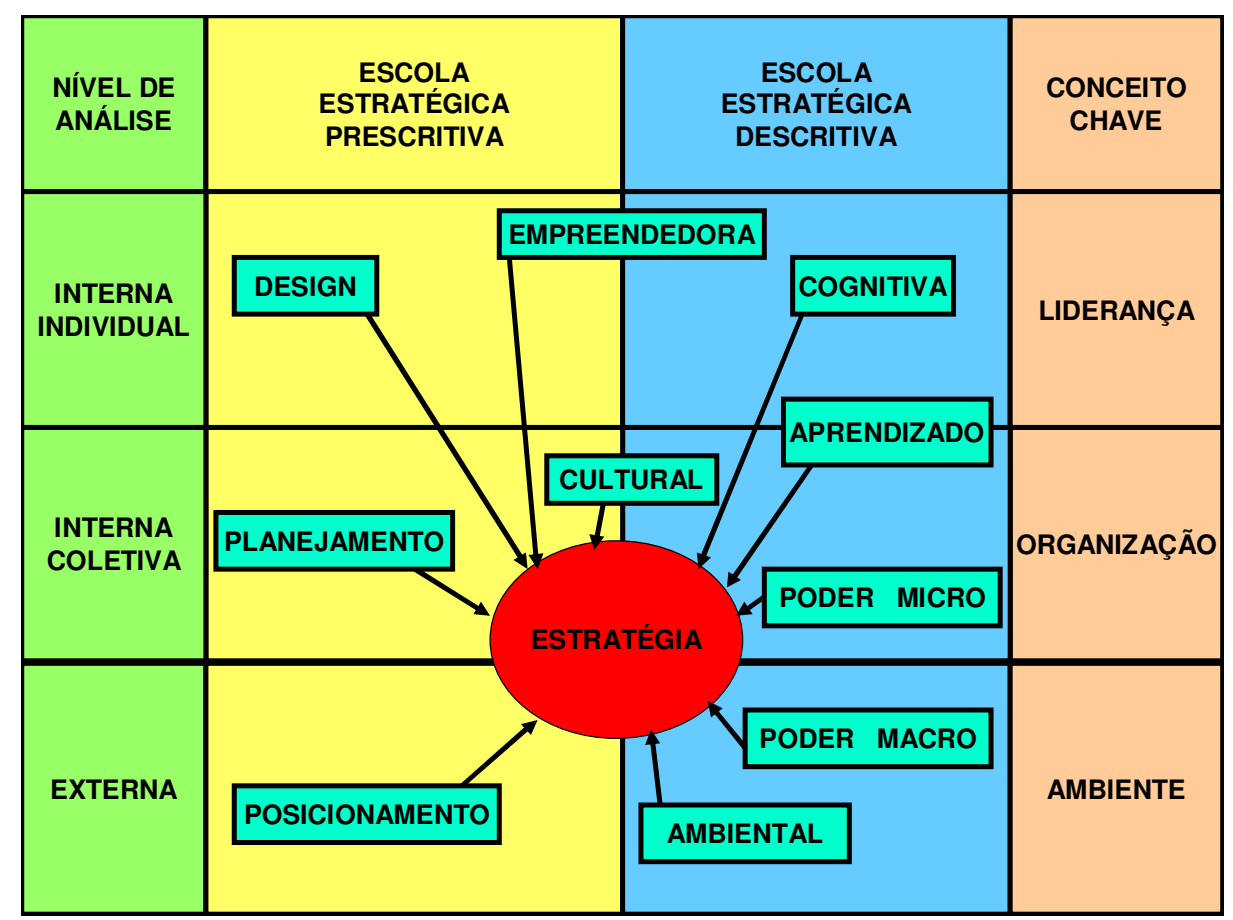

Figura 6 - Conceitos-chave estruturantes das escolas do pensamento estratégico Fonte: Escrivão Filho (2006)

O conceito de liderança abrange processos racionais, visionários e cognitivos de modelos e informação desenvolvidos na mente do estrategista. No âmbito de ação coletiva, compreende processos de planejamento organizacional, de aprendizagem, culturais e de poder, desenvolvidos mediante interação humana. As forças ambientais registram processos de análise de posição no setor de negócios, de aliança e negociação com outras organizações e de adaptação da empresa ao ambiente, todos, portanto, desenvolvidos em comparação com o comportamento de outras organizações (ESCRIVÃO FILHO; PERUSSI FILHO; TERENCE, 2007). A interação destas dimensões e seus elementos compõem um sistema de administração estratégica (figura 7). 


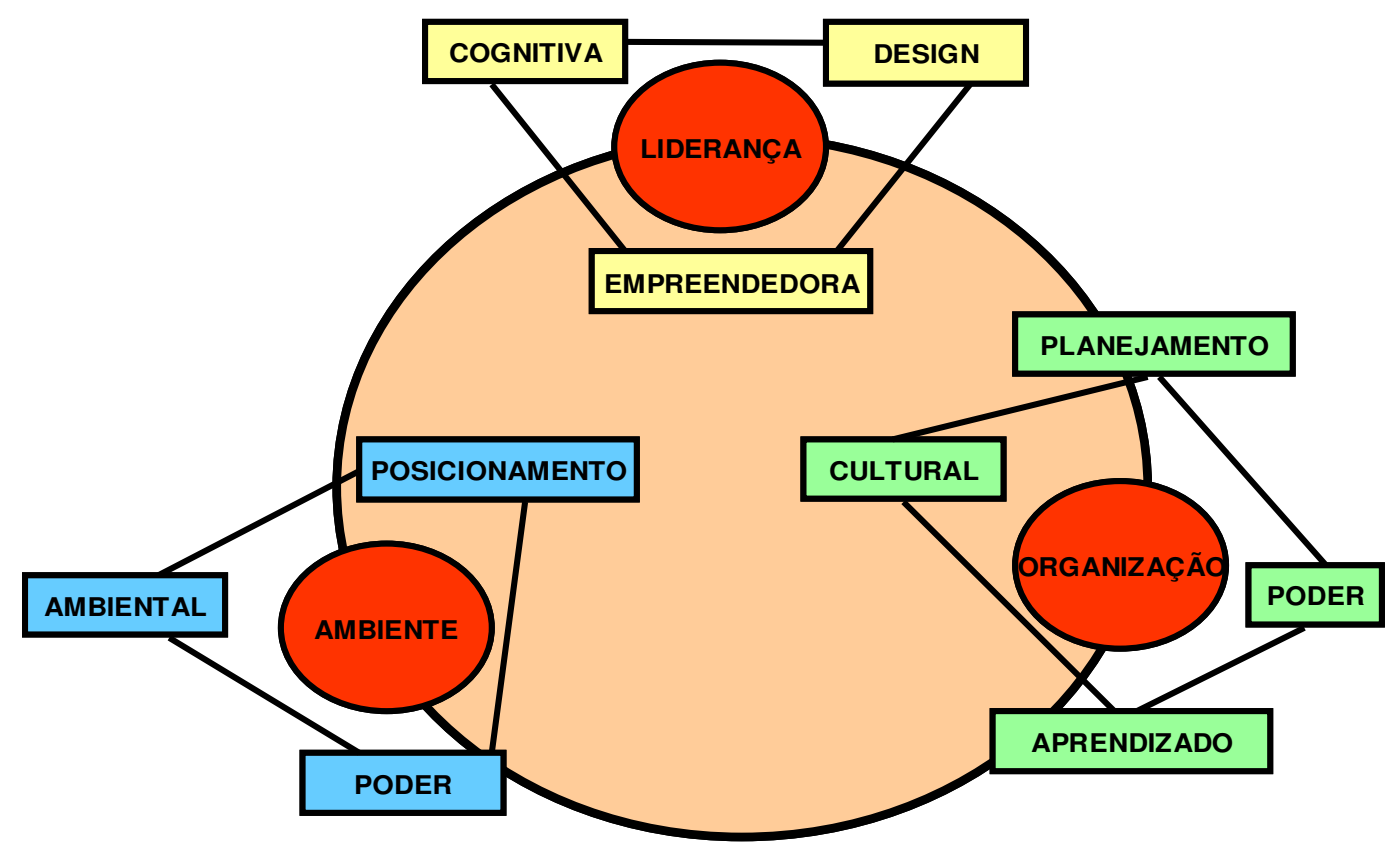

Figura 7 - Sistema de Administração Estratégica formado por liderança, organização e ambiente Fonte: Escrivão Filho (2006, p. 153)

Escrivão Filho (2006) esclarece que cabe ao estrategista entender a criação da estratégia como um sistema formado pela orientação do líder, pelos processos organizacionais e pelas forças do ambiente, considerando que cada uma dessas três dimensões pode ter comportamento diverso dentro do sistema, conforme papel desempenhado por seus elementos.

Pode-se afirmar, portanto, que o estudo da estratégia a partir de apenas uma escola um único elemento do sistema - é uma visão míope e reducionista. O sistema reforça a necessidade de uma visão global de liderança, organização e ambiente na administração estratégica. Sob esta ótica, a processo estratégico refere-se ao julgamento, à definição intuitiva de uma visão e ao processo de aprendizagem; implica transformação e permanência, cognição e interação social, cooperação e conflito, análise, negociação e programação em resposta a uma demanda ambiental; concentra-se, enfim, nos atributos de determinadas escolas, pautados nos elementos do sistema de Administração Estratégica.

Possíveis sínteses da Administração Estratégica, de acordo com a classificação de Mintzberg, Ahlstrand e Lampel (2000), podem ser realizadas como: o sistema prescritivo que 
é racionalista e enfatiza a elaboração da estratégia como uma proposição do líder, a partir da análise do ambiente; o sistema empreendedor formado pela visão empreendedora do líder, por valores culturais decorrentes da visão e pela crença da igualdade de concorrência no ambiente e; o sistema de aprendizagem que é formado por um processo individual, intuitivo e de aprendizagem do líder com as estratégias que emergem influenciadas pelas características ambientais (ESCRIVÃO FILHO, 2007). Uma mudança na combinação dos fatores liderança, organização e ambiente gera diferentes sistemas de administração estratégica, limitados pelas condições das organizações. 


\section{PROCESSO DE CRIAÇÃO DE ESTRATÉGIAS}

Definir o processo estratégico como a criação de estratégias para uma determinada organização implica considerar a proximidade entre formar e implementar ações estratégicas (MANDERSCHEID; KUSY, 2005), tendo em vista a sua adaptação às mudanças ambientais. Em outras palavras, trata-se de uma abordagem cuja premissa é conceber estratégias deliberadas e emergentes em uma organização, com o intuito de direcioná-la a um processo contínuo de aprendizagem.

Pode-se considerar o processo de criação de estratégias, sob duas diferentes abordagens, como deliberado ou emergente. A primeira, tida como tradicional e dominante, devido ao seu uso em grande número de pesquisas e publicações e à sua influência no meio empresarial, fundamenta-se na busca racional das melhores alternativas e caminhos, pela utilização de instrumentos analíticos, para se obter o sucesso organizacional e interpretar a realidade. A principal ferramenta desta vertente é o planejamento estratégico e, nos dias atuais, a administração estratégica. Entre os autores que adotam a visão deliberada, estão aqueles que pertencem às escolas do planejamento, do posicionamento e do design. A partir dos anos 80, ganha força a visão emergente, que destaca a possibilidade de criar estratégias em um processo contínuo de aprendizado, com base nos acontecimentos cotidianos da organização. Entre os autores que partilham esta visão estão os que pertencem às escolas: empreendedora, de cognição e de aprendizagem (MINTZBERG; LAMPEL, 1999; MINTZBERG, AHLSTRAND; LAMPEL, 2000; MINTZBERG, 2004).

É oportuno observar que, embora seja um tema amplamente discutido, pouco conhecimento se tem sobre o modo como a estratégia é realizada e de seus benefícios (GLUCK; KAUFMAN; WALLECK, 1982). Em vista disso, pretende-se descrever os aspectos dos processos deliberado e emergente de criação de estratégias, elaborando-se uma síntese das diversas abordagens existentes, a partir da análise e discussão de suas características e dos fatores que os influenciam. 


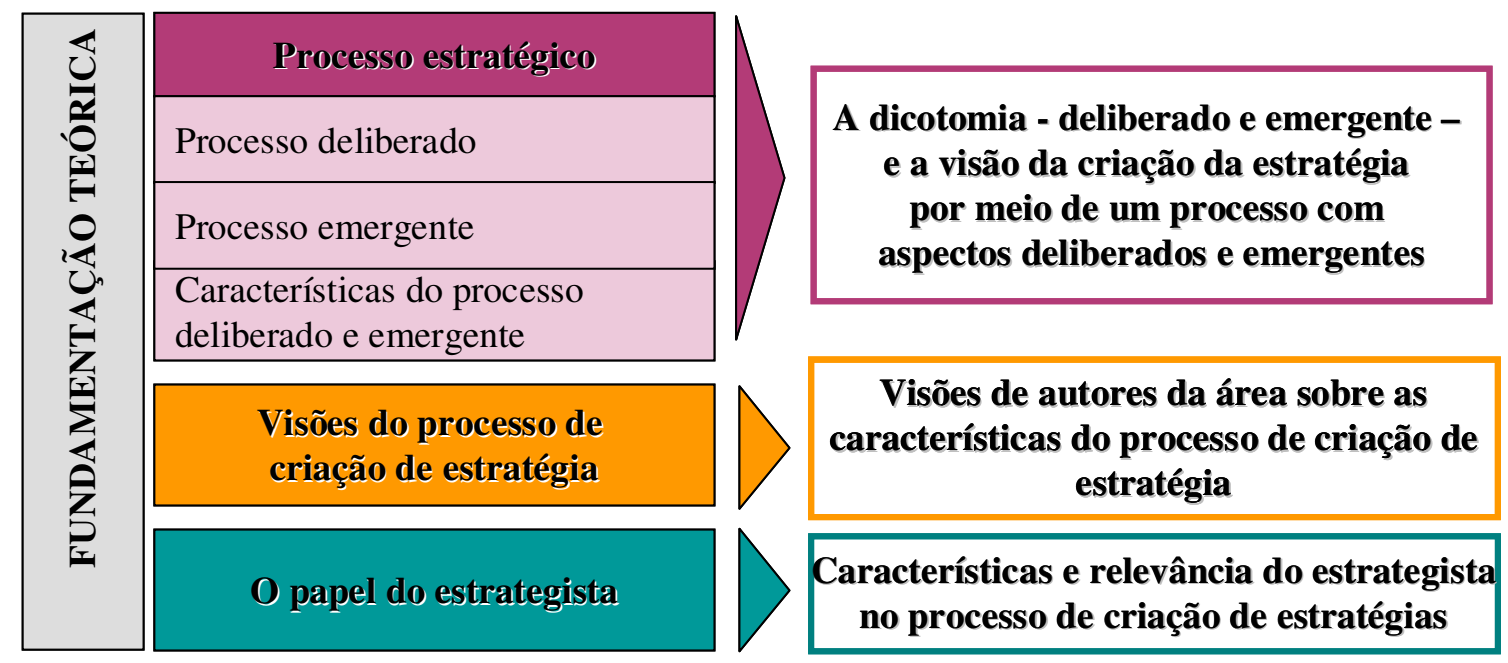

Figura 8 - Estrutura do capítulo processo de criação de estratégia

\subsection{PROCESSO ESTRATÉGICO}

Parnell e Lester (2003) concebem a estratégia como arte e ciência simultaneamente. Discutindo tal concepção, estes autores apresentam algumas de suas características (quadro 4) que se aproximam dos processos deliberado e emergente de criação de estratégias. Por um lado, a estratégia apresenta-se como um modo de desenvolver e implementar estratégias em negócios com baixo nível de incerteza, como um processo racional, que precisa ser gerenciado com ferramentas sistemáticas e analíticas. Por outro, revela uma dimensão criativa, presente em ambientes instáveis e que requerem inovação (PARNELL, 2003).

\begin{tabular}{|l|l|l|}
\hline \multicolumn{1}{|c|}{ Características } & \multicolumn{1}{c|}{ Arte } & \multicolumn{1}{c|}{ Ciência } \\
\hline Análise sistemática do ambiente & Difícil & Possível e essencial \\
\hline Previsibilidade do ambiente & Limitada & Extensa \\
\hline Percepção do ambiente & Subjetiva & Objetiva \\
\hline Etapas & $\begin{array}{l}\text { Variáveis, de acordo com a } \\
\text { organização }\end{array}$ & $\begin{array}{l}\text { Similares na maioria das } \\
\text { organizações }\end{array}$ \\
\hline Influência intelectual & Imaginação & Análise \\
\hline
\end{tabular}

Quadro 4 - Estratégia como arte e ciência

Fonte: Panell e Lester (2003, p. 292) 
Mintzberg (1987c) questiona a dicotomia formulação/formação de estratégia, utilizada pelos pesquisadores da área, de acordo com a qual a estratégia se desenvolve de modo consciente e deliberado ou de forma não intencional. O processo de formação de estratégias, para ser completo, deve abranger características tanto deliberadas quanto emergentes (ANDERSEN, 2004; MINTZBERG, 1978; MINTZBERG; WATERS, 1985). Muitas estratégias são claramente deliberadas e outras claramente emergentes, mas é provável que a maioria delas se localize em uma linha contínua que existe entre os dois tipos, conforme ilustrado na figura 9. Embora algumas estratégias se aproximem de uma ou outra extremidade, a maioria encontra-se nos pontos intermediários, pois, assim como a elaboração de estratégia puramente deliberada impede o aprendizado contínuo, a elaboração de estratégia puramente emergente dificulta ou impede o controle organizacional (MINTZBERG; WATERS, 1985; MINTZBERG et al., 2006).

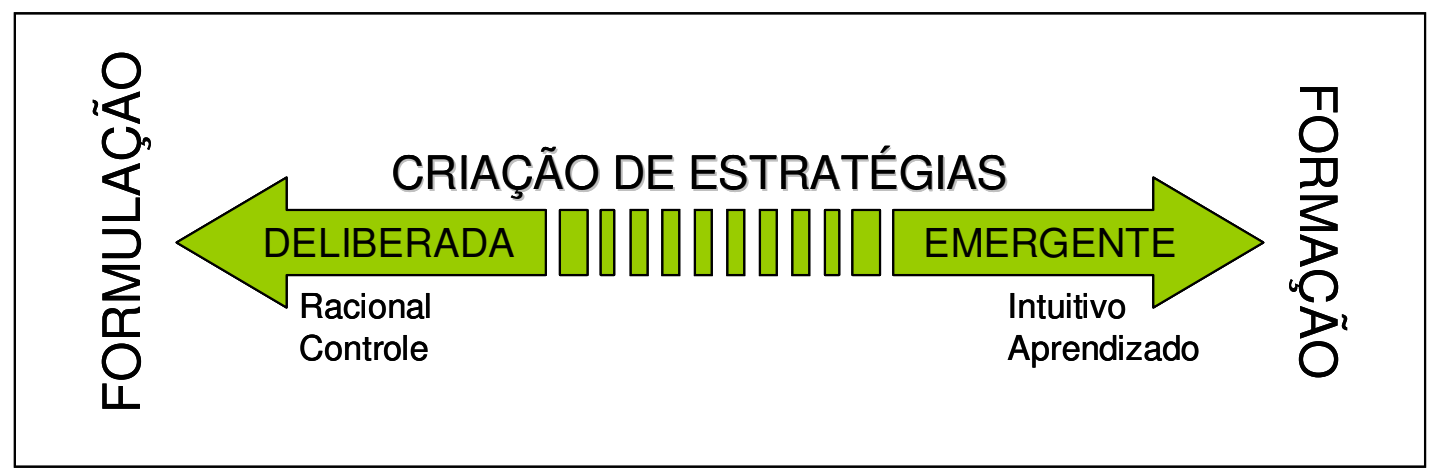

Figura 9 - Linha contínua do processo de criação de estratégias

\subsubsection{Processo deliberado}

As estratégias deliberadas, segundo Mintzberg (1978), podem ser definidas como um padrão de ação que se desenvolve de acordo com um plano, formulado pelos dirigentes de uma empresa, que prevê o estabelecimento de objetivos e programas detalhados e de implementação posterior (MARIOTO, 2003). Implicam intenções articuladas, controles formais e distinção clara entre formulação e implementação. Atribui-se aos líderes a responsabilidade de formular a intenção como planos detalhados. Consideram-se as estratégias puramente deliberadas, isto é, realizadas, portanto correspondentes às pretendidas, desde que atendam a três condições (MINTZBERG; WATERS, 1985): (1) estabelecer 
intenções precisas e detalhadas na organização; (2) não permitir dúvida quanto à consistência e aceitação das intenções pelos atores organizacionais e (3) realizar as intenções exatamente como pretendidas.

A grande maioria das obras da literatura sobre estratégia descreve a formulação e implementação de estratégias como um processo deliberado, racional, a partir do qual se produzem estratégias claras e explícitas. Esta racionalidade diz respeito ao uso de informação previamente coletada, com o intuito de selecionar uma alternativa sensata para perseguir objetivos propostos (HOUGH; WHITE, 2003; MINTZBERG, 1987b). Planejamento, análise e controle são seus conceitos fundamentais.

A dimensão racional, representada por planos, enfatiza a importância da análise exaustiva das alternativas disponíveis para a tomada de decisão, o monitoramento sistemático do ambiente, a adoção de métodos de planejamento e a unificação de estratégias com o fim de identificar e avaliar as consequiências da adoção de cada alternativa e selecionar-se a mais adequada diante das possibilidades (FREDRICKSON; MITCHELL, 1984; HART, 1992; HOUGH; WHITE, 2003). Para concretizar este intento, sugerem-se a análise ambiental sistemática de concorrentes e mercados e a avaliação de forças e fraquezas internas e externas que, combinadas com a produção de estratégias claras e explícitas, tornem possível fixar metas, avaliar cursos alternativos de ação e desenvolver um plano para alcançar as metas. São privilegiados, sobremaneira, modelos que identificam construções lógicas de interpretação da realidade, tais como análise SWOT (strenghts, weaknesses, opportunities, threats), planejamento estratégico, análise da indústria, cadeia de valor, matriz elaborada pelo Boston Consulting Group (BCG), curvas de aprendizagem e diamante da competitividade. Os estudos sobre o caráter deliberado vêm evoluindo, como se pode observar: nos trabalhos pioneiros de Fayol $^{3}$ (1916) sobre a importância do planejamento e da coordenação; nos trabalhos de Selznick $^{4}$ (1957) sobre competências distintivas; na formulação do modelo SWOT por Andrews (1971); no desenvolvimento da teoria do planejamento, como sistema de controle, por Ansoff (1965), e em toda a análise da estrutura da indústria que deriva do trabalho de Porter $(1985,1991)$.

A figura 10 representa o processo deliberado, que se caracteriza como racionalinstrumental e analítico, conforme descrito anteriormente, um processo desenvolvido a partir de um objetivo pré-definido e da análise das capacidades organizacionais (condições internas e externas), que leva à concepção de um plano a ser implementado, à realização de ações

\footnotetext{
${ }^{3}$ FAYOL, H. (1916). General and industrial management. London Pitman., 1949.

${ }^{4}$ SELZNICK, P. (1957) Leadership in Administration. New York Harper \& Row.
} 
previstas e ao alcance de objetivos pré-determinados. Ressalte-se que o processo de elaboração e implementação de estratégias é composto de atividades gerenciais interrelacionadas (análises, cálculos, definições de metas, estabelecimento de ações, entre outras), que podem ser revistas quando há alterações significativas nas condições internas e/ou externas, devido a dificuldades ou falhas na implementação ou alterações de objetivos.

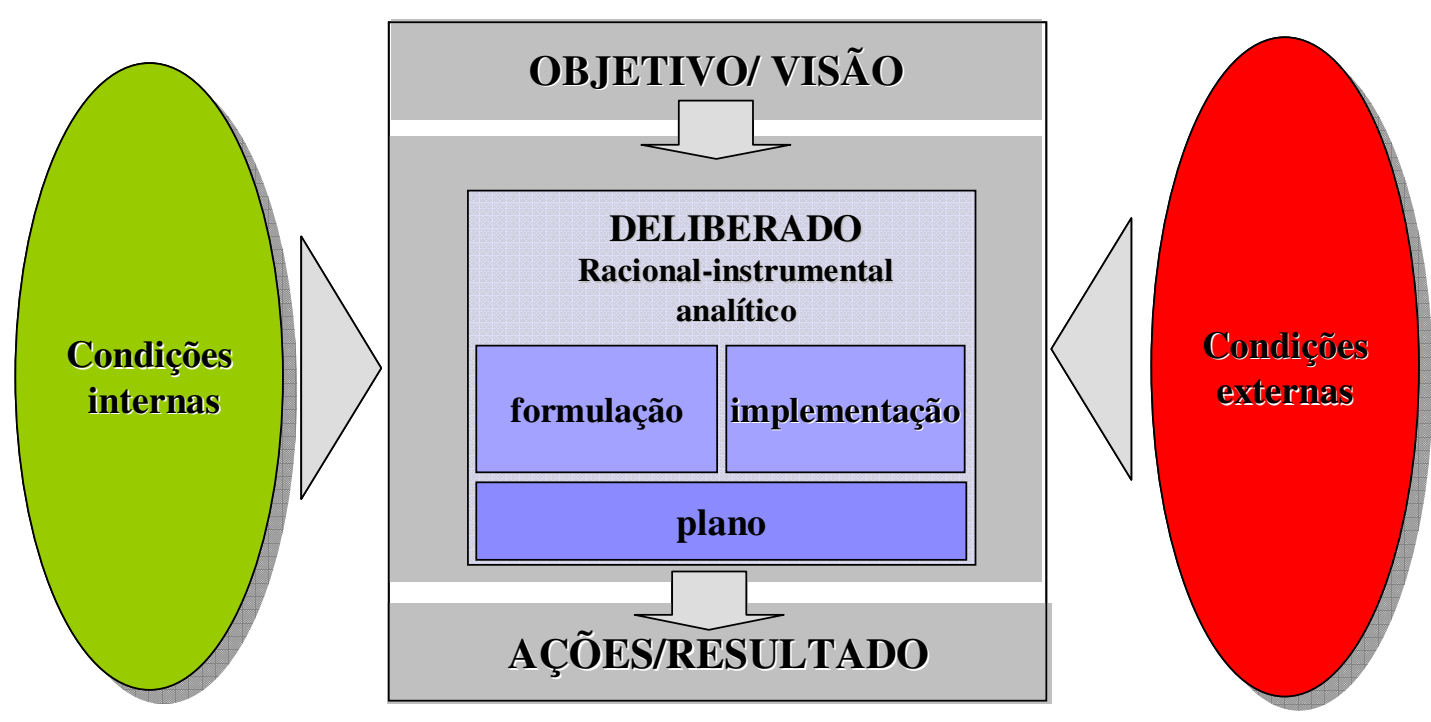

Figura 10 - Processo deliberado de criação de estratégias

O modelo racional do processo de criação de estratégia relaciona-se com o sistema de planejamento estratégico que, por mais de duas décadas, vem sendo utilizado pelas empresas, de maneira ampla. A escola do planejamento surge com a publicação de Ansoff (1965): predomina, na literatura, até meados dos anos 70, hesita nos anos 80 e continua a ter influência nos dias atuais (MINTZBERG, LAMPEL, 1999). A gestão estratégica é fundamentalmente entendida como planejamento estratégico que, por sua vez, se define como ferramenta de crescimento, por meio da expansão e diversificação. Assim compreendido, o planejamento estratégico ajuda a elaborar uma estratégia para as organizações, a estabelecer um curso de ação, identificando seus pontos fortes e fracos e as oportunidades e ameaças advindas do seu ambiente (BERTERO; VASCONCELOS; BINDER, 2003).

A crise do planejamento estratégico ocorre em razão da imprevisibilidade cada vez maior do ambiente de negócios. Trata-se de um processo que, por ser racional e sistemático, leva a melhores resultados, quando aplicado a ambientes estáveis (HOUGH; WHITE, 2003). É neste contexto que a Administração Estratégica ganha espaço, porque é a responsável pelo 
desenvolvimento e pela implantação de estratégias nos diversos níveis funcionais da organização (BERTERO, 1995) de maneira mais dinâmica e integrada.

Apesar de sua grande influência e utilização nos meios acadêmico e empresarial e de ainda ter vários defensores e seguidores, o processo deliberado racional-analítico vem recebendo inúmeras críticas. Mintzberg (1994), um dos seus maiores críticos, conclui que o planejamento estratégico não é sinônimo de formulação de estratégia, mas uma programação da estratégia. O autor apresenta uma série de obstáculos ao uso eficaz da ferramenta, decorrentes de algumas de suas características como, por exemplo, tende a inibir a criatividade e o pensamento estratégico, a ser inflexível, a desencorajar novas idéias e a gerar resistência a mudanças e um clima de conformidade.

A seguir, apresentam-se outras limitações ao processo deliberado, identificadas na literatura:

- as mudanças ambientais, cada vez mais intensas e constantes, dificultando previsões sobre o futuro (MINTZBERG, 1994), tornam inadequado o seu uso nas empresas que atuam em contextos que se modificam rapidamente (BROWN; EISENHARDT, 1997; HOUGH; WHITE, 2003);

- a sua lógica formal nem sempre leva ao consenso na solução de problemas (QUINN, 1980);

- como muitos planos, não resulta em novas estratégias de sucesso (CAMPBELL; ALEXANDER, 1997): pode-se afirmar que não se destina a criar estratégias, mas a programar estratégias anteriormente criadas, e que, portanto, a formulação de estratégias, mediante planejamento, resulta na extrapolação das estratégias existentes ou na convivência com as estratégias dos competidores (MINTZBERG, 1987);

- o seu uso, separando os planejadores do dia-a-dia organizacional, origina uma tendência a confiar em dados (formais) de valor questionável, sem que se considerem observações e dados cotidianos (MINTZBERG, 1994);

- segue um calendário baseado em um ritual de etapas e fases, de acordo com o qual se assume que o futuro será mais ou menos como o presente (HAMEL, 1996) ou como o passado;

- é um processo linear, estático e fragmentado (FARJOUN, 2002).

Destacando os aspectos positivos, autores argumentam que, como processo explícito, auxilia na coleta e análise de dados fundamentais (longo prazo) para se desenvolver e manter o alinhamento da organização com o seu ambiente (ANSOFF, 1990; ARMSTRONG, 1982; QUINN, 1989), para se viabilizarem a integração e o controle de processos (MILLER; 
CARDINAL, 1994) e para se exigirem a comunicação de objetivos e a alocação de recursos (QUINN, 1989). Enfim, proporciona disciplina ao pensamento estratégico na organização e oferece melhores resultados que os métodos de tentativa e erro (ARMSTRONG, 1982; ANSOFF, 1990, 1991).

O planejamento estratégico preconiza o empenho dos administradores em coletar informações sobre uma dada oportunidade empresarial e especificar como serão utilizadas para se criar uma nova empresa, capaz de explorá-la adequadamente (DELMAR; SHANE, 2003). Assim, a sua grande contribuição não está na formulação de estratégias, mas no preparar as mentes dos administradores para a tomada de decisões estratégicas. Sob esta ótica, é uma ferramenta de aprendizado capaz de auxiliar os gestores a tomar decisões estratégicas sólidas, fundamentadas em condições ambientais turbulentas e incertas (KAPLAN, BEINHOCKER, 2003). O real propósito do planejamento estratégico é facilitar o desenvolvimento do pensamento estratégico (HERACLEOUS, 1998).

\subsubsection{Processo emergente}

Trata-se de uma outra abordagem do processo de criação de estratégias, que ressalta a possibilidade de moldá-las. Demanda dedicação e esforço na busca de perfeição mediante o domínio de detalhes e a conexão entre pensamento e ação em um processo fluido de aprendizado. O estrategista que molda a estratégia utiliza seu conhecimento, resultante de sua experiência anterior, para moldar o seu futuro (MINTZBERG, 1987c).

O processo emergente, conceito introduzido na literatura por Mintzberg (1978), presta-se a especificar as estratégias que não são preconcebidas, mas formadas por ações que derivam das atividades diárias de negócios, especialmente da relação entre a empresa, seus clientes e o mercado, e se identificam como estratégias à medida que vão se desenrolando ou até mesmo depois que ocorrem (MARIOTTO, 2003). Reiterando, o conceito de estratégias emergentes caracteriza-se como um padrão formado por uma sucessão de ações não determinadas previamente (MINTZBERG, 1978; MINTZBERG; WATERS, 1985).

O processo essencialmente emergente comporta aspectos como inovação, criação, descoberta, originalidade e mudanças, que dizem respeito à dimensão inovadora da estratégia. A evolução desta abordagem pode ser constatada nos trabalhos de Simon (1945) sobre a racionalidade limitada e o foco de atenção, nos estudos de Schumpeter (1954) e dos outros 
membros da escola austríaca de economia, na teoria comportamental da firma de Cyert e March (1963), no incrementalismo lógico de Brian Quinn (1980) e no conceito de competências centrais de Prahalad e Hamel (1990). Trata-se de uma abordagem que implica visão, inovação, mudança, insight e aprendizado.

Assim sendo, as ações desenvolvidas sem uma pré-concepção explícita derivam de um processo criativo e intuitivo, de uma inter-relação de fatores, como as condições internas e externas, a perspectiva da alta direção e a análise de viabilidade dos funcionários que atuam em níveis inferiores (FARJOUN, 2002), em um processo que acontece de maneira irregular, inesperada e, freqüentemente, informal (MINTZBERG, 1994).
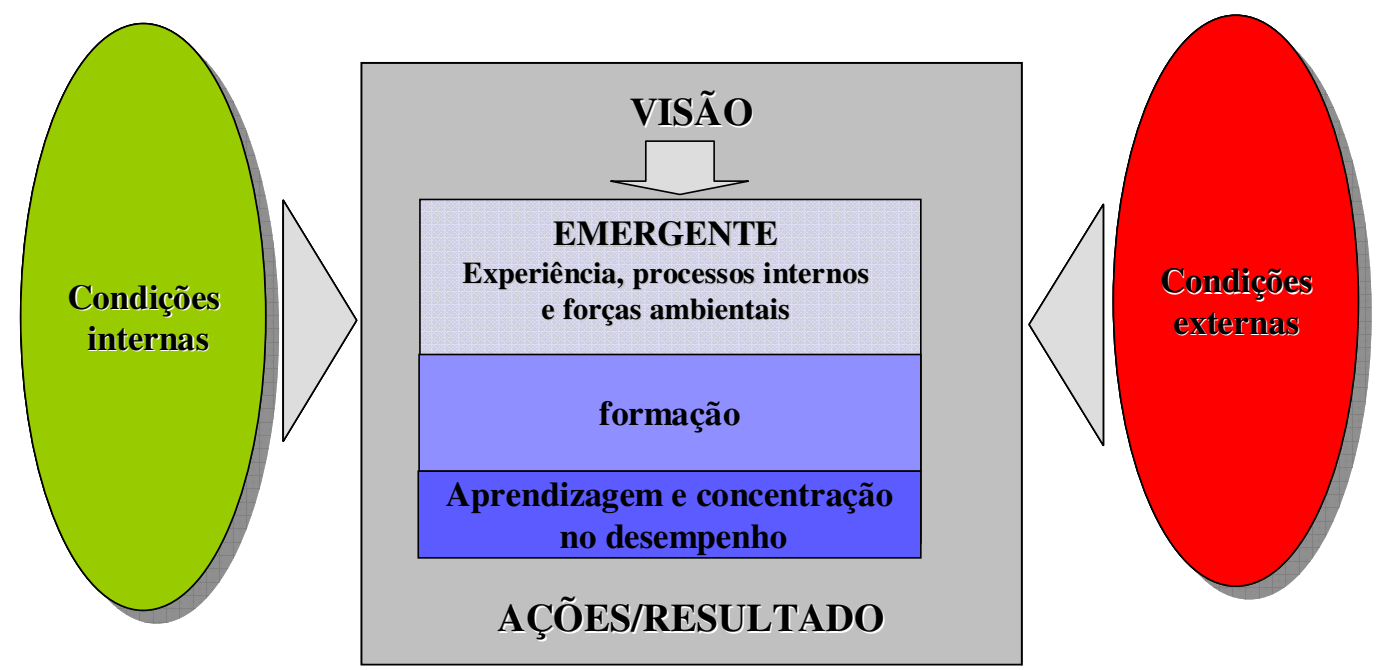

Figura 11 - Processo emergente de criação de estratégias

Prado Júnior (2003) destaca, em primeiro lugar, que as estratégias emergentes se formam a partir de padrões de atuação, produzidos de maneira gradual pela dinâmica interna da empresa e interação desta com o ambiente. Acrescenta que se organizam de modo coerente, mediante dois processos distintos, mas não excludentes: (1) mecanismos de ajuste e controle mútuos e (2) mecanismos organizacionais de seleção de iniciativas e priorização de projetos por meio dos quais emergem do relacionamento entre a gerência média e a alta gestão. Tais padrões originam-se de um processo de aprendizagem estratégica que decorre da otimização do uso da informação disponível pelos diversos atores envolvidos com a estratégia e da posterior identificação de objetivos. Cabe aos administradores reconhecer as estratégias emergentes, construindo estruturas flexíveis, que liberem a criatividade e criem espaço para que estas aflorem e se consolidem (CANCELLIER, 2004). 
Mariotto (2003) apresenta quatro interpretações do processo de criação de estratégias emergentes, segundo as quais pode ser considerado como: (1) um fenômeno hierárquico (surge na base da organização e emerge nos níveis superiores); (2) um fenômeno cognitivo (surge quando os membros da organização começam coletivamente a percebê-la); (3) resultado de auto-organização em sistemas complexos (surge espontaneamente de inúmeras ações não-coordenadas) e (4) fenômeno de aprendizagem (surge quando a organização corrige suas ações ou, em um nível mais elevado, quando corrige seus próprios planos). As interpretações do autor são complementares e podem ser identificadas como perspectivas diferentes de um fenômeno único e complexo.

Entre as críticas ao processo emergente, destacam-se: são imprecisos e vagos, não abordam o contexto complexo em sua totalidade (ANSOFF, 1991; RÉGNER, 2003) e não relacionam as intenções com as ações (MINTZBERG; WATERS, 1985). Ainda a propósito das características deste processo, observe-se que é raro haver estratégias puramente emergentes e que, por se desenvolvem com o propósito de responder a mudanças inesperadas no mercado, são reativas (OSBORN, 1998).

\subsubsection{Considerações sobre o processo deliberado e emergente}

A maneira deliberada e tradicional de desenvolver estratégia - processo periódico, racional e formal - não é suficiente para as empresas diante das mudanças, desafios e pressões que enfrentam dia a dia. Por outro lado, apenas a criação de estratégias emergentes não proporciona pró-atividade e controle. As ações estratégicas, para serem eficazes, devem se realizar em um processo contínuo, levando-se em conta que as estratégias intencionais são desafiadas ou revistas por estratégias emergentes que, por sua vez, formam uma nova estratégia intencionada e assim por diante. Estratégias emergentes integram idéias que surgem das atividades diárias dos negócios, em especial da inter-relação da empresa com seus clientes, mercado (MARIOTTO, 2003) e agentes internos.

A interação dos processos deliberado e emergente, para Mariotto (2003, p. 92), demanda um subprocesso de planejamento, que formula estratégias intencionadas e as transforma em ações planejadas, e um subprocesso de formação contínua de estratégias emergentes, a partir da percepção de padrões eficientes de comportamento, que decorrem das atividades de interação cotidiana da organização com o mercado (figura 12). 


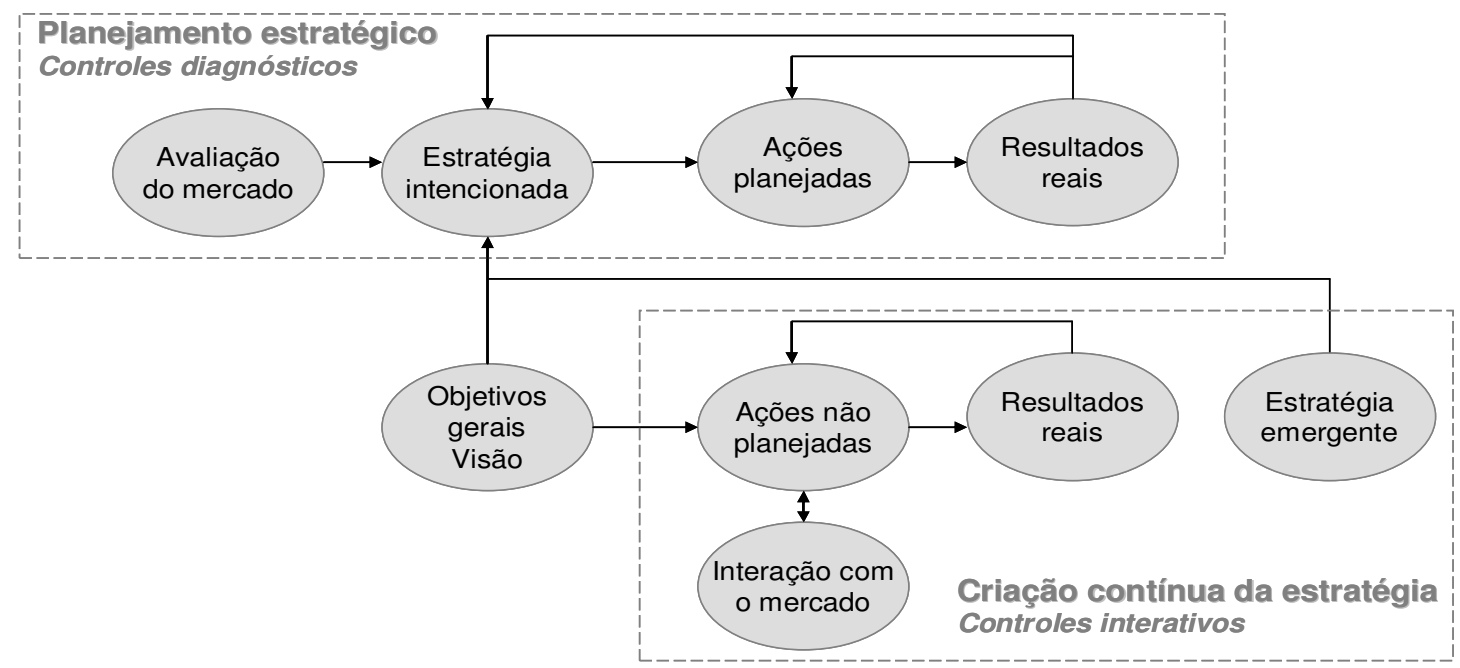

Figura 12 - Modelo de criação contínua da estratégia

Fonte: Mariotto (2003, p. 89)

O modelo proposto por Mariotto (2003) refere-se a condições específicas das empresas inseridas em ambientes competitivos e complexos e em fase avançada de seu ciclo de vida e/ou capitalizadas, condições que possibilitam criar um ambiente favorável à formulação contínua de estratégias. Para Perussi Filho (2006), o processo de criação de estratégia não é contínuo, como afirma Mariotto (2003), e segue um padrão associado às fases do ciclo de vida da empresa - sua criação, busca da eficácia externa e busca da eficácia interna. A apresentação do processo de criação de estratégias baseado no ciclo de vida encontra-se no item 4.5.3 deste trabalho.

Régner (2003), em seus estudos sobre estratégias periféricas e centrais, constatou que os processos de criação das estratégias deliberada e emergente se relacionam a contextos administrativos distintos. Segundo o autor, em sua essência, pode-se identificar a estratégia emergente como um processo exploratório de tentativa e erro, que envolve dados, contatos informais e experiências e resulta em novas estratégias. Ao contrário, as estratégias deliberadas apresentam-se como dedutivas e implicam análise, relatórios formais e rotinas administrativas, resultando em adaptação e aperfeiçoamento da estratégia.

A investigação realizada pelo autor sugere que o processo tradicional, baseado em práticas dedutivas, é relevante para refinar a estratégia prevalecente, enquanto as atividades cotidianas exploratórias e indutivas parecem cruciais para a criação e o desenvolvimento de estratégias. Assim considerando, pode-se afirmar que as estratégias emergentes e deliberadas coexistem permanentemente, em maior ou menor grau, no processo geral de criação de 
estratégias de qualquer organização. O que define o quanto são deliberadas ou emergentes são alguns aspectos: (1) a pré-existência de intenções estratégicas explícitas ou o grau com que foram explicitadas para todos os envolvidos; (2) o nível de controle centralizado da organização e (3) o nível de previsibilidade em relação ao ambiente externo ( MINTZBERG; WATERS, 1985; PRADO JÚNIOR, 2003). Osborn (1998) declara que as empresas necessitam rever seus planos de intenção, para ajustá-los a intenções emergentes. A seguir, apresentam-se, no quadro 5, as características básicas dos processos deliberado e emergente de criação de estratégias.

\begin{tabular}{|l|l|l|}
\hline \multicolumn{1}{|c|}{ Características } & \multicolumn{1}{c|}{ Processo deliberado } & \multicolumn{1}{c|}{ Processo emergente } \\
\hline Contexto & Estável & Dinâmico \\
\hline Estrategista & Alta direção & Interação da alta direção com níveis inferiores \\
\hline Processo principal & Formal & Informal \\
\hline Aspecto predominante & Análise & Intuição e criatividade \\
\hline Forma & Plano & Padrão \\
\hline Foco & Intenção e decisão & Ação e aprendizado \\
\hline Tipo & Explícita & Implícita \\
\hline
\end{tabular}

Quadro 5 - Características dos processos deliberado e emergente de criação de estratégias

Na prática, portanto, conforme as duas perspectivas sob as quais é vista, a estratégia classifica-se como: (1) deliberada - princípio de ação racional-instrumental cujos objetivos e procedimentos se relacionam com um conjunto de ações deliberadamente traçados para a resolução de situações específicas - e (2) emergente - processo de cognição, eliciado pelos conteúdos e mecanismos que ocupam a mente do dirigente, que ocorre de maneira irregular e informal (FONSECA; MACHADO-DA-SILVA, 2002). Ressalte-se, entretanto, que ambas são influenciadas por condições internas e externas e não são excludentes, ao contrário coexistem em um mesmo processo (figura 13). 


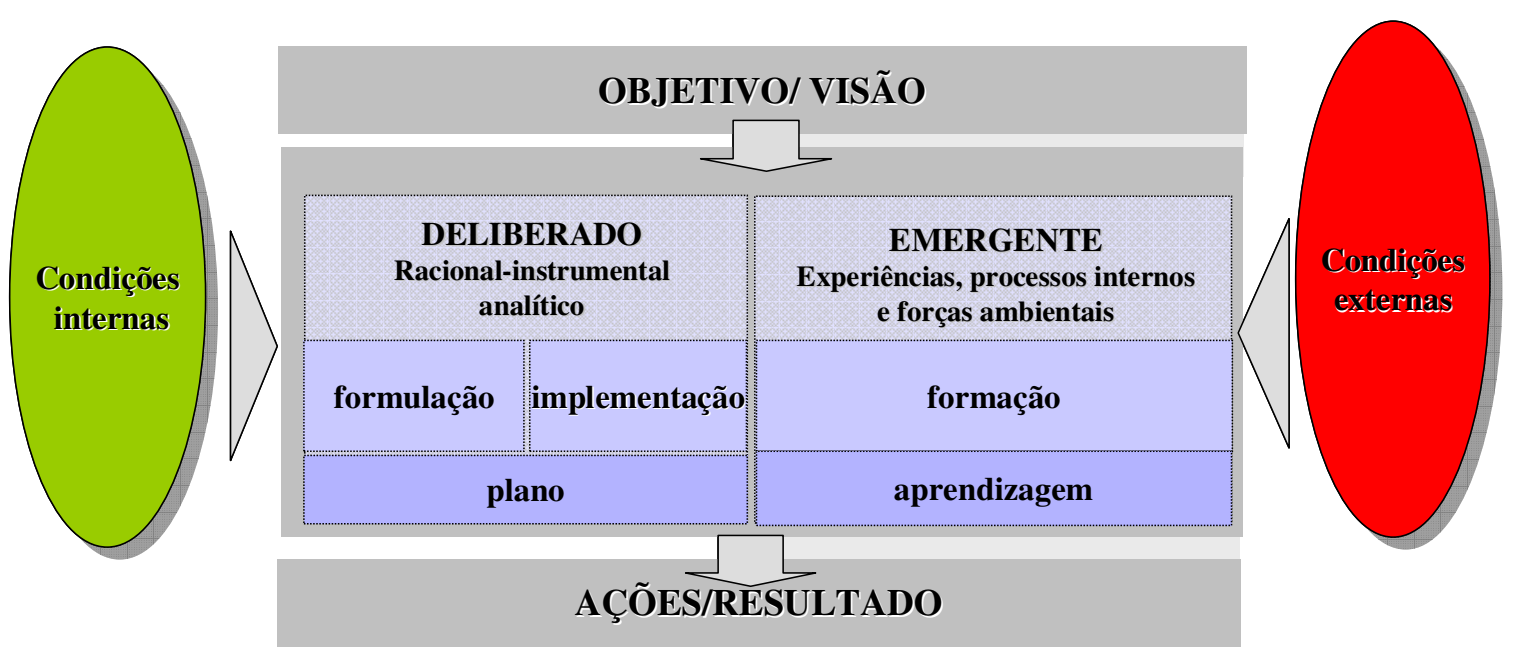

Figura 13 - Processo emergente e deliberado: visão de coexistência

Sob este enfoque, a estratégia é retratada como um processo racional, analítico, lógico e, ao mesmo tempo, cognitivo, intuitivo, subjetivo e de aprendizagem, que concilia o pensamento e a ação para alcançar os objetivos organizacionais. Na formação contínua de estratégia, expressão sugerida por Mariotto (2003), os processos deliberado e emergente, além de coexistirem, devem interagir por meio de estruturas, técnicas e processos adequados, conforme apresentados no quadro 6.

\begin{tabular}{|c|c|c|c|}
\hline Estruturas, processos e técnicas & Condições & Promoção & Resultado \\
\hline $\begin{array}{l}\text { Controles interativos } \\
\text { Conexões em tempo real } \\
\text { Reuniões estratégicas freqüentes } \\
\text { Modelos mentais explícitos } \\
\text { Modelos computacionais de } \\
\text { simulação } \\
\text { Construção de cenários } \\
\text { Produtos experimentais etc. }\end{array}$ & $\begin{array}{l}\text { Atenção contínua } \\
\text { Partilha da informação } \\
\text { Envolvimento pessoal } \\
\text { Intimidade com as } \\
\text { questões } \\
\text { Compreensão coletiva e } \\
\text { explícita } \\
\text { Comprometimento }\end{array}$ & $\begin{array}{l}\text { Mudança contínua } \\
\text { Aproveitamento de } \\
\text { oportunidades } \\
\text { Otimização de recursos } \\
\text { Aprendizado } \\
\text { organizacional }\end{array}$ & $\begin{array}{l}\text { Finalidade e } \\
\text { objetivos gerais } \\
\text { da organização }\end{array}$ \\
\hline
\end{tabular}

Quadro 6 - Estruturas, processos e técnicas para a formação contínua de estratégia Fonte: Mariotto (2003, p. 91)

Acerca das características do modo prescritivo e orgânico de formação de estratégia, isto é, deliberado e emergente, respectivamente, além da coexistência e interação, deve-se considerar o seu aspecto integrativo (FARJOUN, 2002), ou seja, de unicidade - é um 
processo que demanda análise, intuição, formalidade, informalidade, envolvimento da alta direção e dos níveis inferiores (figura 14). O que determina a influência maior ou menor dos processos deliberado ou emergente são as condições internas e/ou externas. A escolha estratégica deve levar em conta perspectivas objetivas e subjetivas do ambiente organizacional, pois os estrategistas estão submetidos à avaliação das relações e transações impessoais, às técnicas de análise de mercado e ainda à avaliação de outros tipos de relações e padrões de conduta institucionalizados e compartilhados por pessoas, dentro e fora dos limites organizacionais (CHILD, 1997).

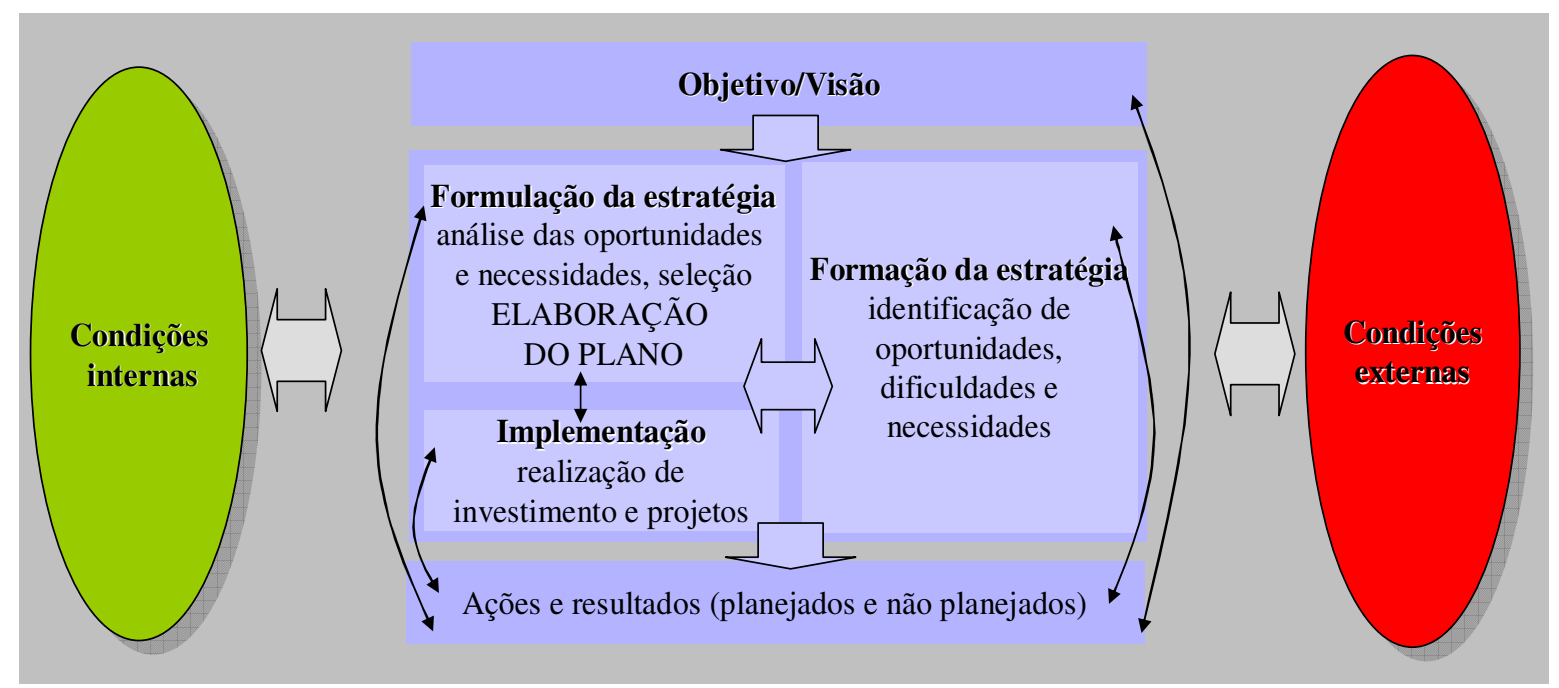

Figura 14 - Processo deliberado e estratégico: visão de coexistência, interação e integração

O processo de criação de estratégias, base para a tomada de decisão estratégica, deve ser compreendido como um processo que relaciona as estratégias (deliberadas ou emergentes) com a tomada de decisão e sua operacionalização (GLUCK, KAUFFMAN; WALLECK, 1982), levando em conta o envolvimento de atores organizacionais e variáveis ambientais (RÉGNER, 2003). É, enfim, um processo de coordenação e adaptação contínua dos objetivos e das ações da organização. 


\subsection{MODELOS DO PROCESSO DE CRIAÇÃO DE ESTRATÉGIA}

As pesquisas sobre o processo estratégico, em sua maioria, descrevem categorias de classificação das estratégias e, em alguns casos, apresentam aspectos particulares deste processo (HART, 1992), como: modos de interpretação, rotinas decisórias ou ações específicas (RÉGNER, 2003). Diversos autores preocupam-se com os modos ou modelos diferentes de formação de estratégias. Destacam-se, a seguir, os modelos apresentados por Hitt, Ireland e Hoskisson (2005), Quinn (1978), Mintzberg (1973), Chaffee (1985) e Hart (1992).

3.2.1 O processo deliberado de criação de estratégias: a visão de Hitt, Ireland e Hoskisson

Hitt, Ireland e Hoskisson (2005) declaram que o processo de administração estratégica é fator crítico para o êxito da organização. Definido como dinâmico por natureza, é representado por compromissos, decisões e ações necessários para a empresa obter maior competitividade e retornos superiores aos da média de seus competidores. Para tanto, deve ser uma abordagem racional que ajude a empresa a responder eficazmente aos desafios impostos pelo ambiente. O processo estritamente deliberado, descrito pelos autores, é apresentado em um modelo composto de três partes: (1) insumos e informações estratégicas; (2) ações estratégicas e (3) resultados estratégicos.

A primeira parte - insumos e informações estratégicas - implica a coleta de informações e análise destas para a formulação de estratégias. A análise das condições internas e do ambiente da organização faz-se necessária, para que se identifiquem as oportunidades e ameaças do mercado e se determine como serão utilizadas as suas competências essenciais na busca de resultados. Com base nas informações e nos conhecimentos obtidos pela análise realizada (interna e externa), constitui-se a intenção estratégica, que sugere como os recursos internos, capacidades e competências essenciais devem ser alavancados, e define-se a missão estratégica, que é a aplicação da intenção estratégica, mediante declaração do propósito e do alcance da empresa em termos de produtos e mercados a atende, conforme ilustrado na figura 15. 


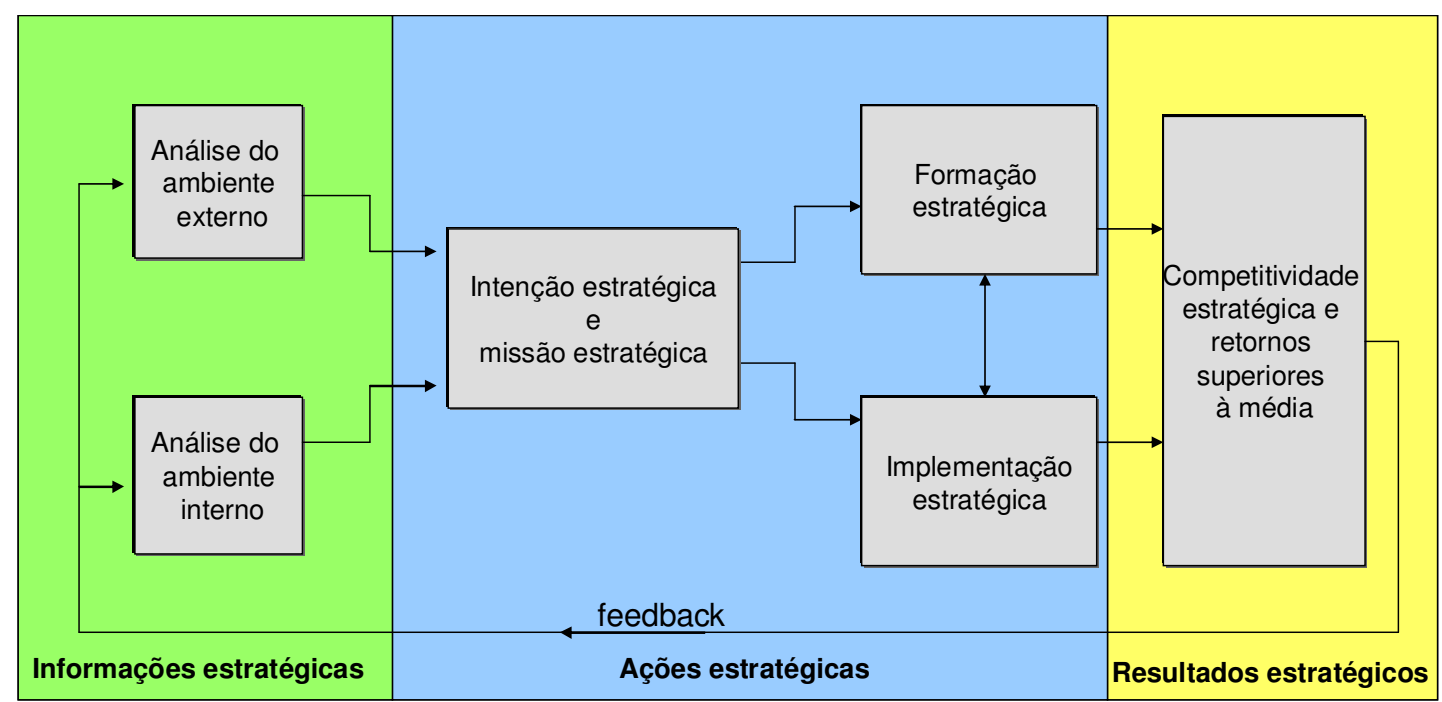

Figura 15 - Processo de administração estratégica

Fonte: Hitt, Ireland e Hoskisson (2005, p. 6)

Os insumos estratégicos fornecem a base para a formulação e implementação de estratégias. Assim considerando, na segunda parte - ações estratégicas - estabelecem-se as estratégias e a forma como serão implementadas. A implementação permite identificar possibilidades de melhoria na estratégia adotada. Os autores ressaltam que as ações estratégicas são eficazes em um contexto de formulação e implementação integradas. A separação entre formulação e implementação, no modelo apresentado, tem o intuito de demonstrar as atividades existentes no processo.

A terceira parte - resultados estratégicos - visa verificar a competitividade da organização e o retorno obtido. As três partes apresentadas se inter-relacionam por um sistema de retroalimentação que as caracteriza como um processo contínuo.

A análise do modelo proposto por Hitt, Ireland e Hoskisson (2005) revela uma visão racional do processo de criação de estratégias. Para Escrivão Filho (2006), a partir de uma linguagem moderna de competitividade e vantagem competitiva, o modelo apresentado faz uma síntese dos conceitos das escolas do design, do planejamento e do posicionamento e representa um "Sistema de Administração Estratégica Prescritivo" apresentado ao final do capítulo 2. 


\subsubsection{O incrementalismo lógico proposto por Quinn}

A literatura sobre estratégia enfatiza o processo normativo e sistemático, que se caracteriza por análises que determinam passo a passo o que deve ser feito. Neste processo destacam-se os aspectos quantitativos, não os qualitativos como, por exemplo, as questões comportamentais, que determinam o resultado das estratégias. Em seus estudos, Quinn (1978) conclui que o sistema formal de planejamento não caracteriza o processo estratégico, uma vez que as estratégias tendem a emergir de forma incremental, de acordo com oportunidades, configurando uma dimensão fragmentada, evolucionária e fortemente intuitiva. A formação de estratégias se insere em um processo analítico-político, que não tem início certo ou final definido. Segue, geralmente, uma sequiência de passos que não são lineares, mas cíclicos e com frequientes interrupções ou demoras (QUINN, 1978; 1989). Para o autor, as estratégias tendem a emergir de vários subsistemas estratégicos que implicam classes específicas de desafios, como aquisições e diversificação, cabendo aos executivos administrá-las, controlando-as e integrando-as de forma incremental, de modo que se tornem estratégias conscientes (QUINN, 1978, 1980).

Com freqüência os dirigentes deparam com eventos inesperados sobre os quais não têm controle e informações suficientes. Também ocorre que nem sempre dispõem de tempo para uma análise mais detalhada, sistemática e formal das possíveis alternativas de ação e suas conseqüências. A restrição de conhecimento sobre tais eventos que, inclusive, podem modificar a postura estratégia da organização, impõe limites cognitivos e de processo para a formação de estratégias.

Para Quinn (1978), devido aos limites impostos, a maioria dos subsistemas deve associar-se à gestão do incrementalismo lógico - uma aproximação ao processo estratégico que integra, de maneira pró-ativa, aspectos tanto de ordem analítica e racional quanto de cunho comportamental e político na formação de estratégias. Assim sendo, os executivos devem lidar com os eventos gradativamente, tomando decisões em vários estágios e retardando as que puderem ser tomadas em momento mais oportuno.

A formação de estratégias a partir do incrementalismo lógico vai ao encontro da teoria do comportamento que desafia as suposições da racionalidade, ao admitir que os limites cognitivos levam os responsáveis pela tomada de decisões a adotar modelos simplificados do mundo, limitando o seu comportamento na busca de opções e induzindo-os a aceitar o primeiro resultado satisfatório (HART, 1992). A literatura sobre comportamento sugere que atribuir aos gerentes da alta cúpula a responsabilidade pela formulação da estratégia configura 
uma das limitações ao processo. Por reconhecer estas limitações, Quinn (1978) propôs o incrementalismo lógico como a maneira ideal de criar estratégias (HART, 1992). Utilizando este modelo, os executivos têm condições de identificar a direção ampla que a organização deve seguir, mas não a natureza precisa da estratégia a ser formulada, pois os detalhes emergem com o passar do tempo. Assim considerando, este modo de formação de estratégias seria capaz de minimizar as conseqüências da racionalidade limitada dos indivíduos no processo e de auxiliar na construção de consenso e apoio político para adoção de novas estratégias, oferecendo aos executivos a possibilidade de se identificarem coerentemente com os novos direcionamentos.

Quinn (1978; 1989) destaca que o incrementalismo deve ser aplicado de maneira proposital, orientada e pró-ativa, para melhorar e integrar os aspectos dos processos analítico e comportamental na formação de estratégias. É um modo que permite, portanto, o acesso às contribuições dos sistemas racional-analítico, político e comportamental. Observe-se também que, neste processo, a estratégia emerge como resultado de uma "anarquia" organizada (HART, 1992). A abordagem de Quinn vai ao encontro do processo de elaboração de estratégias de forma emergente e marca o desenvolvimento da aprendizagem estratégica, denominada escola de aprendizado por Mintzberg, Ahlstrand e Lampel (CANCELLIER, 2004; ZANNI, 2003).

\subsubsection{O processo de formação de estratégias deliberado e emergente: a visão de Mintzberg}

Conforme se expôs anteriormente, as estratégias organizacionais são formadas de diversas maneiras. Para Mintzberg (1973) existem três modos de formação de estratégias, o empreendedor, o adaptativo e o do planejamento.

O modo empreendedor (entrepreneaurial mode) implica a não elaboração de planos estruturados na busca de oportunidades, sob o pressuposto de que as estratégias devem se originar da visão de futuro do empreendedor. Neste processo, as organizações centralizam o poder nas mãos do dirigente, são ágeis na adaptação a mudanças e, em geral, têm como principal objetivo, o crescimento.

O modo adaptativo (adaptive mode) enfatiza que a busca de soluções para os problemas ambientais deve ocorrer de modo reativo, ou seja, que a tomada de decisão precisa 
ser feita de forma incremental, a partir de resultados obtidos e experiências realizadas, devido à complexidade do ambiente.

O modo do planejamento (planning mode) propõe a elaboração organizada e formal das estratégias, a partir da definição sistemática de objetivos e metas a serem alcançados.

Ao considerar o processo de formação de estratégias, o autor focaliza, principalmente, os motivos que levam à tomada de decisão, o estrategista (quem a toma), o critério de avaliação das alternativas de estratégia e o tempo necessário para executá-las, os objetivos organizacionais, a flexibilidade da organização e do dirigente, a idade da organização e os tipos de ambientes favoráveis ao emprego de cada modo. Mintzberg enfatiza, na criação de estratégias, o processo em vez de seu conteúdo (SEGEV, 1987). Com referência aos tipos de ambiente, Andersen (2004) destaca que o modo do planejamento se estabelece em organizações de maior porte e instaladas em ambientes estáveis e previsíveis, enquanto o modo adaptativo se aplica a empresas que operam em contextos dinâmicos, nos quais as iniciativas estratégicas emergem de acordo com as condições ambientais.

Mintzberg analisa o processo de criação de estratégias organizacionais, apoiando-se no conceito de estratégias deliberadas e emergentes (MINTZBERG, 1978; 1987c; MINTZBERG; LAMPEL, 1999; MINTZBERG; WATERS, 1985). Segundo o autor, dois tipos de estratégias podem ser identificados nas organizações: as pretendidas e as realizadas. As pretendidas subdividem-se em deliberadas e não realizadas. Entre as realizadas encontramse as deliberadas (intencionadas) e as emergentes (não planejadas), por meio das quais os modelos se desenvolvem sem intenções (figura 16).

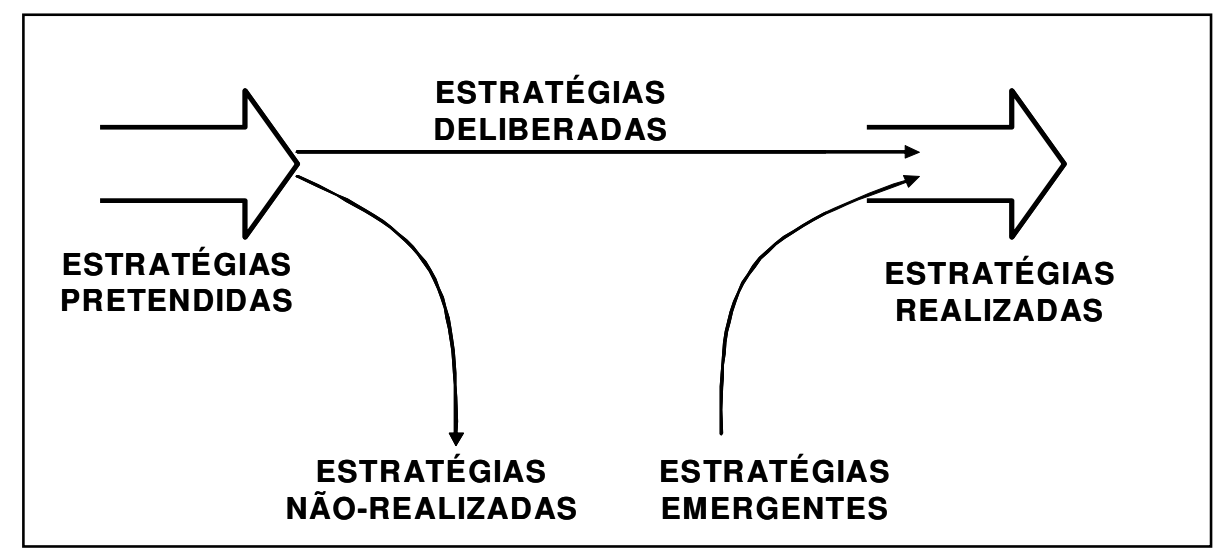

Figura 16 - Tipos de Estratégia

Fonte: Mintzberg (1978, p. 945) 
Ao conceber as estratégias como 5 P, Mintzberg (1987a) ressalta que as definições de estratégia como plano e padrão são independentes, considerando que planos podem não se realizar, enquanto padrões podem surgir sem que tenham sido preconcebidos. $\mathrm{O}$ autor chama a "estratégia como plano" de pretendida e a "estratégia como padrão" de realizada. Costa e Silva (2002) observam, por sua vez, que as estratégias realizadas envolvem tanto as pretendidas quanto as emergentes. É possível ocorrer uma discrepância entre as pretendidas e as realizadas quando a organização é incapaz de traduzir suas intenções em ações, quer por mudanças no ambiente, quer por capacidade limitada de implementação, quer por expectativas irreais.

Os planos estratégicos são pretendidos e geralmente um líder os desenvolve e comunica explicitamente à organização. As estratégias realizadas são os planos implementados com sucesso. As estratégias pretendidas nem sempre são realizadas e muitas estratégias realizadas são emergentes, ou seja, não explicitamente pretendidas e comunicadas. Em essência, o processo estratégico é composto por estratégias pretendidas e emergentes (MANDERSCHEID; KUSY, 2005).

As estratégias não são puramente deliberadas ou emergentes, portanto podem formarse e ser formadas. A estratégia realizada pode surgir em resposta a uma situação que evolui, mas pode também ser criada deliberadamente, a partir de um processo de formulação seguido de implementação. Quando as intenções planejadas não produzem as ações pretendidas dão origem a estratégias não-realizadas. Destaque-se, a propósito, que a noção de que estratégia é algo que deve seguir seu curso até o fim, longe dos detalhes cotidianos, é uma das maiores falácias do gerenciamento estratégico convencional (MINTZBERG, 1987c).

3.2.4 Os processos linear, adaptativo e interpretativo: a visão de Chaffee

Chaffee (1985) distingue três modelos de formação de estratégias: o linear, o interpretativo e o adaptativo.

O modelo linear caracteriza-se pelo planejamento de ações seqüenciais que têm, como base, um método dirigido. Consiste em decisões integradas, ações ou planos que definem objetivos claros e precisos e a forma de atingi-los. A propósito, para estabelecer tais objetivos, é preciso considerar os relacionamentos da organização com o ambiente, cabendo esta responsabilidade aos gestores da alta cúpula que, por meio de um processo racional, 
analisam a capacidade de mudança da empresa e definem objetivos, alternativas e ações que devem ser implementados. Como expressões associadas a este modelo, identificam-se: planejamento estratégico, formulação de estratégias e implementação de estratégias. Os fatores que o mensuram dizem respeito à lucratividade e produtividade e se configuram como: participação no mercado, lançamento de novos produtos, definição de novos negócios, aquisição ou fusão de negócios e diversificação de produtos, entre outros. Registra-se um grande interesse pelo modelo linear principalmente nos anos 70, com o amplo uso das metodologias do planejamento estratégico. Chandler (1990), Andrews (1971), Child (1972), Glueck $^{5}$ (1976), Drucker ${ }^{6}$ (1974), Lorange e Vancil $^{7}$ (1976) são autores que também o destacam.

O modelo adaptativo prevê o alinhamento da organização com as características ambientais ou, mais especificamente, a definição de capacidades e recursos da empresa para explorar as oportunidades e inibir as ameaças do ambiente, que é complexo e dinâmico, comportando tendências, eventos, competidores e stakeholders. Sob esta ótica, as estratégias são preestabelecidas, isto é, são formuladas a partir de uma avaliação contínua do ambiente e das condições internas da organização. É esta avaliação que possibilita, por um lado, identificar as oportunidades e ameaças ambientais e, por outro, estabelecer o necessário ajustamento das capacidades e dos recursos da empresa, visando coibir as ameaças e aproveitar as oportunidades.

De acordo com este modelo, as ações administrativas focam o ambiente e, assim sendo, implicam respostas pró-ativas ou reativas às pressões ambientais, isto é, respostas que configurem mudanças ou ajustes. Já a organização, orientando-se por condições internas e externas, efetua uma espécie de equilíbrio de forças, de modo a compor alinhamentos satisfatórios entre as capacidades e riscos e oportunidades do ambiente. Contudo, enfatizando o processo de experimentação, deixa-se levar mais pelas demandas do ambiente que pela própria vontade e determinação objetiva de sentido. Desta forma, o olhar sobre as capacidades internas se dá apenas com o objetivo de buscar o suporte para atender às demandas do mercado, não à necessidade de definir um posicionamento já estabelecido. Além disso, como o modelo pressupõe o monitoramento ambiental e a realização de mudanças internas constantemente, tais ações são realizadas em fases que compõem um ciclo adaptativo

\footnotetext{
${ }^{5}$ GLUECK, W. F. (1976). Business policy: strategy formation and management action. New York: McGrawHill.

${ }^{6}$ DRUCKER, P. F. (1974). Management: tasks, responsibilities, practices. New York: Harper \& Row.

${ }^{7}$ LORANGE, P.; VANCIL, R. F. (1976). How design a strategic planning system. Harvard Business Review, v. 54, n. 5 , p. $75-81$.
} 
(MILES; SNOW, 1978): a fase empreendedora (escolha das oportunidades e ameaças), a fase de engenharia (construção e escolha da tecnologia) e a fase administrativa (racionalização da estrutura e dos processos e identificação de áreas de inovação). Outra característica relevante do modelo diz respeito ao fato de que os objetivos não são enfaticamente definidos, pois representam o alinhamento da organização com suas condições ambientais.

Deste modo, o comportamento estratégico da organização ultrapassa a incorporação de mudanças principais nos produtos e mercados, abrangendo alterações de estilo, de comercialização e outros aspectos mercadológicos e de qualidade. Deve-se observar ainda que a responsabilidade pelo desenvolvimento da estratégia adaptativa, embora diluída na organização, cabe aos gestores da alta cúpula. Para designar o modelo adaptativo, usam-se os termos: gestão estratégica, escolha estratégica, concepção da estratégia (design) e ajuste estratégico. Como medidas de mensuração, citam-se: preço, política de distribuição, investimentos em marketing e diferenciação de produtos. Os autores que se identificam com este modelo são Hofer e Schendel ${ }^{8}$ (1978), Miles e Snow (1978), Mintzberg (1978), Steiner ${ }^{9}$ (1979), Snow e Hambrick (1980), Quinn (1980), Gluck, Kaufman e Walleck (1982), entre outros.

O modelo interpretativo assume que a realidade organizacional é socialmente construída - não é algo objetivo ou externo, que pode ser observado de maneira correta ou incorreta. Propõe que as relações interorganizacionais culminem na construção social dos elementos ambientais. Sob este enfoque, a realidade é fruto da construção social e a própria organização resulta de um contrato social, à medida que é concebida em um processo de intercâmbio no qual as percepções dos agentes são confirmadas, modificadas ou substituídas de acordo com a sua coerência e a percepção de outros agentes. A estratégia interpretativa é definida por metáforas ou quadros de referência que permitem compreender a organização e seu ambiente por meio da ação individual de seus stakeholders. O termo usualmente associado ao modelo é norma estratégica. A forma utilizada para sua mensuração é contextual e requer avaliação qualitativa. Entre os modelos apresentados, o interpretativo é o mais recente na literatura administrativa e os principais autores que o enfocam são Pettigrew ${ }^{10}$ (1977), Van Cauwenbergh e Cool (1982), Dirsmith e Covaleski ${ }^{11}$ (1983).

\footnotetext{
${ }^{8}$ HOFFER, C.; SCHENDEL, D. (1978). Strategy formulation: analytical concepts. St Paul: West.

${ }^{9}$ STEINER, G. A. (1979). Strategic planning. New York: Free Press.

10 PETTIGREW, A. M. (1977). Strategy formulation as a political process. International Studies of Management and Organization, v. 7, p. 78-87.

11 DIRSMITH, M. W.; COVALESKI, M. A. (1983). Strategy, external communication and environment context. Strategic Management Journal, v, 4, 137-151.
} 
Os modelos de formação de estratégias concebidos por Chaffee (1985) podem ser apresentados sumariamente, como descritos a seguir. A abordagem linear pressupõe que os líderes planejam como alcançar os objetivos organizacionais frente aos competidores (a estratégia é pretendida). A abordagem adaptativa presume que a organização sofre mudanças pró-ativas ou reativas, de acordo com o ambiente. A estratégia interpretativa implica a utilização de símbolos que possibilitam compreender a organização e seu ambiente, assim motivando os stakeholders a agir a seu favor. É oportuno observar que, para a autora, estes modelos não se excluem nem são independentes.

\subsubsection{O modelo de construção de estratégias de Hart}

$\mathrm{Na}$ literatura sobre estratégia três temas emergem e devem ser levados em conta na formação de estratégias bem-sucedidas: (1) a racionalidade, que implica questionar se o processo estratégico deve ser analítico, valorizando aspectos comportamentais na formação de estratégia; (2) o papel dos gerentes e (3) o envolvimento dos sócios da organização neste processo (HART, 1992).

De acordo com o modelo concebido por Hart (1992), o processo estratégico comporta cinco modos de formação, definidos com base no papel do gerente: comando (command), simbólico (symbolic), racional (rational), transitivo (transactive) e gerador (generative). $\mathrm{O}$ autor entende que este modelo integra e reconcilia os vários modelos e as tipologias previamente apresentados na literatura.

A seguir faz-se a descrição de cada modo identificado por Hart (1992), destacando-se as suas características gerais, apresentadas no quadro 7.

- Comando: processo consciente e concentrado no topo da organização. De acordo com este modo, analisa-se a situação estratégica, consideram-se alternativas e decide-se o curso de ação. Cabe ao líder ou a alguns gerentes da cúpula a formulação das estratégias, de sorte que estas se apresentem como deliberadas e atendem a um processo que ocorre de cima para baixo na organização. Por se concentrarem no líder ou em um pequeno grupo, adequam-se a ambientes de baixa complexidade e a organizações relativamente pequenas, nas quais uma pessoa pode manter o controle efetivo.

- Simbólico: processo no qual a estratégia é criada pela cúpula administrativa. Este modo implica que os líderes desenvolvam a missão e estabeleçam a visão e os valores da 
empresa, para que se dê um direcionamento às ações. Neste processo, em que se destaca o uso de símbolos, metáforas e emoção, a administração de cúpula cumpre o papel de motivar e inspirar os sócios organizacionais. Complementando, o modelo se amolda às grandes organizações presentes em ambientes dinâmicos e de rápido crescimento.

- Racional: processo caracterizado por análises sistemáticas e relações hierárquicas. Neste modo há um alto nível de processamento de informação, por meio do ajuste e uso de dados internos e externos. As análises formais ajudam a definir estratégias explícitas e a integrá-las em um plano predeterminado. Normalmente, este processo é institucionalizado pelo planejamento estratégico. Em suma, no modo racional, a alta cúpula deve considerar tantos dados quanto possíveis na formulação de uma estratégia empresarial explícita. Devido à demanda na administração de cúpula, o modo racional se ajusta a ambientes estáveis e empresas de grande porte, com posições estratégicas estabelecidas, nas quais se podem perceber os benefícios do planejamento formal e dos sistemas de controle.

- Transitivo: processo que se fundamenta na interação contínua da organização com seus stakeholders, para se determinar uma direção estratégica. Desenvolve-se em ambientes complexos e heterogêneos, em particular nas empresas de grande porte, que fazem parte de indústrias maduras.

- Gerador: processo no qual os gerentes de cúpula ajustam a estratégia ao padrão de inovações que emerge dos níveis inferiores. Neste modo, idéias e iniciativas dos colaboradores afloram e passam a integrar a direção estratégica da empresa. Trata-se, portanto, de um processo caracterizado pela inovação, em que o papel da administração de cúpula é estimular a experimentação e o desenvolvimento de idéias potenciais, e que se aplica a empresas inseridas em ambientes turbulentos, dinâmicos e complexos.

Hart (1992) observa que, em cada modo de formação de estratégias, os gerentes focam aspectos distintos. Por exemplo, no simbólico, focalizam a missão e a visão, no racional destacam as metas, a estrutura formal e os sistemas de planejamento, em contraste, no transitivo, a ênfase está nos processos internos, enquanto o gerador se concentra nos processos informais e nas pessoas. É oportuno ressaltar que os modos propostos por Hart (1992) não são excludentes, de sorte que as organizações podem, ao contrário, valer-se de dois ou mais deles em seu processo estratégico. 


\begin{tabular}{llllll}
\hline \multicolumn{1}{c}{ Descrição } & Comando & Simbólico & Racional & Transitivo & Gerador \\
\hline Estilo & Imperial & Cultural & Analítico & Procedimento & Orgânico \\
\hline $\begin{array}{l}\text { Formação da } \\
\text { estratégia }\end{array}$ & $\begin{array}{l}\text { Líder ou um } \\
\text { pequeno grupo }\end{array}$ & $\begin{array}{l}\text { Missão e visão } \\
\text { de futuro }\end{array}$ & $\begin{array}{l}\text { Estrutura formal } \\
\text { e sistemas de } \\
\text { planejamento }\end{array}$ & $\begin{array}{l}\text { Processos } \\
\text { internos e } \\
\text { ajustes mútuos }\end{array}$ & $\begin{array}{l}\text { Iniciativas dos } \\
\text { atores } \\
\text { organizacionais }\end{array}$ \\
\hline $\begin{array}{l}\text { Papel do } \\
\text { gerente }\end{array}$ & Comandante. & Treinador. & Chefe. Avalia e & Facilitador. & Patrocinador \\
& Define direção & Motiva, inspira & controla & Autoriza e \\
delega & Endossa e apóia \\
\hline $\begin{array}{l}\text { Papel dos } \\
\text { membros } \\
\text { organizacionais }\end{array}$ & $\begin{array}{l}\text { Soldados. } \\
\text { Obedecem a }\end{array}$ & $\begin{array}{l}\text { Jogadores. } \\
\text { Respondem aos } \\
\text { desafios }\end{array}$ & $\begin{array}{l}\text { Subordinados. } \\
\text { Seguem o } \\
\text { sistema }\end{array}$ & $\begin{array}{l}\text { Participantes. } \\
\text { Aprendem e } \\
\text { evoluem }\end{array}$ & $\begin{array}{l}\text { Empreendedores } \\
\text { Arriscam }\end{array}$ \\
\hline
\end{tabular}

Quadro 7 - Modelo integrativo de formação de estratégias

Fonte: Hart (1992, p. 334; 335)

\subsubsection{Considerações sobre o processo de criação de estratégias}

Pode-se observar que os modelos ou modos de criação de estratégias apresentados, independentemente de suas denominações, têm alguns pontos em comum (CHAFFEE, 1985): as organizações e o ambiente são inseparáveis; as organizações utilizam a estratégia para explorar mudanças ambientais; as mudanças trazem novas circunstâncias às organizações, portanto a estratégia pode ser desestruturada, não programada, sem rotina e não repetitiva; os estudos sobre estratégia referem-se à tomada de decisão e ao processo pelo qual as decisões são tomadas e implementadas; as estratégias intencionais, emergentes e realizadas diferem entre si; a formação de estratégias implica um processo conceitual e analítico; a estratégia é concebida por um líder, emerge de níveis inferiores ou surge em processos internos e ajustes da organização com seus stakeholders.

Os modelos são apresentados de acordo com um processo evolutivo e não cronológico. O primeiro modelo, proposto por Hitt, Ireland e Hoskisson (2005), exemplifica um processo racional, enquanto o segundo, Quinn (1978), apresenta um processo na direção incremental. O modelo de Mintzberg (1973) é apresentado a seguir, como uma síntese dos dois modelos anteriores com a proposição de uma terceira alternativa, o modo empreendedor. O modelo de Chafee (1985) apresenta uma variação de Mintzberg (1973). Por fim, o modelo de Hart (1992), que pode ser analisado como uma variação mais sofisticada em relação aos modelos de Mintzberg (1973) e Chafee (1985).

Os autores, de forma geral, descrevem estilos de criação de estratégia com características que variam conforme o ambiente (dinâmico ou estável), o perfil do estrategista, o nível de racionalidade e formalidade do processo, a cultura organizacional, as relações 
sociais, a estrutura e os procedimentos internos. Percebe-se, nesta evolução, que os modelos propostos se sobrepõem e complementam, evidenciando compatibilidades que permitem agrupá-los em quatro modos cujas características são descritas a seguir.

1) Modo racional: predominantemente deliberado e prescritivo de formação de estratégia. Neste caso, a estratégia é criada, mediante um processo formal, linear, analítico e racional, pelo líder ou por um grupo, na cúpula da organização, tendo em vista o estabelecimento de objetivos e a definição de planos para atingi-los. Este modo é compatível com o processo de administração estratégica de Hitt, o modelo linear de Chaffee, o modo planejamento de Mintzberg e o modo racional de Hart. Trata-se de um processo em que se formulam estratégias e se estabelecem planos detalhados, posteriormente implantados e avaliados nos diversos níveis organizacionais.

2) Modo empreendedor: modo em que a estratégia é de cunho informal e criada a partir da visão do líder. Caracteriza-se como um processo de busca de novas oportunidades por meio de ações definidas pelo executivo principal (de cima para baixo). É deliberado, pois reside nas intenções de um único líder, porém, como estas são, também, amplamente pessoais, detalhes podem aparecer com o seu desenvolvimento, a visão pode mudar com diferentes aprendizados, novas estratégias podem surgir, caracterizando seu aspecto emergente - as ações não são definidas em planos estruturados. Os modos compatíveis com este processo são o empreendedor de Mintzberg e o do comando e o simbólico de Hart.

3) Modo adaptativo: neste, a estratégia é criada, mediante um processo incremental de análise e ação, pelos gestores de alta cúpula em conjunto com membros de níveis inferiores, o que implica uma adaptação contínua da organização ao seu ambiente e às suas condições internas. De acordo com este processo, os objetivos não são definidos claramente, mas buscam-se, além da adaptação, a inovação e o aprimoramento contínuo. Os modos compatíveis com este processo são: a estratégia adaptativa de Chaffee, o modo adaptativo de Mintzberg e o modo transitivo de Hart.

4) Modo emergente: caracteriza-se pela ausência de planos e orientação clara, a partir do pressuposto de que as estratégias surgem da inovação, isto é, da criação e descoberta de novas possibilidades. Constitui, portanto, um processo flexível, pois se entende que mudanças no ambiente ou nos objetivos demandam uma nova situação e ações imediatas. O modo compatível com este processo é o gerador, de Hart e o incrementalismo lógico de Quinn. Ainda com referência a este modo, destaca-se o caráter social do processo de criação da estratégia, formulada pela interpretação dos membros da organização, 
envolvidos em um processo de adaptação aos fatores humanos, sociais e contextuais. Retratada na missão, na visão e nos valores organizacionais, a estratégia é fruto da percepção e interpretação dos membros organizacionais e de seus relacionamentos internos e externos. Neste bloco, enquadram-se o modelo interpretativo de Chaffee.

Os processos apresentados enfatizam eventos diversos. Para juntá-los aos elementos que compõem o "Sistema de Administração Estratégica" - liderança, organização e ambiente - destacam-se os que são determinantes na criação de estratégias, apresentados na figura 17 e a seguir: (1) o processo formal e analítico, no modo racional, que prevê a criação da estratégia pelo(s) líder(es), a partir da influência do ambiente; (2) a visão do líder, no modo empreendedor, que, a partir de oportunidades apresentadas pelo ambiente, delineia as estratégias, que são detalhadas com o seu desenvolvimento; (3) a adaptação ao ambiente, no modo adaptativo, decorrente do processo de análise e ação, das condições internas e externas, realizada pelos gestores da alta administração e demais membros da organização; (4) a interação social e interpretação coletiva, no modo emergente, resultante do processo social de adaptação dos membros da empresa, da expectativa do líder e dos stakeholders externos.

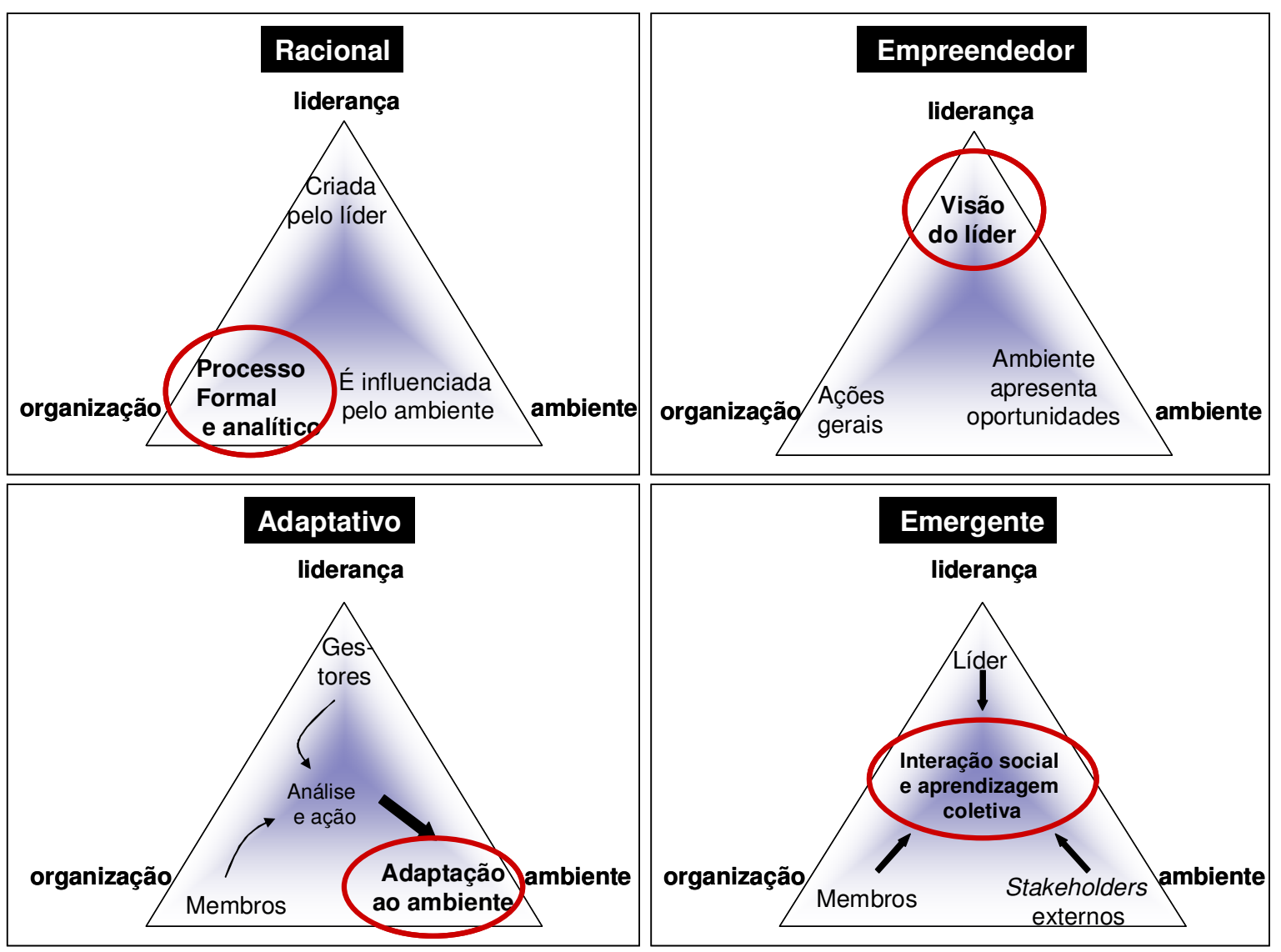

Figura 17 - Eventos determinantes dos modos de criação de estratégias 
Os processos identificados classificam-se, em maior ou menor grau, como deliberados ou emergentes. No entanto, conforme discutido no capítulo anterior, podem existir de maneira simultânea e integrada, configurando um processo de criação contínua de estratégia.

\subsection{O PAPEL DO ESTRATEGISTA}

Os dirigentes estimulam ou impedem o processo estratégico, mas podem também não exercer influência sobre ele. Os modos de formação de estratégias apresentados destacam a importância do líder, do empreendedor, do planejador, ou melhor, dos estrategistas, neste processo. Responsáveis por identificar, definir e selecionar estratégias, eles fazem ajustes, reformulam as estratégias em vigor, definem a estrutura, os processos e as políticas necessárias para que as ações sejam bem sucedidas.

Regnér (2003), ao questionar o papel do estrategista na criação e no desenvolvimento de estratégias, observa que, com freqüência, a este são atribuídas características artísticas, intuitivas, que permitem descrevê-los como arquitetos (pessoas competentes para conceber projetos) ou artesãos. Popularmente, é visto como um planejador ou visionário, capaz de identificar as estratégias que devem ser implementadas.

Mintzberg (1987c) propõe uma visão adicional do estrategista, que o caracteriza como um reconhecedor de padrões ou aprendiz que administra um processo no qual as estratégias podem surgir e, também, ser deliberadamente concebidas. Sob esta perspectiva, cabe ao estrategista não apenas traçar estratégias intencionadas, mas também dirigir o curso do aprendizado no processo de formação contínua de estratégia. Por isso deve atentar para novos acontecimentos que podem afetar sua organização, reconhecendo-os como possíveis estratégias emergentes. Este processo requer flexibilidade para apreciar diferentes modelos e perspectivas de interpretação e direção de uma organização e para mobilizar estratégias emergentes, levando em conta sua estrutura, seus processos e suas técnicas específicas. O processo estratégico não está, portanto, exclusivamente associado à concepção de estratégias deliberadas, liga-se também ao reconhecimento de processos emergentes e à intervenção sobre estes, quando necessário. A função do estrategista é reconhecer padrões tanto quanto produzir decisões (MARIOTTO, 2003; PRADO JÚNIOR, 2003).

Segundo Mintzberg e Westley (2001), os estrategistas envolvem-se em um processo decisório, apoiando-se em dois modelos: o racional e o intuitivo. Podem tomar decisões 
baseadas: na análise (thinking first), que se caracteriza pelo planejamento e pela programação de ações, a partir de fatos; na visão (seeing first), que se fundamenta em idéias derivadas da imaginação ou visão dos líderes, e na ação (action first), que se origina de experiências e resulta em aprendizado.

Muitas vezes o estrategista, por não possuir as informações de que necessita e tampouco capacidade intelectual para lidar simultaneamente com grande quantidade delas, faz escolhas sem analisar todas as alternativas de solução e antecipar os seus respectivos resultados. Em vista disso, procura identificar um curso de ação satisfatório, entre aqueles que conseguiu delimitar, a partir das suas percepções e experiências (FONSECA; MACHADODA-SILVA, 2002).

O dirigente organizacional atua com o objetivo de maximizar esforços para o estabelecimento de cursos de ação estratégica que atendam a aspirações coletivas. Possui autonomia para coordenar as atividades e os rumos da organização e deliberar sobre eles, característica que o enquadra na categoria de agente. Suas atribuições são: selecionar os domínios de produto e mercado, escolher tecnologias apropriadas ao desenvolvimento e à distribuição dos produtos, criar um sistema de informações, comunicação e controle das operações. Enfim, prepara a organização para ajustar-se ao ambiente (FONSECA; MACHADO-DA-SILVA, 2002).

Pitcher (1999) classifica três categorias de dirigentes-estrategistas: os artistas, os artesãos e os tecnocratas. A classificação da autora baseia-se em adjetivos relacionados à personalidade do estrategista, considerados em uma escala. $\mathrm{O}$ artista não se fixa a detalhes, porém demonstra coragem, audácia, intuição, em ações empreendedoras, além de ser imaginativo, imprevisível e inspirador. $\mathrm{O}$ artesão é conservador, apegado à tradição, paciente, utiliza a sua experiência para a tomada de decisões, é tido como sábio, amável, responsável, confiável e realista. Por outro lado, o tecnocrata é determinado, analítico, objetivo, metódico, controlado e racional. As categorias apresentadas raramente existem, pois são arquétipos. Nas organizações podem-se encontrar artesãos conservadores e racionais, tecnocratas emotivos ou mesmo artistas analíticos e determinados. Porém, como ressalta a autora, raramente um dirigente estrategista combina as três categorias (PITCHER, 1993; 1999).

As três categorias de Pitcher $(1993 ; 1999)$ parecem corresponder ao "Sistema de Administração Estratégica" apresentado ano final do capítulo 2. O tecnocrata é analítico, objetivo, metódico e controlador, focado, portanto, na organização. $\mathrm{O}$ artista é empreendedor, corajoso, audacioso e intuitivo com os processos do negócio e corresponde a um estrategista focado no ambiente organizacional. O artesão é tomador de decisão, paciente para lidar com 
as ameaças do ambiente, amável para lidar com as pessoas da organização, perspicaz para combinar recursos e oportunidades e sábio para equilibrar as demandas dos stakeholders, sendo assim, um estrategista focado na liderança do sistema de administração estratégica. 


\section{AS PEQUENAS EMPRESAS E SUAS ESPECIFICIDADES}

Cumpre discutir, neste capítulo, as especificidades que diferenciam as pequenas empresas das grandes organizações, entre as quais se destacam o dirigente, o contexto e a organização. Abordam-se ainda aspectos como a sua relevância sócio-econômica, a importância das etapas do ciclo de vida organizacional na definição da estratégia e as particularidades deste processo. Complementando, realiza-se a caracterização das EBT, quanto ao seu contexto, porte e processo de criação de estratégias. A figura 18 ilustra a estrutura do capítulo.

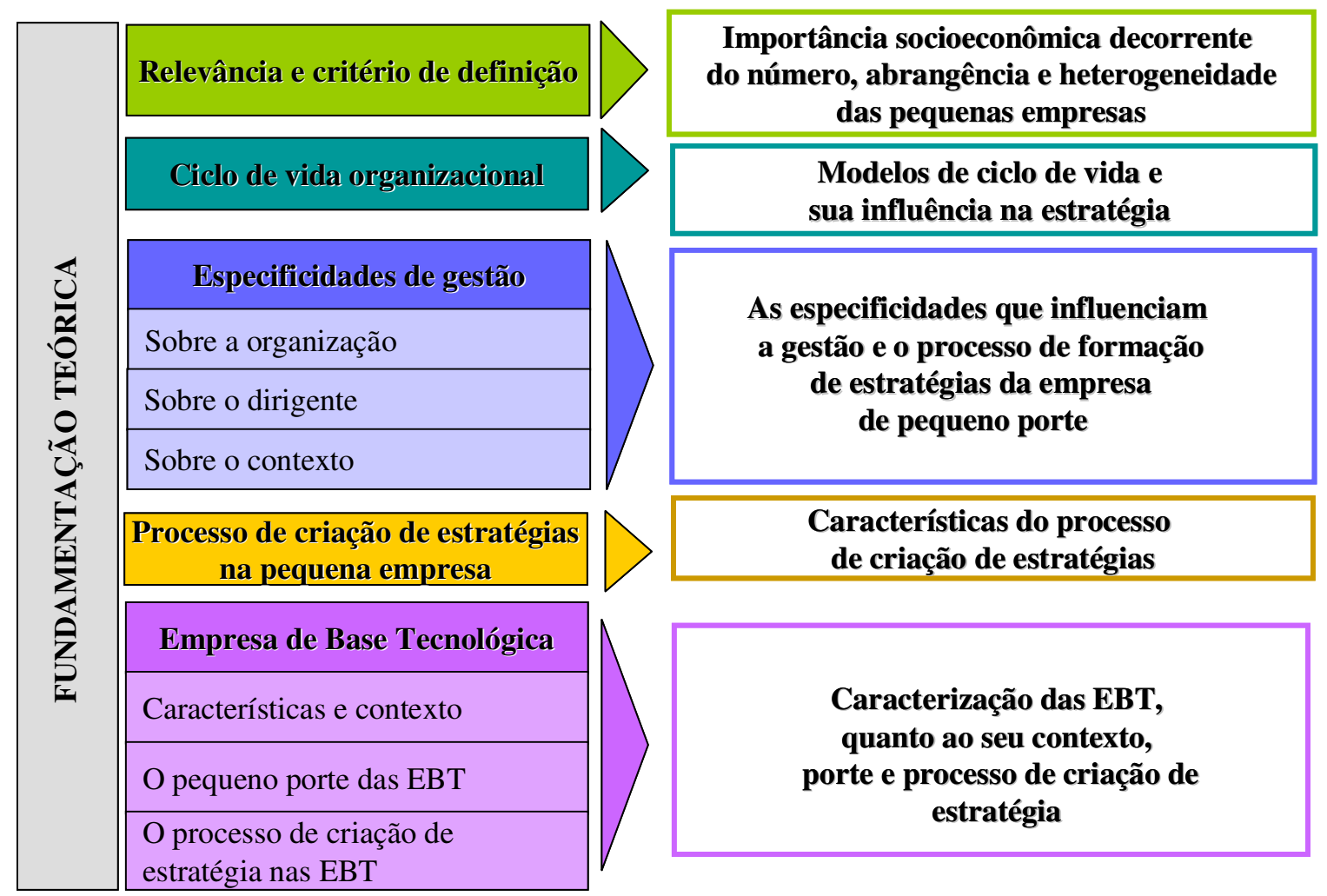

Figura 18 - Estrutura do capítulo: As pequenas empresas e suas especificidades 


\subsection{PEQUENAS EMPRESAS: RELEVÂNCIA E CRITÉRIO DE DEFINIÇÃO}

O pensamento de que o mundo empresarial seria tomado pelas grandes organizações burocráticas vigorou até os anos 70, década em que houve a reemergência das pequenas empresas, até então analisadas como "pequenas grandes empresas" - empresas em processo inicial de desenvolvimento, mas que tendem a crescer (DAY, 2000). A propósito, aplicavamse a esse segmento os mesmos princípios administrativos usados no das grandes organizações, só que em menor escala (WELSH; WHITE, 1981).

A mudança do modelo econômico deu-se devido à crise na economia, ocorrida nos anos 70 e 80, que atingiu vários países desenvolvidos e em desenvolvimento que adotavam o modelo industrial apoiado na produção em massa. As transformações recentes na sociedade e na indústria, como o incremento do setor de serviços, a diminuição dos níveis hierárquicos, o enxugamento das estruturas organizacionais, o desenvolvimento dos negócios virtuais e de empresas "e.com", entre outras, sugerem que as organizações de menor porte adquiriram maior representatividade, despontando como forma empresarial dominante, sendo anunciadas como propulsoras do crescimento econômico (DAY, 2000; LONGENECKER; MOORE; PETTY, 1997).

As pequenas empresas compreendem a maioria dos estabelecimentos industriais, comerciais e de serviços. Day (2000), para quem é universal a sua predominância chega a afirmar que representam $95 \%$ de todos os estabelecimentos. Alerta, entretanto, para o fato de que a prevalência do setor, nos diversos países, muda de acordo com a infra-estrutura econômica, o acesso ao capital de risco e o apoio governamental ao comércio e à educação.

Existem, no Brasil, cerca de 4,6 milhões de empresas, das quais $99 \%$ são micro e pequenas. E acordo com os dados da Pesquisa Nacional por Amostra de Domicílios (PNAD), realizada pelo Instituto Brasileiro de Geografia e Estatística (IBGE) e pela Relação Anual de Informações Sociais do Ministério do Trabalho e Emprego (RAIS/MTE), as micro e pequenas empresas são responsáveis por $67 \%$ das pessoas ocupadas no setor privado formal e informal (incluem-se, neste cálculo, os empregados, os empresários e os indivíduos que possuem seu próprio negócio, mas não têm empregados). Acrescente-se que as microempresas e as pequenas empresas (MPE) representam $28 \%$ de toda a receita bruta do setor formal e correspondem a $20 \%$ do Produto Interno Bruto (PIB) brasileiro (SEBRAE-SP, 2006).

A relevância desse segmento de empresas advém não apenas do número total de estabelecimentos que o representam, de sua abrangência. $O$ setor oferece outras contribuições, como: cumpre importante função social, ao absorver mão-de-obra, gerando emprego e renda; 
desenvolve tecnologia e inovações que atendem a mercados específicos; facilita a dispersão da atividade manufatureira; diminui os desequilíbrios regionais, evitando as concentrações urbanas, desempenhando assim um importante papel na interiorização do desenvolvimento; auxilia na formação de uma classe nacional de empresários; estimula a competição e contribui para a pulverização do mercado (BARROS, 1978; BURKE; JARRATT, 2004; CARDOSO, 1982; CHER, 1990; CYPRIANO, 2004; JULIEN, 1998; KRUGLIANSKAS, 1996; LONGENECKER, MOORE; PETTY, 1997; PINHEIRO, 1996; SEGENBERGER; LOVERMAN; PIORE, 1991; SOLOMON; 1986).

O termo "pequena empresa", comum na literatura administrativa, apresenta muitas possíveis definições. Com o objetivo de caracterizar a empresa de pequeno porte, os pesquisadores têm utilizado parâmetros como o volume de ativos, o faturamento, o volume de vendas e o número de funcionários, sendo os dois últimos os mais usados (D’AMBOISE; MULDOWNEY, 1988). Duas categorias de empresas classificam-se como de pequeno porte a micro e a pequena - assim definidas a partir do número de pessoas ocupadas, um critério estabelecido pelo Instituto Brasileiro de Geografia e Estatística (IBGE), apresentado na tabela 1. Solomon (1986) faz uma distinção ao dividi-las em duas categorias gerais: a microempresa cujo principal operário é o proprietário que, por sua vez, possui um determinado número de funcionários que trabalham como seus assistentes diretos, e a pequena empresa cujo proprietário dirige e supervisiona o trabalho de seus empregados.

Tabela 1 - Classificação das empresas segundo o número de funcionários

\begin{tabular}{lcc}
\hline \hline \multicolumn{1}{c}{ SETOR } & Comércio e Serviços & Indústria \\
\hline Microempresa & Até 09 & Até 19 \\
Empresa de pequeno porte & de 10 a 49 & de 20 a 99 \\
Empresa de médio porte & de 50 a 99 & de 100 a 499 \\
Empresa de grande porte & mais de 99 & mais de 499 \\
\hline
\end{tabular}

Fonte: Sebrae (2004b)

Considerando a dificuldade em se estabelecer o tamanho de uma empresa, Drucker (1981) alega que a estrutura administrativa, especialmente a da alta administração, é o único critério de confiança para defini-lo. Segundo o autor, a organização administrativa exige um nível entre o "chefe" e os trabalhadores, pois, como ressalta, os diferentes portes de empresa apresentam problemas distintos e deficiências típicas e demandam uma estrutura 
administrativa específica. A propósito, observa-se que o maior problema das pequenas e médias empresas é que, geralmente, são pequenas demais para se manter a administração de que precisam.

Julien (1998), mediante um critério abrangente, estabelece seis características das pequenas empresas: (1) o tamanho, definido pelo número de funcionários e turnover; (2) a centralização administrativa, ou seja, a gestão centrada no proprietário; (3) o baixo nível de especialização dos dirigentes, equipamentos e funcionários; (4) a estratégia informal ou intuitiva; (5) o sistema de informações internas simples, repassadas pelo contato direto entre funcionários e dirigente e (6) o sistema de informações externas simples, que resulta do contato direto entre dirigente e clientes.

D’Amboise e Muldowney (1988) e Leone (1991) destacam que é difícil definir as pequenas empresas, devido a uma de suas características - a heterogeneidade - considerando que o segmento agrupa diversos tipos de organização (BIRLEY; WESTHEAD, 1990). Esta dificuldade constitui uma barreira ao desenvolvimento de pesquisas que gerem conhecimento sobre os seus problemas típicos e, conseqüentemente, viabilizem a construção de uma teoria própria. É necessário entender de maneira mais adequada a forma de empresas mais comum e relevante na economia mundial - a pequena empresa - dando maior atenção à especificidade de suas características e de seus problemas. É importante, pois, que se estude o segmento, das pequenas empresas, levando em conta não apenas sua abrangência - o grande número de organizações existentes - mas também sua heterogeneidade.

As pequenas empresas apresentam uma série de problemas que resulta, muitas vezes, em alta taxa de mortalidade. No Reino Unido, $60 \%$ dos estabelecimentos fecham nos primeiros quatro anos, deixando dívidas e clientes insatisfeitos (DAY, 2000). No Brasil, uma pesquisa realizada pelo Sebrae revela que $49,4 \%$ das empresas encerram suas atividades com até dois anos de existência, 56,4\%, chegam aos três e 59,9\% não sobrevivem além dos quatro anos (SEBRAE, 2004a). A taxa de mortalidade das pequenas empresas é atribuída a motivações diversas, como: comportamento empreendedor pouco desenvolvido (conhecimentos, habilidades e atitudes); falta de planejamento prévio; gestão deficiente; insuficiência de políticas de apoio; conjuntura econômica e problemas pessoais dos proprietários. Para os empresários que fecham suas empresas, os principais problemas enfrentados são falta de capital, falta de clientes, inadimplência e dificuldades de gestão do negócio (SEBRAE, 2004a).

Os problemas de sobrevivência das pequenas empresas são significativamente maiores que os das grandes organizações e decorrem de duas causas: (1) administração precária e (2) 
vulnerabilidade a mudanças na economia e no mercado como um todo (DAY, 2000). Aqueles que as levam a altas taxas de mortalidade são também de cunho administrativo. Porém, considerar que são apenas estes os motivos da alta taxa de mortalidade das pequenas empresas e de suas dificuldades de gestão é uma visão limitada de tão complexas organizações.

Day (2000), considerando que as pequenas empresas, apesar de relevantes, apresentam alta taxa de mortalidade, pergunta de que forma se poderia ajudá-las a sobreviver e prosperar. Como resposta, emerge a premente necessidade de usar instrumentos administrativos. Observe-se, a propósito, que tais empresas precisam de abordagens gerenciais mais eficazes para que se tornem competitivas, pois grande parte dos problemas que enfrentam deriva de questões estratégicas (BORTOLI NETO, 2005).

Dandridge (1979) defende a tese de que as pequenas empresas precisam de uma teoria organizacional própria, de estudos focados nos seus problemas e desafios particulares. Como se mostram menos tolerantes à ineficiência, quando comparadas com organizações maiores, é imprescindível que a base teórica que as sustenta contemple suas características específicas. Esta percepção do segmento é compartilhada por um número crescente de pesquisadores que, conforme aponta Leone (1999), vêm buscando compreender melhor a sua realidade, para que possam oferecer conhecimentos administrativos adequados às suas especificidades. Reiterase, portanto, a tese de que as pequenas empresas têm seus próprios problemas e merecem uma teoria específica.

De acordo com Carvalho (2004), para se desenvolver uma "teoria administrativa" das pequenas empresas, é preciso adequar os instrumentos administrativos de que se dispõe, buscando-se, primeiramente, entender as relações entre as especificidades de gestão do setor e as características próprias das grandes organizações. Segundo a autora, esta compreensão não é fácil, mas necessária, uma vez que se pretende, adequando-se as técnicas administrativas que a literatura específica propõe, diminuir a distância entre estas e a gestão da pequena empresa. Afirma-se, portanto, que é preciso compreender: (1) as atitudes do dirigente, a partir de suas ações racionais e não-racionais, e a complexa relação entre os aspectos de seus comportamentos; (2) as restrições estruturais e (3) as imposições do contexto. 


\subsection{CICLO DE VIDA DAS ORGANIZAÇÕES}

As teorias administrativas não consideram a idade, o tamanho e a complexidade das organizações quando tratam de sua efetividade (BEVERLAND; LOCKSHIN, 2001; QUINN; CAMERON, 1983). O ciclo de vida organizacional, composto por diversas fases, contempla o contexto da organização e a sua estrutura. Os modelos que abordam esta questão mostram que as organizações, à medida que crescem linearmente, vão se tornando mais complexas, de acordo com a idade que atingem. Seu desenvolvimento dá-se em fases (ou estágios) previsíveis, nas quais se apresentam desafios, conflitos, problemas diferentes e típicos de cada uma, que exigem estratégias, estruturas e habilidades próprias (ADIZES, 1996; HANKS et al., 1993; BEVERLAND; LOCKSHIN, 2001; McCARTHY, 2003).

As organizações, segundo os modelos de ciclo de vida, crescem e envelhecem e, neste processo, passando por diferentes estágios, são dominadas por um tipo mais burocrático de sistema administrativo.

Para Greiner (1998), o modelo de desenvolvimento das organizações depende diretamente de sua idade e de seu tamanho. Estes fatores determinam os estágios de evolução (períodos de crescimento) e revolução (períodos de crise) e o crescimento da indústria (ritmo apresentado nos períodos de evolução e revolução, de acordo com o seu ambiente). O estágio evolucionário corresponde a práticas organizacionais predominantes, enquanto o revolucionário ressalta um problema administrativo que demanda solução. Assim, períodos de crise são gerados em momentos em cada fase, ou seja, um novo momento de evolução depende de um momento de revolução bem sucedido para o crescimento da empresa. A figura 19 ilustra o modelo de Greiner (1998).

O autor entende que o crescimento da organização se dá em cinco fases de evolução e revolução: (1) de criatividade, voltada para a criação de um produto ou mercado, e conseqüente crise de liderança; (2) de esforço da direção na busca de eficiência das operações e conseqüente crise de autonomia; (3) de delegação impulsionada pela estrutura organizacional descentralizada e expansão do mercado, e conseqüente crise de controle; (4) de coordenação, ou seja, de consolidação da organização com sistemas formais e responsabilidade da alta administração e a conseqüente crise burocrática; (5) de colaboração, na qual se foca a inovação como forma de resolver problemas e se busca a colaboração das equipes de trabalho, e conseqüente crise não identificada previamente pelo autor. 


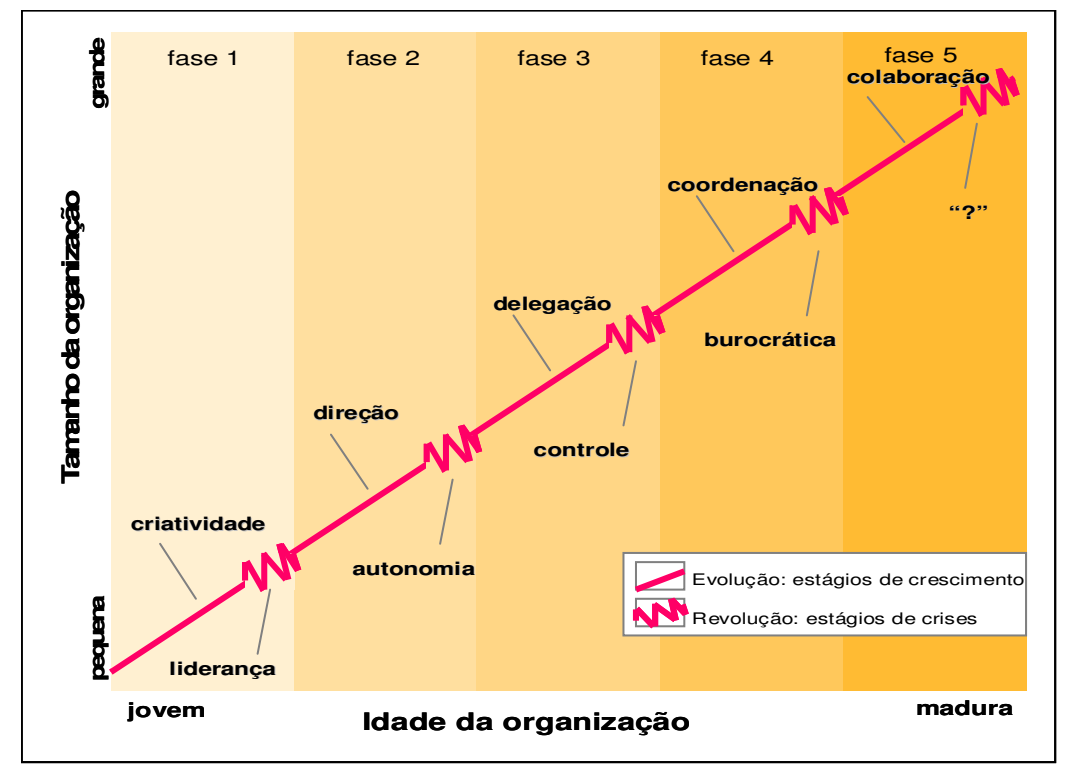

Figura 19 - Fases de crescimento das organizações Fonte: Greiner (1998, p. 58)

Porém, em outra visão, o desenvolvimento da organização não está diretamente relacionado com o seu tamanho ou a sua idade cronológica, mas com as características predominantes de estrutura (complexidade e formalização), comportamento e tomada de decisão, em cada uma de suas fases de vida. No estágio inicial, quando jovem, é altamente flexível, apresenta grande capacidade de mudar, porém, pouco controle. À medida que envelhece, sua flexibilidade diminui, mostra-se pouco propensa a mudanças e o seu controle aumenta. Na plenitude, estágio máximo do ciclo de vida, tem, como desafio, a gestão de sua flexibilidade e o controle. A transição de uma etapa a outra depende, portanto, da capacidade que a empresa tem para lidar com problemas complexos, com fatores relacionados à sua evolução, como a flexibilidade e o controle (ADIZES, 1996; SMITH; MINER, 1983).

Empresas em crescimento dependem de inovações nos produtos e apresentam altos índices de mudanças tecnológicas, sofrem altas taxas de mortalidade e têm disposição maior para assumir riscos. São os empreendedores que as conduzem, que definem seu rumo. Em sua fase de maturidade, os dirigentes passam as atividades operacionais do negócio a outros profissionais e utilizam seu tempo em ações administrativas de rotina. Neste estágio, o desenvolvimento de produtos novos diminui, assim como se tornam menos freqüentes as pesquisas e atividades de desenvolvimento, há maior economia de escala e menor taxa de mudança (BALKIN; GOMEZ-MEJIA, 1987). 
Quinn e Cameron (1983), a partir da análise de nove modelos de ciclo de vida propostos para diferentes organizações, identificam quatro fases principais do ciclo de vida organizacional: (1) empreendedora; (2) coletiva; (3) de formalização e controle e (4) de adaptação e elaboração da estrutura. Para os autores, o estágio em que a organização se encontra determina a forma de controle e a estrutura organizacional.

Miller e Friesen (1984) apresentam um modelo de ciclo de vida organizacional baseado em variáveis ambientais, estratégia, estrutura e métodos de decisão, que distingue cinco fases: nascimento, crescimento, maturidade, renovação e declínio. Segundo os autores, pode-se perceber que, em determinados estágios, dependendo da sua complexidade e do seu crescimento, as organizações apresentam-se mais conservadoras ou mais inovadoras. Assim considerando, são inovadoras nas fases de nascimento, crescimento e renovação, nas quais empreendem a eficácia, e são conservadoras nas fases de maturidade e declínio, focadas na eficiência organizacional.

Churchill e Lewis (1981) propõem um modelo de ciclo de vida para pequenas empresas, baseado em sua capacidade de crescimento, considerando as seguintes variáveis: independência de ação, estrutura organizacional, sistemas formais, objetivos estratégicos, envolvimento do dirigente e estilo de gestão. Estabelecem cinco estágios, nos quais as empresas apresentam problemas e desafios similares em direção ao desenvolvimento. No primeiro estágio, de existência, destacam-se: conquista de clientes e entrega de produtos e/ou serviços contratados; estrutura simples; dirigente como responsável pela maioria das atividades e supervisão direta de seus subordinados; sistemas e planejamento formais praticamente inexistentes e, por fim, estratégia simples, voltada à busca da sobrevivência. No estágio número dois, de sobrevivência, evidenciam-se os seguintes aspectos: organização como uma entidade produtiva, que procura o equilíbrio entre despesas e rentabilidade; número limitado de funcionários; supervisão a cargo de um gerente geral; planejamento financeiro; sobrevivência como objetivo principal e, para finalizar, papel relevante do dirigente na gestão. No terceiro estágio, denominado sucesso, a organização utiliza sua estrutura para estabelecer estratégias de crescimento. No estágio quatro - decolagem - cujo principal problema consiste em identificar a forma de crescer e financiar o crescimento, a organização comporta: gestão descentralizada, estrutura divisionalizada, sistemas sofisticados, planejamento operacional de curto prazo e planejamento estratégico realizado por uma equipe de especialistas. No estágio cinco, maturidade, dois desafios se destacam: consolidar as vantagens e os ganhos obtidos com o crescimento e manter as vantagens de uma pequena empresa, como a flexibilidade e a influência das características do dirigente na estratégia (figura 20). 


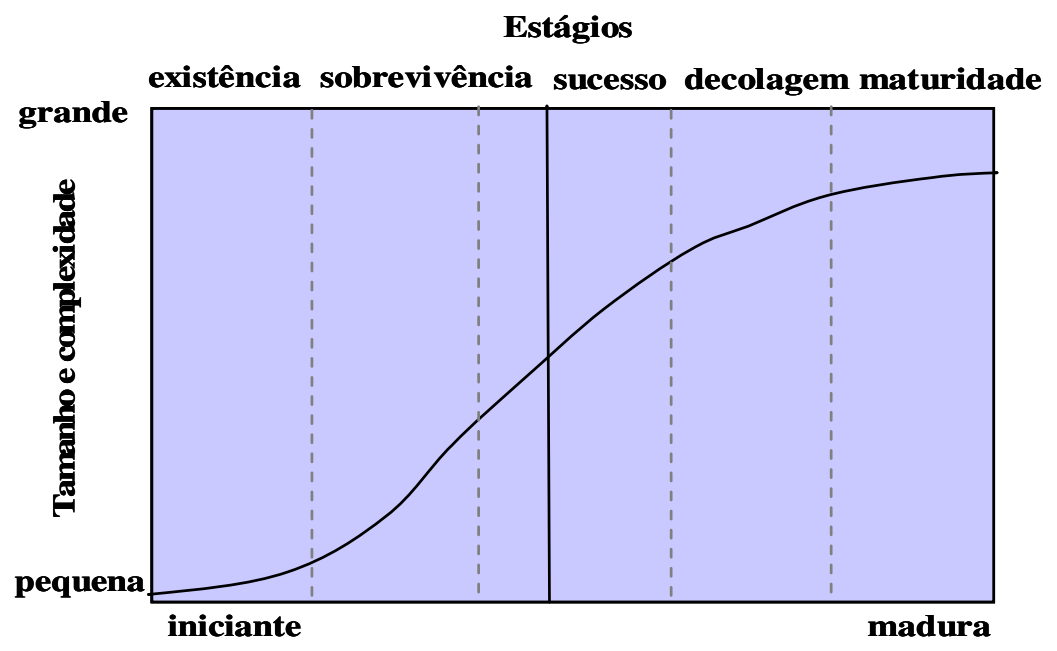

Figura 20 - Estágios do ciclo de crescimento Fonte: Churchill e Lewis (1983, p. 31)

Em geral, os pesquisadores distinguem três estágios principais no ciclo de vida organizacional: (1) crescimento; (2) maturidade e (3) declínio (CHAGANTI, 1987). As estratégias utilizadas pelas pequenas empresas, em cada uma destas etapas, diferem, assim como ocorre na adoção de estratégias em ambientes diversos. Na fase de crescimento, enfocase a inovação dos produtos, o desenvolvimento de patentes e a atuação em um mercado geograficamente restrito. $\mathrm{Na}$ fase de maturidade, busca-se a competitividade em preços. $\mathrm{Na}$ fase de declínio, atua-se em promoções, aumenta-se a linha de produtos e acentua-se a necessidade de manter a imagem da empresa.

O ciclo de vida da organização é uma variável fundamental, pois afeta a sua estratégia e efetividade. $\mathrm{O}$ conhecimento de seus estágios possibilita aos dirigentes organizacionais adotar uma atitude pró-ativa e preventiva (ADIZES, 1996; BALKIN; GOMEZ-MEJIA, 1987). A literatura sobre os modelos de ciclo de vida não só permite compreender o complexo fenômeno de crescimento das organizações como também descreve o modo pelo qual este processo ocorre e os seus efeitos (KAZANJIAN, 1988). Alguns estudos indicam que o processo formal de criação de estratégias vincula-se a organizações em estágio de maturidade do seu ciclo de vida (McCARTHY, 2003).

Em cada uma das etapas do ciclo de vida, a estrutura e os processos da organização se alteram. Deve haver, portanto, uma concordância entre a estrutura e a estratégia do empreendimento bem como entre esta e o ambiente. Aliás, a relação entre a estratégia e o 
estágio de crescimento organizacional tem recebido grande atenção na literatura. Muitas pesquisas, porém, são realizadas em grandes organizações e a sua aplicação, na pequena empresa, ainda não é muito clara (ANDERSON; ZEITHAML, 1984; BALKIN; GOMEZMEJIA, 1987; CHAGANTI, 1987). Os modelos de ciclo de vida têm sido criticados por especialistas em pequenas empresas, pelo fato de não considerarem que muitos empresários são motivados por outros fatores e não apenas pelo lucro e crescimento. Nos modelos, assume-se que o crescimento econômico é desejado e, dessa forma, examinam-se os ciclos de vida em empresas orientadas para esse crescimento (BEVERLAND; LOCKSHIN, 2001; BIRLEY; WESTHEAD, 1990; O’FARRELL; HITCHENS, 1988).

Birley e Weshead (1990) relatam ser mais provável que as organizações não passem por todos os estágios do ciclo de vida, mas por fases que ocorreriam em tempos e sequiências diferentes. Segundo os autores, o padrão de desenvolvimento das empresas seria caracterizado pela forma de conduzir o negócio, seu crescimento dependeria, portanto, do processo e da estrutura definida pelos fundadores.

Apesar dos diversos modelos propostos na literatura, é difícil identificar a razão pela qual as características de uma fase de desenvolvimento emergem (KAZANJIAN, 1988). Em vista disso, Dodge, Fullerton e Robbins (1994) afirmam que não é possível aplicar um modelo universal a todas as organizações, porque possuem características próprias, derivadas de seu ambiente específico e de seus produtos/serviços, apesar do alto grau de compatibilidade entre os fatores que descrevem o desenvolvimento organizacional. Um aspecto que influencia de modo direto este processo e suas fases é a competitividade presente no ambiente da organização, que pode ocorrer mediante o uso dos mesmos produtos ou produtos próximos com um mesmo grupo de compradores. Tal fato revela-se fundamental nas pequenas empresas que, não tendo grande influência no ambiente, precisam adaptar-se às condições que este impõe, senão fecham suas portas (DODGE; FULLERTON; ROBBINS, 1994). Portanto, a natureza da competitividade delimita a operação organizacional: nas empresas inseridas em um ambiente de alta competitividade, percebem-se os problemas e tomam-se decisões adequadas ao seu contexto, que são diferentes daquelas tomadas por organizações cujos ambientes são menos competitivos. Os autores apresentam uma matriz - baseada em duas dimensões competitivas - que possibilita identificar a posição da organização e as iniciativas estratégicas necessárias (figura 21). 


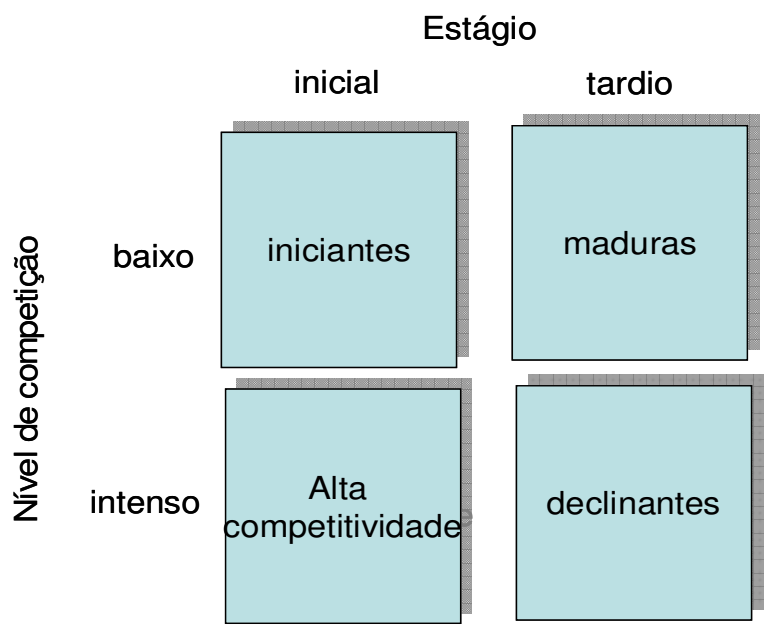

Figura 21 - Ciclo de vida organizacional, competitividade e capacidade de adaptação Fonte: Dodge; Fullerton e Robbins (1994, p. 124)

O quadrante 1 - iniciantes - indica as condições de competir das empresas pequenas, em estágio inicial de desenvolvimento e ambiente restrito e pouco competitivo, circunstâncias em que competem com produtos diferenciados e ações próximas ao seu nicho de mercado. Os seus maiores desafios são a obtenção de recursos, o desenvolvimento de estratégias de produtos e mercado, a formalização da estrutura e a conquista de mercado. No quadrante 2 maduras - relaciona-se o rápido crescimento com a maturidade organizacional. Neste caso, o ambiente não representa ameaças e a empresa não só busca a estabilidade de sua posição no mercado como faz ajustes em sua estrutura e estratégia mercadológica. Assim, realiza mudanças incrementais e, por não haver competição, tem a possibilidade de concentrar esforços na formalização dos processos e no controle das atividades. O quadrante 3 competitivas - mostra um ambiente relativamente turbulento no qual a organização procura desenvolver ou neutralizar seu diferencial competitivo, por meio de uma estratégia mercadológica voltada a características específicas do produto e de sua promoção e distribuição. Empresas pertencentes ao quadrante 4 - declinantes - descobrem que, devido à competição, perderam sua posição no nicho de mercado e, sentindo-se ameaçadas frente aos competidores, procuram explorar sua imagem e utilizam a estratégia de diferenciação com foco.

As organizações, tanto grandes quanto pequenas, são inseparáveis de seus ambientes. Mudanças ambientais trazem novas circunstâncias, que devem ser consideradas em sua gestão, para que sobrevivam e cresçam. As organizações reagem ao ambiente e esta interação 
influencia o estabelecimento de estratégias e a alocação de recursos (DODGE; FULLERTON; ROBBINS, 1994; McCARTHY, 2003).

\subsection{ESPECIFICIDADES DE GESTÃO DAS PEQUENAS EMPRESAS}

Encontram-se, na literatura específica, algumas das características mais comuns das pequenas empresas, a seguir apresentadas: propriedade de um indivíduo ou pequeno grupo de pessoas; administração não-profissional e centralizada no dirigente, o principal responsável por decisões, com tendência a não delegar autoridade; direção pouco especializada; baixo grau de formalidade; relacionamento direto entre dirigentes, funcionários, fornecedores e clientes; falta de qualificação profissional; emprego de mão-de-obra familiar; baixo nível de maturidade; estrutura simples e flexível, na maioria das vezes sem divisão de tarefas; área de operações limitada geralmente à sua localização, ou, quando muito, à região onde está inserida; atividade produtiva que não ocupa um lugar de destaque ou predominante no mercado; não apresentação de produtos em escala; recursos escassos; pouco uso de ferramentas administrativas; falta de poder de barganha, ao negociar com fornecedores e/ou compradores (EL-NAMAKI, 1990; GONÇALVES; KOPROWSKI, 1995; LEONE, 1991, 1999; LONGENECKER; MOORE; PETTY, 1997; MINTZBERG, 2003; PINHEIRO, 1986; SOLOMON, 1986; TERENCE; ESCRIVÃO FILHO, 2001). Por outro lado, destacam-se, nestas empresas, outros aspectos: flexibilidade, agilidade para efetuar mudanças em seus produtos e processos, engajamento dos funcionários, relações próximas com seus fornecedores e clientes e dedicação dos dirigentes.

Para Leone (1999), a compreender as características próprias das pequenas empresas contribui para melhorar sua gestão e, conseqüentemente, para diminuir a taxa de mortalidade de que são vítimas. A autora, de acordo com tais particularidades, classifica as características específicas das pequenas empresas em três tipos: (1) as organizacionais, que apresentam estrutura simples, são centralizadas, necessitam de uma quantidade menor de unidades ou funções administrativas, têm nível de maturidade baixo e gestão personalizada pelo dirigente; (2) as decisionais, cujas decisões são tomadas a partir da experiência ou intuição do dirigente, sob uma ótica operacional de curto prazo, baseando-se, portanto, nos seus valores e na sua racionalidade econômica, política e familiar; e (3) as individuais, onde um só indivíduo tem papel dominante, o proprietário-dirigente, que é paternalista, intuitivo e centralizador. 
Integrantes do Grupo de Estudos Organizacionais da Pequena Empresa (GEOPEEESC/USP) também estudam as suas especificidades, distinguindo três categorias (ALBUQUERQUE, 2004; BIGATON, 2005; CARVALHO, 2004; MORAES, 2005; MOTTA, 2000; NAKAMURA, 2000; TERENCE, 2002): as comportamentais (relacionadas com as características pessoais do empresário), as estruturais (referentes a aspectos internos, que decorrem de divisão do trabalho, departamentalização e interação de pessoas) e as contextuais (relativas ao ambiente externo, refletem no processo estratégico, mas não são controláveis pela ação individual dos dirigentes empresariais). Migliato (2004) classifica as características das pequenas empresas de forma abrangente, a partir do modelo de diagnóstico organizacional, que evidencia fatores ambientais, estruturais, estratégicos, tecnológicos, decisionais e comportamentais.

Neste estudo, enfatizam-se, como aspectos que exercem influência no processo de criação de estratégias das pequenas empresas, as especificidades do dirigente, de organização e do contexto (figura 22).

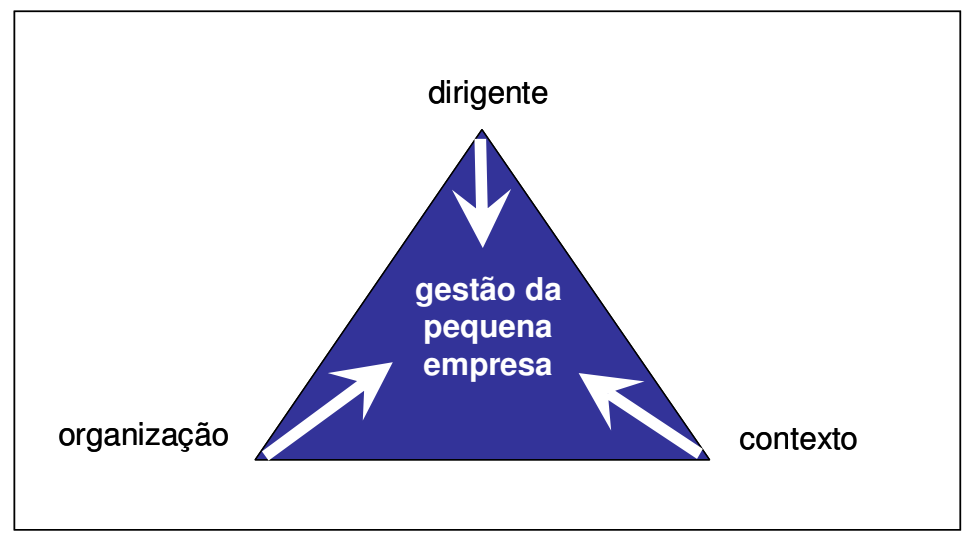

Figura 22 - Especificidades de gestão da pequena empresa

4.3.1 Sobre as especificidades de organização da pequena empresa

Organização social é um sistema que funciona como uma entidade produtiva, combinando esforços individuais para a realização de propósitos coletivos. Schein (1982) classifica dois tipos: (1) a organização informal - na qual os padrões de coordenação surgem, de modo espontâneo ou implicitamente, portanto não racional, das interações pessoais, para a consecução de objetivos explícitos comuns - como a família, a associação de bairro, a comunidade étnica, entre outras, e (2) a organização formal, em que há coordenação planejada 
das atividades de uma série de pessoas para a consecução de algum propósito explícito, implicando divisão do trabalho, estabelecimento de funções, hierarquia de autoridade e responsabilidades.

Portanto, o que é usualmente chamado de organização corresponde à organização formal que é um sistema impessoal e estruturado que integra objetivos explícitos, atividades coordenadas, formas de controle, autoridade, responsabilidade e liderança. Reitere-se que, embora sejam as pessoas que implementam as atividades na organização, o sistema em si é impessoal, ou seja, não depende de uma pessoa em particular nem constitui apenas um agrupamento de indivíduos. É oportuno esclarecer que, para serem percebidas como um grupo, as pessoas precisam interagir e ser psicologicamente conscientes umas das outras (SCHEIN, 1982). A estrutura organizacional, o "sistema formal de regras, tarefas e relações de autoridade que controlam como as pessoas cooperam e utilizam os recursos para atingir os objetivos organizacionais" (JONES, 1995, p.12), deve apoiar a estratégia empresarial e, ao determinar a forma pela qual os recursos devem ser distribuídos e as tarefas divididas, estabelece, em grande parte, como será a gestão da empresa (TERENCE; BENZE; ESCRIVÃO FILHO, 2004).

Diferentemente da organização formal, a pequena empresa pode ser caracterizada como um grupo, pois possui uma estrutura simples, relações informais e é claramente dependente de valores, objetivos e ambições de seu dirigente. De acordo com as configurações organizacionais apresentadas por Mintzberg (2003), as pequenas empresas apresentam aspectos de uma estrutura simples, como: pouca ou nenhuma estrutura, poucos assessores de apoio, divisão do trabalho não rigorosa, diferenciação mínima entre as unidades, supervisão direta, atividades centralizadas na cúpula, pouca hierarquia gerencial e poder decisório nas mãos do executivo principal. Destaque-se ainda que, nas pequenas empresas, o comportamento é pouco formalizado e o uso de planejamento e treinamento é mínimo.

As pequenas empresas possuem estrutura simples, uma vez que não apresentam condições que permitam manter uma estrutura administrativa sofisticada, com o apoio de técnicos e indivíduos funcionais especializados (DRUCKER, 1981; LEONE, 1999; THONG, 2001). Esta limitação, que impõe menor complexidade vertical (número de níveis de gerência) e horizontal (cargos e departamentos), ao mesmo tempo faz com que configurem como organizações com habilidades e funções menos especializadas, menor grau de formalização, menor percentual de administradores de topo e menor volume de comunicações escritas e documentação. 
As características das pequenas empresas possibilitam que sejam mais ágeis na tomada de decisão e, como conseqüência, uma competitividade com base em elementos internos, recursos e capacidades, em especial a flexibilidade e o design organizacional (ARAGÓNSÁNCHEZ; SÁNCHEZ-MARÍN, 2005). A flexibilidade, que deriva de sua estrutura simples, faz com se adaptem e respondam a mudanças mais rapidamente. Comumente são consideradas criativas, inovadoras e flexíveis, em comparação com as grandes organizações. Cancellier (2004) complementa o que se vem expondo, ao afirmar que a grande vantagem das pequenas empresas reside exatamente no fato que são flexíveis e manobráveis. Observe-se que, nestas organizações, os canais de decisão são curtos, as estruturas são mais simples e há senso de equipe, pois os grupos são pequenos ao redor do dono. Estes fatores concorrem para que se percebam oportunidades e se implantem ações com uma rapidez e habilidade difíceis de copiar. Estrategicamente, as pequenas empresas diferenciam-se das grandes corporações pela flexibilidade, velocidade de mudança e capacidade de atuação em nichos de mercado (DEAN-BROWN; BAMFORD, 1998). Note-se que a sua flexibilidade se deve, em grande parte, à ausência de formalização nos processos e meios de comunicação (WOODS; JOYCE, 2003).

\subsubsection{Sobre as especificidades do dirigente da pequena empresa}

Muitos estudos já foram desenvolvidos sobre a gestão das pequenas empresas. Entretanto, conforme Gimenez (2000) destaca, ainda há uma lacuna na compreensão do seu comportamento estratégico, em especial por não serem conhecidas as razões que induzem os administradores a determinadas escolhas. Uma das abordagens que tem contribuído para esclarecer a criação de estratégia na pequena empresa enfatiza a necessidade de compreender a visão que o dirigente tem do processo, as condições ambientais em que esta atua e as escolhas estratégicas (RAMOS; GIMENEZ; FERREIRA, 2005).

Diferentemente do que acontece nas grandes organizações, em que os estilos gerenciais acabam se confundindo devido à elevada quantidade de administradores, nas pequenas empresas os aspectos pessoais do dirigente, tais como seus valores e suas ambições, encontram-se refletidos em seu estilo de administrar. Assim, as características positivas do empresário, como flexibilidade e rapidez com que toma decisões, podem ser a chave do sucesso das empresas do segmento, enquanto as negativas, como resistência a mudanças e 
conservadorismo, podem causar o fracasso destas organizações (WHEELEN; HUNGER, 1993).

Há consenso em admitir que os objetivos das pequenas empresas se confundem com os de seus proprietários (O'FARRELL; HITCHENS, 1988). Sem dúvida, na empresa de pequeno porte, a formulação de estratégia é responsabilidade restrita ao executivo principal e tende a ser um processo altamente intuitivo e não analítico. Portanto, não surpreende que a estratégia resultante, raras vezes declarada, reflita a visão implícita que o dirigente tem de sua organização e de seu ambiente e constitua não só a extrapolação direta de suas crenças pessoais, mas também a extensão de sua própria personalidade (HAMBRICK; MASON, 1984; MINTZBERG, 2003). Nas pequenas empresas, dirigidas em sua maioria pelos proprietários, parece lógico assumir que as convicções, atitudes e ações destes executivos, na administração, organização do trabalho e realização de mudanças, sejam influenciadas por suas crenças pessoais e sua cultura (BHASKARAN, 2006).

O dirigente e também estrategista das pequenas empresas age de acordo com os seus princípios, intuição, instinto e impulso (McCARTHY, 2003). Deve-se, portanto, atentar para o fato de que a sua atitude pode configurar uma barreira à formulação da estratégia, pois tende a confiar na própria experiência e em contatos pessoais ao fazer a coleta de informações pertinentes ao processo. Outra barreira se constitui, quando, devido às condições internas da organização, acaba se responsabilizando por grande parte das funções, de sorte que seu tempo se torna escasso para atividades estratégicas. Aliás, a literatura confirma que a falta de tempo do dirigente para questões estratégicas é comum nas pequenas empresas (GOLDE, 1986; McGEE; SAWYERR, 2003; VAN HOORN, 1979).

Segundo Fillion (1991), o empreendedor concebe e realiza visões, individualmente e de maneira pró-ativa. No entanto, o desenvolvimento de sua visão pressupõe que possua habilidade de comunicar-se e articular, promovendo relações que o ajudem a concretizá-la. Entende-se, assim, que é necessário estabelecer uma visão e colocá-la em prática, a fim de que se instale o processo dinâmico de aprendizagem. Para sustentar a visão neste processo, quatro elementos são fundamentais: (1) a percepção da realidade, que é influenciada por valores, atitudes e intenções; (2) a energia, ou melhor, o tempo e a intensidade para executar atividades, estabelecer relações e desenvolver a visão; (3) a liderança, que afeta o desejo de realizar a visão e determina o seu alcance; (4) as relações, aparentemente o fator mais influente, que condicionam as visões e condicionam as escolha das relações.

Outra característica relevante no segmento das pequenas empresas é a centralização. O dirigente acumula as seguintes funções: ocupa-se, na maior parte do seu tempo, com áreas 
funcionais (finanças, vendas, compras etc.) e, no restante, dedica-se à direção e a tarefas operacionais. O cargo de dirigente de empresa de pequeno porte, quando comparado com posições correspondentes nas grandes organizações, pode ser visto como uma mistura de diversos cargos administrativos, que exige, portanto, maior flexibilidade e versatilidade (DRUCKER, 1981; TEIXEIRA, 1981). Convém destacar que o dirigente da pequena empresa exerce um grande número de atividades de maneira fragmentada, utiliza meios menos formais de comunicação (telefone e contato não-programado), dedica pouco tempo às reuniões programadas e envolve-se na rotina do dia-a-dia (ordens de produção, cheques, duplicatas etc.). Neste segmento, constata-se uma demanda de atuação do dirigente em diversos fluxos operacionais, que lhe exige mudar o foco de atenção, assim caracterizando a fragmentação de seu trabalho e a sua dificuldade em concentrar-se em pontos-chave (TEIXEIRA, 1981; 1982), como análises e criação de estratégias de longo prazo.

\subsubsection{Sobre as especificidades do contexto da pequena empresa}

O ambiente organizacional, composto por uma série de elementos que se localizam além da fronteira da empresa e têm a força de afetá-la em sua perspectiva de crescimento ou mesmo de sobrevivência, impõe às pequenas empresas limitações e dificuldades do sistema vigente. Desta forma, o segmento apresenta alguns aspectos próprios, decorrentes das características do ambiente - tecnológicas, sociais, políticas, econômicas, culturais, legais, entre outras - que influenciam as ações e decisões ao longo do processo de criação de estratégias, mas não são controláveis pela ação individual dos dirigentes empresariais. Tais características são denominadas, neste trabalho, especificidades de contexto.

A identificação das especificidades de contexto é relevante no estudo das pequenas empresas, pois o contexto político-econômico em que se inserem e a sua participação limitada na estrutura produtiva não as isenta das normas que orientam o processo capitalista. Souza (1995) ressalta que seria necessário contribuir para a sua efetiva integração no sistema de mercado, para que tivessem condições de competir e prosperar. As pequenas empresas freqüentemente atuam nos mais diversos nichos de mercado que, conforme relata a autora, apresentam poucas barreiras à entrada de competidores.

Como integrantes do contexto, podem ser citadas as especificidades subseqüentes: falta de controle sobre as variáveis do ambiente; carência de apoio de organismos 
governamentais; excessiva carga tributária; grande complexidade da legislação fiscal; falta de informações sobre a evolução do mercado e de seus produtos; dificuldade de acesso a processos de treinamento gerencial; dificuldade de acesso a fontes de financiamento de novos projetos e pouco poder de barganha para negociar com clientes e fornecedores (ALBUQUERQUE, 2004; ALMEIDA, 1994; GIMENEZ, 1998; LEONE, 1999). A dificuldade de acesso a processos de treinamento gerencial e a inadequação da teoria e das ferramentas administrativas contribuem para uma gestão muitas vezes ultrapassada (BORTOLI NETO, 1980), com inúmeros problemas e sem ausência de uma estratégia definida.

A carência de informações é, segundo Quezada et al. (1999), o principal entrave à concepção de uma estratégia pretendida. No entanto, é possível desenvolver o processo, pois a maioria das informações necessárias pode ser obtida com fornecedores, clientes, funcionários e de outras fontes, de maneira ágil, simples e acessível financeiramente. Menezes e Almeida (1997) complementam, argumentando que o dirigente-estrategista precisa ter, mais do que recursos, atitude para buscar as informações do ambiente. A necessidade desta atitude parece demonstrar que falta consciência da importância destas informações para a concepção de uma estratégia competitiva abrangente, que permita o crescimento ou mesmo a sobrevivência da organização. A propósito, na pequena empresa, a ausência de uma estratégia pretendida decorre da má utilização de recursos financeiros, da falta de avaliação mais precisa de futuro do mercado e da falta de uma forma de se comportar neste mercado (ALMEIDA, 1994).

\subsection{PROCESSO DE CRIAÇÃO DE ESTRATÉGIA NA PEQUENA EMPRESA}

Apesar de ser um tema amplamente investigado, o interesse pela estratégia nos pequenos negócios é recente na literatura e poucos trabalhos consideram suas condições específicas. A despeito do potencial do setor, o seu processo de criação de estratégias não tem sido adequadamente descrito ou compreendido por pesquisadores (BROUTHERS, ANDRIESSEN; NICOLAES, 1998; BURKE; JARRATT, 2004; SMITH, 1998). Analisando estudos publicados em periódicos internacionais da área de estratégia em pequenas empresas, Gimenez (2000) verifica que a maioria apresenta características da escola do planejamento, de caráter prescritivo, recomendando a adoção do planejamento estratégico nos moldes das grandes empresas. Somente a partir da década de 80 , as características próprias do segmento, 
em especial o papel do dirigente no processo de criação de estratégias, passam a ter relevância nos estudos da área. Contudo, cada vez mais se impõe a necessidade de identificar processos adequados às peculiaridades das pequenas empresas, a fim de que se apliquem estratégias que as levem a um desempenho eficiente.

Para compreender o processo de criação de estratégias das pequenas empresas, devese considerar sua característica marcante: a intuição. Brouthers, Andriessen e Nicolaes (1998) concluem que, nestas empresas, as decisões, em várias instâncias do processo de criação de estratégias, não são racionais, isto é, não são tomadas a partir de informações coletadas e resultados obtidos. Ao contrário, os empresários, confiando em sua intuição, tendem a elaborar estratégias com base nas próprias aspirações e experiências e não em análises racionais. Os autores apresentam uma proposta de melhoria relacionada com a análise do ambiente. Ressaltam a necessidade de compreender as mudanças ambientais registradas no contexto das pequenas empresas nos dias atuais, portanto mudanças que não ocorriam no passado. Entende-se, assim, que os dirigentes devem atualizar as informações sobre o seu ambiente, considerando as variáveis que têm impacto nos negócios. Em suma, para que as empresas do setor possam sobreviver e prosperar nas novas condições ambientais, é preciso fortalecer a coleta de informações, realizando-se atividades de análise continuamente.

De acordo com os empresários, as informações necessárias para a gestão estratégica da pequena empresa dependem da situação em que esta se encontra: se a organização está em dificuldades financeiras, necessita de informações do sistema financeiro, se o mercado se mostra favorável, precisa de informações sobre clientes e assim por diante, conforme se apresentem outros tipos de situação. Entretanto, é oportuno observar que o empresário não tem conhecimento amplo das diversas informações que podem ser úteis à sua empresa nem das suas respectivas fontes (MENEZES; ALMEIDA, 1997).

Aragon-Sánchez e Sánchez-Marín (2005) identificam, entre as particularidades da criação de estratégias em pequenas empresas: (1) ausência de um comportamento estratégico formal e estruturado, decorrente da falta de profissionalização; (2) menor capacidade para formular uma resposta estratégica, devido a pouca informação sobre o ambiente e (3) atuação reativa face às transformações ambientais. Por outro lado, os autores constatam, em um grupo de empresas, a orientação prospectiva, que possibilita obter vantagem competitiva sustentável, baseada em flexibilidade e inovação. É possível concluir, portanto, que as empresas com orientação reativa apresentam menor competitividade e resultados aquém de seu potencial. Smith (1998) reitera a constatação, afirmando que, nas pequenas empresas, as estratégias próativas tendem a trazer melhores resultados. 
O processo de criação de estratégias nas pequenas empresas não reflete uma análise exaustiva das condições internas e externas, mas uma análise dirigida, oportuna ou instintiva, realizada em um processo emergente (BURKE; FARRATT, 2004). O estilo e a personalidade do dirigente são fundamentais neste processo, que é informal e de curto prazo e reside na mente do estrategista (McCARTHY, 2003). Por tais razões, acredita-se que o processo formal e estruturado de formular estratégias, utilizado por grandes empresas, não é adequado nem aplicável às de pequeno porte (McCARTHY, 2003; SHRADER; MULFORD; BLACKBURN, 1989).

Day (2000) questiona se a gestão das pequenas empresas, caracterizada por intuição e criatividade, deve se desenvolver sob os preceitos das grandes corporações, com análises extensas e lineares, para a tomada de decisão na busca de oportunidades. Observa o autor que se deve aprender, com as pequenas empresas, a ser criativo e flexível, não impor a elas os modelos rígidos e conservadores das escolas de negócios. O planejamento e as análises exaustivas não fazem parte da rotina das pequenas empresas. Os dirigentes que despendem longas horas em reflexão, análise e planejamento não conseguem assegurar melhor desempenho organizacional que os dirigentes que exploram oportunidades sem planificação. Análises extensas podem ser prejudiciais aos pequenos negócios, pois nestes faltam recurso e tempo para fazê-las (BHIDE, 1994; DAY, 2000).

Quanto às idéias, Day (2000) argumenta que podem ser exploradas em um processo dinâmico e evolutivo, que implica análise e ação simultâneas. Neste caso, os dirigentes utilizam um método rápido e barato, que se situa entre a paralisia do planejamento e a falta total de planejamento, e obedece às seguintes diretrizes: (1) filtrar as oportunidades para descartar os empreendimentos não-promissores; (2) analisar as idéias com parcimônia e concentrar os esforços nas mais importantes e (3) integrar ação e análise. De acordo com este método, os dirigentes não precisam esperar que se chegue a uma análise completa para agir, porém, se necessário, devem estar prontos para mudar o curso de ação. As estratégias surgem a partir da escolha de uma idéia e da decisão de explorá-la em um processo contínuo de suposições, análise e ação (BHIDE, 1994).

A estratégia não-intencional, na empresa de pequeno porte, resulta da emergência de padrões estratégicos não esperados ou não previsíveis, mas que podem ser reconhecidos e modelados pelo dirigente, quando constata que são compatíveis com sua visão genérica ou a completam. O reconhecimento de um padrão estratégico emergente e a iniciativa de modelálo e assimilá-lo à sua visão genérica é um momento intuitivo do dirigente, que acontece quando ele utiliza suas experiências e concentra sua atenção nos elementos situacionais 
presentes, projetando-os no futuro por meio de um insight visionário (LIMA, 1999; MINTZBERG, 1987c). A visão do dirigente pode ser definida como a projeção de uma imagem do espaço de mercado futuro a ser ocupado pelos produtos e do tipo de organização necessária para ser atingido este objetivo (FILION, 1991).

O processo de reflexão não-estruturada implica uma análise superficial e compreensão intuitiva da situação. A reflexão e a ação conjuntas constituem um processo cognitivo informal e natural, que ocorre espontaneamente, quando uma pessoa, ao mesmo tempo, age e procura respostas para problemas não habituais, que surgem no decorrer da ação empreendida. As tentativas feitas na ação produzem novas descobertas, de modo que o processo passa por fases de apreciação, ação e reapreciação (LIMA, 1999).

Deve-se considerar que o processo de criação de estratégias depende da interação da empresa com o seu ambiente e suas condições internas. Pode-se afirmar que o sucesso de uma organização está relacionado com a capacidade que o dirigente tem de perceber as oportunidades de um determinado ambiente, interpretá-las e agir. A interpretação do ambiente que circunda o negócio, feita pelo dirigente, depende de suas crenças. Quando o ambiente é interpretado como concreto, mensurável e determinante, o empreendedor usa dados e coleciona informações, a fim de descobrir qual a combinação que o levará a operar com mais efetividade. Por outro lado, quando o ambiente é interpretado como não determinante, a intuição é a principal ferramenta na busca do sucesso (CAMARA et al., 2005). Para detectar oportunidades é preciso ter intuição, que requer entendimento que, por sua vez, exige conhecimento (FILLION, 1999). O estrategista deve ser capaz de reconhecer as oportunidades e ameaças do contexto ambiental e definir os desafios com os quais sua organização deve lidar. Uma visão mais restrita do ambiente pode levá-lo a certa miopia estratégica, a ignorar pressões e ameaças provenientes de contextos mais amplos (RAMOS; GIMENEZ, FERREIRA, 2005).

Para Hambrick e Mason (1984), a estratégia relaciona-se à maneira de ver, sentir, agir e reagir do estrategista, construída a partir de seu conhecimento, de suas suposições sobre eventos futuros e da sua identificação e análise que faz de alternativas e respectivas conseqüências. As escolhas do dirigente se realizam, portanto, conforme seus valores e sua preferência. Consideram os autores, que o processo de escolha da estratégia da organização é complexo e envolve vários fenômenos dos quais o estrategista não tem total compreensão, ressaltando, portanto, que visualiza os eventos, de forma seletiva, segundo sua percepção. 
O campo de visão dos estrategistas é limitado, pois não conseguem perceber todas as condições internas e externas de sua empresa. Sua percepção é seletiva e os leva a analisar apenas alguns dos fenômenos compreendidos em seu campo de visão, que são escolhidos e interpretados a partir de sua cognição e seus valores (HAMBRICK; MASON, 1984). Reafirme-se, portanto, que a criação da estratégia de uma empresa, dependendo diretamente da percepção dos seus administradores, também se relaciona com a cognição e os valores destes dirigentes. Aliás, o modelo abaixo, proposto pelos autores em destaque, evidencia que as características do dirigente-estrategista e a estratégia estão relacionadas.

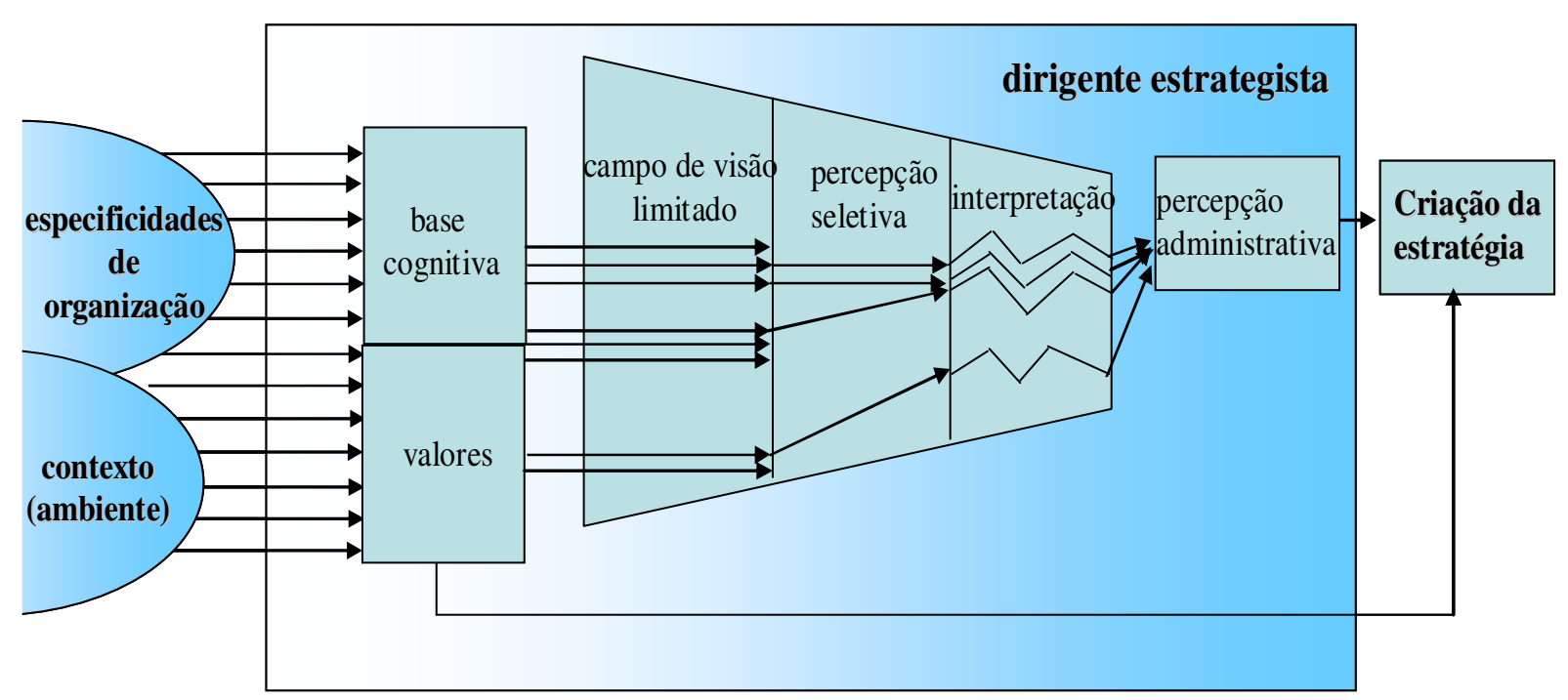

Figura 23 - Processo de criação de estratégia

Fonte: adaptado de Hambrick e Mason (1984, p. 195)

Para Hambrick e Mason (1984), as características do dirigente-estrategista (idade, atividades desenvolvidas, experiências, nível educacional e sócio-econômico e situação financeira, entre outras) influenciam a criação da estratégia e, conseqüentemente, o desempenho da organização (lucratividade, crescimento e sobrevivência), conforme demonstrado na figura 24. Assim sendo, a interação da situação (contexto e especificidades de organização) com as características do dirigente-estrategista e do processo de criação de estratégias determinam o desempenho organizacional. 


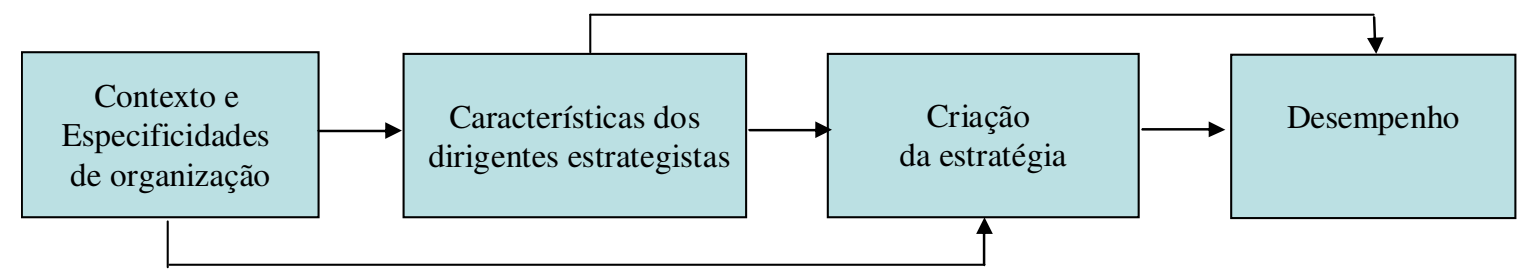

Figura 24 - Perspectiva do dirigente no processo de criação de estratégias Fonte: adaptado de Hambrick e Mason (1984, p. 198)

Bamberger (1986) e Birley e Westhead (1990) reforçam a idéia explicitada acima, alegando que o crescimento e o desenvolvimento da empresa de pequeno porte podem ser analisados de acordo com a sua velocidade de adaptação e aprendizado, ao atuar no ambiente em que está inserida, e as suas condições internas. As condições internas consistem em recursos e características do dirigente, tais como personalidade, estilo de liderança, idade, experiência, objetivos pessoais, estilo de gestão e tomada de decisões, nível educacional, valores pessoais e atitudes. O ambiente inclui fornecedores, compradores, competidores, potenciais entrantes, nível de barganha dos clientes, complexidade e grau de incerteza do mercado, tendências setoriais e políticas governamentais, sociais, legais e econômicas.

Destacam-se, portanto, as seguintes características do processo de criação de estratégias das pequenas empresas: é informal, intuitivo e realizado na mente do estrategista; é pouco estruturado e implica estratégias reativas, associadas à sobrevivência e de curto prazo; é de caráter emergente, não analítico, pois concilia reflexão e ação; suas estratégias não são comunicadas e formalizadas; condiz com a visão e as crenças do dirigente; relaciona-se aos recursos e às características do dirigente e à sua capacidade de analisar o contexto ambiental.

Não há dúvida quanto ao caráter emergente, intuitivo e criativo do processo de criação de estratégias nas pequenas empresas, realizado com base na experiência e no aprendizado. Muitos estudos, entretanto, também relacionam ao desempenho das pequenas organizações a concepção de estratégias deliberadas, por meio do planejamento formal, que as ajuda a aumentar as chances de sucesso ou sobrevivência. Levando em conta questões como previsões de venda, pessoal, caixa, análise de concorrentes e identificação de objetivos, passam a conhecer melhor sua condição competitiva (PERRY, 2001; SMITH, 1998; WOODS; JOYCE, 2003). Este tipo de planejamento, nas pequenas empresas, tem sido 
descrito como não-estruturado, esporádico, de curto prazo, informal, incompleto, pouco sofisticado e inibidor da intuição e criatividade dos estrategistas (ROBINSON; PEARCE II, 1984; CHAN; FOSTER, 2001; GIMENEZ, 2000; SMITH, 1998).

Bracker e Pearson (1986) identificam quatro processos utilizados pelas pequenas empresas, que se diferenciam pelo grau de sofisticação que apresentam: (1) o planejamento estratégico estruturado; (2) o planejamento operacional estruturado; (3) o planejamento intuitivo e (4) o planejamento desestruturado. O estilo de gestão, nestas empresas, é um fator relevante na adoção de um planejamento estratégico mais ou menos sofisticado (GIBBONS; O'CONNOR, 2005). As características dos processos de planejamento em destaque encontram-se no quadro 8.

\begin{tabular}{|l|l|}
\hline \multicolumn{1}{|c|}{ Tipo de planejamento } & \multicolumn{1}{c|}{ Características } \\
\hline Planejamento estratégico estruturado & $\begin{array}{l}\text { Formal, escrito, de longo prazo, com análise da situação passada, } \\
\text { atual e futura, análise ambiental e determinação das forças e } \\
\text { fraquezas. }\end{array}$ \\
\hline Planejamento operacional estruturado & $\begin{array}{l}\text { Formal, escrito na forma do orçamento anual, plano de ação } \\
\text { voltado ao controle da produção, dos custos e de pessoal. }\end{array}$ \\
\hline Planejamento intuitivo & $\begin{array}{l}\text { Desenvolvido e implementado com base na intuição e experiência } \\
\text { do proprietário. Não é escrito e encontra-se na mente do dirigente. } \\
\text { É de curto prazo e está relacionado ao objetivo do proprietário e às } \\
\text { condições ambientais atuais. }\end{array}$ \\
\hline Planejamento desestruturado & Não há planejamento mensurável na empresa. \\
\hline
\end{tabular}

Quadro 8 - Níveis de sofisticação do planejamento

Fonte: Bracker e Pearson (1986, p.507)

Fletcher e Harris (2002), a partir do estudo de aspectos deliberados e emergentes do processo de criação de estratégias (quadro 9), tais como a elaboração de planos, a tomada de decisões, a realização de análises, a formalidade, a identificação de objetivos, a revisão do processo, a análise dos resultados e a utilização de assessores, constatam que tanto aspectos deliberados como emergentes se apresentam no processo de criação de estratégias das pequenas empresas e, em alguns casos, são utilizados concomitantemente. A propósito, verificam que os emergentes predominam e, às vezes, são empregados em conjunto com os deliberados. É oportuno destacar que o aspecto deliberado envolve análise antes da tomada de decisão, que é programada e estabelecida em reuniões e encontros formais, realizados para a discussão da estratégia com os stakeholders. Em contrapartida, o aspecto emergente é 
evolucionário, contínuo e implica discussões não-estruturadas. Conforme os autores concluem, o processo de criação de estratégias é sutil, complexo e multifacetado.

\begin{tabular}{|l|l|l|}
\hline $\begin{array}{c}\text { Aspectos do processo de criação } \\
\text { de estratégias }\end{array}$ & \multicolumn{1}{|c|}{ Processo deliberado } & \multicolumn{1}{|c|}{ Processo emergente } \\
\hline $\begin{array}{l}\text { Plano. O pensamento estratégico e as } \\
\text { ações são realizados... }\end{array}$ & $\begin{array}{l}\text { Mediante metodologia que implica } \\
\text { a elaboração de um plano escrito. }\end{array}$ & $\begin{array}{l}\text { Sem a utilização de um plano } \\
\text { escrito. }\end{array}$ \\
\hline $\begin{array}{l}\text { Escolhas ou decisões? A criação de } \\
\text { estratégias é caracterizada por... }\end{array}$ & $\begin{array}{l}\text { Escolhas ou decisões entre } \\
\text { alternativas de variáveis do } \\
\text { ambiente. }\end{array}$ & $\begin{array}{l}\text { Visão e ações que emergem sem } \\
\text { a influência das variáveis do } \\
\text { ambiente. }\end{array}$ \\
\hline $\begin{array}{l}\text { Processo de análise. Decisões e } \\
\text { ações... }\end{array}$ & $\begin{array}{l}\text { São claramente precedidas por } \\
\text { análises formais e organizadas. }\end{array}$ & $\begin{array}{l}\text { Envolvem continuamente a } \\
\text { relação pensar, analisar e } \\
\text { decidir. }\end{array}$ \\
\hline Formalidade. As discussões são... & $\begin{array}{l}\text { Programadas e desenvolvidas em } \\
\text { encontros ou eventos formais para } \\
\text { a realização do planejamento. }\end{array}$ & $\begin{array}{l}\text { Ad hoc, não planejadas e a } \\
\text { partem de ocorrências não } \\
\text { estruturadas. }\end{array}$ \\
\hline Objetivos... & $\begin{array}{l}\text { Formais, centrais e que fazem parte } \\
\text { do processo de criação de } \\
\text { estratégias. }\end{array}$ & $\begin{array}{l}\text { Não implementados ou } \\
\text { identificados. }\end{array}$ \\
\hline Revisão do resultado... & $\begin{array}{l}\text { Programada, periódica e } \\
\text { objetivos identificados. } \\
\text { em projetos. }\end{array}$ & $\begin{array}{l}\text { Relacionada à visão, não } \\
\text { estruturada, subjetiva e contínua. }\end{array}$ \\
\hline
\end{tabular}

Quadro 9 - Aspectos do processo deliberado e emergente nas pequenas empresas Fonte: Fletcher e Harris (2002, p. 302)

O processo de criação de estratégias nas pequenas empresas deve ser visto como um contínuo aprendizado, pois, com o tempo, os seus membros vão conhecendo cada vez mais as capacidades e limitações de suas organizações, as ameaças e as oportunidades de seu ambiente e o próprio processo. É importante que os dirigentes destas empresas percebam que, da mesma forma que o processo de criação de estratégias, a gestão estratégica de seu ambiente não precisa envolver alto investimento em tecnologia, não precisa ser cara, complexa, quantitativa ou mesmo muito formal, podendo se realizar em escala modesta, com a participação de funcionários e concentrando-se nas informações relevantes para o seu negócio e as suas necessidades.

Em linhas gerais, pode-se afirmar que os estudos sobre estratégia em pequenas empresas são, em sua maioria, prescritivos, ou seja, indicam o que os dirigentes devem fazer 
para conseguir melhores resultados, enquanto os estudos relacionados ao que os dirigentes realmente fazem são raros e contradizem o pensamento normativo dominante na área.

\subsection{EMPRESAS DE BASE TECNOLÓGICA}

$\mathrm{Na}$ literatura existem diversas definições de Empresas de Base Tecnológica (EBT). Um negócio pode ser descrito como de alta tecnologia se comporta um investimento anual em Pesquisa e Desenvolvimento (P\&D) que represente $5 \%$ ou mais do que fatura, segundo o Massachusetts High Technology Council (BALKIN; GOMEZ-MEJIN, 1987). No entanto, não é apenas o volume de investimentos em $P \& D$ que caracteriza uma empresa de base tecnológica.

A princípio definidas como organizações criadas para fabricar produtos ou serviços que demandam alto recurso tecnológico (MARCOVITCH; SANTOS; DUTRA, 1986), as EBT, considerando sua origem, classificam-se distintamente em: (1) criadas a partir de uma empresa e da tecnologia existente; (2) emulação de grandes empresas, criadas a partir de um estímulo ou da ação de uma organização, com o intuito de desenvolver um novo fornecedor ou gerar uma nova empresa sob seu controle acionário e estrutura ad hoc; (3) emulação de universidades ou instituições de pesquisa (FERRO; TORKOMIAN, 1988).

De maneira mais completa, podem ser entendidas como empresas que dispõem de competência rara ou exclusiva na elaboração de projetos, produtos e/ou processos viáveis comercialmente, que utilizam técnicas avançadas e/ou pioneiras e que incorporam grau elevado de conhecimento técnico-científico em ciência aplicada e/ou engenharia, o seu principal insumo (CARVALHO et al., 1998; FERRO; TORKOMIAN, 1988; MCT, 2005).

De acordo com a Associação Nacional de Entidades Promotoras de Empreendimentos Inovadores (ANPROTEC, 2002), a expressão "base tecnológica" refere-se: (a) ao processo ou produto que resulta de pesquisa científica cujo valor agrega tecnologia avançada e (b) à aplicação do conhecimento científico, ao domínio de técnicas complexas e ao trabalho de alta qualificação técnica.

EBT são empresas que realizam esforços tecnológicos significativos, que se destacam no desenvolvimento e na comercialização de novos produtos, processos e tecnologias (KAZANJIAN, 1988; PINHO et al., 2005) e que são, por natureza, geradoras e dependentes de inovação (OLIVA; SOBRAL; SANTOS, 2005). A inovação é a sua principal 
característica, o fator que mais contribui para classificá-las como EBT. Fernandes e Côrtes (1998) distinguem as seguintes dimensões de inovação de uma empresa: (a) a sua capacidade de inovar, (b) o seu esforço inovador e (c) a intensidade de tecnologia incorporada ao seu produto ou processo produtivo. Com base nesta classificação, Rieg (2004) afirma que os conceitos encontrados na literatura derivam destas dimensões e que as divergências entre estes advêm da importância atribuída a cada uma delas.

Sintetizando, pode-se definir as EBT como empresas que combinam a capacidade de inovar com o esforço tecnológico, características que podem ser identificadas, considerandose: a natureza dos produtos que desenvolvem; os gastos com P\&D em relação ao que faturam; a manutenção de um departamento de $\mathrm{P} \& \mathrm{D}$, estruturado formalmente ou não; a proporção de engenheiros e demais profissionais graduados no conjunto de seus funcionários; o seu relacionamento com universidades e/ou centros de pesquisa e, por fim, as despesas com novas aquisições tecnológicas comparativamente às tecnologias acumuladas (FERNANDES; CÔRTES; PINHO, 2004).

Existem diferentes perspectivas sob as quais a inovação pode ser mensurada. De acordo com alguns estudos, a inovação se insere ou em um contexto de desenvolvimento de novas tecnologias ou em um paradigma de invenção. Outros distinguem inovação de invenção, considerando que a invenção é o primeiro modelo resultante de uma tecnologia, enquanto a inovação é a primeira possibilidade de comercializar a invenção (BHASKARAN, 2006).

Inovar implica desenvolver atividades de modo diferente daquele já utilizado em uma organização, tomar iniciativas para a melhoria de produtos, processos ou procedimentos, aumentando o seu valor e desempenho (DAMANPOUR, 1996). Pode-se pôr em prática a inovação de maneira radical ou incremental. No primeiro caso, busca-se, em termos de conhecimentos e desenvolvimento de produtos e processos, um avanço que normalmente exige novas técnicas de produção e novas tecnologias. No segundo, procura-se melhorar de forma contínua os produtos, processos e serviços existentes (BHASKARAN, 2006; TIDD, PAVITT; BESSANT, 2001). As inovações radicais e incrementais caminham juntas, levando em conta que uma inovação radical, com o passar do tempo, pode demandar, para seu aprimoramento e atualização, uma inovação incremental. Apesar de a literatura da área concentrar-se fortemente em inovações radicais, Bhaskaran (2006) destaca que a inovação incremental proporciona vantagem competitiva e maior rentabilidade às pequenas empresas, porque, sendo desenvolvida com mais rapidez, conduz os pequenos negócios ao crescimento bem como à lucratividade e competitividade. Por outro lado, convém destacar que a inovação 
radical cria mercados e constitui a base de atuação de empresas emergentes (HENDERSON; CLARK, 1990; OLIVA; SOBRAL; SANTOS, 2005).

A inovação organizacional configura a introdução, no mercado, de produtos, processos, métodos ou sistemas que não existiam anteriormente, ou que apresentam alguma característica nova, que são, portanto, diferentes daqueles até então em vigor e capazes de fortes repercussões socioeconômicas. Instala-se incremental ou radicalmente na área técnica de produtos e processos, em decorrência da adoção de métodos que resultam de novos conhecimentos, mudança de equipamento e/ou organização da produção e, na área administrativa, pela renovação de procedimentos, métodos de organização e comercialização (ANPROTEC, 2002).

As organizações que têm capacidade de inovar apresentam as seguintes características: (1) investem vultosos recursos em pesquisa e desenvolvimento de novos produtos; (2) confiam nas equipes empreendedoras internas, que investigam, discutem e viabilizam a produção, que lançam e vendem suas idéias, que realizam projetos; (3) são dirigidas por executivos que patrocinam e tornam possível a elaboração de projetos; (4) assumem elevado risco técnico e de mercado (KANTER; KAO; WIERSEMA, 1998; BECKER; LACOMBE, 2003).

A inovação é uma experimentação estratégica que requer atitude (comportamento) para assumir riscos na introdução de produtos diferenciados, na extensão de linhas de produto, no desenvolvimento e na implementação de estratégias para atuar em novos mercados geográficos (ou novos nichos), na identificação e no desenvolvimento de novas fontes de provisão (externas e domésticas), no estabelecimento de novas ações de vendas (como "e.com", franchising) e na criação de formas organizacionais (como redes de negócio). Destaca-se, portanto, que a inovação tecnológica em produtos ou em processos é considerada estratégica para o desempenho de uma empresa e a obtenção de vantagem competitiva, pois fazer algo que nenhuma outra faz, ou agir com mais eficácia, qualidade e rapidez que as demais, é fonte legítima de competitividade e condições para sustentar o seu crescimento e a sua lucratividade (BHASKARAN, 2006; TIDD; PAVITT; BESSAN, 2001). 
4.5.1 Características das empresas e contexto de base tecnológica

As EBT constituem uma categorização do universo empresarial que recorta transversalmente as classificações setoriais. Corroboram a dificuldade de descrição do setor das EBT as diversas definições utilizadas pelos pesquisadores e institutos de pesquisa (PINHO et al., 2005).

Em geral, as EBT concentram suas atividades nas áreas de informática/software, biotecnologia, química fina, novos materiais, eletroeletrônica/telecomunicações e mecânica/automação, situando-se em ambientes favoráveis à implantação de indústrias ou segmentos industriais associados à inovação (ANPROTEC, 2002; BARQUETTE, 2002). Tais empresas tendem a se estabelecer, portanto, em poucos centros privilegiados que tem capacidade e características que viabilizam sua inserção. Nos atuais centros de alta tecnologia, formados sob condições econômicas, históricas e socioculturais específicas, a capacitação técnica, o desenvolvimento dos setores instalados, as formas de interação social, as relações familiares e sociais, a identidade cultural dos cidadãos e os costumes, entre outros fatores, conferem grande complexidade a este processo e inserção das EBT (BARQUETTE, 2002; COURTLET, 1993). É oportuno destacar um outro aspecto que justifica localizar as EBT em determinados centros: a qualificação dos recursos humanos, proporcionada por universidades e centros de pesquisa, que constituem seu principal insumo (COURTLET, 1993).

A localidade onde se concentram EBT denomina-se pólo tecnológico, que pode ser definido como um conjunto dos seguintes componentes: (a) instituições de ensino e pesquisa que desenvolvem novas tecnologias e se especializam em pelo menos uma delas; (b) empresas envolvidas em tais desenvolvimentos; (c) projetos integrados de inovação tecnológica (empresa-universidade), que são usualmente estimulados pelo governo, dado o caráter estratégico das novas tecnologias, e (d) estrutura organizacional apropriada (MEDEIROS, 1990).

No estado de São Paulo encontram-se cinco pólos tecnológicos: as cidades de São Paulo (regiões metropolitana e do ABCD), São José dos Campos, Campinas, São Carlos e Ribeirão Preto. São Carlos, reconhecida, juntamente com Campinas e São José dos Campos, como um dos principais pólos tecnológicos do estado, abriga mais de cem EBT, que geram cerca de dois mil empregos. A vocação da cidade para a tecnologia deve-se, em grande parte, à geração de conhecimento em duas universidades públicas (Universidade de São Paulo, USP e Universidade Federal de São Carlos, UFSCar), duas unidades da Embrapa (Empresa 
Brasileira de Pesquisa Agropecuária) e duas incubadoras de empresas tecnológicas e software (FERNANDES, CORTÊS; PINHO, 2004; PARQTEC, 2006).

AS EBT são relevantes porque provêem um número de empregos maior que o oferecido por outras pequenas empresas tradicionais e representam um mecanismo estrutural que permite inovar e modernizar o parque produtivo nacional, constituir diferentes mercados e atividades e desenvolver novas tecnologias (DELAPIERRE; MADEUF; SAVOY, 1998; FERNANDES; CÔRTES; PINHO, 2004; FONTES; COOMBS, 2001). Freqüentemente associa-se o potencial das EBT a dois fatores: o seu dinamismo, ou seja, a sua habilidade para identificar, desenvolver e comercializar tecnologia e a sua capacidade de crescer rapidamente. Pesquisas recentes destacam sua contribuição na produção e difusão de novas tecnologias, caracterizando-as como empresas potencialmente dinâmicas do ponto de vista tecnológico (FONTES; COOMBS, 2001).

As EBT são relevantes e constituem objeto de interesse dos pesquisadores, entretanto enfrentam muitas dificuldades internas e externas em sua consolidação. Entre as internas, as mais citadas são: poucos recursos financeiros para investir e capacitação gerencial deficiente. A propósito, a literatura informa que estas empresas, em especial as de pequeno porte, no processo de concretizar sua efetividade, encaram problemas internos, como a não utilização de técnicas administrativas, a falta de habilidade para comercializar tecnologias e, em particular, na área gerencial, a escassez de recursos humanos e inexistência de capacitação formal dos dirigentes. (DELAPIERRE; MADEUF; SAVOY, 1998, FONTES; COOMBS, 2001; LEFEBVRE; MASON; LEFEBVRE, 1997; O'REGAN; SIMS; GHOBADIAN, 2004; PINHO; CÔRTES; FERNANDES, 2002). Observe-se, ainda, que outro fator interno afeta a sua competitividade: o processo produtivo, desenvolvido geralmente em pequena escala e com baixo grau de automação (PINHO; CÔRTES; FERNANDES, 2002).

As EBT apresentam rápido crescimento em comparação com organizações tradicionais de manufatura e têm maior chance de sobrevivência que outras empresas iniciantes (DELAPIERRE; MADEUF; SAVOY, 1998). Porém, devido à dinamicidade e turbulência do ambiente em que atuam, encontram obstáculos macroeconômicos ao seu crescimento e à sua consolidação. Entre os fatores externos que interferem na sua consolidação estão: a falta de uma política estatal favorável, o difícil acesso ao crédito, a falta de mão-de-obra altamente qualificada, em especial de técnicos e engenheiros com treinamento e experiência adequados, a dificuldade em obter insumos e as condições do mercado emergente, com limitada capacidade para absorver os produtos de alta tecnologia (FERNANDES; CÔRTES; PINHO, 2004; FERRO; TORKOMIAN, 1988). O difícil acesso a 
fontes de financiamento deve-se à falta de credibilidade e garantias e, sobretudo, à própria natureza das atividades a que se dedicam, uma vez que, centrando-se na introdução de tecnologias em geral não testadas no mercado, o risco do investimento é particularmente elevado (DELAPIERRE; MADEUF; SAVOY, 1998; PINHO; CÔRTES; FERNANDES, 2002; QIAN; LI, 2003).

As EBT, em face dos rápidos avanços tecnológicos, do processo acelerado de globalização, de sua complexidade, da crescente competição em seu setor e da turbulência e incerteza do seu ambiente organizacional, demandam condições competitivas, isto é, condições para responder e se adaptar a tais circunstâncias (McGEE; SAWYER, 2003). Inseridas em ambientes dinâmicos, estas empresas apresentam produtos com ciclo de vida curto - produtos rápidos, que são substituídos por outros ou por suas variantes, devido ao desenvolvimento constante de novas tecnologias - por isso necessitam de habilidade para acompanhar as situações competitivas que se alteram continuamente (EISENHARDT, 1989; MEREDITH, 1987; QIAN; LI, 2003).

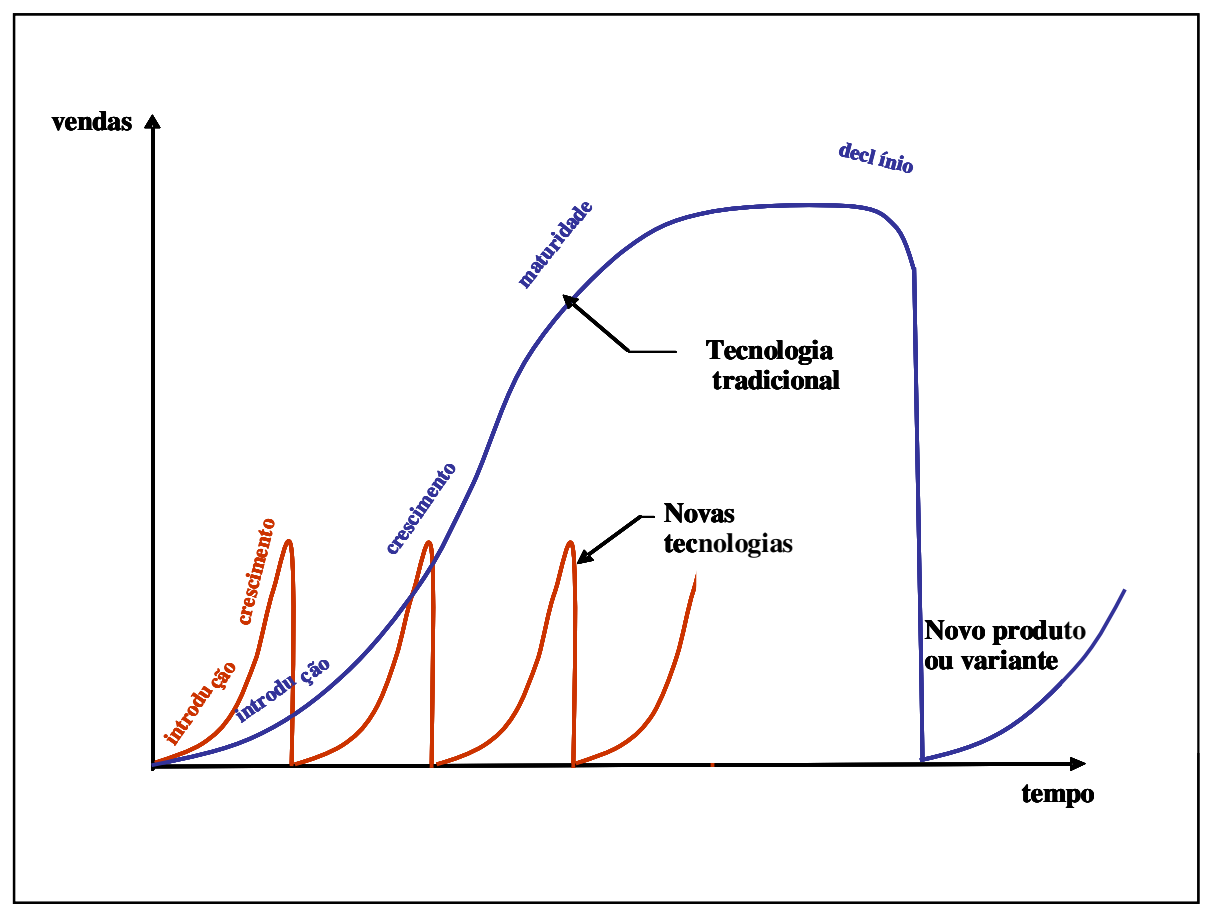

Figura 25 - O impacto da inserção da tecnologia no ciclo de vida dos produtos Fonte: Meredith (1987, p. 253)

O próprio ciclo de vida das EBT influencia o processo de inovação tecnológica. Como evolui em fases previsíveis e distintas, a compreensão destas etapas pode ajudar a organização 
a se prevenir das armadilhas e desenvolver a competência necessária para os desafios de cada uma (KAMPAS, 2003; RODRIGUES; RISCAROLLI; ALMEIDA, 2004). Kazanjian (1988) define quatro estágios para o ciclo de vida de empresas de base tecnológica, relacionando variáveis ambientais, estratégia, estrutura e decisão: (1) etapa de concepção e desenvolvimento de produtos ou tecnologias, na qual a estrutura e os procedimentos formais não existem e todas as atividades são decididas pelo empreendedor; (2) fase de comercialização, em que se desenvolvem, além dos produtos, estruturas, procedimentos e sistemas; (3) estágio de crescimento rápido de vendas e aumento do número de funcionários, no qual se definem a hierarquia e a especialização funcional e (4) fase de estabilidade, concentrada no desenvolvimento da nova geração de produtos, na estabilização da posição de mercado e na procura de novas oportunidades. Nos estágios iniciais, a inovação centraliza-se no desenvolvimento de tecnologia de produto e, nos mais avançados, no de tecnologia do negócio.

$\mathrm{Na}$ fase de inovação em tecnologia de produto, as competências necessárias referemse tanto à capacidade técnica individual para criar e aplicar produtos como ao funcionamento, desempenho e compatibilidade destes. Por outro lado, na fase de inovação em tecnologia de negócio, as EBT procuram dominar a habilidade de adicionar valor aos produtos, desde que os padrões de aceitação do mercado estejam definidos, com ações que possibilitem estabelecer relações mercadológicas, tais como segmentação e posicionamento, alianças estratégicas e marcas (RODRIGUES; RISCAROLLI; ALMEIDA, 2004).

A cultura, as crenças e os valores dos dirigentes e demais membros das EBT modelam as competências destas empresas. As experiências do dirigente e seu padrão cultural influenciam a criação de estratégias e seus respectivos resultados. Os integrantes da organização, em todos os níveis, também são suscetíveis às ações do dirigente, ou seja, a visão do dirigente e os cursos de ação que estabelece influenciam suas percepções e julgamentos, ainda que inconscientemente (KAMPAS, 2003). Observe-se que as inovações também podem ser fruto da habilidade do dirigente em desenvolver e utilizar a rede de contato a que tem acesso, composta por indivíduos atuantes na área política, de pesquisa e empresarial. Assim como o padrão cultural do dirigente, o ambiente influencia a criação de estratégias, define as ações e a infra-estrutura da organização. 
4.5.2 O pequeno porte das empresas de base tecnológica

Em estudo realizado no estado de São Paulo, Fernandes, Côrtes e Oishi (2000) concluem que as EBT são, em sua maioria, de pequeno porte e jovens (menos de 10 anos) e estão concentradas em dois setores, na região metropolitana - precisão de instrumentos médicos (36\%) e informática (23\%). Pinho et al. (2005), ao investigarem 102 EBT do estado de São Paulo, constatam que o pequeno porte das organizações é patente: $86 \%$ da amostra. Estudando 120 EBT, Carvalho et al. (1998) verificam que são de pequeno porte, se formam a partir de tecnologia gerada na relação empresa/universidade e têm seu próprio capital. Entre as principais dificuldades enfrentadas por estas empresas, destacam os problemas de financiamento e comercialização de seus produtos/serviços, bem como a necessidade de treinamento em ferramentas administrativas.

O porte da empresa não condiciona o seu êxito ou fracasso frente à inovação, mas pode auxiliá-la. As pequenas empresas apresentam, como vantagens, capacidade de resposta rápida e eficiente às mudanças do mercado e da tecnologia e gestão desenvolvida por dirigentes dinâmicos, que não hesitam em aproveitar oportunidades. Porém, como possuem canais informais e não sofisticados de comunicação interna, tendem a resolver problemas internos com menos velocidade que as grandes organizações. A vantagem das pequenas empresas face à inovação reside na sua flexibilidade (BARAÑANO, 1998; AUTIO; YLIRENKO, 1998).

A inovação, que representa a incorporação de novas idéias, práticas ou objetos por unidades individuais de operação, é pertinente a pequenas empresas em especial, que precisam de uma análise adequada a seu contexto e suas especificidades. Os seus dirigentes exercem influência na introdução de modificações, na identificação de novidades, na geração de idéias, nas práticas, nos objetos e na percepção de comportamentos para assumir riscos que nutrirão mudanças na criação de bens ou serviços e métodos de produção, no estabelecimento de novos mercados, no uso de fontes de provisão alternativas e na elaboração de novas formas organizacionais (BHASKARAN, 2006; JOHANNESSEN; OLSEN; LUMPIKIN, 2001).

Em sua análise, Barros (2001) constata a grande influência do dirigente no processo de criação de estratégias das EBT: nelas as ações de inovar e definir a política tecnológica estão relacionadas à percepção que o dirigente tem do ambiente e à sua capacidade de assumir riscos e seguir suas crenças (McCARTHY, 2003; LEFEBVRE; MASON; LEFEBVRE, 1997). Os dirigentes com alta qualificação, oriundos de universidades e institutos de pesquisa ou grandes corporações, têm, além das características tradicionais de um empreendedor 
capitalista, como traço peculiar, um forte interesse pela área de tecnologia, geralmente advindo de sua formação técnica, de sua trajetória profissional em organizações avançadas tecnologicamente ou de uma mentalidade configurada por disposições individuais específicas (BECKER; LACOMBE, 2003; CARVALHO et al., 1998; FERRO; TORKOMIAN, 1988; OLIVA; SOBRAL; SANTOS, 2005).

O diferencial entre um empreendedor tradicional e um empreendedor de EBT é a capacidade que este tem de transformar-se, passando de tecnólogo a empresário, o que pressupõe adquirir habilidades de gestão do negócio. No entanto, percebe-se, no segmento, uma forte concentração de funções na figura do dirigente que, de um lado, precisa realizar múltiplas atividades - coordenar pessoas com diversas especializações, desenvolver e posicionar o produto, pensar na organização futura do empreendimento, entre outras - e, por outro, como muitos deles afirmam, tem de assumir papéis que não sabe desempenhar ou funções gerenciais ou administrativas que não gostaria de exercer (BECKER; LACOMBE, 2003).

Um dos problemas que se apresentam às pequenas empresas de alta tecnologia é a necessidade de acompanhar as mudanças tecnológicas radicais. Seus dirigentes, preocupados com tarefas diárias de gestão e problemas típicos da pequena empresa, não se empenham na atualização de conhecimentos (OLIVA; SOBRAL; SANTOS, 2005), indispensável ao desenvolvimento das EBT, uma vez que a inovação é um fator fundamental na definição das regras de competição na indústria. Como os esforços de inovação de uma empresa decorrem da política tecnológica estabelecida, algumas pequenas empresas se revelam mais inovadoras, pois nelas se percebe o ambiente de forma mais dinâmica e competitiva, de sorte que, em longo prazo, tornam-se mais propensas a assumir riscos e implementar estratégias de inovação mais agressivas (GONÇALVES; PAIVA JÚNIOR, 2005).

Complementando, nas empresas de pequeno porte, a percepção que o dirigente tem do ambiente influencia a política tecnológica e define os esforços de inovação. Para Lefebvre, Mason e Lefebvre (1997), esta visão da realidade - e não medidas e informações objetivas - é fundamental no estabelecimento da política tecnológica e, particularmente, no impacto desta política na capacidade de inovar e no desempenho da organização (figura 26). A percepção do dirigente reflete, de maneira mais ou menos fiel, o contexto (ambiente) em que a organização está inserida, como o demonstram os autores, pelo efeito prisma 


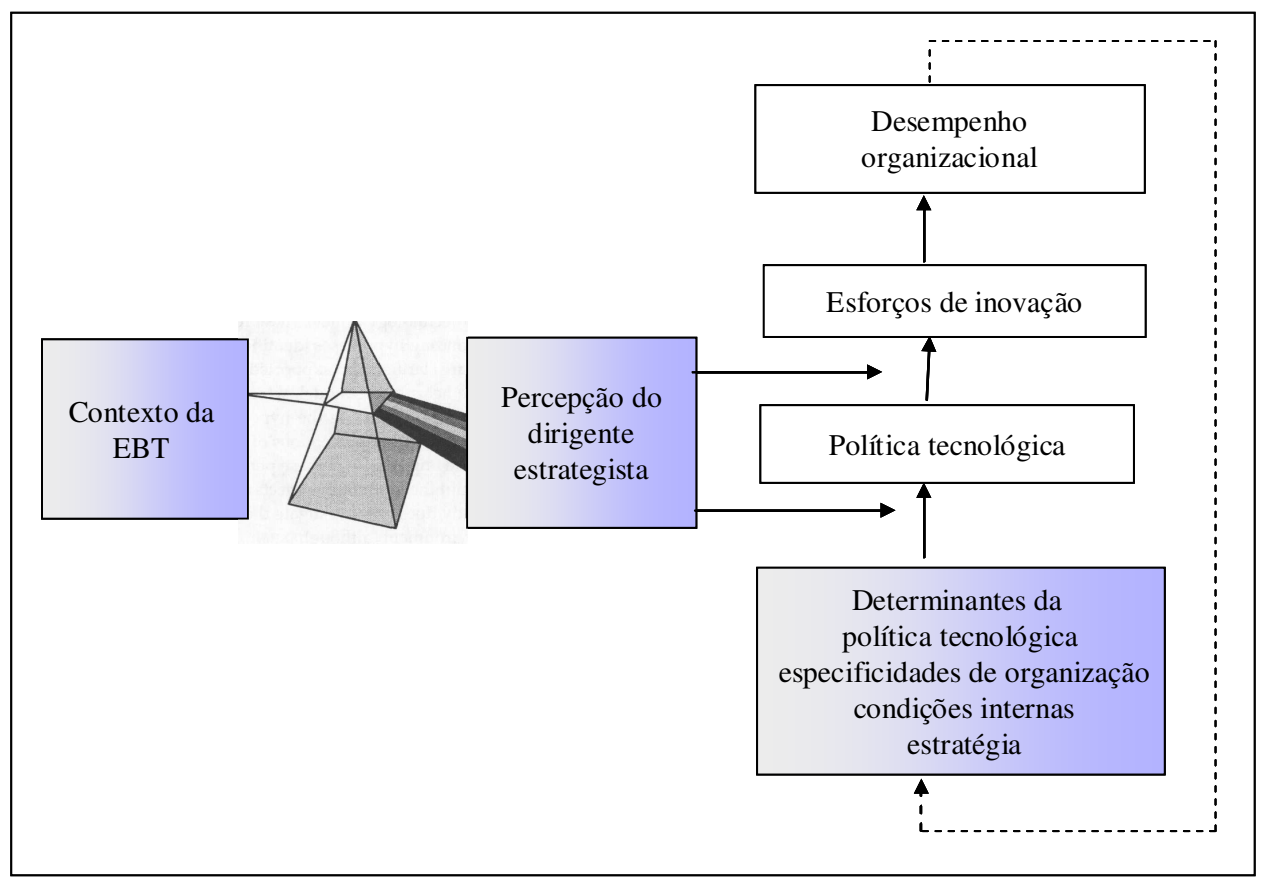

Figura 26 - Influência da percepção do dirigente para a definição da política tecnológica e de inovação na empresa de pequeno porte

Fonte: adaptado de Lefebvre, Mason e Lefebvre (1997, p. 858)

O conhecimento científico e técnico é determinante para inovação, enquanto a administração mais centralizada e a formalização parecem impedir o processo (LEFEBVRE; MASON; LEFEBVRE, 1997). De acordo com estes autores, os esforços de inovação realizados em pequenas empresas são de três tipos: (1) investimento em $\mathrm{P} \& \mathrm{D}$, com o intuito de aprimorar ou modificar produtos existentes ou desenvolver novos produtos; (2) melhoria de práticas administrativas, como adotar sistemas de informações e novas tecnologias de produção, e (3) desenvolvimento e comercialização de novas tecnologias.

\subsubsection{O processo de criação de estratégias das EBT}

A infra-estrutura das EBT não é favorável à coleta adequada de informações em seu ambiente, caracterizado por dinamismo e alto grau de incerteza (McGEE; SAWYER, 2003). Esta coleta se realiza mediante contato com fornecedores, distribuidores, clientes, consultores externos e notícias sobre os negócios da indústria. (BARROS, 2001). 
A adaptação ao contexto organizacional inicia-se com o exame das condições externas à organização, a partir das quais os gestores identificam tendências (KRAJEWSKI; RITZMAN, 2000) e tomam decisões estratégicas. Também relevantes, no processo estratégico, são os aspectos internos, com implicação imediata e específica na gestão, como: tipo de estrutura, políticas, procedimentos, habilidades, sistemas, estilo de gestão, capacidades e competências organizacionais, entre outros. As condições externas e internas referem-se, portanto, a fatores situacionais que devem ser levados em conta na criação de uma estratégia. É importante frisar que os fatores, ou o entrelaçamento destes, que exercem influência sobre o processo estratégico variam de empresa para empresa.

Bhide (1994) constata, porém, que o método analítico de criação de estratégias não se adapta a empresas que atuam em mercados de tecnologia, nas quais devem ser evitadas análises extensas, uma vez que as pesquisas conduzidas sob tais condições não são confiáveis e uma resposta rápida não permite despender tempo para assegurar a cobertura de todos os detalhes.

Em estudo realizado em pequenas empresas de tecnologia, Barros (2001), corroborando o ponto de vista de Bhide, conclui que, nestas, não se adota um processo estruturado ou sistemático para o desenvolvimento de estratégias. Ao contrário, o autor identifica um processo que demonstra a ascendência do enfoque incremental e da rede de relacionamentos na criação de estratégias, com as seguintes características: constante ajustamento da estratégia, para acompanhar as mudanças no ambiente externo; avaliação contínua de novas opções estratégicas; consideração de qualquer opção estratégica como experimental, portanto sempre sujeita a revisões; desenvolvimento da estratégia por meio de experimentação e implementação gradual; destinação de recursos adicionais para alternativas estratégicas bem-sucedidas e, finalmente, evolução da estratégia pela implementação de pequenas mudanças.

Barros (2001) constata que o processo de criação de estratégias, nas pequenas empresas de tecnologia investigadas, resulta da interação dinâmica de três elementos que o caracterizam: (1) a informalidade, pois não obedece a modelos ou ferramentas estruturadas, não atende a uma agenda definida, podendo ocorrer de modo imprevisível, e não segue regras ou planos; (2) a abordagem incremental das atividades, ou seja, de acordo com um ajuste contínuo, para se manter o sincronismo com as mudanças no ambiente, e (3) a rede de relacionamentos, que compreende ações voltadas à criação e ao desenvolvimento de redes sociais com todos os parceiros de negócio. A criação de estratégias em EBT, a partir do incrementalismo, deve-se ao fato de requerer baixo comprometimento de recursos para as 
ações necessárias e de gerar soluções criativas e factíveis, diante dos escassos recursos disponíveis.

Brown e Eisenhard (1997) verificam que organizações inseridas em indústrias de "alta velocidade" realizam mudanças contínuas, a partir de: (1) equilíbrio entre formalidade e liberdade para improvisação; (2) incursões de baixo custo no futuro, como produtos experimentais, alianças com clientes potenciais, planejamento de longo prazo e reuniões freqüentes para se discutir a estratégia e (3) administração cuidadosa da transição entre projetos presentes e futuros. Nestas indústrias, onde a criação de estratégias implica um fluxo de mudanças competitivas contínuas, as escolhas que moldam a estratégia são fundamentais, ocorrem com freqüência e, para o seu desenvolvimento, são utilizadas técnicas que promovem a tomada coletiva de decisões, como: desenvolver a intuição compartilhada, acelerar e estimular o conflito construtivo, manter o ritmo disciplinado e neutralizar o comportamento político. Os processos coletivos de decisão, derivados de uma estrutura limitada, responsabilidades claramente definidas e comunicação extensiva, resultam em estratégias eficazes (EISENHARDT, 1989, 1999).

Para Eisenhardt (1999), as abordagens tradicionais de estratégia concentram-se em estabelecer "para onde se pretende ir". Estas abordagens, porém, são incompletas em mercados de "alta velocidade" e competitivos como o das EBT, em que as estratégias são menos previsíveis e tendem a ser emergentes (MINTZBERG, LAMPEL, 1999). Observa Eisenhardt (1999) que a estratégia eficaz na indústria de alta tecnologia está relacionada à capacidade de tomar decisões rápidas, o que impõe aos dirigentes algumas ações: priorizar a construção da intuição coletiva, estimular a instauração do conflito, visando melhorar a qualidade do pensamento estratégico, manter um ritmo disciplinado na condução do processo decisório e enfraquecer o comportamento político, que cria conflito improdutivo e perda de tempo.

Perussi Filho (2006) apresenta um modelo de criação de estratégia, denominado “formação quântica de estratégia”, por analogia à física quântica, que contempla ações relacionadas com as fases do ciclo de vida organizacional: na fase de criação, a emersão de estratégias se apresenta com maior evidência; na fase de posicionamento efetivo no mercado, a emersão continua, mas aliada a ações de planejamento e, na fase de sistematização operacional, as estratégias emergentes ainda acontecem, porém condicionadas à avaliação da sua viabilidade comercial, técnica e econômica, de acordo com estratégias previamente formalizadas. Assim considerando, a estratégia ocorre, nas organizações, em pacotes específicos, conforme cada fase do seu ciclo de vida: no início é claramente emergente e, com 
a maturidade, tornando-se o processo mais formal, passa a ser intencionada (PERUSSI FILHO, 2006; PERUSSI FILHO; ESCRIVÃO FILHO, 2007).

Segundo os autores, o processo de criação de estratégias passa por momentos explicitados e descritos a seguir:

1) Estratégia de criação da empresa: por demanda do mercado, por solicitação feita a elementos de grupos de pesquisa; por sugestões de amigos; por avaliação de oportunidades pelo grupo de pesquisa. Nas duas primeiras situações a estratégia emerge estimulada por uma demanda específica. Na terceira, a estratégia resulta de uma reflexão sobre as competências existentes no grupo de pesquisa. Assim sendo, em todas as situações não se realiza uma reflexão estruturada sobre o tamanho, as condições do ambiente e a viabilidade econômicofinanceira do empreendimento. Nesta fase, as ações focalizam o produto.

2) Estratégia de busca de eficácia externa: focaliza ações de crescimento por meio da criação de um departamento comercial, ou seja, o foco passa do produto para o mercado. O departamento comercial viabiliza a interação da empresa com o mercado e com o desenvolvimento de novos produtos, pois a criação de estratégias visa atender aos interesses do mercado. Nesta fase inicia-se o estabelecimento de parcerias, a identificação de representantes e distribuidores, tendo em vista concretizar-se um maior volume de vendas ou mesmo a representação de produtos estrangeiros no mercado brasileiro. Surgem elementos superficiais de planejamento formal, restrito à área de vendas, apresentando-se, portanto, ações deliberadas na criação de estratégias, decorrentes principalmente da avaliação de oportunidades sob a ótica do mercado. Porém, neste estágio, a emersão ainda é mais relevante.

3) Estratégia de busca de eficácia externa e interna, pela incorporação de ações que possibilitem consolidar o sistema operacional e atingir o objetivo econômico de rentabilidade. Assim, nesta fase, busca-se a eficiência no uso de recursos e na obtenção de lucro condizente com o custo estabelecido pelo empreendedor. Têm início, nesta etapa: a padronização de modelos de produtos, as certificações em órgãos reguladores setoriais e a padronização de procedimentos operacionais que fundamentem a elaboração de planejamento, atendendo à necessidade de planejar as vendas. Devido a resultados obtidos pela maior interação com o mercado (fase 2), a empresa busca estruturar e consolidar um processo operacional por meio do qual possa cumprir os compromissos assumidos com os clientes. Percebe-se um processo, ainda que informal, de planejamento estratégico, com base em análise técnica e comercial, para atender aos interesses do mercado e da empresa concomitantemente. Nesta fase, aumentam as ações deliberadas na criação de estratégias. 
4) Maturidade estratégica: fase em que os empreendedores já têm forte domínio sobre a tecnologia, o mercado e ações importantes voltadas a resultados econômicos de longo prazo. Nesta etapa, há conversão de interesses mercadológicos e econômicos e uma estabilidade maior, que provém da compreensão de aspectos referentes à interação com o mercado e de procedimentos internos direcionados à qualidade e produtividade da empresa. É uma fase em que as ações deliberadas predominam, em relação às emergentes.

De acordo com o modelo de formação quântica da estratégia, as ações deliberadas predominam. Assim sendo, as condições internas de gestão (competências essenciais internalizadas), o ambiente (representado pelo mercado ou por laboratórios e institutos de pesquisa) e o ambiente dos grupos de pesquisa criam impactos nas estratégias. Porém, conforme ressalta Perussi Filho (2006), nenhuma empresa pesquisada realiza o planejamento estratégico de maneira formal e sistematizada, as estratégias são criadas exclusivamente pelos empreendedores e a emersão de estratégias, após a criação da empresa, dá-se por meio de demanda externa ou análise de competência interna e dos grupos de pesquisa. 


\section{TIPOS E MÉTODOS DE PESQUISA}

Este capítulo, cujo objetivo é contextualizar o trabalho de campo, compõe-se de duas partes. A primeira é de caráter teórico e reúne considerações sobre pesquisa quantitativa versus pesquisa qualitativa, destacando-se não só os pressupostos, as definições e as características de tais tipos de investigação científica, mas também as diferenças entre as duas abordagens. A segunda, que se refere à metodologia da pesquisa feita, descreve os seus passos desde a escolha dos métodos ao objeto de estudo, abrangendo as técnicas utilizadas, as questões e as variáveis. Para visualizar a estrutura do capítulo, apresenta-se, a seguir, a figura 27.

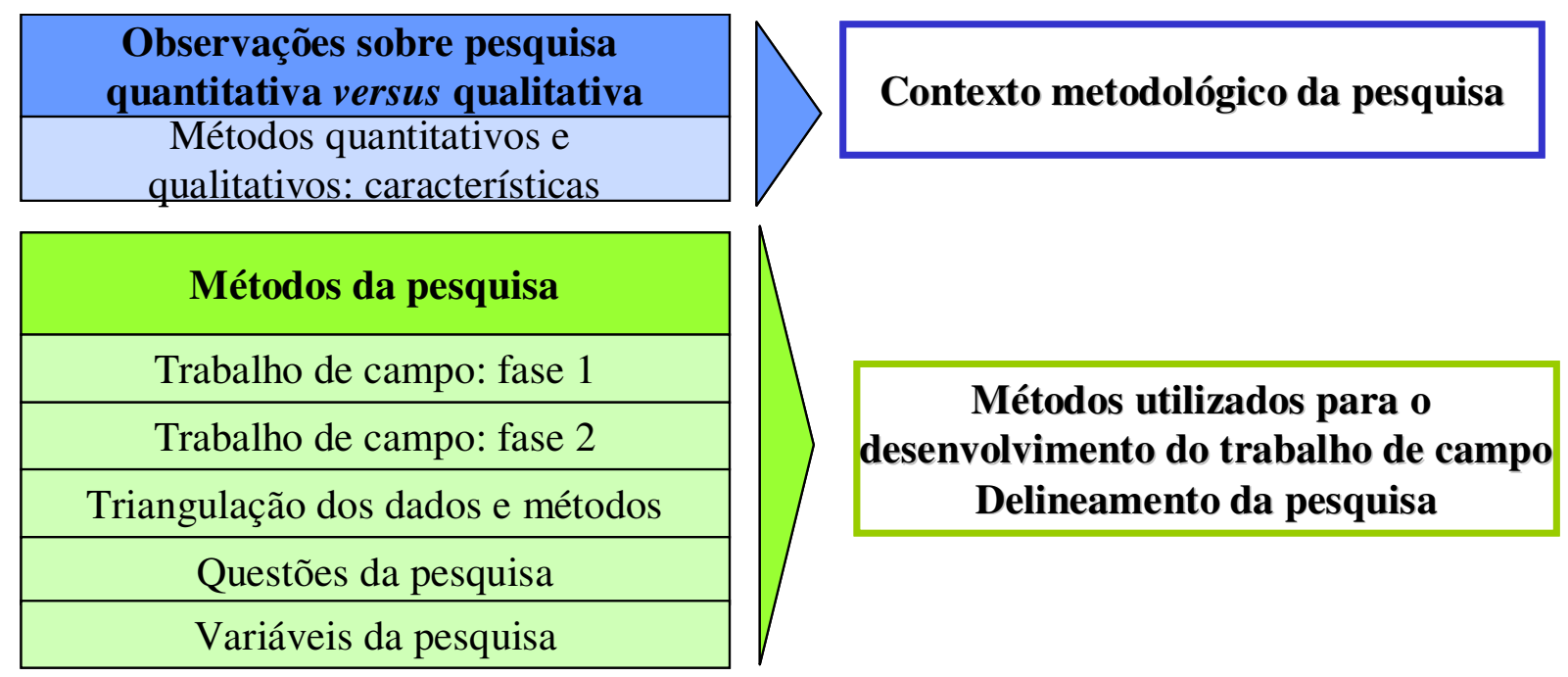

Figura 27 - Estrutura do capítulo trabalho de campo

No âmbito dos estudos organizacionais, utilizam-se diversas abordagens metodológicas, tanto de cunho quantitativo como qualitativo. Observe-se, entretanto, que a escolha de um ou outro tipo deve associar-se, contudo, ao objetivo da pesquisa porque ambos apresentam características específicas, vantagens e desvantagens. Por outro lado, muitas vezes, conjugam-se diferentes métodos, recorrendo-se a mais de uma fonte para coleta de 
dados, unindo-se o qualitativo ao quantitativo (FREITAS et al., 2000). Ressalta, portanto, que a metodologia de pesquisa qualitativa se apresenta como uma entre as diversas possibilidades de investigação. Assim considerando, julga-se relevante e oportuno justificar o seu uso aliado à abordagem quantitativa, explicitando as estratégias e os métodos selecionados para o seu desenvolvimento.

\subsection{ABORDAGENS DE PESQUISA: QUANTITATIVA E QUALITATIVA}

Na pesquisa em ciências sociais - que implicam relações de caráter social e humano desenvolvem-se estudos em que se prioriza o uso de métodos quantitativos, para descrever e explicar fenômenos. Observa-se, porém, que, mais recentemente, os métodos qualitativos surgem, na área, como promissora possibilidade de investigação (GODOY, 1995a; NEVES, 1996).

A seguir apresentam-se os pressupostos e as principais características das abordagens quantitativa e qualitativa, o questionamento acerca da escolha de uma ou outra abordagem e, por fim, a justificativa para emprego de ambas, como forma de atingir o objetivo de uma pesquisa.

\subsubsection{Os paradigmas positivista e alternativo}

Conforme a abordagem metodológica que se adota, os tipos de pesquisas se classificam em dois grupos - o quantitativo e o qualitativo. O primeiro obedece ao paradigma clássico (positivismo), enquanto o outro segue o paradigma chamado alternativo.

Nas ciências sociais, os estudos desenvolvidos segundo a doutrina positivista são influenciados inicialmente pelas ciências naturais, que postulam a existência de uma realidade externa que pode ser examinada com objetividade, pelo estabelecimento de relações de causa e efeito, a partir da aplicação de métodos quantitativos, que permitiriam chegar a verdades universais. Sob esta ótica os resultados da pesquisa são reprodutíveis e generalizáveis (HAYATI; KARAMI; SLEE, 2006). 
O positivismo instaura as ciências como investigação do real, do exato, do certificado, do incontestável, do determinado e, enfim, do útil, presumindo que a sociedade humana é regulada por leis naturais, invariáveis e independentes da ação humana. Esta postura leva a crer que "a metodologia das ciências sociais tem que ser idêntica à metodologia das ciências naturais, posto que o funcionamento da sociedade é regido por leis do mesmo tipo das da natureza” (LÖWY, 1985). Entende-se assim que, da mesma maneira que as ciências da natureza, tidas como objetivas, neutras, livres de juízo de valor, as ciências sociais, que implicam ideologias políticas e sociais, devem ter igual caráter de objetividade científica, assumindo-se o pressuposto de que é necessário e possível o desenvolvimento de uma ciência social livre de valores, ideologias, influências políticas ou vínculo com classes sociais, pois estas influências prejudicariam a sua objetividade (LÖWY, 1985, p. 35).

Compreende-se o positivismo como uma combinação das idéias empiristas com as da lógica moderna, influenciada por descobertas da física, em especial pelas teorias da relatividade e quântica (ALVES-MAZZOTTI; GEWANDSZNAJDER, 2004).

Segundo o positivismo, a lógica e a matemática são válidas por estabelecerem as regras da linguagem, constituindo-se um conhecimento independente da experiência, estabelecido a priori. Em contraste, o conhecimento empírico é obtido a partir da observação e por meio do raciocínio indutivo. Os positivistas entendem que cada conceito de uma teoria deve ter, como referência, algo observável, defendendo assim a verificabilidade dos enunciados científicos e o estabelecimento de relações lógicas entre os estes. Esta lógica impõe um critério "ideal" de agir e pensar, conferindo à ciência um caráter normativo, em vez de descritivo.

As críticas da Escola de Frankfurt (grupo de intelectuais de inspiração marxista) à visão da "ciência tradicional" e o debate iniciado pelo filósofo Thomas Kuhn (1922-1996), ao publicar a obra "Estrutura das revoluções científicas" 12 , no início da década de 60, afetam a maneira de ver a ciência e seu método, contribuindo para o esgotamento do "paradigma positivista”. Sob a ótica de Kuhn, a pesquisa científica é orientada não apenas por teorias, mas, de forma mais ampla, abrange leis, conceitos, modelos, analogias, valores e regras. As revoluções científicas e a mudança de paradigma levam a constatar que é impossível estabelecer uma distinção entre conceitos observáveis e conceitos teóricos.

A nova forma de compreender a ciência possibilita o surgimento de enfoques diferentes do positivista. A constatação de que as abordagens unicamente quantitativas não

\footnotetext{
${ }^{12}$ KUHN, T. S. (1962). The Structure of scientific revolutions. Chicago: University of Chicago Press.
} 
são satisfatórias abre espaço para que se consolide o "paradigma qualitativo", identificado como uso de técnicas qualitativas na geração de conhecimento. No entanto, convém ressaltar que a pesquisa qualitativa não se restringe à adoção de uma teoria, um paradigma ou método, recorre, ao contrário, a uma multiplicidade de procedimentos, técnicas e pressupostos. Logo, nos dias atuais, não faz sentido falar em "paradigma qualitativo", pois diferentes paradigmas podem utilizar as metodologias qualitativas. Convencionou-se, apenas, que as investigações que recaem sobre a compreensão das intenções e do significado dos atos humanos devem ser classificadas como qualitativas (ALVES-MAZZOTTI; GEWANDSZNAJDER, 2004; DENZIN; LINCOLN, 2005; PATTON, 2002).

Os pesquisadores que adotam a abordagem qualitativa se opõem à proposta de um modelo único de pesquisa para todas as ciências, considerando que as ciências sociais têm características próprias. Mormente no campo dos estudos organizacionais, esta diferenciaçãoespecificidade deve-se à natureza do fenômeno estudado - as organizações compostas por pessoas que agem de acordo com seus valores, sentimentos e experiências, que estabelecem relações internas próprias, que estão inseridas em um ambiente mutável, onde os aspectos culturais, econômicos, sociais e históricos não são passíveis de controle e sim de difícil interpretação, generalização e reprodução (CHIZZOTTI, 1995; GAY; DIEHL, 1992; GOLDENBERG, 1999; GUTIERREZ, 1986). Portanto, nos estudos organizacionais, o pesquisador e seu objeto de estudo interagem e esta interação, adequadamente descrita, é um elemento do processo de formulação teórica (WOOD JR, 1998).

$\mathrm{Na}$ abordagem qualitativa, o investigador procura aprofundar-se na compreensão dos fenômenos que estuda - ações dos indivíduos, grupos ou organizações em seu ambiente e contexto social - interpretando-os segundo a perspectiva dos participantes da situação enfocada, sem se preocupar com representatividade numérica, generalizações estatísticas e relações lineares de causa e efeito. Assim sendo, a interpretação, o pesquisador, tido como o principal instrumento de investigação, e a necessidade de contato direto e prolongado deste com o campo, para captar os significados dos comportamentos observados, revelam-se como características da pesquisa qualitativa (ALVES, 1991; GOLDENBERG, 1999; NEVES, 1996; PATTON, 2002). 
5.1.2 Pesquisa quantitativa e qualitativa: características

Os tipos de pesquisa se classificam como quantitativos e qualitativos por apresentarem características contrastantes quanto à forma e ênfase de sua construção teórica, entretanto não são excludentes. Para melhor compreendê-los, apresentam-se, a seguir, as suas principais características.

Nos estudos organizacionais, a pesquisa quantitativa permite a mensuração de opiniões, reações, hábitos e atitudes em um universo, a partir de uma amostra que o represente estatisticamente. Suas características principais são (DENZIN; LINCOLN, 2005; NEVES, 1996; HAYATI; KARAMI; SLEE, 2006):

- obedece rigorosamente a um plano pré-estabelecido, com o intuito de enumerar ou medir eventos;

- recorre à teoria para desenvolver suas hipóteses e variáveis;

- examina as relações entre as variáveis, por meio de métodos experimentais ou semiexperimentais, controlados rigorosamente;

- emprega, geralmente, na análise dos dados, instrumental estatístico;

- confirma as hipóteses da pesquisa ou descobertas por dedução, ou seja, realiza predições específicas sobre princípios, observações e experiências;

- utiliza dados que representam uma população específica (amostra), a partir dos quais os resultados são generalizados;

- usa, como instrumento para coleta de dados, questionários estruturados, compostos predominantemente de questões fechadas, testes e checklists, aplicados mediante entrevistas individuais, direcionadas por um questionário convencional (impresso) ou eletrônico.

A pesquisa qualitativa, utilizada para interpretar fenômenos, pressupõe a interação constante da observação com a formulação conceitual, da pesquisa empírica com o desenvolvimento teórico, da percepção com a explicação (BULMER, 1977). Esta abordagem de pesquisa constitui uma alternativa apropriada aos estágios iniciais da investigação, quando se busca explorar o objeto de estudo e delimitar as fronteiras do trabalho, quando existe especial interesse na interpretação do respondente, considerando seus comportamentos, motivos e emoções, quando o tema da pesquisa envolve tópicos abstratos, sensíveis ou situações de forte impacto emocional para o respondente e/ou quando o universo da pesquisa é pequeno e a quantificação não faz sentido (HEYINK; TYMSTRA, 1993). 
São características da pesquisa qualitativa (ALVES-MAZZOTTI; GEWANDSZNAJDER，2004; BODGAN; BIKLEN，1982; DENZIN; LINCOLN，2005; GODOY, 1995a; HAYATI; KARAMI; SLEE, 2006):

- um design ${ }^{13}$ que evolui durante o seu desenvolvimento: as estratégias utilizadas permitem que se descubram, indutivamente, relações entre fenômenos, fazendo emergir novos pressupostos;

- apresentação da descrição e análise dos dados sob a forma narrativa, sinteticamente;

- busca de significados particulares, em contextos socioculturais específicos, com possibilidade, porém, de generalização;

- o ambiente natural como fonte de coleta de dados;

- o pesquisador como instrumento principal da investigação;

- tendência a ser descritiva;

- maior interesse pelo processo do que pelos resultados ou produtos;

- coleta de dados por meio de entrevista, observação, investigação participativa, entre outros instrumentos;

- compreensão dos fenômenos a partir da perspectiva dos participantes e, finalmente,

- análise dos dados sob enfoque indutivo, ou seja, generalização de observações limitadas e específicas.

Segundo Denzin e Lincoln (2005), a pesquisa qualitativa enfatiza o processo e seu significado, enquanto a quantitativa preocupa-se em medir (quantidade, freqüência e intensidade) e analisar as relações causais entre as variáveis do estudo. A crítica dos pesquisadores quantitativos à abordagem qualitativa baseia-se nos seguintes pontos: não seria uma investigação confiável, pois, introduzindo o viés do pesquisador, seus resultados não seriam reprodutíveis; mesmo que houvesse certo grau de reprodutibilidade, a interpretação seria suscetível a mudanças (WOOD JR, 1998). Por outro lado, os pesquisadores qualitativos relatam que a abordagem quantitativa é restritiva, ou seja, apresenta um retrato reducionista da complexidade social, por não conseguir captar o ponto de vista do indivíduo, por utilizar grandes amostras e afastar o pesquisador do cotidiano em que se insere o objeto estudado (DENZIN; LINCOLN, 2005).

O método qualitativo, sendo útil e necessário para identificar e explorar os significados dos fenômenos estudados e as interações que estabelecem, estimula o desenvolvimento de novas interpretações dos variados e profundos fenômenos sociais

${ }^{13}$ Design da pesquisa qualitativa representa a proposta, o planejamento ou as estratégias utilizadas pelo pesquisador para a resolução do problema proposto. 
(BARTUNEK; SEO, 2002). Deve-se lembrar, porém, que cada método de pesquisa possui características próprias e são adequados a propósitos específicos. Abaixo, no quadro 9, são apresentadas as principais características das abordagens de pesquisa discutidas.

\begin{tabular}{|c|c|c|}
\hline Características & Pesquisa quantitativa & Pesquisa qualitativa \\
\hline Inferência & Dedutivo & Indutivo \\
\hline Objetivo & Comprovação & Interpretação \\
\hline Finalidade & $\begin{array}{l}\text { Teste de teorias, } \text { predição, } \\
\text { estabelecimento de fatos e teste de } \\
\text { hipóteses. }\end{array}$ & $\begin{array}{l}\text { Descrição e entendimento de } \\
\text { realidades variadas, captura da } \\
\text { vida cotidiana e perspectivas } \\
\text { humanas. }\end{array}$ \\
\hline $\begin{array}{l}\text { Princípio da realidade } \\
\text { investigada }\end{array}$ & Objetividade & Subjetividade e complexidade \\
\hline Foco & Quantidade & Natureza do objeto \\
\hline Amostra & Determinada por critério estatístico. & $\begin{array}{l}\text { Determinada por critérios } \\
\text { diversos. }\end{array}$ \\
\hline Característica da amostra & Grande & Pequena \\
\hline $\begin{array}{l}\text { Instrumento de coleta de } \\
\text { dados }\end{array}$ & $\begin{array}{l}\text { Questionários, testes, checklists } \\
\text { (instrumentos formais). }\end{array}$ & $\begin{array}{l}\text { Entrevista, observação, pesquisa- } \\
\text { participante. }\end{array}$ \\
\hline $\begin{array}{l}\text { Característica do } \\
\text { instrumento }\end{array}$ & $\begin{array}{l}\text { Questões objetivas, aplicações em } \\
\text { curto espaço de tempo. Evita-se a } \\
\text { interação entrevistador-entrevistado. }\end{array}$ & $\begin{array}{l}\text { Questões abertas e flexíveis. } \\
\text { Aplicação em longo espaço de } \\
\text { tempo, para explorar a interação } \\
\text { pesquisador-entrevistado. }\end{array}$ \\
\hline Procedimentos & $\begin{array}{l}\text { Isolamento de variáveis. Anônima aos } \\
\text { participantes. }\end{array}$ & $\begin{array}{l}\text { Examina todo o contexto, } \\
\text { interage com os participantes. }\end{array}$ \\
\hline Análise dos dados & Estatística e numérica. & $\begin{array}{l}\text { Interpretativa e descritiva. Uso de } \\
\text { formas variadas de análise, com } \\
\text { ênfase na análise de conteúdo e } \\
\text { interpretação. }\end{array}$ \\
\hline Plano de pesquisa & $\begin{array}{l}\text { Desenvolvido antes de o estudo ser } \\
\text { iniciado. Proposta estruturada e formal. }\end{array}$ & $\begin{array}{l}\text { Inicia-se com uma idéia que } \\
\text { evolui com o aprendizado. } \\
\text { Proposta flexível. }\end{array}$ \\
\hline Resultados & $\begin{array}{l}\text { Comprovação de hipóteses. A base } \\
\text { para generalização dos resultados é } \\
\text { universal e independente do contexto. }\end{array}$ & $\begin{array}{l}\text { Proposições e especulações. Os } \\
\text { resultados são situacionais e } \\
\text { limitados ao contexto. }\end{array}$ \\
\hline Confiabilidade e validade & $\begin{array}{l}\text { Pode ser determinada, dependendo do } \\
\text { tempo e recurso. }\end{array}$ & $\begin{array}{l}\text { Difícil determinação, dada } \text { à } \\
\text { natureza subjetiva da pesquisa. }\end{array}$ \\
\hline
\end{tabular}

Quadro 10 - Características das pesquisas qualitativa e quantitativa

Fonte: elaboração própria a partir de Godoy (1995a); Wood Jr (1988); Lima (2005);

Alves-Mazotti e Gewandsznajer (2005) 
Uma vez discutida a natureza das abordagens de pequisa, faz-se necessário apresentar as estratégias comumente utilizadas. Os principais tipos de pesquisa quantitativa são a survey (levantamento), a correlacional, a causal-comparativa e a experimental. Reconhecem-se como principais formas de pesquisa qualitativa a pesquisa-ação, a pesquisa histórica, o estudo de caso, a etnografia e a grounded theory (VERGARA, 2005). A distinção entre pesquisa quantitativa e qualitativa não significa que se deva optar por um ou outro método de investigação. O pesquisador pode, ao desenvolver o seu estudo, utilizar os dois, usufruindo, por um lado, da vantagem de poder explicitar todos os passos de seu trabalho e, por outro, da oportunidade de prevenir a interferência de sua subjetividade nas conclusões obtidas (NEVES, 1996).

A triangulação de métodos ou multimétodo refere-se à comparação de dados coletados por abordagens quantitativas e qualitativas, ou seja, diz respeito a adotar métodos diversos para a análise de uma única questão ou um só objeto de estudo. Pode ser utilizada de diferentes modos, como opção por um método, empregando-se instrumentos diversos de coleta de dados, combinação alternada de métodos e uso simultâneo dos dois métodos para responder à questão de pesquisa. Portanto, as abordagens qualitativas e quantitativas podem ser complementares e adequadas para minimizar a subjetividade e aproximar o pesquisador do objeto de estudo, assim respondendo às principais críticas das abordagens qualitativa e quantitativa, respectivamente, e proporcionando maior confiabilidade aos dados. É oportuno enfatizar que a triangulação pode ocorrer tanto pelo uso de métodos diversos quanto pelo recurso a diferentes fontes, pesquisadores e/ou teorias (GODOY, 2005; HAYATI; KARAMI; SLEE, 2006; PATTON, 2002).

\subsection{MÉTODOS DA PESQUISA}

Visando atingir o objetivo proposto, foi realizado um estudo empírico, em duas fases, abaixo apresentadas, em pequenas empresas de base tecnológica, localizadas no pólo de São Carlos/SP. Mais especificamente é um estudo empírico cujo objeto de interesse são indústrias de base tecnológica de pequeno porte com menos de 100 funcionários, comprometidas com o projeto, seu desenvolvimento e a produção de novos produtos, caracterizando-se, ainda, pela aplicação sistemática de conhecimento técnico-científico (SEBRAE, 2001). Excluem-se, portanto, as empresas comerciais e de serviços e as indústrias de grande porte. 
No quadro 11, são apresentados os aspectos metodológicos da investigação correspondentes aos expedientes usados nas fases 1 e 2 do trabalho de campo. Os itens a seguir contemplam a descrição dos métodos de pesquisa selecionados para as fases 1 e 2 do trabalho de campo e a triangulação de métodos e dados. O protocolo da pesquisa encontra-se no apêndice A.

\begin{tabular}{|c|c|c|}
\hline Aspectos & Fase 1 & Fase 2 \\
\hline Unidade de análise & $\begin{array}{l}\text { Grupo de empresas industriais de } \\
\text { base tecnológica de pequeno porte }\end{array}$ & $\begin{array}{l}\text { Duas empresas industriais de base } \\
\text { tecnológica de pequeno porte } \\
\text { Uma empresa industrial de base } \\
\text { tecnológica de médio porte }\end{array}$ \\
\hline Abordagem & Quantitativa & Qualitativa \\
\hline Técnicas de pesquisa & Survey & Estudo de caso \\
\hline $\begin{array}{l}\text { Instrumentos de coleta } \\
\text { de dados }\end{array}$ & Questionário & Entrevista e observação. \\
\hline $\begin{array}{l}\text { Técnica de } \\
\text { amostragem }\end{array}$ & Por grupos & Seleção de casos \\
\hline Enfoque principal & $\begin{array}{l}\text { Identificar o processo de criação de } \\
\text { estratégias no grupo de pequenas } \\
\text { empresas de base tecnológica. }\end{array}$ & $\begin{array}{l}\text { Identificar o contexto, as } \\
\text { especificidades de organização e a } \\
\text { influência do dirigente estrategista na } \\
\text { criação de estratégias, com o intuito de } \\
\text { melhor compreender como as variáveis } \\
\text { influenciam o processo. }\end{array}$ \\
\hline
\end{tabular}

Quadro 11 - Aspectos da metodologia da pesquisa

\subsubsection{Métodos da pesquisa para fase 1}

Para a caracterização da fase 1, destacam-se, a seguir, alguns de seus aspectos.

- Quanto aos propósitos, é exploratória.

Para o seu desenvolvimento, fez-se uma análise exploratória dos dados coletados, com o objetivo de identificar as variáveis que influenciam o processo de criação de estratégias no grupo de pequenas empresas de base tecnológica. Destaque-se que a pesquisa exploratória visa proporcionar maior conhecimento sobre o problema que se investiga para torná-lo claro ou construir hipóteses (SILVA; MENEZES, 2005). 
- Quanto à abordagem do problema, é quantitativa.

Com o intuito de chegar a uma compreensão geral do fenômeno estudado, os dados foram classificados e analisados, tendo em vista seu uso na coleta e análise de dados da fase 2 e na elaboração de uma forma de representação do processo de criação de estratégias, isto é, de um mapa estratégico, conforme explicado anteriormente.

- Quanto aos procedimentos técnicos, é uma pesquisa survey.

Na fase 1, procedeu-se a um levantamento de dados - classificado, de acordo com sua natureza científica, como survey - para identificar o processo de criação de estratégias e suas especificidades, as características do dirigente-estrategista e o contexto das empresas de base tecnológica de pequeno porte localizadas no pólo de São Carlos/SP. Observe-se que, como apoio teórico, se fez uso de um trabalho de iniciação científica, elaborado por Silva (2005), cujo propósito é relacionar os planejamentos estratégico e operacional com os resultados de sua utilização, em pequenas empresas do setor industrial e de serviços de São Carlos/SP.

A pesquisa survey representa uma busca de informações pretendidas, diretamente em um grupo de interesse. Trata-se de um procedimento útil, em especial para a pesquisa descritiva (SANTOS, 2000), que implica: explorar aspectos situacionais que possam fornecer dados que expliquem as hipóteses levantadas (testar hipóteses), utilizar amostras grandes e focar o perfil de um grupo, não de um indivíduo. Assemelha-se ao censo, porém aborda apenas uma amostra representativa e não-viesada da população investigada. Reitere-se que, neste tipo de pesquisa, em que o questionário estruturado é em geral usado como instrumento para coleta de dados, procura-se obter informação sobre características, ações ou opiniões de um determinado grupo de pessoas (BABBIE, 2003; FREITAS et al., 2000).

Conforme exposto anteriormente, na fase 1 da pesquisa feita, procurou-se identificar o processo de criação de estratégias das pequenas empresas de base tecnológica pertencentes ao pólo selecionado. A seguir reúnem-se os aspectos da pesquisa survey realizada:

- coleta de dados em um momento específico, para descrição e análise das variáveis, por meio de corte-transversal (cross-seccional);

- composição da amostra - grupo de empresas industriais de pequeno porte de base tecnológica localizadas no pólo de São Carlos/SP - a partir de seleção pautada por critérios previamente definidos, a saber: localização (pólo de São Carlos/SP), área de atuação (indústrias), porte (pequeno) e setor (base tecnológica);

- coleta de dados por meio da aplicação de questionário (apêndice B) elaborado com base na revisão da literatura e constituído de questões objetivas, formuladas conforme três blocos 
temáticos: (1) dados gerais e caracterização das empresas de base tecnológica; (2) processo de criação de estratégias; (3) especificidades de gestão;

- análise dos dados mediante estatística descritiva e análise exploratória multivariada, com o objetivo de agrupar as EBT segundo comportamentos semelhantes, identificados no processo de investigação, para se construir um quadro de influência do contexto, do dirigente-estrategista e das especificidades organizacionais nas características emergentes e deliberadas detectadas.

- Amostragem, coleta de dados e análise dos dados

Para o desenvolvimento desta fase do trabalho de campo foi necessário definir o grupo de empresas de base tecnológica a ser investigado (a população-alvo). Destaque-se que esta etapa foi desenvolvida entre junho e setembro de 2007, com o auxílio de um bolsista de iniciação científica (SILVA, 2005) que teve o apoio da Fundação de Amparo à Pesquisa do Estado de São Paulo (FAPESP), cujo propósito era relacionar os planejamentos estratégico e operacional com os resultados de sua utilização, em pequenas empresas do setor industrial e de serviços de São Carlos/SP.

Procedeu-se, então, a um mapeamento das empresas, utilizando-se inicialmente os cadastros fornecidos pela Fundação Parque de Alta Tecnologia (Parqtec), pela Agência de Inovação da Universidade Federal de São Carlos (UFSCar), pela Secretaria de Desenvolvimento Sustentável, Ciência e Tecnologia da Prefeitura Municipal de São Carlos, pelo Centro de Indústrias Nascentes (CEDIN) e pelo Centro das Indústrias do Estado de São Paulo (CIESP), Diretoria Regional de São Carlos. Também foram usados a listagem de empresas divulgada pelo Ministério da Ciência e Tecnologia (Rede Brasil de Tecnologia) e pelo jornal da Fundação Parque de Alta Tecnologia de São Carlos.

Feito o mapeamento, estabeleceu-se contato telefônico com todas as empresas cadastradas, visando confirmar as seguintes informações: nome da empresa, endereço, endereço eletrônico, nome do(s) proprietário(s), produtos principais, número de funcionários e área de atuação. Verificou-se ainda o interesse do dirigente em participar desta pesquisa.

Identificaram-se 99 empresas industriais de base tecnológica, porém só se estabeleceu contato com 79, uma vez que 02 haviam encerrado as suas atividades e com 18 não foi possível comunicação alguma, mesmo após várias tentativas, em dias e horários diferentes. Como, das empresas contatadas, 04 eram de médio e grande porte, 05 empresas não se situavam em São Carlos/SP, 02 não aceitaram participar da pesquisa e uma não se caracterizava como EBT, compôs-se a população-alvo com as 67 restantes. 
Para os dirigentes-proprietários das empresas selecionadas enviaram-se, primeiramente, por mala postal, uma carta de apresentação da pesquisa, explicitando seus objetivos e os procedimentos para a coleta de dados (APÊNDICE C) e, após 07 dias, um $e$ mail padrão (APÊNDICE D), com instruções para o preenchimento e envio on line do questionário disponibilizado na página do Grupo de Estudos Organizacionais da Pequena Empresa (GEOPE). Ao todo, 33 empresas responderam ao questionário, ou seja, $49 \%$ de toda a amostra (67 empresas). Das respostas que retornaram foram extraídos os dados utilizados nesta etapa da investigação.

Foram feitos alguns ajustes nos critérios adotados para a tabulação dos dados, como, por exemplo: definiu-se o tempo de vida das empresas a partir do ano de sua fundação; converteram-se os índices de crescimento em vendas, de 2004 a 2006, em uma única variável, o crescimento médio em vendas no período; calculou-se o número de funcionários pela soma dos funcionários próprios e autônomos.

Reiterando, com base nas respostas ao questionário mencionado, foi feita a análise descritiva de conteúdo, para caracterizar as empresas de base tecnológica investigadas. A propósito, a identificação e o mapeamento do processo estratégico foram realizados por meio da análise dos componentes principais, utilizando-se o software Statistica ${ }^{\circledR}$ (versão 6.0, Statsoft, EUA).

A Análise dos Componentes Principais (ACP) é uma técnica estatística exploratória, que cria variáveis latentes ortogonais, com centro na região de maior concentração da variabilidade original. Para isso, foi utilizada a matriz de covariância dos dados, da qual foram extraídos os autovalores que originam os autovetores (componentes principais), que são combinações lineares das variáveis originais. A dispersão das unidades experimentais passa a ser representada pelos autovetores construídos com os maiores autovalores, pois preservam maior quantidade da informação original. Segundo o critério de Kaiser, devem ser considerados os autovalores acima de 1 , pois geram componentes com quantidade relevante de informação contida nas variáveis originais. O poder discriminatório de cada variável é avaliado pela fórmula: $\mathbf{r}_{\mathbf{x}_{j}}\left(\mathbf{c p}_{\mathbf{h}}\right)=\frac{\mathbf{a}_{\mathrm{jh}} \sqrt{\lambda_{\mathbf{h}}}}{\mathbf{s}_{\mathbf{j}}}$ onde $\mathbf{r}_{\mathbf{x}_{\mathrm{j}}}\left(\mathbf{c p}_{\mathbf{h}}\right)$ é a correlação entre a variável $\mathrm{x}_{\mathrm{j}} \mathrm{e}$ o componente principal $c p_{\mathrm{h}}, \mathrm{a}_{\mathrm{jh}}$ é o coeficiente da variável j no $h$-ésimo componente principal e $\lambda_{\mathrm{h}}$ é o $h$-ésimo autovalor da matriz de covariância (FERRAUDO, 2006; HAIR et al., 2006).

A percentagem da variância total contida em cada componente $\mathrm{CP}_{\mathrm{h}}$ foi obtida segundo a fórmula: $\mathbf{C P}_{\mathbf{h}}=\frac{\lambda_{\mathbf{h}}}{\mathbf{T}(\mathbf{C})} 100$ onde $\mathrm{T}(\mathrm{C})$ é o traço da matriz de covariância $\left(\lambda_{1}+\lambda_{2}+\right.$ $\left.\ldots+\lambda_{h}\right)$. 
Todas as análises foram processadas após a padronização dos dados pela fórmula: $\mathbf{Z}_{\mathrm{ij}}=\frac{\mathbf{X}_{\mathrm{ij}}-\overline{\mathbf{X}}_{\mathbf{j}}}{\mathbf{S}_{\mathrm{j}}}$ onde $\overline{\mathbf{x}}_{\mathrm{j}}$ e $\mathbf{S}_{\mathrm{j}}$ representam a média e o desvio padrão da coluna $\mathrm{j}$.

5.2.2 Métodos da pesquisa para a fase 2

Para a caracterização da fase 2 , destacam-se, a seguir, alguns de seus aspectos.

- Quanto à ênfase, é aplicada.

A pesquisa aplicada gera conhecimentos que podem ser postos em prática, ou seja, utilizados na solução de problemas específicos. Na fase 2, buscaram-se respostas para a questão que se punha, relacionada ao processo de criação de estratégias condizentes com o contexto e às características das pequenas empresas de base tecnológica.

- Quanto aos propósitos, é descritiva.

A pesquisa descritiva implica o exame de um fenômeno com o objetivo de melhor defini-lo ou diferenciá-lo de outros fenômenos Muitas vezes é utilizada para estudar processos de mudança. Em sua essência, tem o propósito de capturar o atributo que distingue um objeto, uma pessoa ou um evento no momento em que os dados são coletados (DANE, 1990). As questões básicas de uma pesquisa descritiva são as seguintes: Que é? Como ocorre? Por quê?.

Levando em conta a definição proposta pelo autor citado no parágrafo acima, a fase 2 desta pesquisa caracteriza-se como descritiva, pois foi desenvolvida para identificar, examinar e descrever o processo de criação de estratégias de um determinado segmento de empresas, tendo em vista detectar e compreender as variáveis intervenientes nesse processo.

- Quanto à abordagem do problema, é qualitativa.

O caráter qualitativo da fase 2 advém do fato da pesquisa se desenvolver com a análise de conteúdo, em profundidade, em casos individuais, por meio da indução dos dados e com a realização de generalizações sobre a situação investigada. O desenvolvimento dessa etapa buscou identificar o relacionamento entre as variáveis e as características do processo estratégico no segmento de empresas selecionadas, respondendo às questões de pesquisa. $\mathrm{O}$ processo de criação de estratégia constitui o foco principal da pesquisa e a pesquisadora procurou compreendê-lo sob a perspectiva dos dirigentes. 
- Quanto aos procedimentos técnicos, é um estudo de caso.

Essa fase, realizada em três empresas de base tecnológica, localizadas em São Carlos/SP, pode ser classificada como estudo de caso. Yin (2001) afirma que o "estudo de caso é uma forma de pesquisa que busca investigar um fenômeno contemporâneo dentro de seu contexto da vida real, especialmente quando os limites entre o fenômeno e o contexto não estão claramente definidos". O estudo de caso é uma estratégia geralmente utilizada quando o pesquisador tem pouco controle sobre os eventos, ou quando analisa profundamente um ou poucos objetos para obter um amplo e detalhado conhecimento (GIL, 1996; GODOY, 1995b; YIN, 2001).

Para selecionar as empresas participantes, utilizou-se o c critério de seleção de casos, em virtude da imersão da pesquisadora no processo, da extensão do trabalho de campo e do envolvimento dos dirigentes e outros colaboradores na pesquisa. A delimitação do estudo, restringindo-o a três empresas, justifica-se devido a dois fatores fundamentais:

- o tempo demandado para a coleta de dados, considerando-se a disponibilidade da pesquisadora e dos sujeitos envolvidos no processo. Os dados foram coletados em 4 meses, aproximadamente, e

- a realização do estudo em três empresas, duas pequenas e uma de médio porte, para que a análise dos dados não ficasse restrita às peculiaridades de uma única unidade, com o objetivo de comparar os seus processos de criação de estratégias, levando-se em conta diferenças referentes ao grau de formalização e à evolução das etapas do ciclo de vida organizacional.

O estudo de caso desenvolveu-se em três etapas, conforme se explica a seguir:

(1) diagnóstico organizacional: contato inicial com a empresa, definição dos participantes da pesquisa, estudo da viabilidade de aplicação do método, identificação do contexto organizacional e do processo de criação de estratégias vigente;

(2) realização: intensificação da coleta de dados para se elaborar o mapa estratégico;

(3) avaliação: análise dos resultados, em termos práticos e quanto ao avanço nos conhecimentos teóricos e divulgação dos resultados do trabalho investigativo..

Nesta fase interativa - que envolveu pesquisadora e sujeitos investigados - utilizaramse, como instrumentos para coleta de dados, a entrevista e a observação. A seguir são apresentadas as características dos instrumentos selecionados para este estudo.

\section{Entrevistas}

As entrevistas constituem o instrumento mais usado para coletar dados em pesquisas qualitativas. De forma geral, são realizadas individualmente ou em grupos e se classificam 
como estruturadas (as que obedecem a um roteiro pré-definido), semi-estruturadas (as que se baseiam em um roteiro, mas permitem que novas questões sejam incluídas) ou nãoestruturadas (livres). Estes três tipos podem ainda se caracterizar como breves ou em profundidade.

Para se levantarem dados, na pesquisa realizada, foram realizadas entrevistas estruturadas breves e semi-estruturadas em profundidade cujo respondente foi o dirigenteestrategista e professores. Por meio das entrevistas breves, buscou-se identificar os aspectos gerais do contexto organizacional e ambientar a pesquisadora. Mediante as entrevistas em profundidade, procurou-se identificar características específicas do processo de criação de estratégias.

Ressalte-se que a coleta de dados, feita mediante entrevista com os dirigentes, apresenta vieses que derivam de sua visão e do seu comportamento na tomada de decisões, uma das especificidades da pequena empresa. Porém, como na pequena empresa o dirigenteestrategista é o maior responsável pelo seu direcionamento futuro - orientação e tomada de decisão referentes a ações futuras - julgou-se adequado optar por fazer entrevistas breves e em profundidade com o próprio dirigente para se identificar as variáveis presentes e com influência no processo de criação de estratégias.

\section{Observação}

A técnica de observação comporta duas formas de abordagem: observação e observação participativa, que se diferenciam apenas pelo modo como o pesquisador interage no processo de coleta de dados. Na pesquisa feita, utilizou-se primeira abordagem, durante todo o processo de coleta de dados.

- Amostragem e coleta dos dados

Os dados foram levantados predominantemente por meio de entrevistas, conforme já se mencionou. A identificação inicial das empresas com as quais se faria contato posterior, para construir-se a amostra, foi feita com base na lista de EBT elaborada na fase 1. Tendo-se utilizado o número de funcionários como critério para a definição de porte das organizações que integrariam a amostra, foram excluídas as que empregavam menos de 20 , consideradas microempresas. Levando em conta que, na fase 1, as empresas com mais de 100 funcionários não participaram da amostra, escolheu-se uma empresa de médio porte por conveniência. Observe-se, portanto, que a seleção de casos da fase 2 foi feita de forma intencional.

Depois que se definiu a amostra e os dirigentes aceitaram participar da pesquisa, procedeu-se à coleta de dados, que se realizou em um período de quatro (04) meses. As 
entrevistas foram gravadas e feitas na própria empresa, para que se pudesse também fazer a observação e eventual análise de documentos.

Durante o desenvolvimento da fase qualitativa observou-se a importância da fase antecessora à criação da empresa ao processo de criação de estratégias. Assim, foram agendadas entrevistas com professores-pesquisadores envolvidos na criação de empresas de base tecnológica, para identificar as variáveis presentes nesta importante fase do ciclo de vida organizacional. Foram entrevistados professores-pesquisadores do Instituto de Física da Universidade de São Paulo, do Departamento de Engenharia Mecânica da Escola de Engenharia de São Carlos, da Empresa Brasileira de Pesquisa Agropecuária e da Fundação Parque de Alta Tecnologia. Das empresas em questão, selecionaram-se três, identificadas, neste trabalho, como A, B e C. Em tais organizações, os dados coletados com os professorespesquisadores e dirigentes-estrategistas foram sistematizados em um diário de campo para então serem, posteriormente, organizados e apresentados. Fez-se a análise de conteúdo categorial desses dados com o objetivo de esclarecer e complementar a representação realizada na fase 1 .

Visualiza-se, no quadro 12, os respondentes e a suas respectivas denominações utilizadas na apresentação e análise dos dados, realizada nesta pesquisa, além da duração média das entrevistas e o total aproximado relativo a cada uma das empresas.

\begin{tabular}{|c|c|c|c|c|}
\hline Empresa & Respondentes & Denominação & Duração média & $\begin{array}{c}\text { Total } \\
\text { aproximado* }\end{array}$ \\
\hline A & $\begin{array}{l}\text { Sócio-dirigente } \\
\text { Professores } \\
\text { Universitários }\end{array}$ & $\begin{array}{l}\text { Entrevistado1 } \\
\text { Professor } 1 \\
\text { Professor } 2 \\
\text { Professor } 3\end{array}$ & $\begin{array}{l}3 \text { horas } \\
4 \text { horas } \\
2 \text { horas } \\
2 \text { horas }\end{array}$ & 7 horas \\
\hline B & $\begin{array}{l}\text { Dirigente } \\
\text { Gerente da } \\
\text { qualidade }\end{array}$ & $\begin{array}{l}\text { Dirigente B } \\
\text { Dirigente B1 }\end{array}$ & $\begin{array}{l}2 \text { horas } \\
3 \text { horas }\end{array}$ & 5 horas \\
\hline $\mathrm{C}$ & $\begin{array}{l}\text { Sócio-dirigente } \\
\text { Professores } \\
\text { universitários }\end{array}$ & $\begin{array}{l}\text { Dirigente C } \\
\text { Professor } 1 \\
\text { Professor } 3 \\
\text { Professor } 4\end{array}$ & $\begin{array}{l}3 \text { horas } \\
4 \text { horas } \\
2 \text { horas } \\
1 \text { hora }\end{array}$ & 7 horas \\
\hline
\end{tabular}

Quadro 12 - Dados gerais das entrevistas realizadas 
5.2.3 Triangulação dos métodos e dos dados

Uma das principais críticas à pesquisa qualitativa questiona a qualidade e confiabilidade do processo de coleta e análise dos dados. A partir disso, entende-se que, para melhorar a qualidade, a credibilidade e, portanto, a validade da investigação, o pesquisador deve recorrer a diversas fontes, coletando os dados em circunstâncias ou momentos variados. É oportuno ressaltar que se pode aplicar a triangulação a vários aspectos da pesquisa, como metodologia, dados, investigador e teoria, ou proceder-se à triangulação múltipla (EDEN; HUXHAM, 2001).

Na pesquisa feita, recorreu-se à triangulação dos métodos e dados. A triangulação metodológica foi usada na comparação das fases 1 e 2 do trabalho de campo, por meio de abordagem quantitativa (survey) e qualitativa (estudo de caso), respectivamente. A triangulação dos dados foi aplicada, mediante os instrumentos utilizados nas fases 1 (questionário) 2 (entrevista simples e em profundidade e observação).

\subsubsection{Questões da pesquisa}

Considerando que, nas pequenas empresas, o contexto, as especificidades organizacionais e o comportamento do dirigente-estrategista influenciam o processo de criação de estratégias deliberadas e emergentes, buscou-se responder às questões abaixo apresentadas.

Q1: Qual é a natureza da inter-relação dos processos de criação de estratégias deliberadas e emergentes?

Q2: Qual é a dinâmica das variáveis organizacionais no processo de criação de estratégias em pequenas empresas de base tecnológica?

Q3: As estratégias deliberadas diferem das estratégias realizadas?

Q4: O ciclo de vida da organização influencia a intensidade das variáveis organizacionais e o processo de criação de estratégias?

Q5: Há algum outro fator não enfatizado na revisão da literatura a afetá-las? 
5.2.5 Variáveis da pesquisa

De acordo com o objetivo proposto, consideraram-se, na pesquisa, as seguintes variáveis:

- Processo de criação de estratégias: compreendido como um processo que contempla características deliberadas e emergentes na criação de estratégias;

- Especificidades de organização da pequena empresa: características referentes à estrutura (divisão do trabalho, definição de cargos e tarefas), tomada de decisão (tipo e nível) e comunicação (formalização);

- Especificidades de contexto da pequena empresa: características do ambiente organizacional em relação à complexidade (segmentação, características dos clientes e dos concorrentes), capacidade (nível de oportunidades) e volatilidade (dinamicidade e nível de mudanças);

- Especificidades do dirigente da pequena empresa: características relacionadas ao dirigente artista, artesão e tecnocrata. 


\section{APRESENTAÇÃO E ANÁLISE DOS RESULTADOS DA FASE 1}

Neste capítulo faz-se a apresentação e a análise dos dados empíricos da fase 1, agrupando-os de acordo com comportamentos semelhantes identificados no processo de investigação, para se construir um quadro de influência do contexto, do dirigente-estrategista e da organização nas características emergentes e deliberadas detectadas. Inicialmente são caracterizadas as empresas de base tecnológica de São Carlos/SP.

\subsection{CARACTERÍSTICAS GERAIS DAS EMPRESAS DE BASE TECNOLÓGICA}

Para a caracterização do grupo de pequenas empresas industriais de base tecnológica de São Carlos/SP, partiu-se da identificação e apresentação de alguns de seus aspectos, a saber: ramo de atuação, número e escolaridade dos sócios, número de funcionários, tempo de vida da empresa, faturamento, estrutura de P\&D e motivação para a criação da empresa.

Relativamente ao ramo de atuação das 33 empresas participantes, constatou-se que: uma atua no ramo de biotecnologia (3\%), nove, no de eletrônica/telecomunicação (27\%), sete, no de informática/software (21\%), duas, no de mecânica/automação (6\%), quatro, em novos materiais (12\%) e dez, em diferentes ramos, sob a classificação "outros" (31\%). A distribuição das EBT por ramo de atuação encontra-se na figura 28.

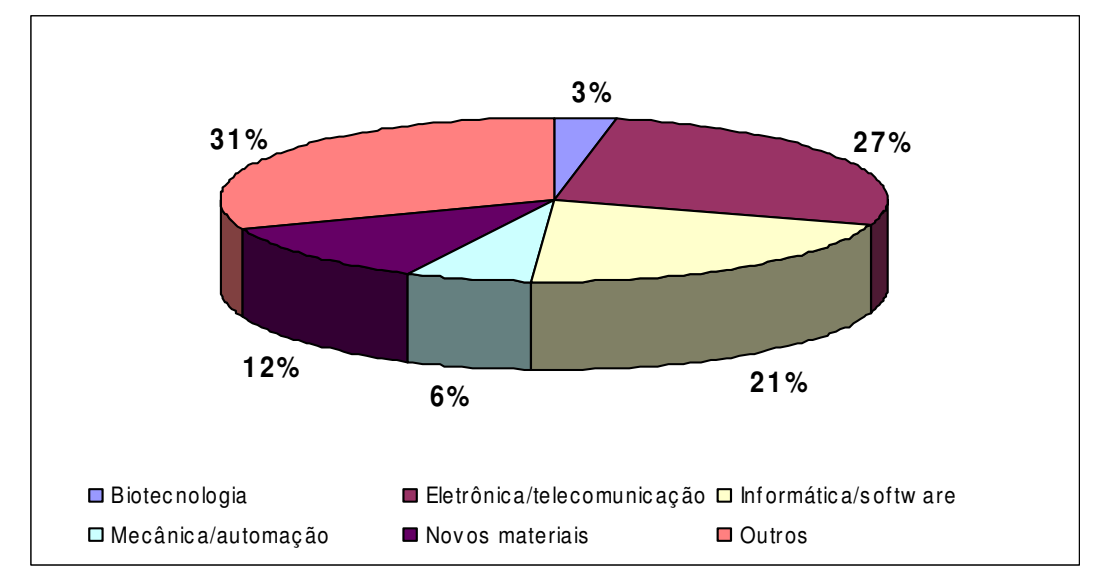

Figura 28 - Ramo de atuação das empresas pesquisadas 
As diversas atividades econômicas das empresas que integram a amostra apresentadas no quadro 13 e na figura 29 - demonstram que o segmento é bastante heterogêneo. O ramo de atuação denominado "outros", incluindo $31 \%$ das empresas pesquisadas e $36 \%$ do número total de funcionários, evidencia a grande diversidade do setor de EBT. Entre estas empresas, encontram-se as que atuam na área de robótica, análises químicas e ambientais, equipamentos científicos, tratamento de resíduos, equipamentos médicos e odontológicos e cerâmicas especiais. O número de empresas que atuam nos ramos de informática/software (21\%) e de eletrônica/telecomunicação (27\%) também confere a estes segmentos grande representatividade, observando-se que o último é responsável por cerca de $30 \%$ do número de funcionários, enquanto informática e software respondem por apenas $7 \%$ dos funcionários, enquanto é grande a porcentagem (38\%) de autônomos.

\begin{tabular}{|c|c|c|}
\hline Ramo de atuação & $\begin{array}{l}\text { Número de } \\
\text { empresas }\end{array}$ & Atividade econômica \\
\hline Biotecnologia & 1 & Produtos tecnológicos \\
\hline $\begin{array}{l}\text { Eletrônica/ } \\
\text { telecomunicação }\end{array}$ & 9 & $\begin{array}{l}\text { Instrumentos ultra-sônicos e materiais piezoelétricos } \\
\text { Equipamentos para automação industrial } \\
\text { Equipamentos de automação predial } \\
\text { Equipamentos de automação de aparelhos microprocessados } \\
\text { Equipamentos de telemetria } \\
\text { Equipamentos eletrônicos para leitura de chips, transponder, } \\
\text { Equipamentos para diagnóstico de eletrônica embarcada } \\
\text { Equipamentos para controle dimensional }\end{array}$ \\
\hline Informática/software & 7 & Softwares, sistemas de informação e fabricação de computadores \\
\hline Mecânica/automação & 2 & $\begin{array}{l}\text { Máquinas bobinadeiras } \\
\text { Equipamentos laboratoriais }\end{array}$ \\
\hline Novos materiais & 4 & $\begin{array}{l}\text { Materiais vitrocerâmicos } \\
\text { Componentes em cerâmica técnica para aplicações industriais } \\
\text { Materiais de borrachas e poliuretanos } \\
\text { Materiais com nanotecnologia }\end{array}$ \\
\hline Outros & 10 & $\begin{array}{l}\text { Robótica } \\
\text { Materiais químicos } \\
\text { Equipamentos científicos } \\
\text { Cerâmicas especiais } \\
\text { Equipamentos odontológicos } \\
\text { Equipamentos médicos e lasers. }\end{array}$ \\
\hline
\end{tabular}

Quadro 13 - Classificação das empresas segundo ramo de atuação e atividade econômica correspondente 


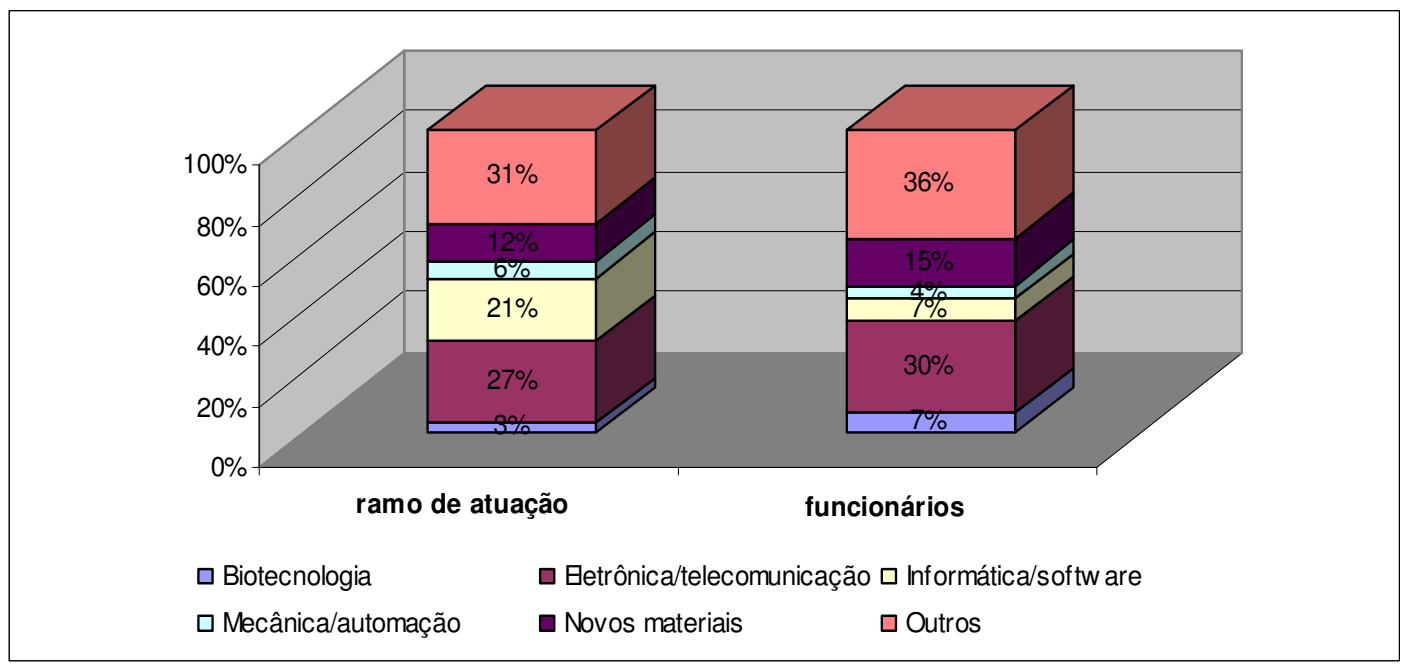

Figura 29 - Ramo de atuação e número de funcionários das empresas pesquisadas

A classificação das EBT distribuídas em diferentes ramos de atuação, levando em conta seu número de funcionários e tempo médio de vida ${ }^{14}$ encontra-se na tabela 2 , que reúne suas características gerais. De acordo com o número de funcionários, podem ser classificadas, em sua maioria, como microempresas, atendendo ao critério "pessoas ocupadas", estabelecido pelo IBGE, uma vez que $67 \%$ delas empregam até 19 funcionários. Entre as consideradas pequenas empresas (33\%) estão aquelas que possuem 23 a 72 funcionários de diversos segmentos, como robótica, novos materiais, biotecnologia, química, eletrônica/telecomunicações e equipamentos odontológicos. Observe-se ainda que as EBT investigadas empregam, ao todo, 633 funcionários, em média: 19 funcionários/empresa. É importante ressaltar que, para se definir o porte da empresa, realizou-se a estratificação da amostra por número de funcionários, pelo fato de ser esta a informação disponibilizada mais facilmente e com maior confiabilidade pelos dirigentes.

Tabela 2 - Características gerais das EBT

\begin{tabular}{|c|c|c|c|c|c|c|c|c|}
\hline \multirow[t]{2}{*}{ Ramo de atuação } & \multicolumn{2}{|c|}{ empresas } & \multicolumn{5}{|c|}{ número de funcionários } & \multirow{2}{*}{$\begin{array}{c}\text { tempo médio } \\
\text { de vida }\end{array}$} \\
\hline & $\mathrm{n}$ & $\%$ & médio & próprio & autônomo & total & $\%$ & \\
\hline Biotecnologia & 1 & $3 \%$ & 42 & 42 & 0 & 42 & $7 \%$ & 31,0 \\
\hline Eletrônica/telecomunicação & 9 & $27 \%$ & 21 & 181 & 11 & 192 & $30 \%$ & 14,9 \\
\hline Informática/software & 7 & $21 \%$ & 7 & 34 & 13 & 47 & $7 \%$ & 9,0 \\
\hline Mecânica/automação & 2 & $6 \%$ & 14 & 25 & 3 & 28 & $4 \%$ & 8,0 \\
\hline Novos materiais & 4 & $12 \%$ & 25 & 77 & 21 & 98 & $16 \%$ & 14,3 \\
\hline Outros & 10 & $31 \%$ & 23 & 190 & 36 & 226 & $36 \%$ & 12,7 \\
\hline Total & 33 & $100 \%$ & 19 & 549 & 84 & 633 & $100 \%$ & 13,0 \\
\hline
\end{tabular}

Nota: $n$ é igual ao número de empresas que participaram da pesquisa

\footnotetext{
${ }^{14}$ Tempo médio de vida representa a idade atual da empresa, considerando-se o ano corrente.
} 
O tempo médio de vida das EBT pesquisadas é 13 anos. Uma única empresa, a do ramo de biotecnologia, diferencia-se com um tempo de 31 anos. As que têm menor tempo de vida pertencem aos ramos de mecânica/automação e informática/software: 08 e 09 anos, em média, respectivamente. Em um levantamento realizado pelo SEBRAE (2005) sobre a taxa de mortalidade (número de empresas criadas x número de empresas com atividades encerradas) das empresas paulistas, verificou-se que 56\% tiveram suas atividades encerradas antes de completar 05 anos. Na amostra investigada, 73\% das empresas têm mais de 05 anos de atividade, destacando-se assim a longevidade das EBT do pólo de São Carlos/SP.

Tabela 3 - Porte das empresas de acordo com o número de funcionários

\begin{tabular}{lccccccc}
\hline & & & \multicolumn{3}{c}{ funcionários } & tempo médio de \\
\cline { 5 - 7 } Porte & $\mathrm{n}$ & $\%$ & média & total & $\%$ & vida \\
\hline até 19 funcionários & 22 & $67 \%$ & 8 & 167 & $26 \%$ & 10,8 \\
de 20 a 99 funcionários & 11 & $33 \%$ & 42 & 466 & $74 \%$ & 17,4 \\
\hline total & 33 & $100 \%$ & 19 & 633 & $100 \%$ & 13,0 \\
\hline
\end{tabular}

Os dados apresentados nas tabelas 2 e 3 permitem fazer a seguinte inferência - há uma associação positiva entre o tempo médio de vida e o porte da empresa. Correlacionando-se o porte e o tempo médio de vida das empresas estudadas, é possível dividi-las em três grupos, assim constituídos: o grupo constituído de uma só empresa, a do ramo de biotecnologia, com o maior tempo médio de vida e número de funcionários; o grupo formado pelas empresas dos ramos de eletrônica/telecomunicações e novos materiais e aquelas reunidas sob o rótulo “outros", com tempos médios de vida próximos (14,9, 14,3 e 12,7); e o ainda um terceiro, integrado pelas empresas dos ramos de informática/software e mecânica/automação, com 09 e 08 anos, respectivamente. Nas figuras 30 e 31 visualiza-se a relação entre o número de funcionários e o tempo médio de vida das empresas, por ramo de atuação. 


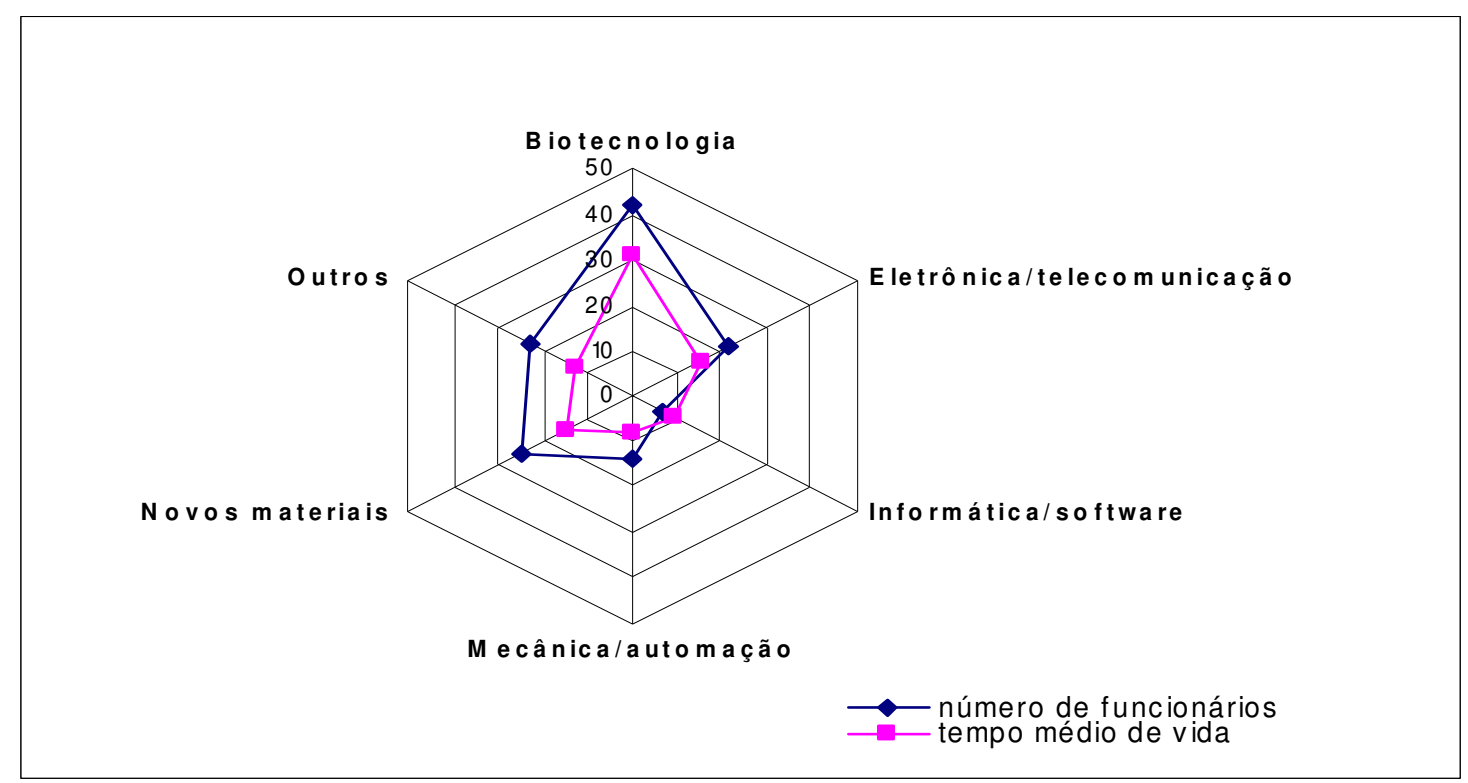

Figura 30 - Tempo médio de vida e número de funcionários das empresas

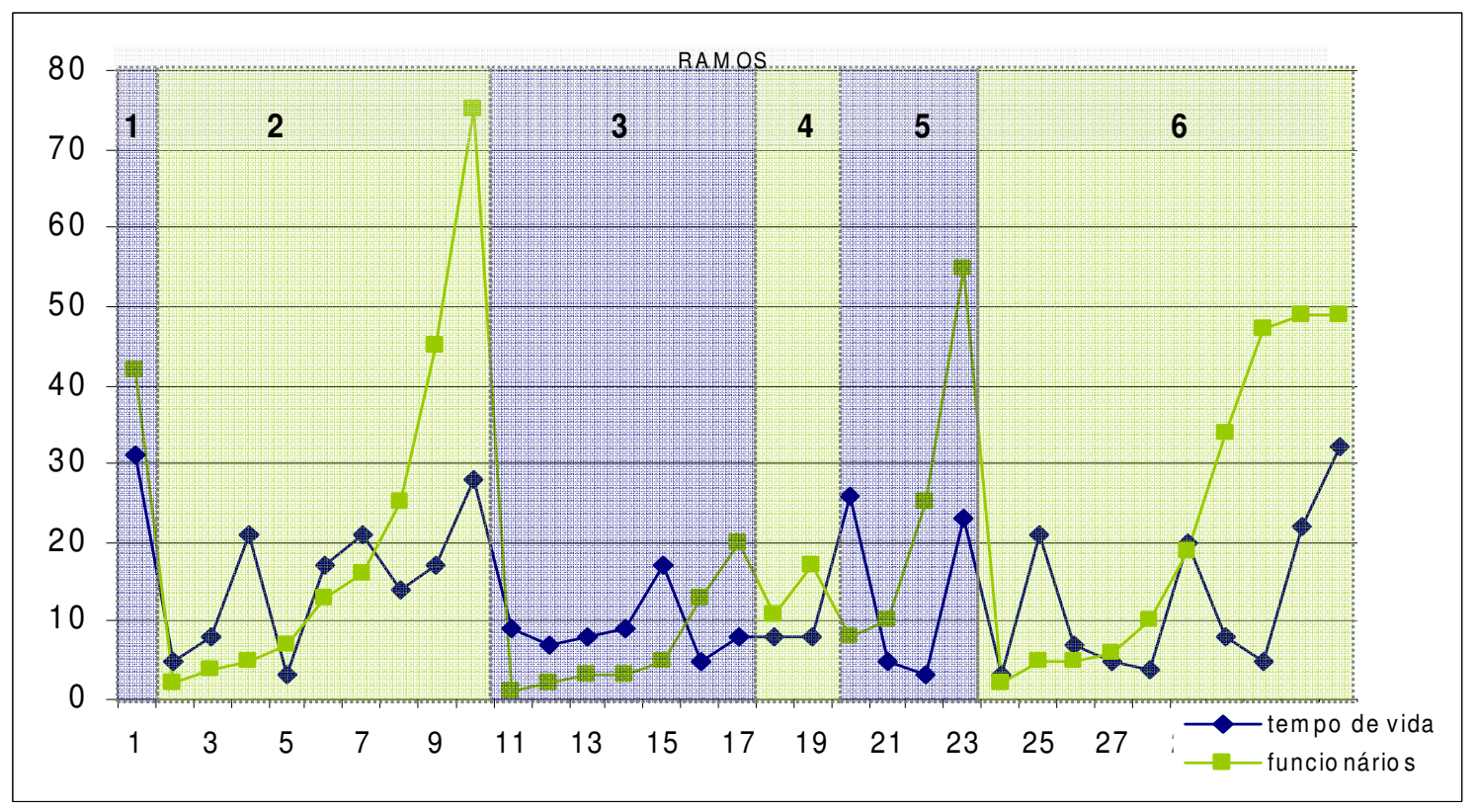

Nota: ramos 1 (biotecnologia); 2 (eletrônica/telecomunicação); 3 (informática/software); 4 (mecânica/automação); 5( novos materiais); 6 (outros).

Figura 31 - Tempo de vida e número de funcionários por ramo de atuação

O faturamento, outro critério utilizado para classificar as empresas investigadas, permite caracterizá-las da seguinte forma: $42 \%$ destas, as que faturam até R \$240 mil, são microempresas e 39\%, as que faturam $\mathrm{R} \$ 241$ mil a $\mathrm{R} \$ 2.400$ milhões, são pequenas empresas. Do total, restam 18\%, que não podem ser classificadas como micro ou pequenas empresas, de acordo com o mesmo critério. Estabelecendo-se uma correlação entre o 
faturamento, o porte e o número de funcionários, constata-se que: das 14 classificadas como microempresas, pelo faturamento, 12 são também classificadas como micro, pelo número de funcionários e, consequentemente, as outras 02 são pequenas. Das 13 classificadas como pequenas empresas, por seu faturamento, 03 também são classificadas como pequenas empresas, conforme o número de funcionários e, consequentemente, as outras 10 são classificadas como micro. Relacionando faturamento e tempo de vida, verifica-se que as EBT com faturamento maior que $\mathrm{R} \$ 2.400$ milhões possuem um tempo médio de vida de 23,2 anos - 78\% superior à média de 13 anos do segmento - e as empresas que faturam até R $\$ 240$ mil têm um tempo médio de vida de 8,4 anos - 35\% menor que a média de todo o setor (tabela 3). Finalmente, é importante registrar que o faturamento das empresas estudadas, nos últimos três anos (2004 a 2006), cresceu, em média, 42,7\%.

Tabela 4 - Faturamento das empresas, porte e tempo médio de vida

\begin{tabular}{lcccccccc}
\hline & & & \multicolumn{3}{c}{ funcionários } & tempo médio de \\
\cline { 5 - 7 } Faturamento & $\mathrm{n}$ & $\%$ & até 19 & $\%$ & 20 a 99 & $\%$ & & vida \\
\hline até 240 mil & 14 & $42 \%$ & 12 & $36 \%$ & 2 & $6 \%$ & 8,4 \\
de $\mathrm{R} \$ 241$ mil a $\mathrm{R} \$ 2.400$ milhões & 13 & $39 \%$ & 10 & $30 \%$ & 3 & $9 \%$ & 13,2 \\
acima de $\mathrm{R} \$ 2.400$ milhões & 6 & $18 \%$ & 0 & $0 \%$ & 6 & $18 \%$ & 23,2 \\
\hline total & 33 & $100 \%$ & 22 & $66 \%$ & 11 & $33 \%$ & 13,0 \\
\hline
\end{tabular}

Com referência ao número de sócios, 91\% das EBT possuem de 01 a 03 sócios (figura 32). Quanto à escolaridade dos sócios, verifica-se que $17 \%$ não possuem nível superior, $5 \%$ têm nível médio e $12 \%$ apresentam nível técnico. O perfil dos sócios revela que $42 \%$ possuem mestrado, doutorado e/ou pós-doutorado, dado que evidencia seu alto nível de escolaridade, possivelmente oriundo da estreita relação das empresas investigadas com universidades e centros de pesquisa (figura 33). No perfil dos funcionários destas empresas, identificam-se outros dados que reiteram o alto nível de escolaridade - $42 \%$ do total de funcionários e $69 \%$ dos funcionários das empresas do ramo de informática/software têm nível superior. Característica própria do ramo, o elevado nível de escolaridade também se deve ao fato de a cidade de São Carlos/SP ter vocação para a tecnologia e contar com o conhecimento gerado em duas universidades públicas (Universidade de São Paulo, USP, e Universidade Federal de São Carlos, UFSCar) e duas unidades da Embrapa (Empresa Brasileira de Pesquisa Agropecuária), que ensejam a formação de um número relevante de pesquisadores aptos a trabalhar no segmento. 


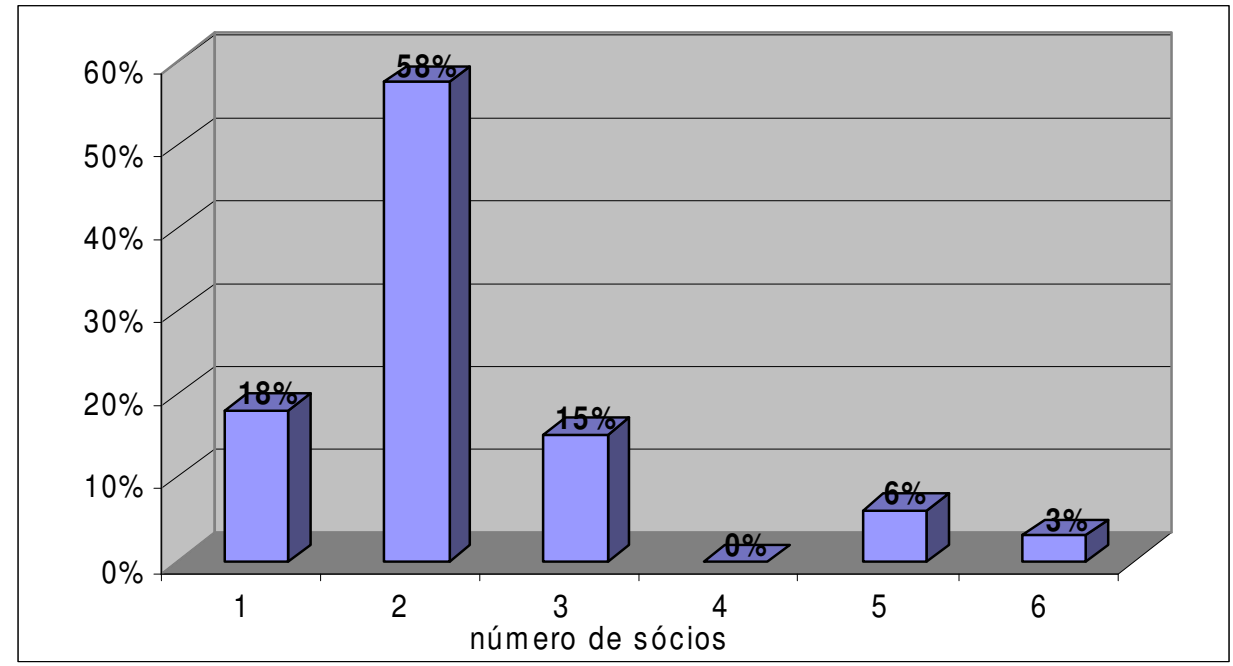

Figura 32 - Número de sócios

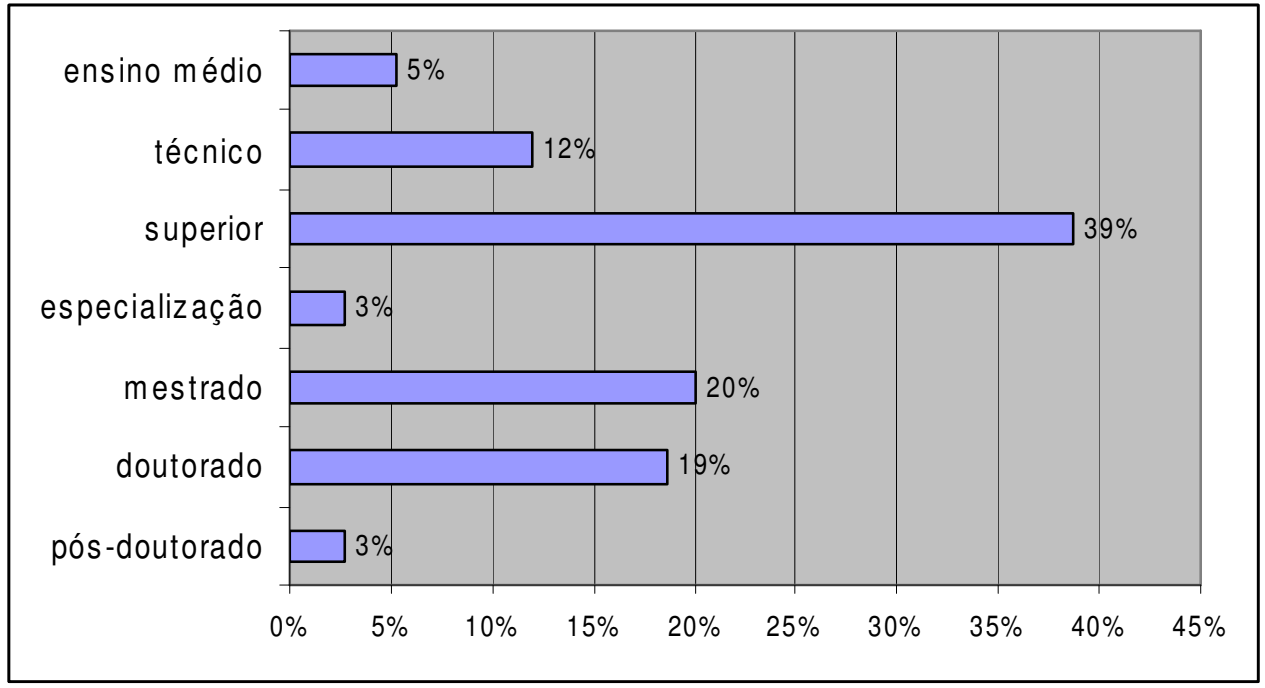

Figura 33 - Escolaridade dos sócios

Para verificar se as empresas estudadas apresentam características de inovação, foram utilizados três indicadores: a existência de um departamento de P\&D (estruturado, semiestruturado ou em fase de estruturação), o nível de investimento em $P \& D$ e a relação com universidades e centros de pesquisa. 


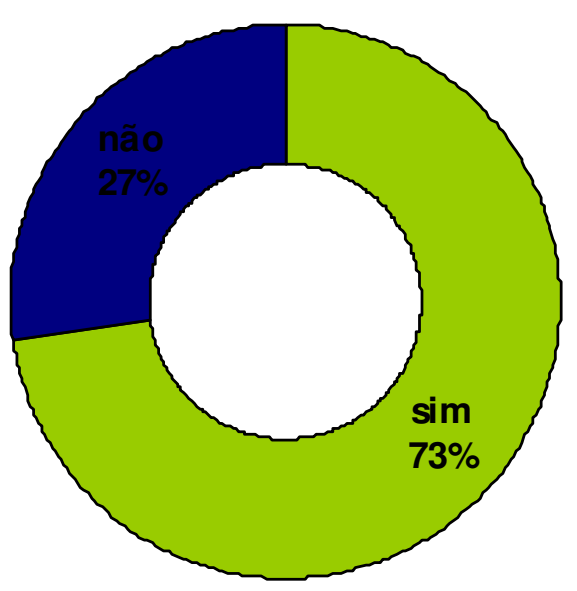

Figura 34 - Empresas e o departamento de P\&D

Buscando identificar as EBT que contam com departamentos de P\&D e analisar o nível de estruturação que estes apresentam, constata-se que, em $73 \%$ das empresas, eles existem, o que evidencia uma característica marcante do setor: a inovação proveniente de P\&D (figura 34). Na tabela 5 pode-se verificar, por ramo de atuação, quantas empresas têm departamento de P\&D e, na tabela 6, o nível de estruturação deste. Destaca-se que, no ramo de informática/software, apenas uma mantém, com investimento de 21,3\% de seu faturamento, um departamento de P\&D, que é, aliás, caracterizado como estruturado.

Tabela 5 - Empresas com departamento de P\&D

\begin{tabular}{lccc}
\hline & $\mathrm{n}$ & $\operatorname{sim}$ & não \\
\hline Biotecnologia & 1 & 1 & 0 \\
Eletrônica/telecomunicação & 9 & 8 & 1 \\
Informática/software & 7 & 1 & 6 \\
Mecânica/automação & 2 & 2 & 0 \\
Novos materiais & 4 & 4 & 0 \\
Outros & 10 & 8 & 2 \\
\hline Total & 33 & 24 & 9 \\
\hline
\end{tabular}

Tabela 6 - Nível de estruturação de P\&D por ramo de atuação

\begin{tabular}{lcccrr}
\hline \multicolumn{1}{c}{ Ramo de atuação } & fase estruturação & semi-estruturado & estruturado & total & \% investimento \\
\hline Biotecnologia & 0 & 0 & 1 & 1 & 1,0 \\
Eletrônica/telecomunicação & 0 & 3 & 5 & 8 & 9,8 \\
Informática/software & 1 & 0 & 0 & 1 & 21,3 \\
Mecânica/automação & 2 & 0 & 0 & 2 & 5,5 \\
Novos materiais & 0 & 2 & 2 & 4 & 4,5 \\
Outros & 1 & 5 & 2 & 8 & 16,5 \\
\hline Total & 4 & 10 & 10 & 24 & 12,8 \\
\hline
\end{tabular}

Nota: o percentual de investimento em P\&D foi considerado independente da existência do departamento de P\&D e do nível de estruturação deste. 
A tabela 6, que apresenta os dados referentes aos departamentos de P\&D em fase de estruturação, semi-estruturados e estruturados, foi elaborada a partir dos seguintes critérios de análise: número de funcionários, faturamento, percentual de crescimento em vendas e investimento em P\&D. Segundo estes dados, das 24 empresas que declararam ter departamento de $\mathrm{P} \& \mathrm{D}$, as que o possuem em fase de estruturação são microempresas, considerando o seu número de funcionários, e pequenas empresas, por seu faturamento. Em relação ao porte, de acordo com o faturamento, $41 \%$ são classificadas como pequenas empresas, sendo que, destas, $50 \%$ possuem um departamento estruturado. Quanto ao crescimento em vendas, percebe-se que $71 \%$ (17 empresas) apresentam um índice maior de $10 \%$, destacando-se 06, que apresentam um índice entre 31,1 e 50\%, e 09, com o crescimento em vendas acima de 50\%. Das empresas que declararam possuir departamento de P\&D, 80\% investem, anualmente, até $10 \%$ de seu faturamento no departamento, o que denota ser alto o investimento em P\&D uma característica do setor (tabela 7). De acordo com o Massachusetts High Technology Council, as EBT são empresas que empregam 5\% ou mais de seu faturamento em pesquisas para o desenvolvimento de inovações e tecnologia (BALKIN; GOMEZ-MEJIN, 1987).

Tabela 7 - Nível de estruturação de P\&D

\begin{tabular}{|c|c|c|c|c|}
\hline & fase estruturação & semi-estruturado & estruturado & total \\
\hline \multicolumn{5}{|l|}{ número de funcionários } \\
\hline até 19 funcionários & 3 & 8 & 5 & 16 \\
\hline de 20 a 99 funcionários & 0 & 3 & 5 & 8 \\
\hline Total & 3 & 11 & 10 & 24 \\
\hline \multicolumn{5}{|l|}{ faturamento } \\
\hline até 240 mil & 0 & 8 & 0 & 8 \\
\hline de $\mathrm{R} \$ 241$ mil a $\mathrm{R} \$ 2.400$ milhões & 3 & 2 & 5 & 10 \\
\hline acima de $\mathrm{R} \$ 2.400$ milhões & 0 & 1 & 5 & 6 \\
\hline Total & 3 & 11 & 10 & 24 \\
\hline \multicolumn{5}{|l|}{ crescimento em vendas } \\
\hline até $10 \%$ & 1 & 4 & 2 & 7 \\
\hline $10,1 \%$ a $30 \%$ & 0 & 3 & 5 & 8 \\
\hline $31,1 \%$ a $50 \%$ & 2 & 2 & 2 & 6 \\
\hline acima $50 \%$ & 0 & 2 & 1 & 3 \\
\hline Total & 3 & 11 & 10 & 24 \\
\hline \multicolumn{5}{|l|}{ investimento em P\&D } \\
\hline $1 \%$ a $5 \%$ & 2 & 7 & 4 & 13 \\
\hline $6 \%$ a $10 \%$ & 0 & 1 & 5 & 6 \\
\hline $11 \%$ a $20 \%$ & 1 & 1 & 0 & 2 \\
\hline acima $20 \%$ & 0 & 2 & 1 & 3 \\
\hline Total & 3 & 11 & 10 & 24 \\
\hline
\end{tabular}


Finalmente, resta analisar os estímulos que viabilizaram a criação das empresas investigadas e as características tecnológicas que apresentam. Com referência à motivação, constata-se que as EBT foram criadas a partir: de uma empresa e de tecnologia já existentes $(21,2 \%)$; de um estímulo ou da ação de uma empresa, com o intuito de desenvolver um novo fornecedor ou criar uma nova empresa sob seu controle acionário e estrutura, ou seja, como emulação de grandes empresas $(33,3 \%)$; de grupos de pesquisa e conhecimentos gerados em universidades ou instituições de pesquisa $(33,3 \%)$; de outras formas $(12,1 \%)$ como, por exemplo, aproveitando a oportunidade de produzir componentes de alta tecnologia não existentes no Brasil ou o desejo dos sócios de montar um negócio próprio (tabela 8).

Tabela 8 - Motivação para abertura das EBT

\begin{tabular}{lrr}
\hline Criação das empresas & $\mathbf{n}$ & $\%$ \\
\hline empresa ou tecnologia existente & 7 & $21,2 \%$ \\
estímulo ou ação de uma empresa & 11 & $33,3 \%$ \\
grupos de pesquisa & 11 & $33,3 \%$ \\
outra forma & 4 & $12,1 \%$ \\
\hline total & $\mathbf{3 3}$ & $\mathbf{1 0 0 , 0 \%}$ \\
\hline
\end{tabular}

Nas empresas investigadas, identificou-se, em maior ou menor grau, a presença das seguintes características: fabricação de produtos tecnológicos; detenção de tecnologia única; emprego de tecnologia desenvolvida por centros de pesquisa ou universidades; inovação como diferencial; aprimoramento dos processos de produção e realização de alianças para desenvolver novos produtos e processos ou incrementar os atuais.

O uso de tecnologia desenvolvida por centros de pesquisa ou universidades não foi identificado como sendo uma característica atual das empresas por 33\% dos respondentes. Este fato não minimiza a importância da universidade e dos centros de pesquisa para a criação das empresas (33,3\% delas foram criadas a partir de conhecimentos gerados nas universidades ou centros de pesquisa), porém, para a sua sobrevivência e desenvolvimento, as inovações são desenvolvidas pelas próprias empresas ou mediante alianças firmadas com fornecedores (16\%), clientes (30\%), outras empresas $(21 \%)$ ou mesmo com universidades ou centros de pesquisa $(33 \%)$.

Observe-se ainda, a respeito do uso da tecnologia, que $73 \%$ dos respondentes fabricam produtos que demandam alto recurso tecnológico e 58\% possuem tecnologia única em seus produtos e/ou processos produtivos. Relativamente às inovações, $76 \%$ aprimoram 
constantemente os processos de produção, buscando melhorias contínuas e otimização dos recursos, sendo que $82 \%$ entendem que o diferencial competitivo da empresa é a inovação tecnológica.

\subsection{ESPECIFICIDADE DA PEQUENA EMPRESA E A CRIAÇÃO DA ESTRATÉGIA}

Nesta seção reúnem-se os resultados da análise quantitativa dos dados coletados nas 33 EBT investigadas, destacando-se as variáveis que influenciam a criação de estratégias. Este registro implica:

- a apresentação das variáveis isoladamente, para que se identificar as características relevantes do contexto, da organização, do dirigente e do processo estratégico;

- a análise do processo de criação de estratégia integral, a partir das características das variáveis selecionadas.

6.2.1 Análise das variáveis de pesquisa: método descritivo

Conforme já se mencionou pretende-se analisar, particularmente, cada uma das variáveis deste estudo - o processo de criação de estratégias e as especificidades de gestão relacionadas ao contexto, à organização e ao dirigente.

Quanto às particularidades de contexto, buscou-se verificar como os dirigentes caracterizam alguns atributos que dizem respeito ao nível de incerteza do ambiente organizacional: 1) a complexidade, avaliada a partir da diversidade nos relacionamentos; 2) a capacidade, avaliada a partir do crescimento do setor e; 3) a volatilidade, avaliada a partir da velocidade de mudança do ambiente. O quadro 14 sintetiza a caracterização feita. A propósito, convém informar que, para se se caracterizar o ambiente da organização, solicitouse aos dirigentes que assinalassem um ponto em uma escala, de acordo com características de ambientes mais ou menos incertos (Apêndice B). 


\begin{tabular}{|l|l|l|}
\hline Atributos & Características & Nível de incerteza \\
\hline \multirow{4}{*}{$\begin{array}{l}\text { Complexidade } \\
\text { (diversidade nos } \\
\text { relacionamentos) }\end{array}$} & Clientes & $\begin{array}{l}\text { Semelhantes } \\
\text { Diversas }\end{array}$ \\
\cline { 2 - 3 } & Concorrentes & $\begin{array}{l}\text { Semelhantes } \\
\text { Diversas }\end{array}$ \\
\cline { 2 - 3 } & Segmentação & Pouco segmentado \\
& Muito segmentado \\
\hline Capacidade & Nível de oportunidades & $\begin{array}{l}\text { Muitas oportunidades } \\
\text { Poucas oportunidades }\end{array}$ \\
\hline \multirow{2}{*}{ Volatilidade } & Dinamicidade & $\begin{array}{l}\text { Estável } \\
\text { Dinâmico }\end{array}$ \\
\cline { 2 - 3 } & Nível de mudanças & $\begin{array}{l}\text { Lenta e previsível } \\
\text { Rápida e imprevisível }\end{array}$ \\
& &
\end{tabular}

Quadro 14 - Atributos relacionados ao nível de incerteza do ambiente organizacional

Na tabela 9, onde se registra a freqüência identificada de cada uma das opções que caracterizam o ambiente organizacional, é possível verificar que as EBT investigadas possuem, predominantemente, clientes e concorrentes com relacionamentos diversificados quanto a porte, tecnologia e perfil e que o ambiente em que estão inseridas é heterogêneo, dinâmico e oferece muitas oportunidades. De acordo com tais atributos, o ambiente das EBT pode ser definido como incerto, entendendo-se que a incerteza ambiental é maior quanto mais o ambiente é escasso (com baixa capacidade de crescimento), instável (com alto grau de mudança) e heterogêneo (de alta complexidade). Destaque-se que, em relação ao nível de mudanças e à segmentação do ambiente, a freqüência de respostas encontra-se em uma faixa intermediária, não revelando maior ou menor incerteza ambiental.

Tem-se que, a baixa capacidade de crescimento do ambiente leva a maior incerteza ambiental. No entanto, após a coleta os dados, identificou-se, na compreensão dos dirigentes, que o nível de incerteza é maior em um ambiente com muitas oportunidades, pois com o rápido desenvolvimento tecnológico, muitas oportunidades surgem sem que a empresa tenha a mesma agilidade que seus concorrentes - de maior porte ou possíveis novos entrantes - para identificá-las e explorá-las e, por outro lado, muitas ameaças surgem, como a defasagem de sua tecnologia empregada ou o desenvolvimento de uma tecnologia substituta. Optou-se, desta forma, em relação à capacidade do ambiente, considerar que a presença de muitas 
oportunidades reflete em maior incerteza ambiental e, inversamente, um ambiente com poucas oportunidades é menos incerto, para o caso das pequenas empresas de base tecnológica.

Tabela 9 - Caracterização do ambiente organizacional

\begin{tabular}{|c|c|c|c|c|c|c|c|c|}
\hline \multicolumn{9}{|c|}{ Ambiente } \\
\hline maior & & & & $\%$ & & & & menor \\
\hline muito segmentado & 9 & 12 & 18 & 21 & 21 & 15 & 3 & pouco segmentado \\
\hline $\begin{array}{l}\text { clientes com características } \\
\text { diversas }\end{array}$ & 21 & 39 & 21 & 18 & 0 & 0 & 0 & $\begin{array}{r}\text { clientes com características } \\
\text { semelhantes }\end{array}$ \\
\hline & 21 & 45 & 24 & 9 & 0 & 0 & 0 & $\begin{array}{r}\text { concorrentes com características } \\
\text { semelhantes }\end{array}$ \\
\hline $\begin{array}{l}\text { mudanças rápidas e } \\
\text { imprevisíveis }\end{array}$ & 6 & 18 & 27 & 21 & 15 & 9 & 3 & mudanças lentas e previsíveis \\
\hline dinâmico & 15 & 45 & 24 & 15 & 0 & 0 & 0 & estável \\
\hline com muitas oportunidades & 21 & 36 & 15 & 24 & 0 & 3 & 0 & com poucas oportunidades \\
\hline
\end{tabular}

Procurou-se identificar as variáveis do ambiente organizacional que exercem influência no direcionamento futuro da empresa. Com referência ao desenvolvimento tecnológico, registra-se uma significativa incidência de respostas que o consideram como de alta ou muito alta influência. A propósito, observe-se que nenhum dirigente o considera de muito baixa influência. Destaca-se também que $24 \%$ dos respondentes não identificam a influência da variável ambiental "órgãos reguladores” na criação de estratégias.

Tabela 10 - Influência das variáveis ambientais na criação de estratégias

\begin{tabular}{|c|c|c|c|c|c|c|}
\hline Variáveis & muito baixa & baixa & média & alta & muito alta & $\begin{array}{c}\text { não } \\
\text { identificadı }\end{array}$ \\
\hline $\begin{array}{l}\text { desenvolvimento } \\
\text { tecnológico }\end{array}$ & $0 \%$ & $3 \%$ & $9 \%$ & $39 \%$ & $48 \%$ & $0 \%$ \\
\hline condições políticas & $27 \%$ & $21 \%$ & $15 \%$ & $21 \%$ & $3 \%$ & $12 \%$ \\
\hline condições econômicas & $9 \%$ & $12 \%$ & $27 \%$ & $30 \%$ & $21 \%$ & $0 \%$ \\
\hline $\begin{array}{l}\text { condições do meio- } \\
\text { ambiente }\end{array}$ & $27 \%$ & $18 \%$ & $9 \%$ & $12 \%$ & $18 \%$ & $15 \%$ \\
\hline $\begin{array}{l}\text { condições sócio- } \\
\text { culturais da população }\end{array}$ & $12 \%$ & $39 \%$ & $9 \%$ & $15 \%$ & $6 \%$ & $18 \%$ \\
\hline $\begin{array}{l}\text { ações dos } \\
\text { concorrentes }\end{array}$ & $12 \%$ & $27 \%$ & $21 \%$ & $27 \%$ & $6 \%$ & $6 \%$ \\
\hline $\begin{array}{l}\text { características dos } \\
\text { fornecedores }\end{array}$ & $12 \%$ & $27 \%$ & $27 \%$ & $24 \%$ & $0 \%$ & $9 \%$ \\
\hline $\begin{array}{l}\text { características dos } \\
\text { clientes }\end{array}$ & $3 \%$ & $6 \%$ & $15 \%$ & $42 \%$ & $27 \%$ & $6 \%$ \\
\hline $\begin{array}{l}\text { atuação de órgãos } \\
\text { reguladores }\end{array}$ & $9 \%$ & $15 \%$ & $15 \%$ & $24 \%$ & $12 \%$ & $24 \%$ \\
\hline
\end{tabular}


Excluindo-se as freqüências das variáveis não identificadas e reduzindo-se a escala de 05 para 03 pontos, tem-se que as variáveis que influem na criação de estratégias, orientação e tomada de decisão quanto a ações futuras distribuem-se em três blocos: o primeiro inclui o desenvolvimento tecnológico (88\%) e as características dos clientes (74\%), variáveis consideradas como de alta ou muito alta influência; o segundo é composto pelas variáveis condições econômicas (52\%) e atuação dos órgãos reguladores (48\%), com influência moderada; e o terceiro conta com as variáveis condições políticas (28\%), condições de meio ambiente (36\%), condições socioculturais (26\%), ações dos concorrentes (35\%) e características dos fornecedores $(27 \%)$, com influência baixa ou muito baixa na criação de estratégias. É importante assinalar que apenas $3 \%$ dos respondentes consideram o desenvolvimento tecnológico e 10\% indicam a variável "características dos clientes" como de baixa ou muito baixa influência no estabelecimento de ações futuras de longo prazo. Registrese, ainda, que as variáveis condições políticas (55\%), do meio-ambiente (54\%) e socioculturais da população (63\%), com um percentual acima de 50\%, são identificadas como variáveis de baixa ou muito baixa influência.

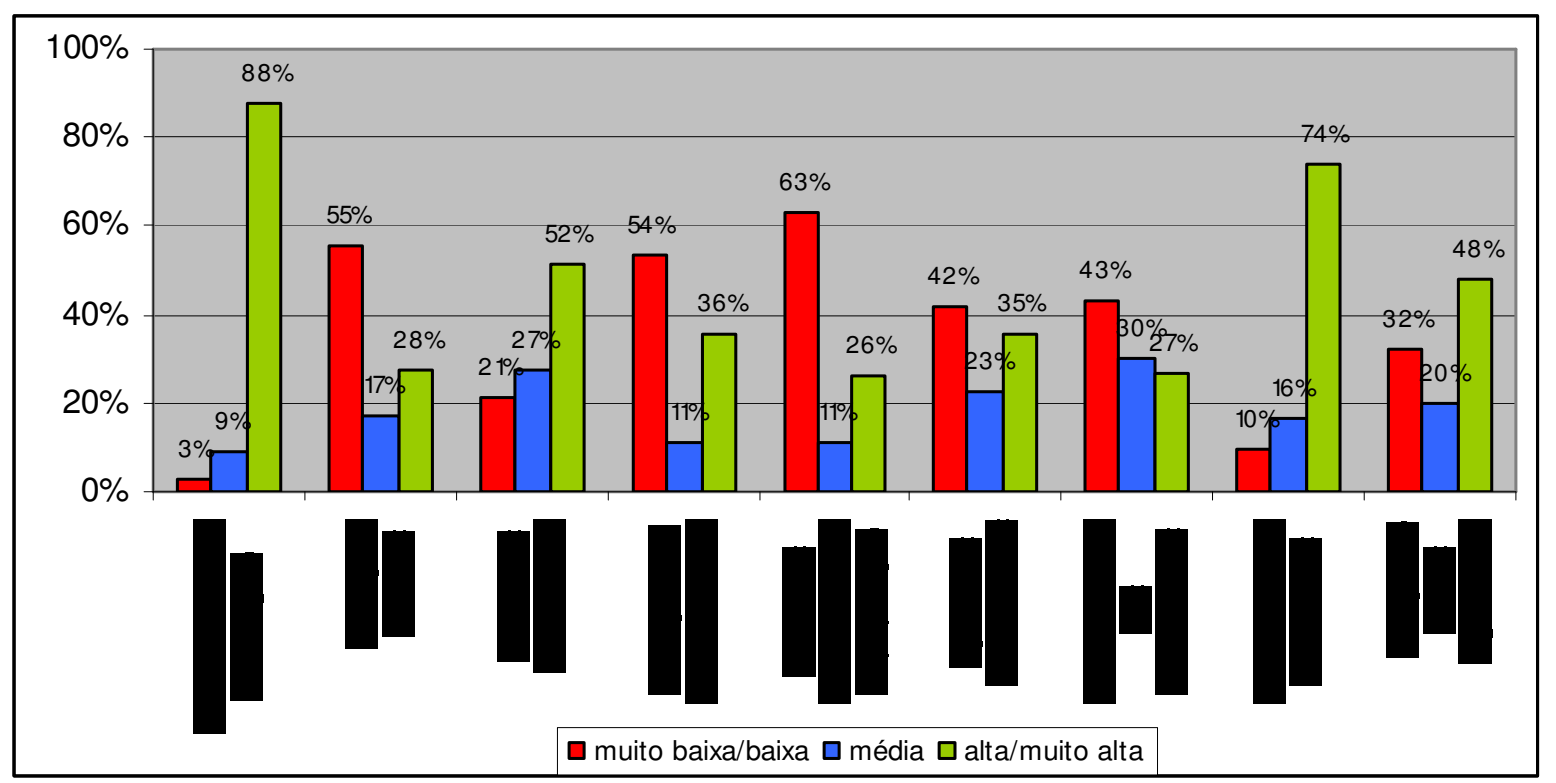

Figura 35 - Influência das variáveis ambientais

Quanto à organização, procurou-se identificar características relativas à divisão do trabalho, definição de tarefas e ocupação dos cargos, ao tipo e nível de decisão e à formalização da comunicação. Buscou-se detectar, enfim, atributos relativos à estrutura, tomada de decisão e comunicação (quadro 15). Para se caracterizar a organização da 
empresa, solicitou-se aos dirigentes que assinalassem um ponto, em uma escala, de acordo com características orgânicas ou mecânicas de organização (Apêndice B).

\begin{tabular}{|l|l|l|}
\hline Atributos & Características & Tipo de Organização \\
\hline \multirow{4}{*}{ Estrutura } & Divisão do trabalho & $\begin{array}{l}\text { Flexível com pouca divisão } \\
\text { Rígida com ampla divisão }\end{array}$ \\
\cline { 2 - 3 } & Cargos & $\begin{array}{l}\text { Continuamente redefinidos } \\
\text { Definição fixa (especialistas) }\end{array}$ \\
\cline { 2 - 3 } & Tarefa & $\begin{array}{l}\text { Variadas, não rotineiras e flexíveis } \\
\text { Rotineiras e rigidamente estabelecidas }\end{array}$ \\
\hline Tomada de decisão & Tipo e nível & $\begin{array}{l}\text { Descentralizada e delegada a níveis inferiores } \\
\text { Centralizada e concentrada na alta administração }\end{array}$ \\
\hline Comunicação & Formalização & $\begin{array}{l}\text { Maior confiabilidade nas comunicações informais } \\
\text { Ênfase nas regras e procedimentos formais }\end{array}$ \\
\hline
\end{tabular}

Quadro 15 - Atributos relacionados à organização

De acordo com os dados apresentados na tabela 11, as organizações não possuem características orgânicas ou mecânicas predominantemente. Os dados demonstram haver maior incidência de características que configuram organizações flexíveis, com pouca divisão do trabalho, cujos cargos, porém, são ocupados por especialistas da área e cujas decisões se centralizam e concentram na alta administração. As tarefas, nestas empresas, são variadas, não rotineiras e flexíveis, a comunicação tem caráter informal e, em determinadas situações, regras e procedimentos são enfatizados. Tais organizações apresentam-se como mais rígidas quanto à ocupação de cargos e centralização das decisões na alta administração e revelam um caráter mais flexível na divisão do trabalho não rigorosa e na apresentação de tarefas variadas, não rotineiras e flexíveis.

Tabela 11 - Caracterização da organização

\begin{tabular}{|c|c|c|c|c|c|c|c|c|}
\hline \multicolumn{9}{|c|}{ Organização } \\
\hline mecânica & & & & $\%$ & & & & orgânica \\
\hline $\begin{array}{l}\text { rígida com ampla divisão do } \\
\text { trabalho }\end{array}$ & 6 & 6 & 6 & 27 & 27 & 12 & 15 & flexível com pouca divisão do trabalho \\
\hline $\begin{array}{l}\text { cargos ocupados por } \\
\text { especialistas }\end{array}$ & 12 & 33 & 15 & 12 & 15 & 6 & 6 & $\begin{array}{r}\text { cargos são continuamente redefinidos } \\
\text { por meio da interação com outras } \\
\text { pessoas que participam da tarefa }\end{array}$ \\
\hline $\begin{array}{l}\text { decisões centralizadas e } \\
\text { concentradas na alta } \\
\text { administração }\end{array}$ & 12 & 27 & 45 & 15 & 0 & 0 & 0 & $\begin{array}{r}\text { decisões descentralizadas e delegadas } \\
\text { a níveis inferiores }\end{array}$ \\
\hline $\begin{array}{l}\text { ênfase nas regras e } \\
\text { procedimentos }\end{array}$ & 3 & 15 & 18 & 21 & 18 & 15 & 9 & $\begin{array}{r}\text { maior confliabilidade nas comunicações } \\
\text { informais }\end{array}$ \\
\hline $\begin{array}{l}\text { apresenta tarefas rotineiras e } \\
\text { rigidamente estabelecidas }\end{array}$ & 0 & 9 & 3 & 18 & 18 & 30 & 21 & $\begin{array}{r}\text { apresenta tarefas variadas, não } \\
\text { rotineiras e flexíveis }\end{array}$ \\
\hline
\end{tabular}


Para definir a personalidade e postura do dirigente-estrategista, utilizou-se a seleção de adjetivos utilizada por Pitcher (1993; 1999), que os caracteriza como artistas, artesãos ou tecnocratas. A autora esclarece que dificilmente um dirigente possui características de apenas um tipo de perfil, sendo provável que tenha características de dois ou três perfis, com maior ou menor intensidade. Assim, a partir de 18 adjetivos propostos, apresentados no quadro 16, os dirigentes-estrategistas indicaram o grau de precisão com que as qualidades se aplicavam a seus perfis ou não as assinalaram.

\begin{tabular}{|l|l|l|l|}
\hline Perfil & Artista & Artesão & Tecnocrata \\
\hline \multirow{4}{*}{ Características } & Ousado & Responsável & Aplicado \\
& Emotivo & Estável & Determinado \\
& Imaginativo & Previsível & Eficiente \\
& Visionário & Equilibrado & Cerebral (racional) \\
& Empreendedor & Realista & Exigente \\
& Intuitivo & Justo & Detalhista \\
\hline
\end{tabular}

Quadro 16 - Características relacionadas ao perfil do dirigente

Com base nos dados coletados, em 94\% das respostas, atribuem-se aos dirigentes os adjetivos "determinados" e "aplicados", registrados como características de alta ou muito alta precisão em sua personalidade e postura. Observe-se que, em nenhuma opção de resposta, estas qualidades registram-se como de muito baixa/baixa precisão. Destaca-se ainda, em 88\% das respostas, como de alta/muito alta precisão, a aplicação dos adjetivos "justo", "responsável" e "empreendedor". Por outro lado, as características "emotivo" e "previsível" apresentam-se com um índice de precisão equivalente a muito baixo/baixo, em $42 \%$ e $31 \%$ das respostas, respectivamente. Com referência a perfil, os dirigentes-estrategistas das EBT classificam-se, em primeiro lugar, como tecnocratas, depois, como artesãos e, por fim, como artistas, considerando-se o grau de precisão alto/muito alto das características aplicáveis ao dirigente, conforme visualizado no gráfico 36. 


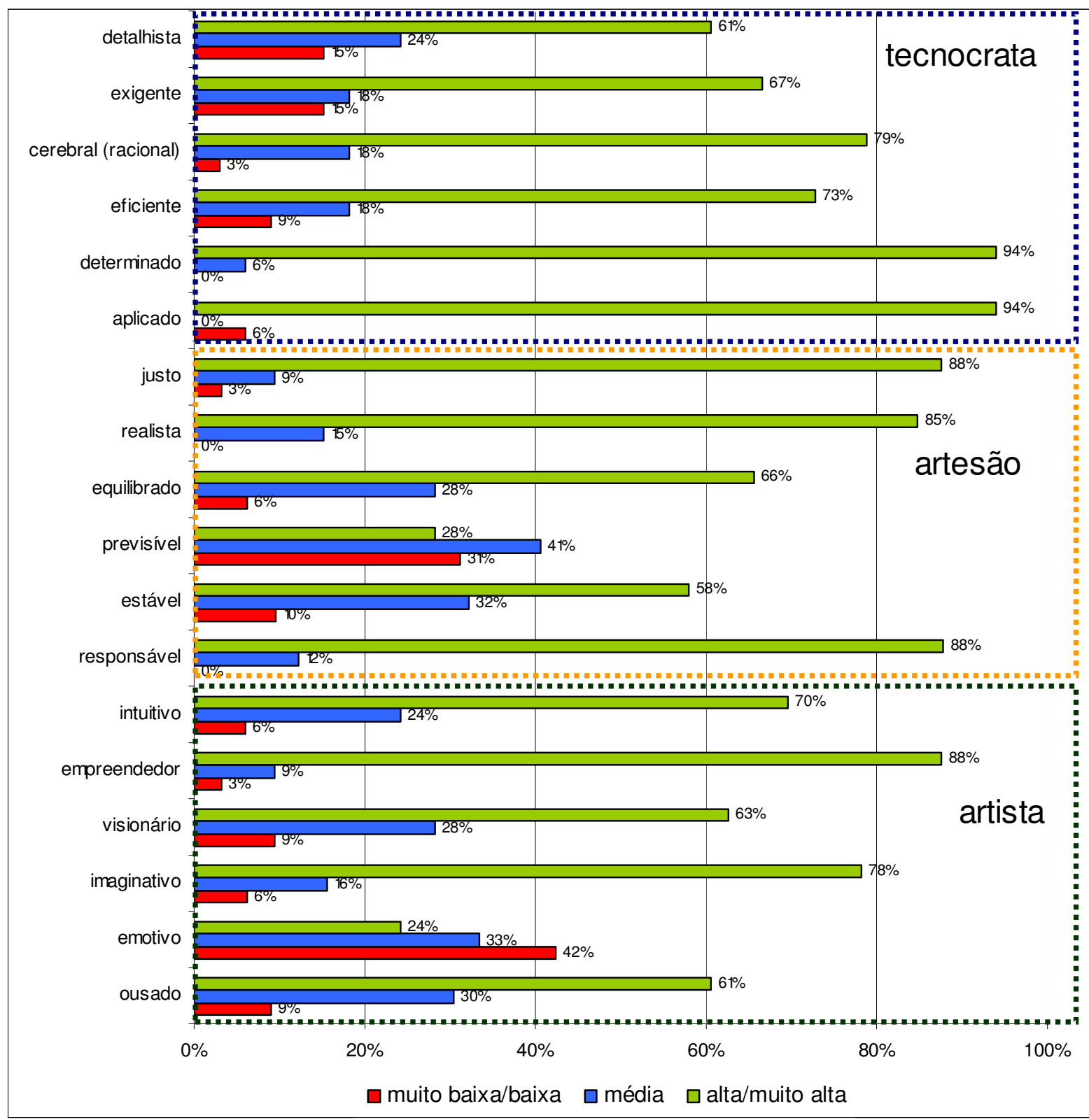

Figura 36 - Caracterização do dirigente estrategista

Apresenta-se, a seguir, um gráfico, elaborado a partir dos adjetivos com índice de precisão alto/muito alto, em mais de $70 \%$ das respostas, para se delinear um perfil para os dirigentes das EBT investigadas. Conforme o argumento de Pitcher (1993; 1999), estes dirigentes dificilmente apresentam apenas características relevantes de artista, artesão ou tecnocrata. Pode-se visualizar, no gráfico, que os dirigentes das EBT identificaram-se com as seguintes características descritivas de sua personalidade e postura na criação de estratégias: 1) tecnocrata - eficiente, cerebral, determinado e aplicado; 2) artista - realista, justo e responsável; 3) artesão - intuitivo, imaginativo e empreendedor. Ainda, segundo a autora, raramente o dirigente apresentar as características dos três tipos perfis, como se encontrou 
neste grupo de EBT. Acredita-se que esta situação deve-se à solicitação feita ao dirigente para se indicar o grau de precisão e não a seleção de alguns adjetivos, o que, provavelmente, resultou em um grande número de adjetivos apontados com alta/muito alta precisão, dificultando a identificação do perfil do dirigente.

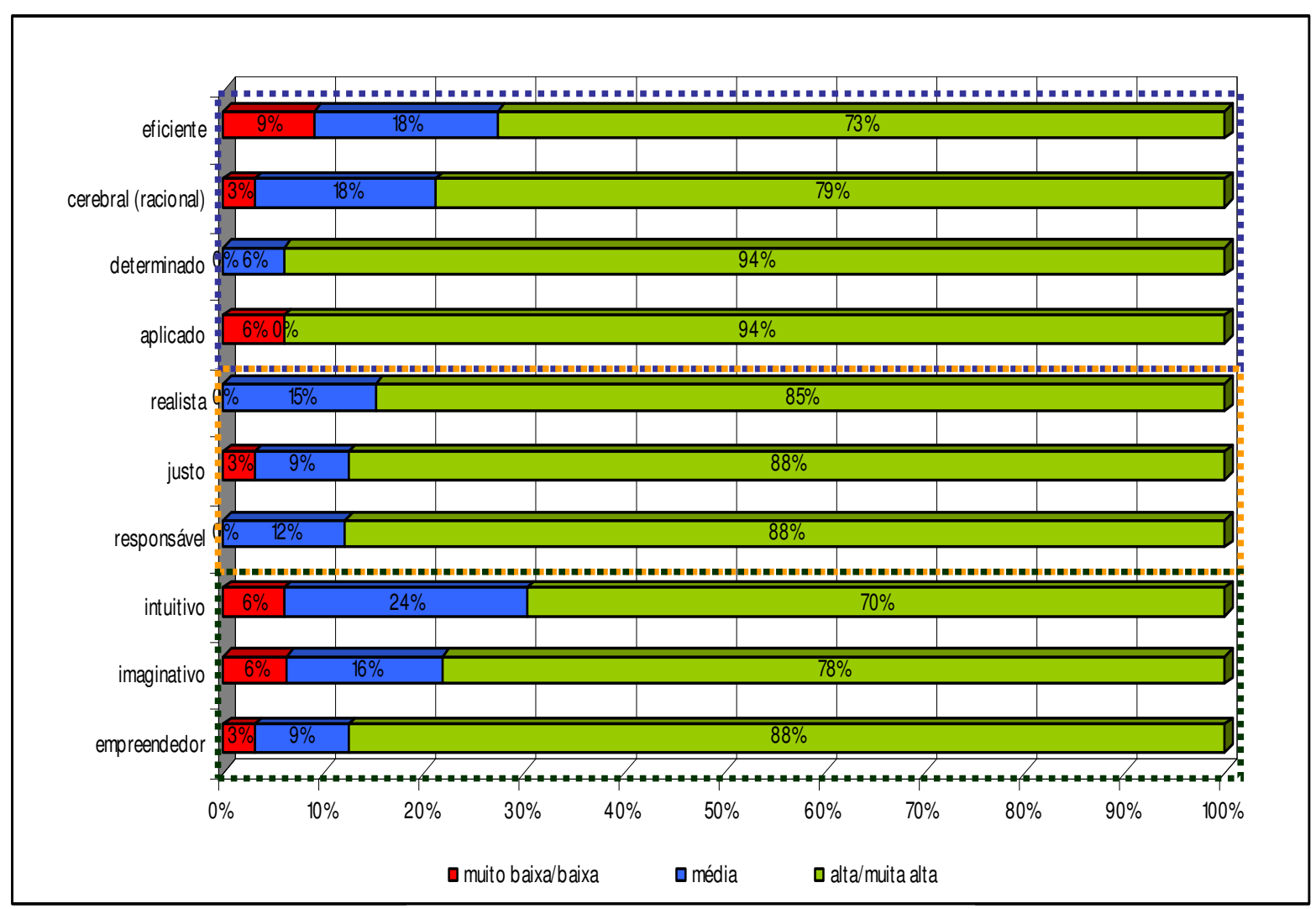

Figura 37 - Características do dirigente estrategista com nível de precisão alto/muito alto

Das EBT investigadas, 64\% declararam realizar um processo de planejamento formal, com as seguintes características:

- $\quad$ estratégico: $90 \%$ dos respondentes que fazem a declaração (58\% do total) realizam um planejamento de longo prazo, a partir da identificação de oportunidades e ameaças ao negócio, a definição de objetivos e projetos para um período médio de 03 anos, análise de fatores externos, como concorrentes, clientes, tecnología e economia, entre outros;

- $\quad$ operacional: $64 \%$ de todas as empresas investigadas e $100 \%$ das que fazem a declaração, realizam planejamento de curto prazo, apresentando um plano de ação - anual, mensal ou semanal - voltado a ações específicas de produção, finanças e mercadologia e outras.

As demais empresas (36\%) não realizam um processo de planejamento formal. Destas, $67 \%$ desenvolvem um planejamento baseado na intuição e experiência do dirigente. Este 
planejamento não é escrito, encontra-se na mente do dirigente, é de curto prazo e está relacionado às condições atuais da empresa, do seu ambiente e aos objetivos do dirigente. Os outros 33\% dos dirigentes declararam que não há planejamento mensurável em sua empresa. Destaque-se que, entre os respondentes que não realizam um processo de planejamento formal, $42 \%$ discordam quanto a não haver planejamento mensurável na empresa, denotando a presença de um processo de planejamento informal.

Para que se identificasse a orientação principal ou o direcionamento da organização, solicitou-se aos respondentes que assinalassem o ponto que melhor descrevesse a estratégia, considerando características deliberadas e emergentes. A princípio, verifica-se que a estratégia não é puramente deliberada ou emergente, apresentando os dois tipos antagônicos. No entanto, outras constatações se destacam: as decisões estratégicas são tomadas pela alta administração, não há interação entre esta com os níveis inferiores para a criação de estratégias; as estratégias não são definidas com base na experiência e alteradas de acordo com acontecimentos cotidianos, características claramente emergentes, e, sim, de acordo com o cronograma estabelecido com base em análises de informações (tabela 12).

Tabela 12 - Características das estratégias

\begin{tabular}{|c|c|c|c|c|c|c|c|c|}
\hline \multicolumn{9}{|c|}{ Estratégia } \\
\hline Deliberada & & & & $\%$ & & & & Emergente \\
\hline razão & 6 & 21 & 21 & 36 & 12 & 0 & 3 & intuição \\
\hline informação & 6 & 24 & 21 & 48 & 0 & 0 & 0 & experiência \\
\hline análise de informações & 6 & 15 & 9 & 30 & 33 & 3 & 3 & utilização da criatividade \\
\hline $\begin{array}{l}\text { antecipação de } \\
\text { acontecimentos }\end{array}$ & 6 & 15 & 15 & 33 & 6 & 18 & 6 & ocorrências do dia-a-dia \\
\hline $\begin{array}{l}\text { definida de acordo com o } \\
\text { cronograma }\end{array}$ & 9 & 30 & 39 & 21 & 0 & 0 & 0 & $\begin{array}{l}\text { definida e alterada de acordo } \\
\text { com acontecimentos cotidianos }\end{array}$ \\
\hline decisões da alta administração & 3 & 58 & 18 & 21 & 0 & 0 & 0 & $\begin{array}{l}\text { interação entre alta } \\
\text { administração e níveis inferiores }\end{array}$ \\
\hline $\begin{array}{l}\text { objetivos claramente definidos } \\
\text { e detalhados }\end{array}$ & 6 & 9 & 15 & 24 & 30 & 12 & 3 & definição de objetivos gerais \\
\hline
\end{tabular}

O processo de criação de estratégias das EBT apresenta-se como rígido, regular, realizado em etapas e com base em ações previstas. As características do processo flexível e que se baseia em ações inesperadas não foram assinaladas pelos dirigentes. Ressalta que, da mesma forma que as estratégias, o processo de criação apresenta características deliberadas e emergentes, porém as deliberadas são mais intensas. 
Tabela 13 - Características do processo de criação de estratégias

\begin{tabular}{lrrrrrrrrr}
\hline \multicolumn{10}{c}{ Processo de criação de estratégias } \\
\hline deliberado & 9 & 30 & 18 & 21 & 3 & 15 & 3 & emergente \\
\hline processo regular & 12 & 30 & 12 & 24 & 9 & 9 & 3 & não segue etapas previstas \\
realizado em etapas & 6 & 27 & 36 & 30 & 0 & 0 & 0 & baseado em ações inesperadas \\
baseado em ações previstas & 6 & 24 & 15 & 27 & 12 & 9 & 6 & informal \\
formal & 15 & 58 & 21 & 6 & 0 & 0 & 0 & flexível \\
rígido & 15 & & & & & & & &
\end{tabular}

6.2.2 Análise da estrutura das variáveis: análise dos componentes principais

Apresentam-se, nesta parte, as variáveis que influem nas características da pequena empresa de base tecnológica e do seu processo de criação de estratégias, definidas a partir de comportamentos semelhantes observados na investigação, para se construir um quadro de influência do contexto, do dirigente e das especificidades organizacionais nas características emergentes e deliberadas detectadas.

Inicialmente, foram selecionadas as seguintes variáveis para a $\mathrm{ACP}$, apresentadas no quadro 17, de acordo com critérios adotados na pesquisa. Tais critérios encontram-se no apêndice $\mathrm{F}$, no qual são descritos os procedimentos realizados para a ACP das variáveis selecionadas.

\begin{tabular}{|l|l|l|}
\hline Categorias & \multicolumn{1}{|c|}{ Variáveis selecionadas } \\
\hline Ambiente & Características dos concorrentes & $\mathrm{A}_{3}$ \\
& Nível de mudanças & $\mathrm{A}_{4}$ \\
\hline Organização & Estrutura e divisão do trabalho & $\mathrm{O}_{1}$ \\
& Tomada de decisão & $\mathrm{O}_{3}$ \\
\hline Dirigente- & Imaginativo & $\mathrm{D}_{\text {im }}$ \\
& Visionário & $\mathrm{D}_{\text {vis }}$ \\
& Eficiente & $\mathrm{D}_{\text {efi }}$ \\
& Detalhista & $\mathrm{D}_{\text {deta }}$ \\
\hline Processo & Razão/intuição & $\mathrm{X}_{1}$ \\
& Antecipação dos acontecimentos/ocorrências do dia-a-dia & $\mathrm{X}_{4}$ \\
& Decisões da alta administração/interação com níveis inferiores & $\mathrm{X}_{6}$ \\
& Objetivos definidos e detalhados/definição de objetivos gerais & $\mathrm{X}_{7}$ \\
& Processo regular/irregular & $\mathrm{X}_{8}$ \\
& Baseado em ações previstas/ações inesperadas & $\mathrm{X}_{10}$ \\
& Formal/informal & $\mathrm{X}_{11}$ \\
& Rígido/flexível & $\mathrm{X}_{12}$ \\
\hline
\end{tabular}

Quadro 17 - Variáveis selecionadas para a ACP 
Duas questões de interesse, neste trabalho, são: a identificação da dinâmica das variáveis no processo de criação de estratégias e o levantamento das inter-relações dos processos deliberado e emergente. Assim, apresentam-se, a seguir, as representações gráficas dos casos e das variáveis na ACP realizada.

A figura 38 traz a distribuição das 33 EBT nos dois primeiros componentes principais, que explicam 40,36\% da variabilidade presente nos dados. Percebe-se que as empresas com valores extremos no primeiro componente principal apresentam um processo deliberado (direita) ou emergente (esquerda). Com referência ao segundo componente principal, nas empresas alocadas na parte superior, constata-se um processo emergente, com estrutura rígida, ampla divisão de trabalho e um dirigente pouco imaginativo e visionário, enquanto as empresas alocadas na parte inferior do eixo são flexíveis, apresentam pouca divisão do trabalho e possuem um dirigente imaginativo e visionário.

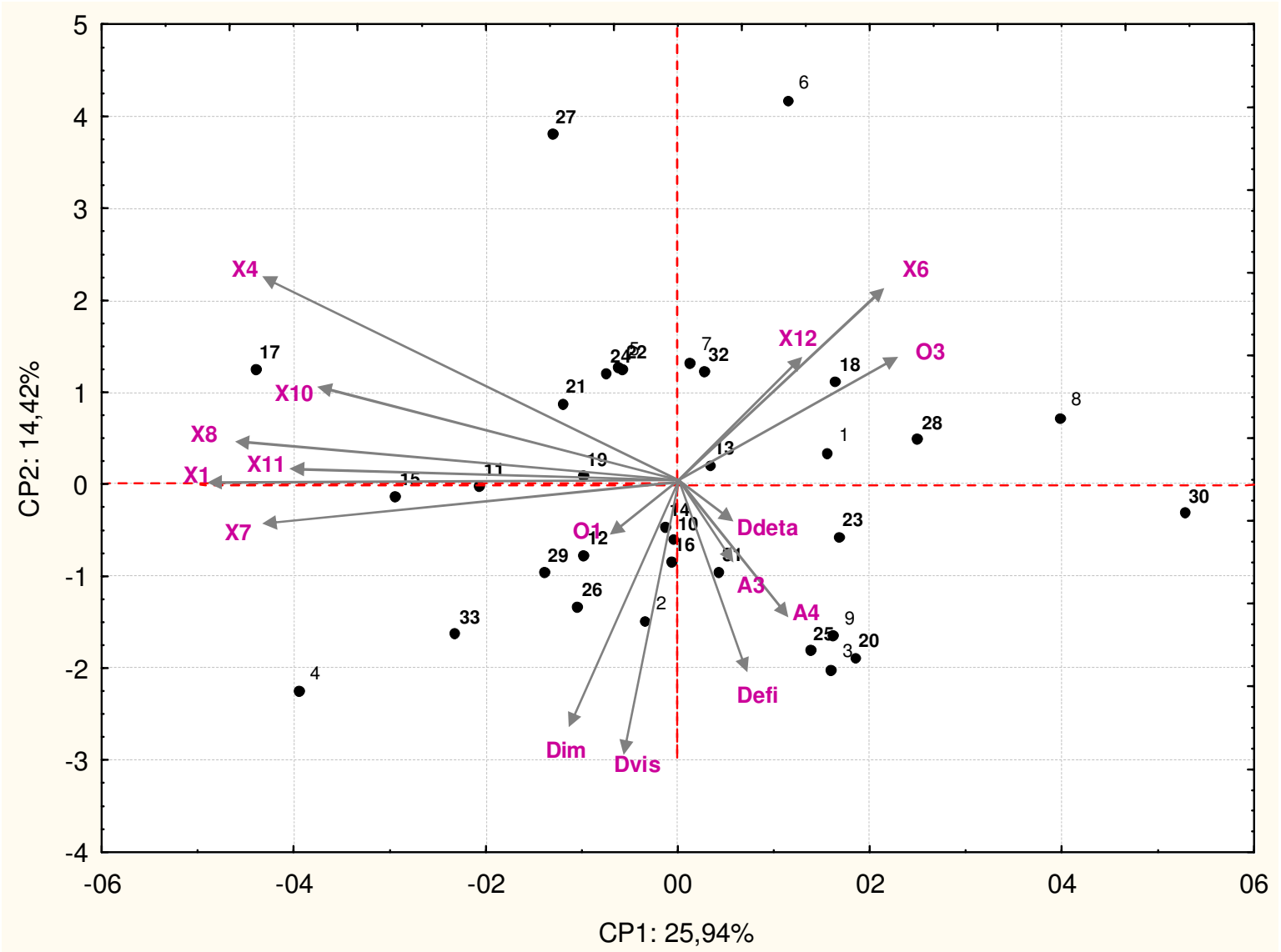

Figura 38 - Distribuição das empresas e projeção das variáveis determinantes nos dois primeiros componentes principais, $\mathrm{CP} 1$ e $\mathrm{CP} 2$

Na figura 38 apresentam-se também as variáveis determinantes na formação dos dois primeiros componentes principais. As variáveis do processo de criação de estratégias que 
exercem grande influência no primeiro componente são, principalmente, $X_{1}, X_{7}$ e $X_{8}$, seguidas por $\mathrm{X}_{10}, \mathrm{X}_{11}$ e $\mathrm{X}_{4}$. Com relação ao mesmo componente, verifica-se que as variáveis $\mathrm{X}_{6}, \mathrm{X}_{12} \mathrm{e}$ $\mathrm{O}_{3}$ exercem influência oposta à exercida por $\mathrm{X}_{4}, \mathrm{X}_{8}$ e $\mathrm{X}_{10}$. $\mathrm{O}$ dirigente-estrategista influi diretamente no segundo componente com as variáveis $\mathrm{D}_{\mathrm{im}}$ e $\mathrm{D}_{\text {vis. }}$. A contribuição das empresas para a formação dos componentes em destaque, de acordo com a correlação dos dados (apêndice F), demonstra a importância das empresas 04, 08, 17 e 30 para o primeiro e das empresas 06 e 27 para o segundo componente principal.

Ao se analisar o processo de criação de estratégias destas empresas investigadas, percebe-se que predominam, em algumas, as características emergentes e, em outras, deliberadas. Em um primeiro momento identificam-se, claramente, dois grupos de empresas, destacadas em vermelho e azul na figura 39, nas quais predominam características emergentes e deliberadas, respectivamente.

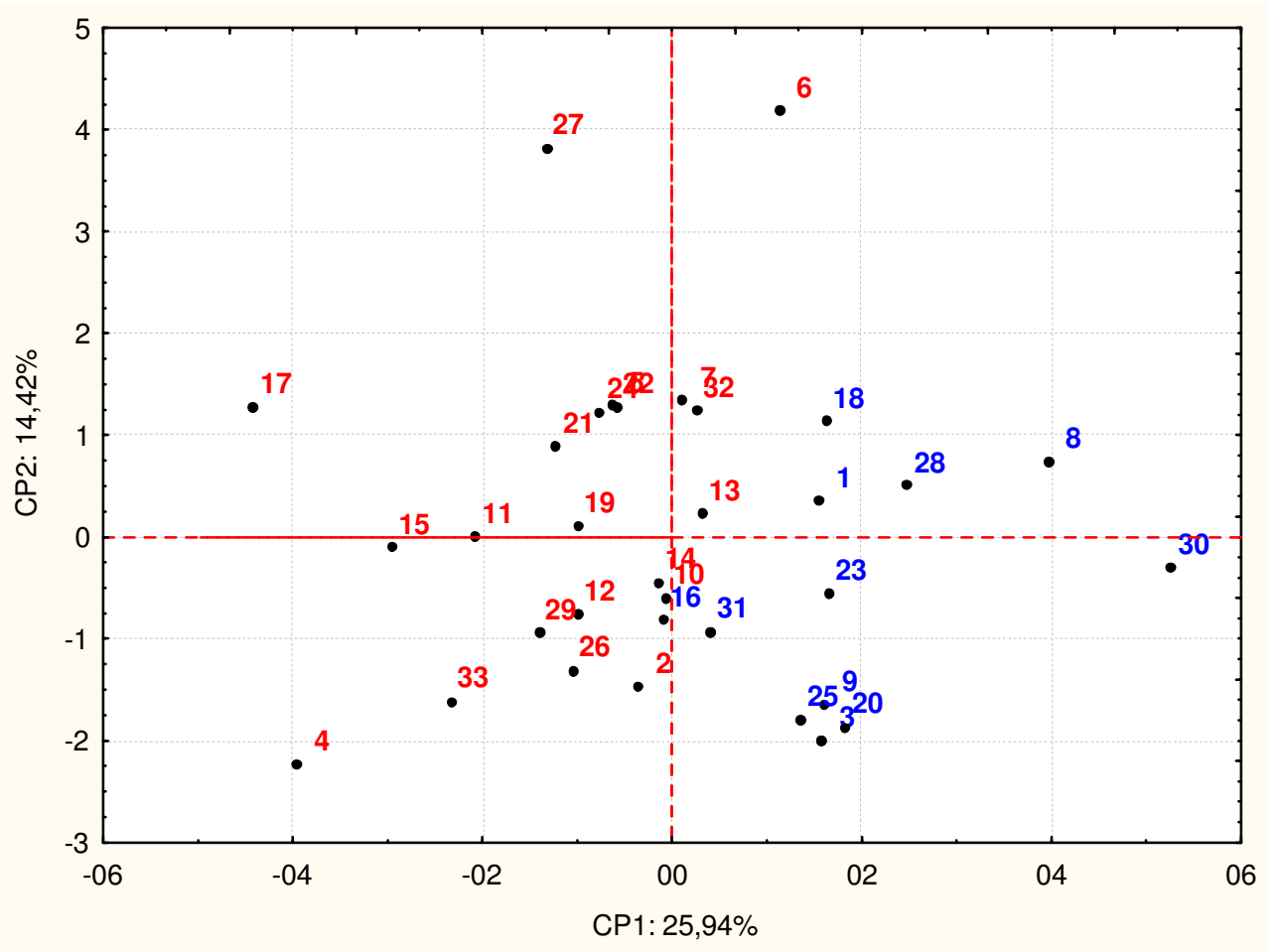

Figura 39 - Processo de criação de estratégias das EBT - grupo deliberado e emergente

No entanto, ao se estudar mais detalhadamente o processo de criação de estratégias de tais empresas, além dos dois grupos que apresentam, em maior número, características marcantes do processo emergente ou deliberado, identifica-se um terceiro, denominado misto, que reúne características de ambos os processos. O primeiro grupo - emergente - é formado 
por empresas com características predominantemente emergentes, como as de número 04,11 , $15,17,19,24$ e 27 . As que pertencem a este grupo são microempresas com menos de 10 funcionários e apresentam, como características determinantes, a definição de estratégias com base em ocorrências do dia-a-dia e o estabelecimento de objetivos gerais, de forma irregular, intuitiva e informal. No segundo grupo - deliberado - estão empresas de micro e pequeno porte cujo processo de criação de estratégias, embora seja flexível, também se caracteriza como regular, formal, racional, implicando antecipação de acontecimentos, objetivos claros e delimitados. O terceiro grupo - misto - é formado por 19 empresas que apresentam um processo de criação de estratégias homogêneo, com características deliberadas e emergentes em maior ou menor grau. A representação do processo de criação de estratégias das EBT dos três grupos identificados encontra-se na figura 40.

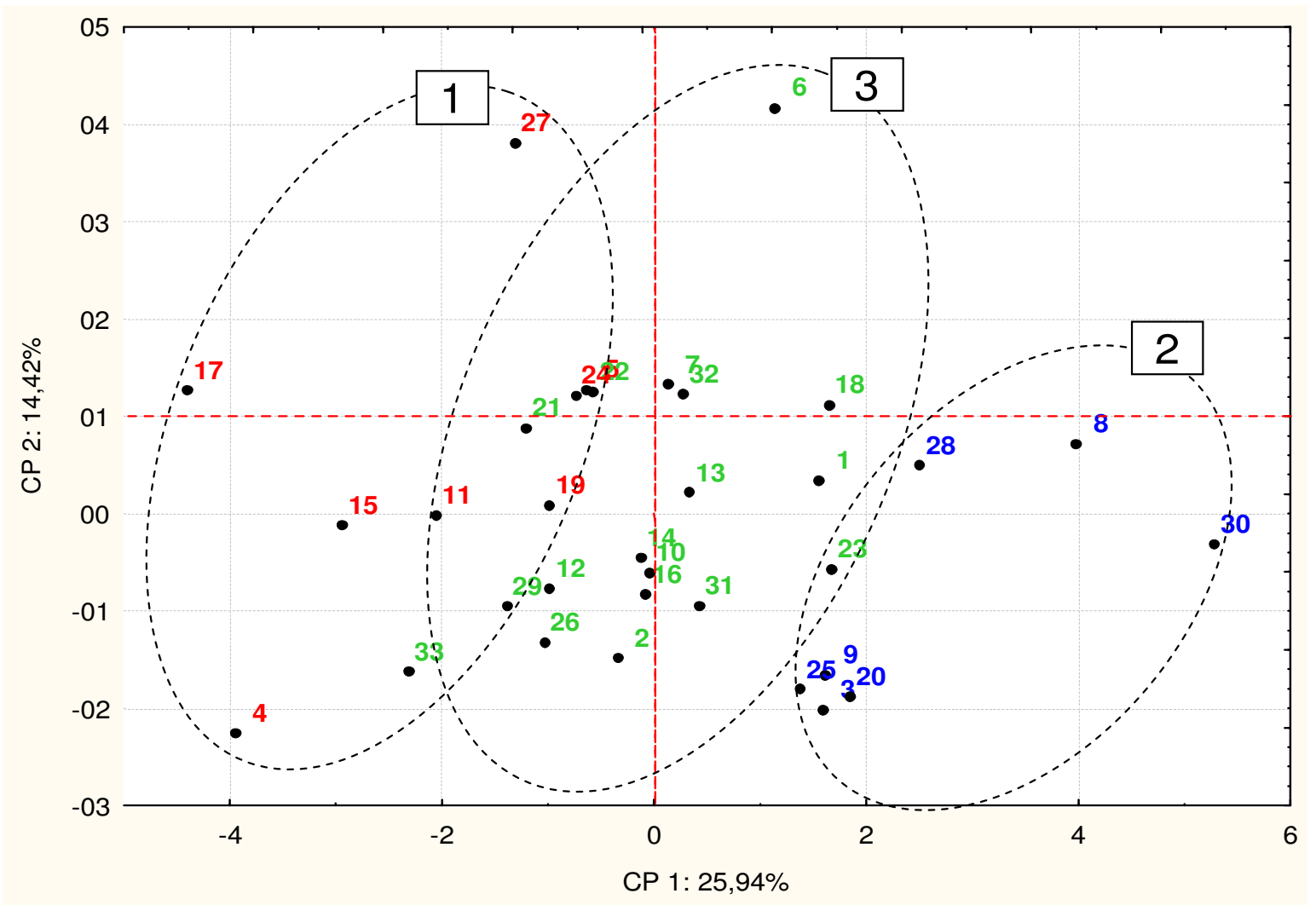

Figura 40- Processo de criação de estratégias das EBT - grupo emergente, deliberado e misto

Reiterando, a partir da análise mais detalhada do processo de criação de estratégias das EBT investigadas, é possível constatar que tais empresas se distribuem em três grupos e de acordo com os primeiro e segundo componentes principais, algumas se destacam das demais. Esta situação leva, portanto, a reconhecer um grupo homogêneo de empresas, um 
conglomerado, sem um fator discriminante em seu processo de criação de estratégias, e também algumas empresas periféricas. A situação é ilustrada na figura 41.

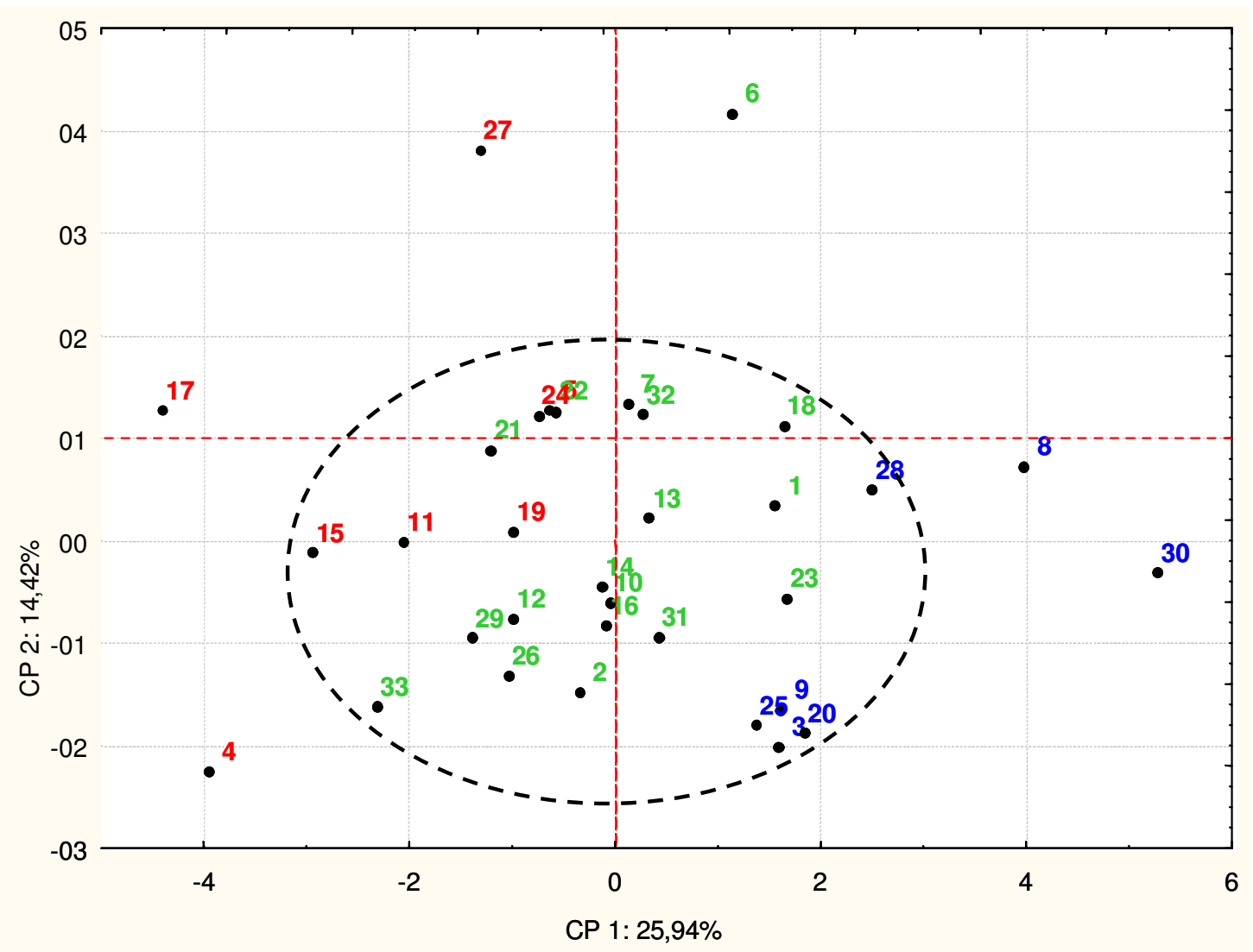

Figura 41 - Processo de criação de estratégias - visão de um conglomerado e de empresas periféricas para $\mathrm{CP} 1$ e CP2

A presença de algumas empresas periféricas e de um grupo homogêneo também é identificada nos demais componentes principais. A figura 42 mostra que esta situação ocorre nos componentes principais três, quatro, cinco e seis. Em todos os casos, algumas empresas apresentam fatores discriminantes que as afastam do grupo homogêneo. As periféricas, de acordo com os componentes principais, são:

- $\quad \mathrm{CP} 1$ e CP2: 04, 06, 08, 17, 27 e 30;

- CP1 e CP3: 04, 06, 08, 17, 30 e 33;

- $\mathrm{CP} 1$ e CP4: 04, 07, 08, 17, 28 e 30;

- CP1 e CP5: 04, 08, 15, 17, 28 e 30;

- CP1 e CP6: 04, 08, 09, 17, 29 e 30. 

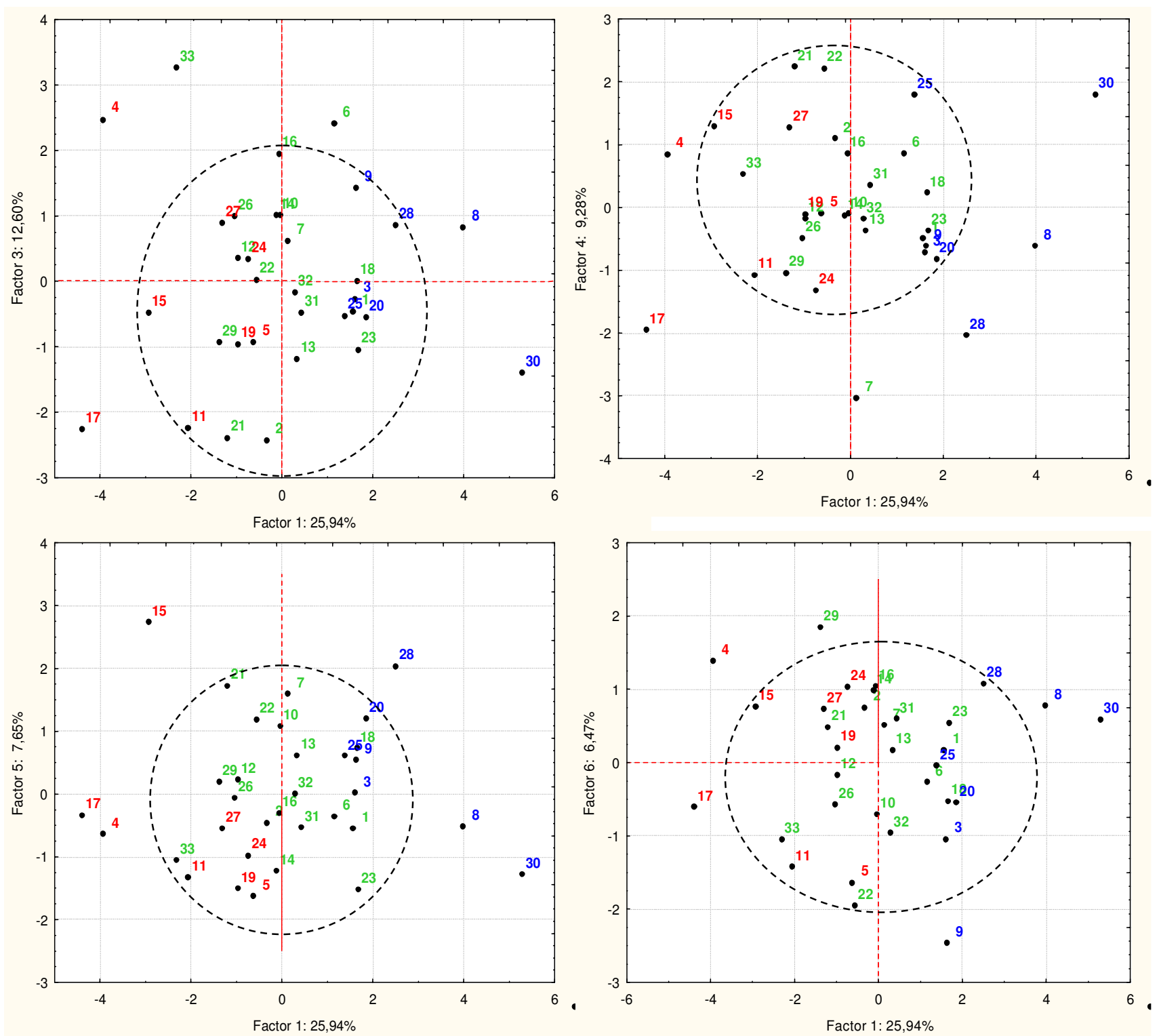

Figura 42 - Processo de criação de estratégias - visão de um conglomerado e de empresas periféricas (CP1 e CP3; CP1 e CP4; CP1 e CP5, CP1 e CP6)

Constata-se que as empresas 04, 08, 17 e 30 são periféricas em todas as composições realizadas. As demais, denominadas secundárias, apresentam-se como periféricas de acordo com a influência de determinadas variáveis. O fator que discrimina as empresas periféricas em seus componentes pode ser identificado nas cargas dos autovetores apresentados no apêndice F. Como as empresas 04, 08, 17 e 30 são periféricas nos seis componentes principais, há um maior número de fatores discriminantes em seus comportamentos. Em tais empresas percebem-se características extremas de um processo deliberado ou emergente. Os fatores relacionados ao processo (como a intuição/razão, a antecipação de acontecimentos/ocorrências do dia-a-dia e o processo regular/regular) e à imaginação e visão 
do dirigente-estrategista na criação de estratégias são identificados como determinantes para o seu posicionamento.

Para melhor visualização do grupo homogêneo e das empresas periféricas, apresentam-se duas projeções tridimensionais das EBT e das variáveis com os três primeiros e mais relevantes componentes principais. Percebe-se a presença de empresas nos extremos dos eixos de cada componente principal.
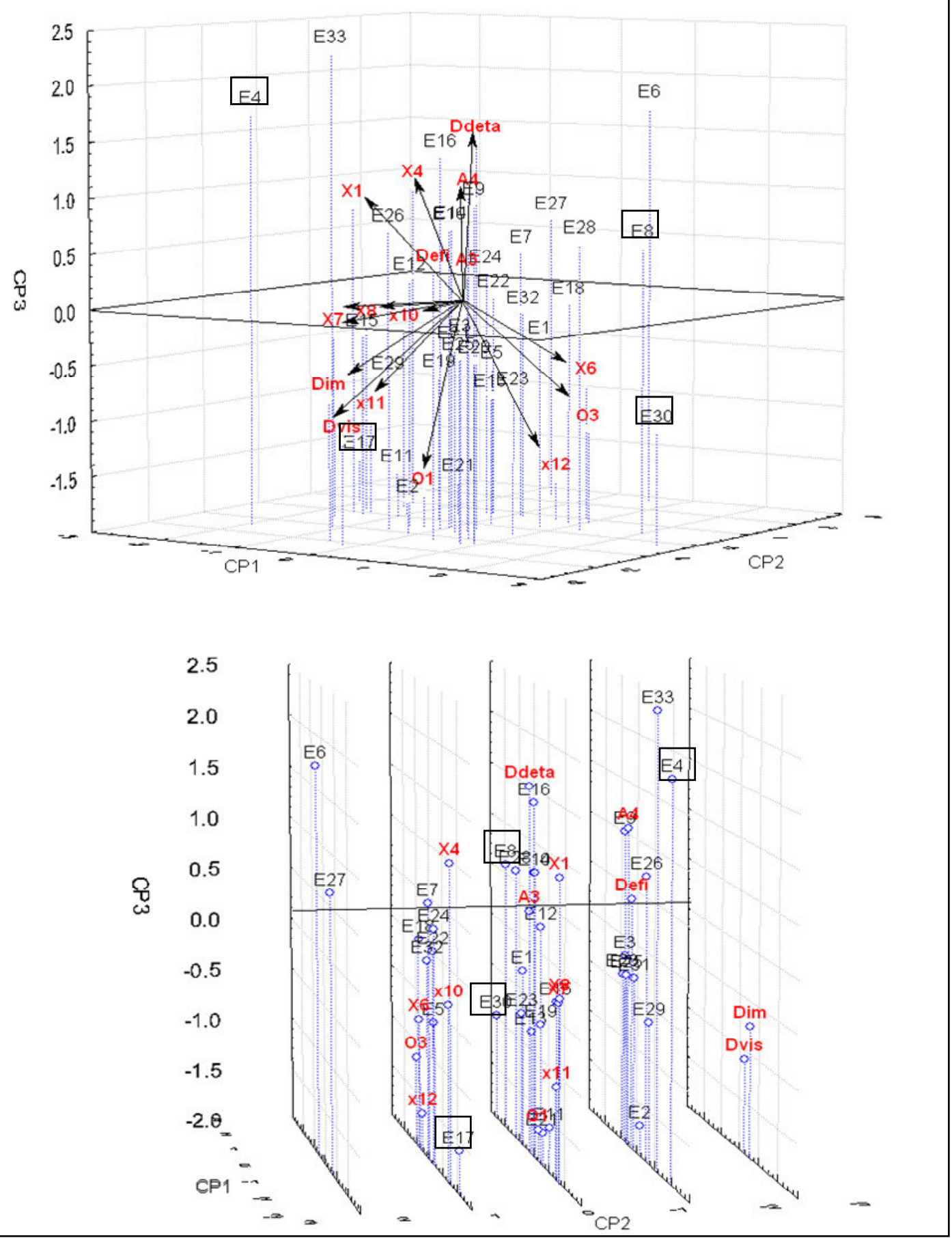

Figura 43 - Projeções tridimensionais das empresas e das variáveis determinantes para os três primeiros componentes principais, $\mathrm{CP} 1, \mathrm{CP} 2$ e $\mathrm{CP} 3$ 
A figura 43 retrata também a dinâmica das variáveis no processo de criação de estratégias. As variáveis refletidas nos componentes são: no primeiro, o processo; no segundo, o dirigente-estrategista e, no terceiro, a rigidez/flexibilidade do processo e da estrutura e o dirigente detalhista. A inter-relação dos processos deliberado e emergente evidencia-se com a identificação de três grupos de empresas - o emergente, o deliberado e o misto. Considera-se o último um grupo cujas empresas têm características emergentes e deliberadas, presentes em maior ou menor grau em diversas variáveis, ou seja, um grupo cujo processo é emergente e deliberado em vários aspectos simultaneamente. A identificação do grupo homogêneo de empresas reforça a idéia da inter-relação, da interação e da coexistência dos processos deliberados e emergentes na criação de estratégias.

A análise do processo de criação de estratégias e das especificidades de gestão das empresas de base tecnológica leva a algumas considerações, desenvolvidas nos parágrafos subseqüentes.

1) Hair et al. (2006) alertam para a precaução que se deve ter quando se interpretam dados resultantes de análises feitas a partir de um reduzido número de amostras ou objetos. Assim, a identificação de dois grupos de empresas com características distintas em seu processo de criação de estratégias (emergente e deliberado), que podem ser subdivididos em três grupos (emergente, deliberado e misto) deve ser compreendida apenas como uma representação das 33 EBT investigadas, não como um modelo para todas as EBT. É necessário cautela na extrapolação dos resultados a outras empresas.

2) Entende-se que a dispersão de algumas empresas deve-se a uma forte característica deliberada ou emergente do processo aliada a características do dirigente-estrategista, em especial a alta ou baixa presença de sua visão e imaginação na criação de estratégias.

3) Evidenciam-se, como fatores importantes na dispersão das empresas, algumas características:

- do dirigente-estrategista, como sua visão e imaginação, sua preocupação com o detalhe e sua eficiência na busca de resultados;

- do contexto, como os concorrentes e o nível de mudanças relevantes;

- da organização, como uma estrutura rígida, com ampla divisão do trabalho ou flexível, com pouca divisão; 
- da criação da estratégia, como a gestão racional, com alta influência de aspectos como a antecipação de acontecimentos ou a gestão intuitiva, com decisões baseadas no diaa-dia;

- do processo de definição da estratégia, como a determinação dos objetivos (gerais ou claramente definidos), a regularidade, a formalização e a antecipação das ações. 


\section{APRESENTAÇÃO E ANÁLISE DOS RESULTADOS DA FASE 2}

Neste capítulo, busca-se descrever e analisar as EBT que constituem objeto de estudo nesta pesquisa, assim denominadas: Empresa A, Empresa B e Empresa C. Primeiramente, apresentam-se as características que se referem ao seu histórico e a dados gerais, como porte, descrição dos produtos, mercado de atuação e estrutura organizacional e, depois, aquelas que se relacionam com o processo de criação de estratégias e as especificidades de gestão, em particular com o contexto, a organização e o dirigente-estrategista.

Como se pode observar no quadro 18 - apresentação geral das empresas investigadas todas são de base tecnológica, duas se classificam como pequenas empresas e uma é considerada média, conforme se expôs anteriormente, nos procedimentos metodológicos desta pesquisa.

\begin{tabular}{|c|c|c|c|c|}
\hline Empresa & $\begin{array}{c}\text { Ramo de } \\
\text { atuação }\end{array}$ & $\begin{array}{c}\text { Ano } \\
\text { fundação }\end{array}$ & $\begin{array}{c}\text { Número de } \\
\text { funcionários }\end{array}$ & $\begin{array}{c}\text { Criação da } \\
\text { Empresa }\end{array}$ \\
\hline A & $\begin{array}{c}\text { Materiais cerâmicos de } \\
\text { alta precisão }\end{array}$ & 1985 & 70 & Grupo de pesquisa \\
\hline B & Materiais odontológicos & 1977 & 47 & Tecnologia existente \\
\hline C & Materiais óticos & 1985 & 350 & Grupo de pesquisa \\
\hline
\end{tabular}

Quadro 18 - Apresentação geral das empresas investigadas na fase 2

\subsection{CARACTERIZAÇÃO DAS EMPRESAS}

\subsubsection{Empresa A}

Os dados utilizados na caracterização foram obtidos em entrevistas realizadas com dois professores universitários (professor 1 e professor 2) que foram sócios fundadores da 
empresa e com um dos atuais sócios (dirigente A), diretamente envolvido na gestão e um dos responsáveis pela criação das estratégias.

\subsubsection{Histórico}

A empresa A foi criada, em 1985, por seis sócios - professores universitários do Instituto de Física da Universidade de São Paulo e do Departamento de Materiais da Universidade Federal de São Carlos - em parceria com engenheiros recém-formados e técnicos especializados, a partir de conhecimentos gerados em um grupo de pesquisas e do estímulo de uma grande empresa que tinha o intuito de desenvolver um novo fornecedor. Suas operações ganharam maior intensidade em 1987, uma vez que os anos anteriores foram dedicados a outras atividades, como implantação das operações, aquisição de equipamentos e construção do prédio. Observe-se que foi uma das primeiras empresas incubadas de São Carlos, sendo a sua fundação coincidente com a do Parqtec, que data de 1985.

A motivação para criar a empresa foi o sucesso da experiência feita em outra EBT, por um dos seus fundadores, que decidiu utilizar o mesmo modelo, buscando repetir o êxito alcançado. Estabeleceu-se, então, que o objetivo inicial da empresa seria a produção de cerâmicas avançadas, especificamente sensores de siderurgia, resultado de uma pesquisa desenvolvida pelos sócios do negócio. "A idéia inicial era ampla. Iniciou com um sensor, mas pretendíamos trabalhar com cerâmicas avançadas, em especial, as cerâmicas eletrônicas. $O$ sensor de siderurgia era o brinco de ouro do projeto" - comentou o professor 2.

A empresa A "não possuía um produto comercialmente viável”, como relatou o professor 1. Porém, dela faziam parte indivíduos que tinham conhecimento de tecnologia e a intenção de tornar esse conhecimento um empreendimento de sucesso. Dessa maneira, passou por uma fase experimental, em que surgiu a decisão favorável à sua abertura, devido à descoberta de um produto de alto teor tecnológico, do qual se tinha o domínio na Universidade. Seus sócio-fundadores, sendo pesquisadores de renome na área de cerâmica eletrônica, detinham o conhecimento necessário para se desenvolver o produto, fato que, aliado ao mercado de sensores em expansão, motivou a abertura da empresa.

A empresa parceira que demandou o produto inicial, sensores de oxigênio, não concordou em cooperar com os investimentos necessários à fase de desenvolvimento do produto. Assim, o projeto fracassou e "a gente teve que procurar novas oportunidades" relatou o professor 2. A partir desse evento foram criadas outras linhas de produtos, como peças para siderurgia, bicos de fundição, guias-fio, bocais de soldagem, isoladores, peças 
especiais e pó destinado a polimento ótico, que é atualmente um dos principais produtos da empresa.

Para que fosse possível fazer o investimento e financiar a empresa A, os fundadores optaram pela entrada de um sócio-investidor no negócio que ocorreu em 1987. Devido à desistência da parceria e às condições econômicas da época (sucessivos planos econômicos, alta taxa de inflação e recessão econômica), a empresa passava por dificuldades financeiras. "Precisávamos honrar os compromissos, mas com a inflação da época se perdeu o controle", justificando as crises enfrentadas pela organização, comentou o professor 2. Entretanto, acrescentou que, apesar das questões econômicas do momento (uma das conseqüências do plano Collor foi o enxugamento das atividades, como a redução do quadro de funcionários, de 58 a 20, em questão de dias), houve, em todo o processo, responsabilidade dos dirigentes, que não tinham experiência administrativa.

O sócio-investidor alocou um funcionário para auxiliar na gestão da empresa, especificamente na área financeira. Desentendimentos entre os dirigentes começaram a surgir. Tentando saldar as dívidas, os fundadores venderam a participação que possuíam em outras empresas de tecnologia de São Carlos. Mesmo assim, por ter a empresa A contraído muitas dívidas, a investidora assumiu o seu controle.

"Tinha que desenvolver tecnologia, business e ter dinheiro em caixa", ressaltou o professor 2 ao exaltar que, em toda a fase anterior à criação da empresa e na etapa inicial de sua existência, houve muita emoção e, sobretudo, dedicação e esforço diário para viabilizar o negócio e o sonho dos empreendedores. "Foi uma aventura", finalizou.

Em 1992 dois ex-funcionários da investidora assumiram o controle gerencial e acionário, da Empresa A, com participação igualitária: um formado em Engenharia Mecânica, com pós-graduação em Administração, e outro formado em Direito. Os sócios atuais, que não haviam atuado na criação do negócio, com o objetivo de equacionar a situação financeira da empresa, providenciaram a reprogramação dos débitos em atraso e a resolução das pendências jurídicas. Esse período de consolidação do negócio se estendeu até meados de 1996, quando a empresa, buscando crescer, guiou-se pela análise de novos mercados, clientes e produtos, adquiriu novos equipamentos e retomou parceria com a universidade, o Instituto de Pesquisas Tecnológicas (IPT) e o Serviço Nacional de Aprendizagem Industrial de Santa Catarina/SC (SENAI-SC). Para o mercado de polidores foi firmada uma parceria com a empresa inglesa Optical Surface, do grupo London Scandinavian Metalurgy.

A partir de 1997 a empresa entrou em uma nova fase, que o dirigente A denominou "refinamento do conhecimento técnico", baseada em uma perspectiva de eficiência 
operacional com a redução de custos, otimização de processos e redefinição de atividades. Nos últimos anos, os dirigentes passaram a enfatizar o desenvolvimento de mercado, com ações voltadas à expansão das atividades, conquista de novos cliente e identificação de outros mercados de atuação.

\subsubsection{Dados gerais: estrutura, produto e mercado}

A empresa A está instalada em uma área de $2.000 \mathrm{~m}^{2}$ e possui hoje 70 funcionários, assim alocados: 07, no departamento de vendas; 03, no administrativo e financeiro e 60, no de produção. A área de $\mathrm{P} \& \mathrm{D}$ aloca 03 funcionários da área de produção, que atuam também na Gestão da Qualidade, e recebe um investimento que representa cerca de $2 \%$ do faturamento da empresa.na qual as ações se voltam ao desenvolvimento de processos produtivos mais eficientes. Constata-se que a área de P\&D está voltada apenas ao desenvolvimento de processos produtivos mais eficientes.

Quanto à sua estrutura, é considerada simples e "enxuta", pois comporta 03 níveis hierárquicos e as seguintes áreas funcionais: de produção, vendas, administração geral e financeira. A organização do trabalho classifica-se como manual, levando-se em conta que o operário utiliza ferramentas na fabricação do produto. Com referência à área de vendas, consta que a empresa possui grupos de vendedores formados segundo a especialização do tipo de produto e segmento dos clientes.

Ao se analisar o faturamento da empresa, constatou-se que, nos últimos 10 anos, aumentou 06 vezes - o equivalente a uma média de $15 \%$ ao ano, aproximadamente. Entretanto, em alguns anos, apresentou-se reduzido por situações específicas de alguns setores. A propósito, a empresa fornece seus componentes aos setores: agrícola, químico, automobilístico e de embalagens, entre outros. A diversidade dos setores que compõem a sua carteira de clientes é vista como algo positivo pelo dirigente A, pois "a empresa não sente tanto as dificuldades e crises de setores específicos, mas por outro lado precisa conhecer as particularidades e necessidades de cada um".

Os produtos da empresa A são feitos sob encomenda, de acordo com a especificação apresentada pelos clientes (dimensão, material, resistência etc). Apenas um é produzido em série, uma cerâmica em pó, usada para polimento ótico. Este produto atende a toda a indústria de espelhos. 
A empresa fornece seus produtos a dois tipos de mercado: indústrias que agregam os componentes cerâmicos em seus produtos e empresas que fazem a reposição dos componentes cerâmicos para o usuário final. O primeiro é formado por clientes de maior porte, que representam cerca de $40 \%$ do faturamento da empresa. O segundo é um mercado diversificado, que registra $60 \%$ do faturamento da empresa e cerca de 500 clientes na carteira. Atualmente os produtos encontram-se divididos em duas linhas: os polidores oftálmicos, de vidros planos, espelhação e modelagem e as peças cerâmicas, como tubos, anéis e polias, peças de laboratórios, placas, guias-fio, pistões e buchas, camisas, bocais e insertos e peças especiais.

É importante destacar que a Empresa A, em época recente, registrou perda de clientes e, portanto, menor participação de mercado em determinados segmentos, devido à importação mais intensa de produtos chineses. Verificou-se que o mercado de cerâmica técnica, no qual os produtos são fabricados sem muita exigência dimensional, foi absorvido quase que totalmente pelos chineses, porque suas indústrias competem com base em preços. O dirigente A, para esclarecer o que vinha ocorrendo, ofereceu um exemplo: um dos produtos da área teve seu preço, no mercado, reduzido em cerca de $900 \%$, passando de US\$7,00 a US\$ 0,70, nos últimos dez anos. O mesmo dirigente ressaltou que as indústrias chinesas trabalham com outro processo de fabricação, outra matéria-prima, condicionantes ambientais diferentes etc, que, entretanto, atendem à funcionalidade do produto e a uma boa relação custo/benefício.

A Empresa A compete, no mercado de cerâmicas, com a estratégia de diferenciação e nicho com diferenciação. "O modelo competitivo é focado em especialização e não em preços baixos, mesmo em mercados mais amplos" destacou o dirigente A. Os produtos da empresa apresentam, em geral, preços superiores aos dos concorrentes e o seu diferencial, para competir no mercado, é o atendimento à necessidade do cliente. "Estamos sempre atentos aos problemas dos clientes e procuramos a todo o momento identificar as soluções adequadas" afirmou o dirigente $\mathrm{A}$.

Por causa da barreira à entrada de novos concorrentes - barreira tecnológica - existem apenas duas empresas que competem na área de componentes de alta precisão: a empresa A e uma multinacional de grande porte. A concorrente possui um sistema automático que produz altos volumes, em série, de um produto padronizado. A Empresa A, por ter uma produção manual, atende a um mercado com baixa escala produtiva, mas com necessidade de especificações técnicas diferenciadas. "Somos especializados em atender estas necessidades" - observou o dirigente $\mathrm{A}$ - justificando por que a empresa não conseguia competir em altos volumes e margens menores. 
Outros concorrentes identificados são as empresas que importam produtos cerâmicos dos Estados Unidos e da China e os revendem no mercado interno. Porém, tais empresas atendem à necessidade de indústrias que buscam um produto padronizado e em alto volume. Assim, o diferencial competitivo voltado ao atendimento de necessidades específicas mantém a empresa A competitiva.

A empresa importa grande parte da matéria-prima de fornecedores instalados na Alemanha e França, em Israel, nos Estados Unidos e no Japão. Devido aos procedimentos de importação e à necessidade de negociar preços com volumes maiores, a compra da matériaprima é realizada uma vez por ano. O dirigente A argumentou que, para minimizar o impacto da flutuação cambial ao longo do ano, tinha estabelecido algumas ações para aumentar o volume de exportação de seus produtos. Atualmente a empresa exporta cerca de $5 \%$ de sua produção. Justificou ainda que, na composição de preços de seus produtos, a matéria-prima não tem grande representatividade, destacando-se a mão-de-obra com maior impacto nos custos.

\subsubsection{Empresa B}

Os dados utilizados na descrição da empresa foram obtidos em entrevistas realizadas com a Gerente Geral (dirigente B) e principal responsável pela criação de estratégias com o Gerente da Qualidade (dirigente B1).

\subsubsection{Histórico}

A empresa B foi fundada, em 1976, por um técnico da Universidade de São Carlos (UFSCar), especialista em mecânica, que prestou assistência a um dentista local que demandava pela manutenção de um equipamento odontológico, denominado articulador. Satisfeito com a qualidade do serviço, o dentista sugeriu ao técnico que produzisse os equipamentos e este, logo a seguir, fabricou algumas unidades. Um professor universitário da Universidade Estadual Paulista (UNESP), campus de Araraquara, comprovou a qualidade do aparelho e vislumbrou a possibilidade de utilizá-lo em substituição aos articuladores que até então eram importados. Professores da USP, campus de Bauru, também se interessaram pela tecnologia do produto nacional. Assim, com uma demanda inicial garantida pela UNESP, 
campus de Araraquara e pela USP, campus de Bauru, o técnico passou a produzir os equipamentos, de maneira artesanal, em sua residência. Em 1977, formalizou a abertura da empresa B.

A empresa é de propriedade de um casal - o técnico em mecânica e sua esposa - e cada um detém $50 \%$ do capital. No cotidiano da empresa, o técnico foi o responsável principal por sua gestão até meados da década de 90, como explicitado a seguir, sendo considerado, por este trabalho, como dirigente.

A princípio realizava as atividades de compra, venda e produção dos equipamentos em sua casa. Contratou dois funcionários para auxiliá-lo na produção e financiou o seu primeiro torno. Como diz a dirigente B, "ele tocou a fábrica praticamente sozinho por vários anos", referindo-se à concentração das atividades em sua pessoa. Aos poucos contratou novos funcionários, sendo a maioria alocada em atividades operacionais, especificamente na produção dos equipamentos.

Em seus primeiros anos, a empresa fabricou um único produto. Com o aumento da demanda e do faturamento, o dirigente vislumbrou a oportunidade de investir no desenvolvimento de novos produtos, ao longo dos anos, todos voltados à área odontológica.

Com uma linha de produtos consolidada, estabeleceu parcerias com empresas estrangeiras, inicialmente com uma importadora mexicana. Depois, associando-se a uma distribuidora de equipamentos odontológicos, começou a exportar parte de sua produção a alguns países da América Latina e dos Estados Unidos. No Brasil, encontrando problemas para atender a seus clientes diretamente, passou a vender seus produtos aos distribuidores instalados em todo o país. A empresa, líder de mercado em alguns de seus produtos, exporta para cerca de 20 países e tem o Brasil e a América Latina como seus principais mercados.

Devido a dificuldades econômicas enfrentadas no final da década de 80 e início da década de 90, a empresa precisou diminuir a sua produção. Aos poucos, porém, retomou a expansão de suas atividades, com o lançamento de outros produtos. Em 1992, inaugurou sua nova instalação: um prédio próprio e com maior estrutura física para as instalações industriais.

A empresa, até então em constante crescimento, passou a apresentar dificuldades em atender à demanda de seus produtos. Com ações voltadas à melhoria da produção, o dirigente adquiriu um torno $\mathrm{CNC}$, para automatizar alguns processos produtivos, tornando-os mais eficientes, e contratou um engenheiro para auxiliá-lo na gestão.

Após alguns anos, iniciou-se uma fase de reestruturação da empresa, quando os filhos do dirigente passaram a atuar em sua gestão. Uma de suas filhas, formada em engenharia, promoveu novas ações: reorganizou a produção, implantou programas de qualidade, expandiu 
a exportação e informatizou diversos processos, entre outras. Seu filho, dentista, assumiu as atividades comerciais e sua outra filha, advogada e assistente social, responsabilizou-se pela área financeira. A família compunha a direção da empresa e as decisões estratégicas eram definidas em grupo.

Com o auxílio de um consultor de empresas, a empresa B definiu uma nova estrutura organizacional e a criação de um conselho administrativo, composto pelos membros da família. A filha, engenheira, assumiu a gerência geral e está efetivando o processo de sucessão iniciado com seu ingresso na empresa, em 1994.

Com a nova estrutura administrativa, as atividades de gestão ficaram pulverizadas. A empresa estabeleceu ações pró-ativas para a entrada de seus produtos em novos mercados, passando em poucos anos a exportá-los para quase 40 países.

Com tecnologia própria desde o primeiro lançamento, cada vez mais os produtos passaram a se diferenciar pela inovação e qualidade, características que se intensificaram a partir da década de 90, devido à fabricação pautada em tecnologia de ponta. Esse desenvolvimento tecnológico mais forte iniciou-se com parcerias firmadas com outras empresas da área, porém é suportado pela criação de um departamento de $\mathrm{P} \& \mathrm{D}$, denominado "projetos". Atualmente a empresa realiza, de maneira experimental, algumas ações relacionadas ao desenvolvimento de novos mercados, iniciado com o lançamento de produtos no setor de estética.

\subsubsection{Dados gerais: estrutura, produto e mercado}

A empresa B atua no ramo de biotecnologia, produzindo equipamentos odontológicos. Está instalada em uma área de aproximadamente $1.500 \mathrm{~m}^{2}$. Hoje tem 47 funcionários, 15 alocados em atividades administrativas e 32, em atividades de produção. Não possui um departamento de $\mathrm{P} \& \mathrm{D}$ propriamente dito, mas um departamento de produtos e projetos, que recebe investimento de $1 \%$ do faturamento, dispõe de 03 funcionários, dedicados integralmente a atividades de desenvolvimento de novos produtos ou de melhoria dos atuais, que são apoiadas pela parceria estabelecida com a Fundação de Apoio Institucional ao Desenvolvimento Científico e Tecnológico (FAI) da UFSCar.

Pequena empresa, de acordo com o número de funcionários, e média empresa pelo seu faturamento anual, apresenta 03 níveis hierárquicos e encontra-se estruturada funcionalmente nas seguintes áreas: administração geral, marketing, finanças, industrial e de qualidade. 
Quanto à organização do trabalho, é semi-automática, levando-se em conta os processos manuais empregados no desenvolvimento de alguns componentes, como o uso de ferramentas pelo operário. Em outros produtos, utilizam-se processos automáticos, como os tornos CNC. A eficiência do processo produtivo é da ordem de $65 \%$.

O faturamento da empresa cresce $15 \%$ ao ano, aproximadamente. As flutuações decorrem de questões econômicas, como a recessão das décadas de 80/90 e o aumento na taxa de câmbio em alguns períodos, que fizeram diminuir a competitividade no mercado externo e prejudicaram as exportações. A empresa fornece seus produtos ao mercado odontológico e recentemente ingressou no mercado de estética.

Os produtos da empresa B são feitos em série, de acordo com a demanda. A sazonalidade existente deve-se ao ano letivo das universidades que oferecem cursos de odontologia, pois o seu principal produto consta na lista de material a ser adquirida pelos estudantes no início de cada semestre. A empresa fabrica diversos modelos de articuladores, jatos abrasivos, fresadores/delineadores, plastificadores, géis e aparelhos para clareamento dental, fotopolimerizadores e lasers. O principal produto da empresa é o articulador, responsável por $51 \%$ do seu faturamento.

A empresa B compete com a estratégia de diferenciação de seus produtos pela qualidade e recursos extras, porém apresenta preço competitivo, principalmente em seu produto principal - o articulador. "Procuramos atender nossos clientes com agilidade e, principalmente, oferecemos um produto superior em termos de qualidade, mas o preço é uma variável importante" - explicou o dirigente B1. "O mercado odontológico, em certo ponto, está saturado, apesar de haver alguns nichos a explorar. É um mercado muito competitivo. Percebo que a indústria odontológica está prostituída, com uma competição baseada em preço" - disse a dirigente B, ao justificar a estratégia da empresa e a decisão de investir em um novo mercado.

Os concorrentes são de pequeno e médio porte e apresentam características semelhantes às da empresa, em termos de tecnologia e estrutura. Concentram-se no estado de São Paulo, principalmente no interior, estando alguns situados na cidade de São Carlos/SP. A China representa uma ameaça aos produtos da empresa, pois oferece um produto com preço competitivo e qualidade. Com o ingresso em outro mercado, a diversificação passa a ser uma tendência para a empresa $\mathrm{B}$, pois " a concorrência em alguns produtos odontológicos aumentaram excessivamente nos últimos anos, como no caso da lavadora ultrassônica que passou a concorrer com produtos chineses" - observou o gerente da qualidade. 
Os clientes diretos da empresa são os distribuidores, denominados dentais. A carteira de clientes é diversificada e conta com centenas de distribuidores, nacionais e estrangeiros, apesar da homogeneidade do mercado. Embora a empresa atenda a mais de 40 países, o Brasil e a América Latina são o seu principal mercado. Sua atuação, nos demais, é pulverizada e registra-se em pequenas quantidades. Atender a um único mercado fez a empresa se especializar e conhecer as necessidades de seu mercado-alvo.

Os fornecedores da empresa B, cuja maioria é constituída por produtores de peças de alumínio e plástico injetado, estão localizados no interior do estado de São Paulo, principalmente em Campinas e Limeira. Alguns são empresas estrangeiras que fornecem componentes específicos. O porte e a estrutura destas empresas são semelhantes. Como ressaltou o gerente da qualidade, "os fornecedores estão voltados ao porte da empresa (B), pois empresas maiores fazem exigências de quantidade e não atendem a necessidade da empresa".

\subsubsection{Empresa C}

Os dados utilizados na descrição da empresa foram obtidos em entrevistas realizadas com o professor universitário e ex-sócio da empresa (professor 1), com o sócio e atual Diretor Industrial (dirigente C), diretamente envolvido na gestão e um dos responsáveis pela criação das estratégias e complementados com observações realizadas pelo professor 4 .

\subsubsection{Histórico}

A Empresa C foi criada, em 1985, por dois professores universitários, dois técnicos especializados em ótica e filmes finos e dois mestrandos, todos ligados a pesquisas desenvolvidas na Oficina de Ótica do Instituto de Física da Universidade de São Paulo.

Em 1981, um dos sócio-fundadores retornou do seu pós-doutoramento, feito no Massachusetts Institute of Technology (MIT), na área de ótica e laser, tecnologia emergente na época. Por volta de 1982, em conjunto com outro sócio-fundador, professor universitário e diretor do Instituto de Física e Química, implantou a oficina de ótica, com o intuito oferecer, aos professores universitários, oportunidades para realizar suas pesquisas acadêmicas. A 
criação da oficina foi fundamental para que a área de ótica do Instituto se desenvolvesse, assim possibilitando o surgimento de mais de 20 empresas, entre as quais a empresa $\mathrm{C}$.

Os professores pretendiam fabricar os componentes a serem usados na oficina, porque sua importação era difícil e a disponibilidade do produto se fazia necessária. "A intenção era montar uma oficina de ótica para fazer os componentes ao invés de importá-los para montar o laboratório de ótica" - comentou o professor 1. Para a criação da oficina, por meio do Fundo de Incentivo à Pesquisa Técnico-Científica (FITEC), obtiveram do Banco do Brasil um financiamento que foi utilizado para desenvolver a tecnologia utilizada na fabricação de laser.

Em 1985, com a demanda por componentes óticos e o desenvolvimento de novas tecnologias pelas indústrias nacionais, vislumbrou-se a oportunidade de se criar uma empresa para fabricar os referidos componentes. Uma das motivações iniciais foi a atitude tomada por alguns empresários, que procuraram a oficina para a resolução de problemas de suas organizações, uma das quais era de equipamentos odontológicos e outra pretendia fabricar aparelhos para medir o teor de açúcar na cana (refratômetro). Com referência à última, a partir de serviços de consultoria prestados pelos professores para o desenvolvimento de um módulo ótico para o refratômetro, adquiriu-se um terreno para a sua instalação.

A empresa C foi a primeira organização incubada de São Carlos, com o apoio da Fundação Parque de Alta Tecnologia, também criada em 1985. No começo de suas operações, esse apoio foi limitado, mas fundamental, pois o desenvolvimento e o reconhecimento da incubadora, no meio empresarial, auxiliaram na conquista de clientes. A partir do conhecimento obtido na consultoria para desenvolver o refratômetro, os professores deram início à produção artesanal de um prisma e às atividades que possibilitaram a compra dos primeiros equipamentos. Contaram com a ajuda da Financiadora de Estudos e Projetos (FINEP),

O primeiro produto da empresa foi o laser de Hélio-Neônio (HeNe), utilizado na produção de leitores óticos, uma de suas aplicações. Porém, os fundadores, embora detivessem a tecnologia, não tinham uma clara visão do mercado - não haviam desenvolvido uma pesquisa de mercado para identificar os possíveis usos e os potenciais clientes. A única avaliação existente - a percepção de que o mercado nacional deveria corresponder a $10 \%$ do americano - baseava-se na experiência dos professores, adquirida na fase de pós-doutorado. Os sócios se espelharam nos produtos e na tecnologia americanos, mas o mercado brasileiro não estava apto a absorver esses produtos. Como disse o dirigente C: "Tínhamos uma solução à procura de um problema". 
Para dar continuidade à montagem do parque industrial, foi necessário comprar equipamentos de alto valor, como uma evaporadora adquirida com recursos financiados pela FINEP. Assim, após as ações voltadas à instalação da empresa, os sócios passaram a lidar com os problemas mercadológicos enfrentados pela organização, pois não tinha havido a absorção esperada da tecnologia do laser Hélio-Neônio, devido a limitações de sua aplicação na indústria brasileira. Paralelamente, a empresa começou a produzir e comercializar filtros usados em equipamentos polimerizadores de resinas e filtros de absorção térmica, utilizados em refletores.

A dificuldade na conquista de clientes e as altas despesas levaram a empresa $\mathrm{C}$ a uma crise financeira que quase determinou a sua falência. Nesse período, um dos sóciosfundadores entrou em contato com o dirigente de um grupo que tinha interesse em investir em empresas de tecnologia e ele se tornou sócio-investidor da empresa C em 1987. A primeira ação do novo sócio foi transformá-la em sociedade anônima. Sua incorporação foi primordial para a sobrevivência da empresa, pois, além do investimento que realizou, utilizado para sanar as principais dívidas, fez uma série de modificações na gestão da empresa e designou um funcionário para atuar na área financeira.

Visando identificar aplicações para a tecnologia que a empresa detinha, foi contratado um engenheiro (um dos seus atuais sócios) e criada a área de P\&D. A empresa desenvolveu novos produtos, como, por exemplo, uma linha de equipamentos de medição à base de laser de diodo.

Promoveram-se ações de reestruturação, como a associação feita com o Departamento de Engenharia de Produção da UFSCar e a criação de um departamento comercial na cidade de São Paulo. "As vendas estavam ruins e a produção era ineficiente. Houve então uma reestruturação no departamento de vendas e produção" - assinalou o professor 1, que na época vendeu a sua parte acionária na empresa C. A decisão de situar o departamento comercial em São Paulo deveu-se à proximidade com o mercado consumidor da capital paulista.

Assim, com ações voltadas ao mercado e uma série de produtos em linha, a empresa passou a investir em outros segmentos, como, por exemplo, na área médica, especialmente na de oftalmologia. A princípio, mediante representação de uma empresa americana para prestar assistência técnica no Brasil, a empresa $\mathrm{C}$, mantendo estreito relacionamento com os médicos, desenvolveu conhecimento específico na área. Com a identificação do potencial do mercado e a falência da empresa americana, começou a fabricar, com tecnologia própria, seu 
equipamento, que hoje é um produto de grande representatividade no faturamento da organização.

A empresa C desenvolveu outras linhas de produtos, como componentes óticos (prismas) para sistemas de emissão de imagens e sensores a laser para sistemas de defesa militar. Por volta de 1995, começou a exportar seus produtos e em pouco tempo tornou-se líder em vendas em alguns segmentos, como no dos refletores oontológicos. Desde o desenvolvimento da tecnologia, seu aprimoramento, a produção dos componentes e equipamentos e sua comercialização perfazem um período de aproximadamente 10 anos.

Logo a seguir, tornou-se a primeira empresa nacional a oferecer serviços de tratamento anti-reflexo, utilizado em lentes de óculos, tecnologia dominada para produzir filmes finos, usados na produção de tubos de laser (produto inicial da empresa), e filtros para refletores odontológicos.

Novas tecnologias e mercados foram desenvolvidos, como a utilizada nos equipamentos empregados em tratamentos médico-oftálmicos, não apenas para diagnóstico como até então: a aplicação do laser verde em foto-coagulação da retina e um equipamento para tratar a degeneração macular, são exemplos da expansão das atividades em seu mercadoalvo.

Outro projeto relevante e estratégico da empresa $\mathrm{C}$ foi a fabricação de câmeras multiespectrais, utilizadas em satélites desenvolvidos mediante parceria Brasil-China, para monitoramento, por meio de imagens, dos recursos naturais da superfície terrestre.

Em 2005 os sócios da empresa C não só recompraram as ações do sócio-investidor como também se tornaram acionistas de uma empresa australiana que passou a representar seus produtos oftalmológicos em praticamente todo o mundo, exceto nos Estados Unidos, atendidos pela unidade situada em Miami, e na América Latina, atendida diretamente pelo escritório comercial da empresa.

\subsubsection{Dados gerais: estrutura, produto e mercado}

A empresa C está instalada em uma área de $7.200 \mathrm{~m}^{2}$ de uma planta de aproximadamente $8.000 \mathrm{~m}^{2}$. A propósito, além desta unidade em São Carlos, conta com unidades produtivas no Nordeste, em Porto Alegre e em São Paulo, onde também possui um escritório comercial. Mantém uma unidade de representação em Miami, EUA. As unidades 
produtivas do Nordeste, Porto Alegre e São Paulo oferecem apenas o tratamento anti-reflexo, enquanto a de São Carlos possui toda a linha de produto da empresa.

Hoje a empresa está estruturada em seis áreas de atuação cujos principais produtos e respectivas percentagens de faturamento são: 1) na área médico-oftalmológica, representando cerca de $60 \%$ do faturamento: auto-refrator e ceratômetro, biômetro, sistema para avaliação da acuidade visual, campímetro, lâmpada de fenda, lasers, microscópios, tomógrafo e lentes; 2) na área de odontologia, representando $6 \%$ do faturamento, microscópio cirúrgico e refletores; 3 ) nos serviços de anti-reflexo, com tratamentos anti-reflexo e anti-risco para lentes de óculos, representando cerca de $15 \%$ do faturamento; 4) na divisão industrial, responsável por $6 \%$ do faturamento, equipamentos e projetos para medição a laser, como os medidores de distância, de espessura, de circunferência, centralizadores, multiposicionadores de diodo e o sistema para alinhamento de direção, entre outros; 5) na área de componentes óticos, que representam 3\% do faturamento, refletores odontológicos, filtros, espelhos, prismas e lentes; 6) no setor aeroespacial, representando cerca de $10 \%$ do faturamento, vários projetos, como a câmera multiespectral (mux) para o satélite sino-brasileiro CBERS e componentes militares.

A empresa, classificada como de médio porte, tem cerca de 350 funcionários alocados nos seguintes departamentos: de contabilidade, finanças, exportação e importação, vendas/marketing, engenharia de produto e processo, gestão e certificações, pesquisa e desenvolvimento e produção. O departamento de P\&D é estruturado, desenvolve tecnologia própria, aplicada nos produtos e serviços que a empresa desenvolve, e possui 48 funcionários, dos quais $75 \%$ realizam atividades relacionadas com a produção. A empresa investe cerca de $8 \%$ do seu faturamento anual em P\&D.

A estrutura da empresa é divisional e apresenta quatro (04) níveis hierárquicos: direção, gerência, coordenação e operação. A organização do trabalho é semi-automática, porém, como um dos sócios deixou claro, dependendo do processo produtivo, é extremamente manual - como na montagem eletrônica de alguns componentes óticos, fabricados a partir da especificação do cliente - ou automática, como na produção de peças óticas e mecânicas em tornos CNC.

Com os recursos técnicos e humanos disponíveis, a empresa pretende cumprir a seguinte missão: gerar riqueza, fabricando e comercializando produtos e serviços de tecnologia de ponta. A visão da empresa volta-se à conquista de liderança e reconhecimento nos mercados em que atua. Em sua gestão destacam-se valores como o conhecimento, a confiança, o profissionalismo, a agilidade, a flexibilidade e a qualidade. 
A empresa $\mathrm{C}$ apresenta, em sua linha de fabricação, produtos fabricados em série e alguns desenvolvidos de acordo com especificações do cliente. Na área de P\&D, considerada um setor de negócios, não apenas se projetam novos produtos para uso próprio e/ou para terceiros, com o intuito de introduzir diferentes tecnologias e aplicações na área de atuação e em mercados potenciais, mas também se fazem adaptações que atendam de forma adequada às necessidades dos clientes, em particular os que utilizam os produtos industriais a laser.

A empresa $\mathrm{C}$ comporta segmentos e portes diversos, desde profissionais liberais, distribuidoras, laboratórios, clínicas médicas, oficinas e órgãos governamentais até indústrias de pequeno, médio e grande porte. Se, por um lado, esta diversificação configura uma variável positiva, pois crises específicas de determinados segmentos não refletem intensamente no faturamento da empresa, por outro, exige que se conheçam mais as especificidades tecnológicas e de mercado de cada um dos setores.

Um dos mercados de atuação da empresa é o de refletores médico-odontológicos. Representativo no passado, este mercado vem sofrendo concorrência direta dos produtos da indústria chinesa, que compete com a estratégia de custo. Comentou o dirigente C: "A China tomou o nosso mercado. Eles apresentam qualidade aceitável pela maioria dos fabricantes de equipamentos odontológicos. O custo do refletor chinês no mercado brasileiro é $30 \%$ menor que o nosso custo de produção". Como a empresa $\mathrm{C}$ atende a clientes que buscam refletores de maior qualidade e durabilidade, "O mercado ficou restrito" - concluiu o dirigente C.

Um outro mercado a que a empresa atende é o de anti-reflexo, reconhecido como de grande potencial. Utiliza-se o mesmo equipamento para produzir o refletor e o anti-reflexo. Estima-se que, atualmente, menos de $30 \%$ das lentes de óculos recebe algum tipo de tratamento anti-reflexo. A empresa $\mathrm{C}$ é a única indústria brasileira a oferecer este serviço, sendo sua principal concorrente uma grande organização de capital francês, que também atua no Brasil, realizando ações mercadológicas intensas com óticas e laboratórios. Assim sendo, a empresa C emprega a estratégia de diferenciação, que implica agilidade, qualidade e atendimento especializado. Recentemente, definiu sua vocação para desenvolver produtos aplicáveis à área médica, em diagnóstico e tratamento, sendo este o atual foco das ações estratégicas. Tais produtos estão voltados, em sua grande maioria, à oftalmologia, como os equipamentos para tratar a retina e a córnea. Também fornece microscópios à otorrinolaringologia.

Os concorrentes, na área de equipamentos médicos, foco da empresa, são as indústrias alemãs, japonesas e americanas, cujos produtos são de alta qualidade. "A imagem do Brasil é muito positiva no mercado, mas ainda é difícil vender tecnologia brasileira" - disse o 
dirigente $\mathrm{C}$, referindo-se às barreiras de entrada em certos mercados. Também a indústria chinesa é vista como uma ameaça para a linha de equipamentos médicos. A empresa C "tem qualidade e custo, mas se a China entrar no mercado... Por enquanto eles competem em mercados de alto volume, mas e ofuturo?" - comentou o dirigente C.

A empresa $\mathrm{C}$ exporta cerca de $40 \%$ de sua produção e, devido à qualidade e ao preço competitivo de seus produtos, é líder mundial de vendas em alguns segmentos.

\subsection{ANÁLISE DOS DADOS}

\subsubsection{Empresa A}

\subsubsection{Processo de criação de estratégias}

O processo de criação de estratégias da empresa A apresenta características emergentes e deliberadas, em diferentes escalas, de acordo com as diversas fases pelas quais passou desde que foi criada até os dias de hoje.

$\mathrm{Na}$ fase 1, as decisões voltavam-se à consolidação dos objetivos do grupo de pesquisadores, que se reuniam diariamente (inclusive nos finais de semana) para discutir a criação da empresa. Apesar do objetivo geral que se pretendia alcançar - a criação da empresa - as ações também se estendiam ao desenvolvimento da tecnologia do produto. Não se fazia, entretanto, um planejamento, a partir de análise de mercado ou de viabilidade financeira. Assim sendo, considera-se que o processo de criação de estratégias da empresa A, na época de sua fundação, se caracterizava como emergente - irregular, baseado na intuição e criatividade dos sócio-fundadores. Esta fase será denominada de criação da empresa. Nesta fase as ações focavam a criação da empresa a partir de um grupo de pesquisadores que detinha o conhecimento técnico adequado a tal propósito.

A fase 2 constituiu um momento experimental, no qual as decisões eram intuitivas e de curto prazo. Nos primeiros anos foram realizados investimentos para a construção da empresa (compra de lotes, construção do prédio e aquisição de equipamentos). "A empresa nasceu de uma idéia. Tinha produtos cerâmicos, mas não tinha cliente quando começou" relatou o dirigente A. Nesta fase, as decisões estratégicas relacionavam-se às instalações 
físicas e, posteriormente, ao processo produtivo, tipo de material, especificação do produto, sempre pautadas pela competência técnica dos sócios, desenvolvida na universidade. Não houve ações planejadas nesse período. A criação de estratégias configurava um processo emergente - flexível, informal, baseado no conhecimento dos dirigentes e em ações inesperadas, com objetivos gerais. Esta fase será denominada de concepção do negócio.

A fase 3 correspondeu a uma etapa de reestruturação da empresa, posterior a uma crise financeira. Nessa ocasião contou-se com um sócio-investidor, que designou um funcionário da área financeira para auxiliar na gestão da empresa. Com o objetivo de tornar o processo produtivo eficiente, foram contratados uma engenheira de produção e um diretor industrial. Paralelamente, para viabilizar o negócio, expandir as atividades e conquistar novos clientes, realizaram-se alguns financiamentos. Com a instabilidade do mercado, provocada pela recessão econômica e questão inflacionária, a empresa A passou a enfrentar dificuldades em saldar seus compromissos, inclusive com o sócio-investidor, tendo contraído dívidas. Também encontrou problemas para gerir a estratégia mercadológica de conquista de clientes, devido à falta de conhecimento administrativo. O déficit da empresa chegou a ser igual a 15 vezes o seu faturamento mensal. Surgiram então desentendimentos com o sócio-investidor cujos objetivos e expectativas eram diversos dos estabelecidos pelos fundadores. Nessa fase, que terminou com a transferência da empresa aos novos sócios, o processo de criação de estratégias delineava-se como emergente, mas apresentando algumas características deliberadas. Era flexível e informal, baseava-se em ações inesperadas e definidas pela alta administração, mas já iniciava a realização de análises fundamentadas em informações, ou seja, mostrava-se mais racional que intuitivo. Esta fase será denominada de viabilização do negócio.

A fase 4 foi um período de ajuste para se conhecer o mercado, um período de 03 anos no qual a empresa sanou suas dívidas e identificou as potencialidades do mercado de atuação. Nessa etapa, os sócios estabeleceram ações para reduzir custos e despesas e melhorar o processo produtivo, mediante novas parcerias. Eliminaram ou ao menos minimizaram os "comportamentos incompatíveis com o porte e faturamento da empresa" - disse o dirigente A - referindo-se à situação encontrada quando assumiu a empresa. O ponto de equilíbrio foi atingido em 03 anos, com a redução dos custos operacionais e o aumento do faturamento. Entende-se que, nessa fase, o processo de criação de estratégias, que detinha muitas características emergentes, passava também a se definir como deliberado - os dirigentes faziam análises de viabilidade das novas ações de maneira racional, apoiando-se na informação, formulavam objetivos de forma clara e com maior nível de detalhe, estabeleciam 
as ações que deviam ser realizadas e as que precisavam de alteração, de acordo com acontecimentos cotidianos, decorrentes das decisões tomadas pelos dirigentes. Esta fase é a de refinamento técnico, denominação usada pelo próprio dirigente A.

A fase atual da empresa reflete a sua consolidação. Uma das estratégias utilizadas, nesta etapa, é a busca contínua de novos clientes. As oportunidades são identificadas pela equipe de vendas ou pelos próprios sócios, a partir da análise de mercado ou demanda de clientes. Realizam-se pesquisas para identificar novas aplicações, seja em produtos que têm componentes cerâmicos, seja em novos nichos de mercado. Para se proceder à análise de mercado, usam-se, como ferramentas para a coleta de informações: a internet, os sindicatos de empresas, as feiras de negócios, os fornecedores e os clientes. Feitas a identificação e a análise do mercado potencial, ações são estabelecidas para a conquista de novos clientes ou mercados. De acordo com o dirigente A, este processo requer um investimento de longo prazo, uma vez que os componentes cerâmicos têm uma durabilidade de 03 anos, aproximadamente, e a troca de fornecedores pelos clientes exige negociação e experiência. A estratégia adotada pela empresa para a conquista de clientes e mercados é o empenho diferenciado dos vendedores tanto na identificação de necessidades dos clientes quanto na proposição de soluções adequadas. O dirigente A considera que o atendimento, o prazo de entrega e a qualidade do produto são fatores que contribuem para que a empresa se destaque em relação aos concorrentes que, muitas vezes, não têm conhecimento ou tecnologia para gerar soluções adequadas. Além das ações voltadas à conquista de clientes, a empresa estabelece estratégias, que visam à identificação de novas aplicações de seus componentes a equipamentos e produtos dos clientes. O dirigente A elabora um planejamento estratégico de médio prazo, do qual derivam as metas de todos os funcionários da empresa. Trata-se de uma visão do futuro que permite definir as principais ações, pois o desenvolvimento dos equipamentos e do processo produtivo demanda 02 ou 03 anos, devido à especificidade do negócio. Segundo o dirigente A, alguns setores de atuação encontram-se saturados, com poucas oportunidades de crescer, motivo pelo qual a empresa visa identificar outros mercados de atuação com novos produtos e/ou novos segmentos. As estratégias são, em parte, geradas no dia-a-dia da empresa, ou seja, são emergentes, porém os dirigentes procuram alinhá-las às estratégias intencionadas. $O$ processo de criação de estratégias, embora implique características emergentes, é deliberado: mediante um processo formal de planejamento, a alta administração estabelece objetivos claros e ações que deverão obedecer a um cronograma específico. Este processo caracteriza-se como regular (anual), formal e realizado em etapas. Esta fase será denominada de desenvolvimento do negócio. 
O quadro 19 traz uma síntese destas fases e características.

\begin{tabular}{|l|l|l|l|}
\hline \multicolumn{1}{|c|}{ Fases } & \multicolumn{1}{|c|}{ Característica } & \multicolumn{1}{c|}{ Principais ações } & \multicolumn{1}{|c|}{ Foco } \\
\hline $\begin{array}{l}\text { Fase 1-Criação da } \\
\text { empresa }\end{array}$ & Emergente & $\begin{array}{l}\text { Decisão de fundar a empresa e } \\
\text { desenvolvimento da tecnologia } \\
\text { do produto }\end{array}$ & Produto \\
\hline $\begin{array}{l}\text { Fase 2 - Concepção do } \\
\text { negócio }\end{array}$ & Emergente & $\begin{array}{l}\text { Investimentos em instalações } \\
\text { físicas e operacionalização do } \\
\text { processo produtivo e produto }\end{array}$ & $\begin{array}{l}\text { Produto } \\
\text { Clientes }\end{array}$ \\
\hline $\begin{array}{l}\text { Fase 3 - Viabilização do } \\
\text { negócio }\end{array}$ & $\begin{array}{l}\text { Emergente e } \\
\text { Deliberada }\end{array}$ & $\begin{array}{l}\text { Estrutura organizacional, } \\
\text { eficiência do processo } \\
\text { produtivo e transferência da } \\
\text { empresa para os novos sócios }\end{array}$ & Processo \\
\hline $\begin{array}{l}\text { Fase 4 -Refinamento } \\
\text { técnico }\end{array}$ & $\begin{array}{l}\text { Deliberada e } \\
\text { emergente }\end{array}$ & $\begin{array}{l}\text { Redução de custos e despesas } \\
\text { e melhoria do processo } \\
\text { produtivo }\end{array}$ & Processo \\
\hline Fase 5 - Desenvolvimento & $\begin{array}{l}\text { Deliberada e } \\
\text { emergente }\end{array}$ & $\begin{array}{l}\text { Conquista de novos clientes e } \\
\text { identificação de novos } \\
\text { mercados de atuação }\end{array}$ & Clientes \\
\hline
\end{tabular}

Quadro 19 - Fases do processo de criação de estratégias da empresa A

\subsubsection{Especificidades de gestão}

- Especificidades contextuais

O contexto da empresa A configura um ambiente segmentado e heterogêneo, com baixo grau de mudanças: as mudanças são previsíveis e não acontecem em alta velocidade. Em determinados segmentos há sinais de escassez, o que motiva a empresa a identificar novos mercados de atuação.

Os fornecedores de matéria-prima são de grande porte e estão instalados em diversos países. A empresa procura desenvolver fornecedores estrangeiros periodicamente, por meio de participação em feiras internacionais. Em época recente, um dos fornecedores tornou-se um cliente da empresa e passou a revender os produtos cerâmicos em todo o mercado europeu. A interação empresa/fornecedor propicia o acesso à informação sobre tecnologia, clientes e mercados. "O mercado da cerâmica é muito específico e os canais são muito restritos" - comentou o dirigente A sobre a importância do relacionamento com o fornecedor. 
A área de atuação da empresa A é basicamente nacional, representando $95 \%$ de seu faturamento, porém a organização exporta para dezenas de países e pretende expandir esta atividade. Destaca-se como líder em alguns segmentos, como, por exemplo, no fornecimento de pó para polimento ótico a praticamente $100 \%$ das indústrias de espelhos. Possui dois grupos de clientes: empresas que utilizam os componentes que desenvolve em seus produtos e clientes que revendem os componentes aos usuários finais. $\mathrm{O}$ primeiro grupo é diversificado em relação a alguns de seus aspectos, como: porte, área de atuação, tipo de tecnologia, atendimento diferenciado e qualidade dos produtos. O segundo é mais homogêneo e requer qualidade, quantidade, prazo de entrega e preço competitivo. Devido a tais características, as crises em setores específicos dos clientes não repercutem com intensidade na empresa. A propósito, atualmente, as principais inovações nos produtos da empresa A originam-se de demandas de clientes.

A organização recorre à parceria com a Universidade e outras Instituições para desenvolver a tecnologia do processo produtivo. O desenvolvimento da tecnologia do produto não é um dos seus focos no presente. Novas tecnologias podem representar novas oportunidades e, ao mesmo tempo, significar um potencial produto substituto.

A variável econômica exerce grande influência na gestão da empresa, seja pela taxa cambial, que influi na exportação de produtos e na importação de matéria-prima, seja pelo seu impacto na expansão das atividades industriais de maneira geral. Registre-se, ainda, que o mercado corporativo é a principal área de atuação da empresa.

Os concorrentes da empresa A são organizações de grande porte, multinacionais, que oferecem um produto-padrão, obtido por meio de um processo automático de produção, ou empresas de pequeno porte, com estrutura e tecnologia semelhantes à da empresa A. Recentemente as indústrias chinesas passaram a competir com a empresa $\mathrm{A}$, com forte impacto sobre o seu faturamento e a sua participação em determinados setores de mercado.

Para iniciar as atividades produtivas da empresa A, os seus fundadores visitaram empresas de tecnologia semelhantes, em outros países, com o objetivo de verificar se seria possível desenvolver produtos com tecnologia semelhante no Brasil. Quanto a acessar fontes de financiamento, a empresa $\mathrm{A}$ fez uso do recurso por diversas vezes, não sendo este um fator que limita as suas atividades.

Pode-se afirmar que, entre as variáveis contextuais, as que exercem influência na definição do direcionamento da empresa, na criação de estratégias, são, em ordem de importância, os clientes, os concorrentes, a tecnologia e as condições econômicas. Nas diversas fases evolutivas da empresa, destacam-se as seguintes variáveis: tecnológica, nas 
fases de criação da empresa e concepção do negócio; econômica, na fase de viabilização do negócio; tecnológica na fase de refinamento técnico; a econômica, os clientes e os concorrentes, na fase de desenvolvimento (quadro 20). Como especificidades contextuais destacam-se a dificuldade em identificar ameaças advindas do desenvolvimento tecnológico, a necessidade de fontes de recursos externos para se realizar investimentos, o baixo poder de barganha em negociações com clientes e fornecedores, a vulnerabilidade em situações econômicas desfavoráveis e a possibilidade de se estabelecer parcerias devido à particularidade da tecnologia empregada.

\begin{tabular}{|l|l|}
\hline \multicolumn{1}{|c|}{ Fases } & \multicolumn{1}{c|}{ Especificidades } \\
\hline Criação da empresa & Tecnologia: domínio para aplicação em um produto \\
\hline Concepção do negócio & $\begin{array}{l}\text { Clientes: dificuldade de comercialização do produto de alta tecnologia } \\
\text { Tecnologia: desenvolvimento e produção de um produto de alta } \\
\text { tecnologia }\end{array}$ \\
\hline $\begin{array}{l}\text { Viabilização do } \\
\text { negócio }\end{array}$ & $\begin{array}{l}\text { Financiamentos: a necessidade de fontes de recursos externos para se } \\
\text { realizar investimentos } \\
\text { Economia: vulnerabilidade em situações econômicas desfavoráveis } \\
\text { Tecnologia: dificuldade em identificar aplicações comerciais da } \\
\text { tecnologia }\end{array}$ \\
\hline Refinamento técnico & $\begin{array}{l}\text { Tecnologia: possibilidade de se estabelecer parcerias com } \\
\text { Universidade/Centro de Pesquisas devido à particularidade da tecnologia } \\
\text { empregada }\end{array}$ \\
\hline Desenvolvimento & $\begin{array}{l}\text { Clientes: busca continua de novos clientes e novos mercados } \\
\text { Concorrentes: intensificação da concorrência em alguns segmentos } \\
\text { Economia: perda de competitividade em mercados externos devido à taxa } \\
\text { de câmbio }\end{array}$ \\
\hline
\end{tabular}

Quadro 20 - Especificidades contextuais de acordo com as fases evolutivas: empresa A

- Especificidades de organização

Em primeiro lugar são apresentadas as que se referem à gestão dos sócio-fundadores e, em segundo, as que dizem respeito à gestão dos atuais sócios.

Mediante entrevistas e observação, constatou-se que a organização da empresa A apresenta características mecanicistas: clara divisão do trabalho, decisões estratégicas tomadas na cúpula administrativa, com pouca participação de níveis inferiores, ênfase em procedimentos formais e tarefas pré-estabelecidas. Verificou-se, contudo, que a estrutura, o 
processo de tomada de decisões e as formas de comunicação se modificaram de acordo com as fases de evolução da empresa.

Inicialmente, a organização da empresa A configurava uma estrutura com as seguintes características: baixo nível de maturidade; não utilização ou uso reduzido de ferramentas administrativas; pouca ou nenhuma divisão do trabalho; administração não-profissional; cargos e atividades continuamente redefinidos, a partir da interação dos membros da empresa com os seus dirigentes; comunicação informal (não obedecia a procedimentos préestabelecidos); decisões centralizadas nos dirigentes, mas com participação ampla dos demais membros; flexibilidade; agilidade na realização de mudanças; grande proximidade entre os dirigentes e fornecedores, clientes e funcionários; grandes somas de recursos obtidos mediante financiamentos e investimentos.

A primeira mudança na organização da empresa deu-se com a entrada do sócioinvestidor, que designou um funcionário para auxiliar em sua gestão, especificamente na área financeira, para maior controle e formalização das ações. A seguir, os sócios contrataram um diretor industrial e uma engenheira de produção, visando a um processo produtivo mais eficiente e melhores resultados. Assim, passou-se a uma divisão mais clara do trabalho e à utilização de procedimentos formais, porém ainda se registrava pequena quantidade de funções administrativas. As decisões tornaram-se mais racionais, mas persistiam as características intuitivas e baseadas na experiência de trabalho dos atuais sócios em grandes empresas.

Quando os novos sócios assumiram o controle da empresa, os procedimentos e as regras foram revistos, dando origem a modificações em sua organização: a divisão do trabalho e das tarefas foi redefinida, visando à diminuição de custos e despesas; as decisões passaram a ser tomadas quase que totalmente pela alta administração, com pouca participação dos níveis inferiores, mas forte influência dos valores e da racionalidade econômica dos dirigentes; deuse maior ênfase à formalidade na comunicação.

Atualmente, a estrutura administrativa da empresa abrange $10 \%$ de seus funcionários. Contando com especialistas nas áreas funcionais e um processo produtivo praticamente manual, a empresa desenvolve tarefas rotineiras, tem metas a cumprir, estabelecidas em planejamentos anuais. "A gestão da empresa é baseada em planejamento, metas e resultados" - ressaltou o dirigente $\mathrm{A}$.

A empresa tem um sistema de informações simples e eficiente, que abrange toda a sua gestão financeira e administrativa. A integração entre a área de contabilidade e os demais 
setores gera relatórios esporádicos, que fornecem dados sobre clientes, faturamento, produtividade e não-conformidades.

Os dirigentes elaboram planejamentos de médio e curto prazo. O planejamento de médio prazo, desenvolvido anualmente, define uma perspectiva de futuro e estratégica, a partir da identificação de oportunidades e ameaças ao negócio. Estabelecem-se, assim, objetivos claros, como definição de novos projetos, desenvolvimento ou alteração de produtos, identificação de novos mercados de atuação, entre outros.

O planejamento de curto prazo, que é um desdobramento do plano de médio prazo e de seus objetivos, comporta ações específicas, relacionadas a: produção (quantidade, processo produtivo e novos materiais), recursos humanos (treinamento, contratação e avaliação de desempenho, basicamente), novos investimentos e ações mercadológicas. O plano de curto prazo abrange outros tipos de planejamento: o semanal (produção - quantidade, horas trabalhadas, custo etc.), o quinzenal (discussão de não-conformidades, definição de ações corretivas e follow up das ações definidas anteriormente) e o mensal (foco nos resultados alcançados, de acordo com os indicadores de qualidade, satisfação dos clientes e produtividade da operação).

Observe-se que os diversos tipos e níveis de planejamento descritos interagem. A empresa, entretanto, não faz um planejamento estratégico, voltado a um horizonte de tempo maior (cerca de 03 anos), devido à dificuldade de visualizar o desenvolvimento tecnológico a longo prazo e suas possíveis aplicações. O dirigente A frisou que, de acordo com a filosofia da empresa, o "planejamento é tudo. O tempo é uma variável escassa, mas o risco é mais danoso que o tempo ... A questão de análise é fundamental para o processo da empresa".

A principal questão para a sobrevivência e o sucesso da empresa é o mercado, segundo informou o dirigente A. "A empresa precisa ter cliente. Empresa de sonho é criada a partir de tecnologia e produto", disse ele, referindo-se ao foco atual das ações (conquista contínua de clientes) e às dificuldades enfrentadas nas primeiras fases da empresa A. O dirigente classifica a gestão da empresa como "madura", um sistema pouco sofisticado, mas profissional e formal, pautado em controles rígidos das atividades. "Os procedimentos burocráticos trazem mais segurança para as operações, porém reduzem a flexibilidade. Quanto mais maduro se fica, menos riscos se assumem e menor a chance de descobrir coisas novas", finalizou.

A seguir são apresentadas as especificidades de organização de acordo com as fases evolutivas da empresa A (quadro 21). 


\begin{tabular}{|c|c|}
\hline Fases & Especificidades \\
\hline \multicolumn{2}{|l|}{ Criação da empresa } \\
\hline Concepção do negócio & \multirow{2}{*}{$\begin{array}{l}\text { estrutura flexível } \\
\text { concentração das atividades no dirigente } \\
\text { administração não-profissional } \\
\text { pouca divisão do trabalho } \\
\text { comunicação informal } \\
\text { informalidade nas relações }\end{array}$} \\
\hline Viabilização do negócio & \\
\hline Refinamento técnico & \multirow{2}{*}{$\begin{array}{l}\text { centralização das decisões } \\
\text { divisão do trabalho } \\
\text { comunicação formal } \\
\text { tarefas rotineiras } \\
\text { divisão do trabalho e das tarefas } \\
\text { formalização dos procedimentos }\end{array}$} \\
\hline Desenvolvimento & \\
\hline
\end{tabular}

Quadro 21 - Especificidades de organização de acordo com as fases evolutivas: empresa A

- Especificidades do(s) dirigente(s)-estrategista(s)

A princípio os estrategistas da empresa A buscavam implantar a competência tecnológica em um empreendimento. Focalizando o produto a ser desenvolvido e, posteriormente, o processo produtivo e as instalações físicas, os dirigentes tomavam as decisões estratégicas com base em suas intuições e conhecimentos técnicos. Devido à falta de visão de mercado, experiência administrativa e estratégia de longo prazo, a empresa passou por diversas dificuldades de gestão que culminaram em uma crise financeira. Por esse motivo, os dirigentes, seus sócios e fundadores, passaram o controle do negócio a dois outros sócios cuja gestão se caracterizou de modo diverso.

Os sócio-fundadores apresentavam uma característica marcante, o desejo de empreender tecnologia em um negócio. "Para ser empreendedor, algumas qualidades são necessárias, como ter a capacidade de arriscar e aprender com os erros. Não existe uma empresa se não existirem pessoas com capacidades de enfrentar dificuldades" - comentou o professor 1, o principal responsável pela criação da empresa A. Além da liderança, exercida, sobretudo, por um deles, eram características dos sócio-fundadores: a criatividade, a capacidade de assumir riscos, a ousadia, a falta de conhecimento administrativo e a gestão intuitiva e emotiva. 
Os sócios que assumiram o controle, após a crise financeira, não haviam participado das decisões para se criar o negócio nem enfrentado as dificuldades iniciais, por isso não tinham, como os sócio-fundadores, vínculo afetivo com a empresa. Nessa etapa de vida da empresa A, a racionalidade dos dirigentes estava presente nas suas principais ações estratégicas. "Não se desenvolve um produto e depois se verifica a sua aplicabilidade" comentou o dirigente A sobre a situação inicial da maioria das EBT, inclusive a empresa sob sua gestão.

Os sócios e atuais dirigentes-estrategistas possuem conhecimento administrativo e experiência na gestão de uma grande empresa nacional do setor financeiro. Seus valores, como esforço e dedicação, racionalidade na tomada de decisões, responsabilidade ao assumir compromissos e conservadorismo, estão presentes na gestão da empresa A, em especial no relacionamento dos dirigentes com seus funcionários. "A liderança é fundamental para o sucesso da pequena empresa que, tem a cara de seus gestores. Ele interfere diretamente na forma de atuação, em ser mais conservadora ou agressiva" - observou o dirigente A que se classifica como "conservador. Arrisco com os riscos muito calculados". O conservadorismo do dirigente também pode ser identificado quando justifica que a empresa não realiza inovação radical em seus produtos nem desenvolve novas tecnologias, devido à limitação criativa.

O individualismo e a centralização caracterizam a gestão dos atuais dirigentes. " $O$ modelo (da empresa A) não tem abertura para posicionamento individual. Não existe a prerrogativa individual. As decisões devem atender aos objetivos relacionados à satisfação do cliente e ao resultado". Por outro lado, o dirigente A argumenta que esta característica está pautada na importância atribuída ao cliente em sua gestão. "A empresa não sou eu. Eu oriento as ações e estabeleço os objetivos. O patrão é o cliente". Segundo o dirigente A, o objetivo desta filosofia é fazer com que os funcionários assumam responsabilidades e a se esforcem para aumentar a qualidade, a produtividade e a satisfação dos clientes da empresa.

Pode-se concluir que os dirigentes responsáveis pela gestão e criação de estratégias da empresa A apresentam-se como aplicados, determinados, eficientes, racionais, exigentes, responsáveis, realistas e coerentes. A seguir são apresentadas as especificidades do dirigente-estrategista de acordo com as fases evolutivas da empresa A (quadro 22). 


\begin{tabular}{|l|l|}
\hline \multicolumn{1}{|c|}{ Fases } & \multicolumn{1}{c|}{ Especificidades } \\
\hline Criação da empresa & $\begin{array}{l}\text { Conhecimento técnico } \\
\text { Intuição }\end{array}$ \\
\hline Concepção do negócio & $\begin{array}{l}\text { Falta de visão de mercado } \\
\text { pouca experiência administrativa } \\
\text { Dedicação ao negócio } \\
\text { Emotivo }\end{array}$ \\
\hline Viabilização do negócio & $\begin{array}{l}\text { Racionalidade } \\
\text { Conservadorismo } \\
\text { individualismo } \\
\text { Conhecimento administrativo } \\
\text { Determinação }\end{array}$ \\
\hline Desento técnico &
\end{tabular}

Quadro 22 - Especificidades do dirigente-estrategista de acordo com as fases evolutivas: empresa A

\subsubsection{Empresa $B$}

\subsubsection{Processo de criação de estratégias}

O processo de criação de estratégias da empresa B apresenta características emergentes e deliberadas, de acordo com suas fases evolutivas.

A partir da manutenção de um equipamento importado, atendendo ao pedido de um profissional, e da conseqüente sugestão deste para se produzir tal equipamento, estabeleceram-se algumas ações para a criação da empresa. Com base na tecnologia existente e na demanda inicial de fornecimento do produto por unidades ligadas à Universidade, professores identificaram a oportunidade de substituir o equipamento importado por outro de igual qualidade a um preço acessível. As principais ações dessa fase inicial, que focaram a produção das primeiras unidades, relacionavam-se a - compra de material, produção e venda do produto e posterior formalização da empresa. Observe-se que, nessa etapa, o processo de criação de estratégias era totalmente emergente e decorria de ações intuitivas. Esta fase será denominada criação da empresa.

Fundada a empresa, o dirigente passou investir em infra-estrutura, principalmente em máquinas e equipamentos, e contratando funcionários para a produção. Guiado por um objetivo geral, fabricar equipamentos odontológicos, suas ações voltavam-se a atender à demanda e produção das unidades. Responsável pela direção e operacionalização das atividades, o dirigente programava ações que resolvessem os problemas cotidianos, com a 
intenção de viabilizar o empreendimento. Não havia, nessa fase, planejamento. O processo de criação de estratégias era emergente, baseava-se na intuição e experiência do dirigente, e objetivava atingir resultados em curto prazo. Esta fase será denominada concepção do negócio.

A fase 3 deu-se com a ampliação da linha de produtos, o estabelecimento de parcerias com empresas distribuidoras estrangeiras e a mudança do canal de venda. Tais ações proporcionaram um aumento na demanda de produtos da empresa. Ao longo de vários anos foram lançadas dezenas de produtos, uma média de 02 lançamentos ao ano, para atender às necessidades do mercado de equipamentos odontológicos. As oportunidades para lançar os produtos foram identificadas em feiras, eventos, contato com clientes ou, ainda, em ações dos concorrentes. Visando à atuação no mercado externo, estabeleceram-se parcerias com empresas estrangeiras a partir de contatos realizados em eventos da área. Com o crescimento das vendas no mercado interno, a empresa optou por realizar suas vendas exclusivamente por meio de distribuidores, para atender aos clientes com qualidade. Nessa fase, as ações estratégicas, voltadas ao atendimento de clientes e à expansão das linhas de produto, apresentavam características emergentes e, em alguns momentos, deliberadas. O processo de criação de estratégias caracterizava-se por flexibilidade, informalidade, intuição e ações inesperadas do dirigente. Por outro lado, em certos momentos, com a decisão de alterar o canal de venda, verificou-se um objetivo delineado de maneira genérica, a partir de uma decisão mais racional que intuitiva. Esta fase será denominada consolidação do negócio.

O período seguintes caracterizou-se como uma fase de expansão das atividades no mercado interno e, principalmente, no externo. Nessa etapa, os filhos do dirigente assumiram certas atividades, dando início à reestruturação da empresa. Um dos principais problemas enfrentados na época era a dificuldade em atender à demanda. Assim, visando aumentar a eficiência do processo produtivo, iniciou-se a sua reorganização, definindo-se suas atividades, estabelecendo-se o planejamento da produção e implementando-se programas de qualidade. A seguir, definiram-se ações pró-ativas para a exportação dos produtos a outros países. Nessa fase, o processo de criação de estratégias era deliberado, com características emergentes. Definiam-se objetivos de forma clara e maior nível de detalhe e formalização, porém eram de curto prazo. Algumas ações eram estabelecidas pela alta administração e constantemente alteradas e redefinidas, de acordo com os seus resultados e os acontecimentos cotidianos. Esta fase será denominada crescimento da empresa.

A fase atual da empresa B representa o foco em novos produtos e na atuação em novos mercados. Inicia-se, nesta etapa, o processo de sucessão. Como os filhos do dirigente 
trabalham na empresa, forma-se um conselho administrativo com todos os membros da família. A filha assume a gerência geral, passando a ser a principal responsável pela criação de estratégias. Com o aumento do investimento em P\&D, a partir da criação do departamento de projetos e produtos, a empresa intensifica o lançamento de novos produtos e passa a analisar outros mercados, em busca de oportunidades de negócio. Utiliza-se o planejamento estratégico para definir as ações e os investimentos da empresa. "Fazemos um planejamento estratégico formal (...) com um horizonte de tempo de cerca de 05 anos, mas com um detalhamento maior a curto prazo. A partir da análise SWOT, definimos o posicionamento dos produtos no mercado, utilizamos a matriz BCG e definimos os projetos" - comentou a dirigente $\mathrm{C}$, referindo-se a algumas técnicas utilizadas para a criação de estratégias que ilustra: "do que planejamos, chegamos a cumprir cerca de $70 \%$ do plano (...) mas, às vezes, algumas adaptações durante o percurso são necessárias". As adaptações a que se refere são ações emergentes ou estratégias intencionadas que passam a ser não-realizadas. Pode-se afirmar que, nesta fase, o processo de criação de estratégias é deliberado e se caracteriza por ações estabelecidas de forma regular (anualmente), com base em informações e análises racionais. Estabelecem-se objetivos claros, delineados pela alta administração, que se desdobram em objetivos específicos e metas. Esta fase será denominada desenvolvimento.

A síntese das fases e características da empresa B é apresentada no quadro 23.

\begin{tabular}{|l|l|l|l|}
\hline \multicolumn{1}{|c|}{ Fases } & \multicolumn{1}{|c|}{ Característica } & \multicolumn{1}{c|}{ Principais ações } & \multicolumn{1}{|c|}{ Foco } \\
\hline $\begin{array}{l}\text { Fase 1 - Criação da } \\
\text { empresa }\end{array}$ & Emergente & $\begin{array}{l}\text { Fabricação de protótipos e } \\
\text { fundação da empresa }\end{array}$ & Produto \\
\hline $\begin{array}{l}\text { Fase 2 - Concepção do } \\
\text { negócio }\end{array}$ & Emergente & $\begin{array}{l}\text { Realização de investimentos } \\
\text { em infra-estrutura }\end{array}$ & Processo \\
\hline $\begin{array}{l}\text { Fase 3 - Consolidação do } \\
\text { negócio }\end{array}$ & $\begin{array}{l}\text { Emergente } \\
\text { Deliberada }\end{array}$ & $\begin{array}{l}\text { Desenvolvimento da linha de } \\
\text { produtos, estabecimento de } \\
\text { parcerias para exportação e } \\
\text { alteração do canal de venda }\end{array}$ & $\begin{array}{l}\text { Produto e } \\
\text { clientes }\end{array}$ \\
\hline Fase 4 -Crescimento & $\begin{array}{l}\text { Emergente e } \\
\text { Deliberada }\end{array}$ & $\begin{array}{l}\text { Definição da estrutura } \\
\text { organizacional, foco na } \\
\text { eficiência do processo } \\
\text { produtivo e expansão das } \\
\text { atividades }\end{array}$ & $\begin{array}{l}\text { Clientes e } \\
\text { Processo }\end{array}$ \\
\hline Fase 5 - Desenvolvimento & $\begin{array}{l}\text { Deliberada e } \\
\text { emergente }\end{array}$ & $\begin{array}{l}\text { Início do processo de sucessão } \\
\text { e início de atuação em novos } \\
\text { mercados. }\end{array}$ & $\begin{array}{l}\text { Processo e } \\
\text { produto }\end{array}$ \\
\hline
\end{tabular}




\subsubsection{Especificidades de gestão}

\section{- Especificidades contextuais}

O ambiente da empresa B é homogêneo e apresenta baixo grau de mudança: as mudanças são previsíveis, relativamente lentas e podem ser acompanhadas. É também um ambiente dinâmico, que oferece muitas oportunidades para produtos de alta tecnologia. Entretanto, em alguns segmentos, registram-se sinais de saturação e alta competição, o principal motivo que levou s empresa $\mathrm{B}$ a desenvolver tecnologia para seus produtos em outros mercados.

Os concorrentes da empresa B, instalados em vários países, principalmente na Europa e nos Estados Unidos, são de pequeno e médio porte. No Brasil, constituem empresas de base tecnológica com porte, estrutura e tecnologia semelhantes aos da empresa B, concentradas no estado de São Paulo. Em sua maioria, apresentam a estratégia de custo, competindo no mercado com preços inferiores. Recentemente, em alguns setores que absorvem alta escala de produtos, a indústria chinesa demonstrou ser uma ameaça, por oferecer produtos a preços competitivos, muitas vezes inferiores aos custos da empresa B. As indústrias chinesas concorrem diretamente com um dos produtos da empresa $\mathrm{B}$, que não é o seu principal produto. Por outro lado, uma indústria americana de médio porte está à procura de uma empresa brasileira para estabelecer uma parceria e fabricar um produto que concorra com o principal da empresa B. Esta parceria permitiria o fornecimento de produtos, a preços competitivos, para todo o Brasil e América Latina, principais mercados da empresa B. Hoje esta é a principal ameaça para a empresa B. O dirigente B1, fazendo um comentário sobre a influência da variável concorrência na definição da estratégia, disse: "Uma vez feito o planejamento estratégico as ações são definidas, mas durante o caminhar ocorrem alguns imprevistos que requerem mudanças. Tais imprevistos são geralmente oriundos do ambiente externo, principalmente das ações da concorrência".

Os fornecedores de matéria-prima são empresas de médio e pequeno porte com estrutura e tecnologia semelhantes às da empresa $\mathrm{B}$, localizadas, em sua maioria, no interior do estado de São Paulo. Alguns fornecedores são de grande porte, mas a empresa B prioriza a parceria com organizações cuja flexibilidade possa favorecer o atendimento de suas necessidades relacionadas com a quantidade de matéria-prima e o prazo de entrega. $\mathrm{O}$ dirigente B justificou a parceria estabelecida, comentando: "fornecedores maiores fazem exigências de quantidade e não atendem a necessidade da empresa”. 
Os clientes finais da empresa são dentistas, protéticos e estudantes de odontologia que compram os produtos por meio de distribuidores, denominados dentais. A carteira de clientes é composta por centenas de distribuidores de diversos portes que, no exterior, estão instalados em mais de 40 países. Apesar de abranger vários países, o volume de vendas é pequeno, exceto para a América Latina. Líder no mercado, a empresa não apresenta dificuldades de relacionamento e negociação com os distribuidores, principalmente pelo fato de ter preço semelhante ao dos concorrentes, diferencial de qualidade e recursos superiores.

A variável econômica influencia diretamente os resultados da empresa B. Exporta cerca de $30 \%$ de sua produção, índice que cresceu nos últimos anos. Para contornar a queda de competitividade no mercado externo, devido à alta taxa de câmbio, passou a definir seus preços em euro, o que reduziu o impacto da valorização da moeda nacional, porém manteve os preços dos produtos pouco competitivos. A inflação e a recessão econômica, que impactaram os resultados nas décadas de 80/90, constituem uma variável relevante e constantemente monitorada pela dirigente B.

As alianças firmadas com a universidade, clientes, fornecedores e outras empresas, para desenvolver novos produtos ou processos ou incrementar os atuais, garantem a constante inovação na empresa $\mathrm{B}$, sendo esta um de seus diferenciais competitivos. Produtos atualmente em linha foram desenvolvidos a partir de tais parcerias, que são viáveis para o desenvolvimento de tecnologia ou de mercado.

A variável tecnológica também se identifica como relevante. A tecnologia incorporada nos produtos possibilita sua inserção em novos mercados ou mesmo sua manutenção nos atuais. Assim, investimentos em $\mathrm{P} \& \mathrm{D}$ aliados a parcerias propiciam à empresa atualizar-se tecnologicamente, para atender às necessidades de seus clientes.

Os órgãos reguladores também são considerados importantes, pois estabelecem regras e procedimentos que toda a indústria de equipamentos odontológicos deve seguir.

As variáveis contextuais que exercem maior influência na criação de estratégias da empresa B são, em ordem de importância, as seguintes: concorrentes, clientes, economia, tecnologia, órgãos reguladores e fornecedores. Considerando cada uma de suas fases evolutivas, registra-se a influência das seguintes variáveis, em maior ou menor grau: tecnologia, clientes e fornecedores, nas fases de criação da empresa e concepção do negócio; economia, tecnologia e parcerias com universidade e clientes, na fase de consolidação do negócio; tecnologia na fase de crescimento; e economia e clientes, na fase de desenvolvimento (quadro 24). 


\begin{tabular}{|l|l|}
\hline \multicolumn{1}{|c|}{ Fases } & \multicolumn{1}{c|}{ Especificidades } \\
\hline Criação da empresa & $\begin{array}{l}\text { Tecnologia: domínio para aplicação em um produto } \\
\text { Clientes: solicitação de fabricação do produto }\end{array}$ \\
\hline Concepção do negócio & $\begin{array}{l}\text { Clientes: demanda pelo produto } \\
\text { Tecnologia: desenvolvimento e produção do produto } \\
\text { Fornecedores: dificuldade de barganha com fornecedores de grande porte }\end{array}$ \\
\hline $\begin{array}{l}\text { Consolidação do } \\
\text { negócio }\end{array}$ & $\begin{array}{l}\text { Economia: vulnerabilidade em situações econômicas desfavoráveis } \\
\text { Tecnologia: aplicações possibilitam a ampliação da linha de produtos } \\
\text { Parcerias: estabelecimento de parcerias com fornecedores de pequeno } \\
\text { porte e distribuidores nacionais e internacionais }\end{array}$ \\
\hline Crescimento & $\begin{array}{l}\text { Tecnologia: possibilidade de se estabelecer parcerias devido à } \\
\text { particularidade da tecnologia empregada }\end{array}$ \\
\hline Desenvolvimento & $\begin{array}{l}\text { Clientes: expansão das atividades em novos mercados de atuação } \\
\text { Economia: taxa de câmbio dificulta as exportações e atuação em novos } \\
\text { países }\end{array}$ \\
\hline
\end{tabular}

Quadro 24 - Especificidades contextuais de acordo com as fases evolutivas: empresa B

\section{- Especificidades de organização}

A organização da empresa B configura uma estrutura simples, com poucos níveis hierárquicos. Evidencia-se a formalização dos processos e da comunicação no cotidiano da empresa. As decisões se concentram na alta administração, constituída pelos membros da família, havendo pouca participação dos níveis inferiores. Nas fases evolutivas da empresa, identificam-se duas etapas de organização, com características diversas: a primeira, correspondente à gestão exclusiva do dirigente-fundador, compreende a criação, concepção e consolidação do negócio; a segunda, iniciada no momento em que os filhos assumiram atividades administrativas, pulverizando a gestão, compreende as fases de crescimento e desenvolvimento do negócio.

$\mathrm{Na}$ primeira etapa, a organização era totalmente flexível, não havia divisão do trabalho, não se utilizavam ferramentas administrativas, as atividades não eram preestabelecidas, a comunicação era informal e havia constante interação do dirigente com os membros da empresa. Por outro lado, devido à informalidade existente nas relações internas e externas, com clientes e fornecedores, a empresa se mostrava ágil na tomada de decisões, na atualização e lançamento de produtos e na identificação de necessidades dos clientes. $\mathrm{O}$ 
dirigente atendia diretamente aos clientes, procedimento esse considerado um diferencial da empresa, que possibilitou identificar diversas oportunidades de negócio. Apesar dos lançamentos consecutivos de produtos, os negócios pautavam-se por um único produto - o articulador.

A empresa B recorreu a fontes de financiamento para a compra dos equipamentos iniciais, porém os investimentos, em sua maior parte, foram feitos, ao longo dos anos, com recursos próprios. A limitação de capital para expandir as atividades e contratar mão-de-obra qualificada, em especial para a área administrativa, foi uma constante.

$\mathrm{Na}$ empresa $\mathrm{B}$, não se utilizavam técnicas gerenciais, havendo dificuldade em definir metas e objetivos de maneira clara e obter informações gerenciais para a análise dos resultados. O dirigente, que tinha um amplo conhecimento da tecnologia e do negócio, assumia o compromisso de melhorar os resultados da empresa, dedicando-se integralmente a essa tarefa.

A segunda etapa revela um aumento na maturidade da organização da empresa, que se apresenta simples e com poucos níveis hierárquicos. É uma fase que se iniciou com o ingresso os filhos do dirigente no negócio, assumindo atividades e passando a reestruturar a empresa. "A estrutura administrativa começou a ser montada quando ingressamos (os filhos) no negócio. As atividades foram sendo descentralizadas, mas mudou muito pouco, pois agora está centralizada em mim" - comentou a dirigente B, aludindo ao processo de transição e sucessão ocorrido. Quando teve início esse processo as atividades das áreas funcionais foram delineadas, os procedimentos tornaram-se mais formais e estabeleceram-se controles e relatórios gerenciais para se obter informações sobre as condições internas de gestão. Evidenciavam-se, assim, maior formalidade nas relações e na comunicação e decisões pautadas por informações.

$\mathrm{Na}$ segunda etapa, as decisões centralizam-se na alta administração (membros da família). Reestruturando-se a empresa, definiram-se a sua missão e visão. Foram contratados funcionários especializados, mas, em algumas áreas, a empresa ainda apresentava limitações como, por exemplo, na de exportação, diretamente relacionada com as suas ações estratégicas. "Chegamos a um limite de capacidade do departamento, com o crescimento das exportações nos últimos anos. Não conseguimos mais estabelecer ações pró-ativas - apenas atendemos pedidos" - concluiu a dirigente $\mathrm{B}$.

Tendo conhecimento administrativo, a dirigente $\mathrm{B}$ procedeu à reestruturação dos processos, usando diversas ferramentas para controle e tomada de decisões. Passou-se a realizar planejamento de curto e médio prazo. O processo foi aprimorado e hoje se elabora um 
planejamento estratégico de longo prazo, que implica análise dos concorrentes e das características de clientes e identificação de oportunidades e ameaças. "Já tentamos várias vezes, mas por falta de tempo não foi possível. O primeiro planejamento foi em 2006, realizado a partir de estudos de mercado. Fizemos a análise SWOT e da matriz BCG e definimos o posicionamento de nossos produtos. Hoje fazemos por um período de 5 anos, mais detalhado no ano corrente e mais genérico nos próximos" - detalhou a dirigente B, referindo-se ao processo de planejamento da empresa, que é centralizado nos dirigentes, embora haja alguma interação destes com outros membros, como explicou a seguir: "o primeiro ano fiz praticamente sozinha e no próximo reuni a direção, apresentei as análises e solicitei sugestões para lapidá-lo e entrarmos em um consenso". Do planejamento estratégico derivam as diretrizes para as áreas funcionais. "Há um desdobramento do planejamento estratégico, principalmente para projetos. Do planejamento geral são estabelecidos os outros, como de vendas marketing e produção" - disse o dirigente B1, ressaltando a hierarquia de planejamentos existente na empresa. Tratando do mesmo assunto, a dirigente B fez a seguinte comparação: "sem planejamento parece que estou dirigindo sem a mão no volante. Ele me dá direção e segurança. Não consigo mais administrar sem fazer planejamento".

Porém, nem todas as ações realizadas na empresa são deliberadas. Algumas estratégias são abandonadas ou postergadas em função de mudança de prioridades. Face à ameaça da concorrência americana, citada anteriormente, a empresa procura identificar maneiras de reduzir o custo de seu principal produto. Outra especificidade da empresa é a falta de tempo para realizar análises mais elaboradas, que dêem suporte ao processo de planejamento.

Contando com uma carteira de clientes diversificada, o faturamento da empresa B não se concentra em poucos clientes. Constata-se, entretanto, que se concentra, até os dias de hoje, no desenvolvimento de um único produto do qual depende, o articulador, apesar de todo o esforço em aumentar sua linha de produtos. Pulverizar o faturamento na linha de produtos é um dos objetivos da empresa, que ressalta para tanto a importância da inovação. A seguir são apresentadas as especificidades de organização da empresa B de acordo com as suas fases evolutivas (quadro 25). 


\begin{tabular}{|l|l|}
\hline Fases & Especificidades \\
\hline Criação da empresa & pouca divisão do trabalho \\
\hline Concepção do negócio & $\begin{array}{l}\text { estrutura flexível } \\
\text { concentração das atividades no dirigente } \\
\text { pouca divisão do trabalho }\end{array}$ \\
\hline Consolidação do negócio & $\begin{array}{l}\text { tarefas não rotineiras } \\
\text { comunicação informal }\end{array}$ \\
\hline Crescimento & $\begin{array}{l}\text { divisão do trabalho } \\
\text { centralização das decisões } \\
\text { divisão do trabalho } \\
\text { tarefas rotineiras } \\
\text { formalização dos procedimentos } \\
\text { criação conselho administrativo (familiar) }\end{array}$ \\
\hline Desenvolvimento
\end{tabular}

Quadro 25 - Especificidades de organização de acordo com as fases evolutivas: empresa B

\section{- Especificidades do(a) dirigente-estrategista}

O dirigente-estrategista que, inicialmente, apenas se dispunha a auxiliar um amigo, vislumbrou a possibilidade de utilizar seu conhecimento tecnológico na fabricação de um produto e acabou fundando a empresa B. Foi o responsável direto pela organização durante mais de 20 anos e continua atuante até os dias de hoje. Em sua gestão, a empresa alternou fases de dificuldade e expansão. Com o foco no produto, suas ações voltavam-se ao processo produtivo, às instalações físicas e aos clientes. Tomava decisões estratégicas com base em sua intuição e conhecimento técnico, destacando-se o seu empenho e a sua dedicação ao negócio. Não tinha conhecimento administrativo nem visão de longo prazo, mas algumas de suas características foram relevantes em sua gestão: conservador, realista, justo, equilibrado, empreendedor e intuitivo.

As especificidades do dirigente-estrategista se alteraram com o ingresso dos seus filhos na empresa. A filha (dirigente B) assumiu a gestão, como destacou o dirigente B1, ao comentar que é "a principal liderança da empresa hoje". Especializada em administração, busca aplicar ferramentas administrativas, de modo que, no presente, a gestão tem um caráter mais racional e formal, implicando decisões estratégicas baseadas em análises relativamente estruturadas. "Sou exigente, duro na queda e procuro sempre aprender" - falou a dirigente B, 
descrevendo-se. Optou por atuar em outras empresas, no Brasil e no exterior, antes de iniciar o processo sucessório, para "adquirir experiência", conforme comentou.

Como a gestão está centralizada na dirigente B, suas características influenciam as decisões estratégicas da empresa. Ao longo dos anos vem estabelecendo ações, como contratar especialistas para áreas específicas e preparar um funcionário de sua confiança para auxiliá-la, com o objetivo de delegar maior responsabilidade e autoridade a pessoas-chave. Com ampla vivência no exterior e visão de longo prazo, voltada às oportunidades de mercado e ações dos concorrentes, expandiu as atividades da empresa no exterior e estabeleceu controles, processos e procedimentos que a ajudam na tomada de decisão estratégica. A centralização e o individualismo presentes na gestão da empresa impedem a dirigente $\mathrm{B}$ de dedicar-se, em tempo integral, à direção: muitas atividades funcionais encontram-se sob a sua responsabilidade. Na gestão e criação de estratégias, destacam-se as seguintes características da dirigente da empresa B: responsável, visionária, empreendedora, determinada, racional, exigente e detalhista. A seguir são apresentadas as especificidades do dirigente-estrategista de acordo com as fases evolutivas da empresa B (quadro 26).

\begin{tabular}{|c|c|}
\hline Fases & Especificidades \\
\hline Criação da empresa & Conhecimento técnico \\
\hline Concepção do negócio & \multirow{2}{*}{$\begin{array}{l}\text { Intuição } \\
\text { Informalidade } \\
\text { Conservadorismo } \\
\text { Dedicação ao negócio } \\
\text { Experiência }\end{array}$} \\
\hline Consolidação do negócio & \\
\hline Crescimento & \multirow{2}{*}{$\begin{array}{l}\text { Visão } \\
\text { Empreendedorismo } \\
\text { Racionalidade } \\
\text { Determinação } \\
\text { Exigente }\end{array}$} \\
\hline Desenvolvimento & \\
\hline
\end{tabular}

Quadro 26 - Especificidades do dirigente-estrategista de acordo com as fases evolutivas: empresa B 


\subsubsection{Empresa C}

\subsubsection{Processo de criação de estratégias}

Em seus primeiros anos, a empresa $C$ apresentava um processo de criação de estratégias com características predominantemente emergentes. Hoje este processo comporta características deliberadas e emergentes.

Para ser fundada a empresa $\mathrm{C}$, considerou-se de extrema relevância a criação de uma oficina de ótica na universidade. Assim, a primeira fase do processo de criação de estratégias da empresa $\mathrm{C}$ corresponde ao período que se estendeu da criação da oficina de ótica à decisão de fundar a empresa, em 1985. A oficina, criada por professores universitários entusiastas da ótica e do laser, foi o ambiente que proporcionou o convívio direto dos pesquisadores, no qual a tecnologia do produto inicial foi aprimorada. Montada a oficina, adquiriram máquinas e começaram a produzir os componentes. "Foi um aprendizado", disse o dirigente C. Em decorrência da sinergia obtida na oficina e da demanda de empresas pelos componentes nela fabricados, surgiu o projeto de criação do Parqtec, com o intuito de que este viesse a "ser uma ponte para que o pesquisador da universidade fosse um empresário ou desenvolvesse tecnologia a ser aplicada por outras empresas", lembrou o dirigente C. Como um dos sóciosfundadores da empresa $\mathrm{C}$ foi o responsável pela criação do Parqtec, todo esse contexto levou os sócios-fundadores a vislumbrar a possibilidade de aplicar o domínio tecnológico em um produto que parecia promissor, segundo a sua percepção. Nessa fase, as ações tinham um caráter totalmente emergente, baseavam-se na intuição e experiência dos envolvidos. $\mathrm{O}$ processo de criação de estratégias era, portanto, emergente, baseado na experiência e intuição dos sócios-fundadores. Esta fase será denominada aprendizado.

Assim considerando ressalta que a empresa $\mathrm{C}$ foi criada a partir de uma tecnologia e do produto resultante de sua aplicação. Passou, depois, para uma outra etapa: "Começamos sem a noção do que é uma empresa, pois tínhamos apenas a experiência das atividades desenvolvidas na universidade", justificou o dirigente $\mathrm{C}$, ao relembrar as dificuldades iniciais. E complementou, dizendo: "no começo foi muita pressão, pois havia dificuldade de todo o tipo". Os problemas da empresa nessa fase, decorriam da falta de verba para a compra dos equipamentos necessários, pois os sócios não possuíam recursos suficientes nem garantias para financiar os projetos. Os recursos derivados de consultorias e uma pequena produção foram investidos nas instalações físicas (aquisição do terreno, construção do prédio e compra dos primeiros equipamentos), para se viabilizar a produção do primeiro produto, o laser 
HeNe. Logo a seguir, os sócios verificaram que havia um gap tecnológico dificultando a absorção da tecnologia no mercado brasileiro, ou seja, que a percepção do potencial de mercado estava equivocada. Viram-se com uma empresa de um único produto para o qual não havia mercado. "Foi um choque", comentou o dirigente $\mathrm{C}$, ao relatar que havia constatado que a empresa enfrentava uma crise financeira e vivia uma fase de pré-falência. "Foi uma fase de aprender o que é uma empresa", acrescentou. Nessa etapa, o processo de criação de estratégias era emergente, baseava-se em ações estabelecidas conforme a percepção dos sócios (alta administração). Não havia um objetivo definido e, de acordo com o dirigente $\mathrm{C}$, na ocasião "não houve nenhum tipo de planejamento". Esta fase será denominada concepção do negócio.

Na nova fase evolutiva da empresa C, para sair da crise financeira, recorreu-se a um investidor, contatado por um dos fundadores. O novo sócio investiu cerca de US\$ 300 mil, quantia suficiente para saldar as dívidas, mas não para realizar novos investimentos. Porém, para o dirigente $\mathrm{C}$, o sócio-investidor foi fundamental. Referindo-se ao seu ingresso, disse: "nos educamos administrativamente". O novo sócio, que não possuía vínculo com a tecnologia e, conseqüentemente, com a ótica, designou um funcionário para auxiliar na gestão. Ao se transformar a empresa em S.A., tornou-se obrigatório fazer balanços e demonstrações financeiras, atividades praticamente inexistentes na empresa C. Foram contratados especialistas e, na mesma fase, dois sócio-fundadores venderam suas partes acionárias. $\mathrm{O}$ processo de criação de estratégias da empresa era, então, emergente. $\mathrm{O}$ ingresso do sócio-investidor, que marcou essa etapa, iniciou-se em um contato eventual, não programado, do sócio-fundador (professor 1). Entende-se, assim, que as ações se baseavam em acontecimentos cotidianos e implicavam objetivos gerais, voltados à sobrevivência da empresa. Esta fase será denominada reestruturação.

Como a empresa ainda enfrentava dificuldades relacionadas à falta de clientes, os dirigentes decidiram contratar um engenheiro que, posteriormente, tornou-se um dos sócios, para identificar possíveis aplicações do laser. A área de P\&D foi estruturada e passou a ser responsável por inúmeras inovações que contribuíram para desenvolver novos produtos e mercados. "Começamos a entrar em vários mercados, mas nunca fizemos uma pesquisa. Verificávamos possíveis aplicações, seguindo a intuição dos dirigentes, verificando as ações dos concorrentes ou mesmo outras aplicações, a partir de visitas a clientes. As descobertas de oportunidades eram quase que por acaso", relatou o dirigente C. Para dar suporte ao desenvolvimento de mercado, um dos sócios, que tinha formação em tecnologia e era responsável pela área comercial, especializou-se em gestão mercadológica. Novas linhas de 
produto foram desenvolvidas e novas divisões criadas. A mudança do departamento comercial para a cidade de São Paulo foi também uma ação estratégica importante, pois permitiu maior proximidade da empresa com seus clientes, propiciando um relacionamento mais ágil e dinâmico. O processo de criação de estratégias apresentava, nessa fase, características emergentes e deliberadas. Para identificar novas aplicações da tecnologia e conquistar clientes, as ações estratégicas eram tomadas de maneira informal e sem análises específicas, não se fundamentavam em informações, mas, sim, na intuição dos dirigentes. Aos poucos, a partir das experiências no desenvolvimento e na comercialização de produtos de alta tecnologia, os dirigentes passaram a fazer análises mais detalhadas, com base em informações de clientes e concorrentes. Esta fase será denominada desenvolvimento de mercado.

Os dirigentes viram a necessidade de estabelecer um foco em suas ações. "Avaliamos a direção que deveríamos seguir e decidimos a área a investir", ressaltou o dirigente $\mathrm{C}$ sobre a identificação da vocação da empresa e a decisão de focar as ações na área médica, considerada um mercado em expansão e de grande potencial para produtos com alta tecnologia incorporada. Paralelamente, ações focadas no tratamento anti-reflexo foram estabelecidas, devido ao potencial de mercado e domínio da tecnologia. A empresa, investindo no desenvolvimento de tecnologia em sua área de $\mathrm{P} \& \mathrm{D}$, desenvolveu diversos produtos para diagnóstico e tratamento oftalmológicos. "Estamos focados no mercado de equipamentos médicos e não queremos mais atuar em todo tipo de mercado. Antigamente, atirávamos para todo lado e demoramos muito tempo para identificar a vocação da empresa. É difícil saber se estamos acertando e se esse é o melhor mercado, mas foi uma opção que fizemos", disse o dirigente C sobre a decisão estratégica deliberada. Assim, o processo de criação de estratégias passou a apresentar características deliberadas e emergentes concomitantemente. Ora com ações planejadas, ora com ações inesperadas, revelava-se flexível, comportando um objetivo geral pré-estabelecido, porém redefinido e alterado de acordo com acontecimentos cotidianos, derivados de decisões tomadas pelos dirigentes (alta administração). Esta fase será denominada foco.

Com as ações direcionadas à sua vocação, a empresa passou para a sua atual fase. Mediante ações mercadológicas mais efetivas e com maior experiência em seu mercado de atuação, investe na expansão de suas atividades e em novas tecnologias. Projetos de alta tecnologia e grande visibilidade encontram-se em desenvolvimento. Tendo contratado um consultor em gestão, planeja profissionalizar sua administração. Seu processo de criação de estratégias, hoje predominantemente deliberado, contempla objetivos de longo prazo, derivados de sua missão, sua visão, seus valores, da análise que faz do ambiente 
organizacional e da identificação de oportunidades e ameaças para a elaboração de estratégias. Observe-se, entretanto, que mesmo constituindo um processo mais racional, ações não planejadas são realizadas com certa freqüência na empresa. Esta fase será denominada consolidação.

No quadro 27, destacam-se as características identificadas nas diversas fases evolutivas da empresa.

\begin{tabular}{|l|l|l|l|}
\hline \multicolumn{1}{|c|}{ Fases } & \multicolumn{1}{|c|}{ Característica } & \multicolumn{1}{c|}{ Principais ações } & \multicolumn{1}{c|}{ Foco } \\
\hline Fase 1 - Aprendizado & Emergente & $\begin{array}{l}\text { A partir da experiência obtida } \\
\text { na oficina de ótica, } \\
\text { identificou-se a oportunidade } \\
\text { de fundar a empresa }\end{array}$ & Produto \\
\hline $\begin{array}{l}\text { Fase 2 - Concepção do } \\
\text { negócio }\end{array}$ & Emergente & $\begin{array}{l}\text { Investimentos em instalações } \\
\text { físicas e operacionalização do } \\
\text { processo produtivo e produto }\end{array}$ & $\begin{array}{l}\text { Produto e } \\
\text { processo }\end{array}$ \\
\hline Fase 3 - Reestruturação & Emergente & $\begin{array}{l}\text { Ingresso do sócio-investidor, } \\
\text { saída de dois sócios- } \\
\text { fundadores e aprimoramento } \\
\text { da gestão }\end{array}$ & Processo \\
\hline $\begin{array}{l}\text { Fase 4 - Desenvolvimento } \\
\text { de mercado }\end{array}$ & $\begin{array}{l}\text { Emergente e } \\
\text { Deliberada }\end{array}$ & $\begin{array}{l}\text { Criação da área de P\&D para } \\
\text { identificar aplicações da } \\
\text { tecnología e mercados } \\
\text { potenciais }\end{array}$ & Processo \\
\hline Fase 5 -Foco & $\begin{array}{l}\text { Deliberada e } \\
\text { emergente }\end{array}$ & $\begin{array}{l}\text { Identificação da vocação da } \\
\text { empresa }\end{array}$ & $\begin{array}{l}\text { Cliente e } \\
\text { produto }\end{array}$ \\
\hline Fase 6 - Consolidação & $\begin{array}{l}\text { Deliberada e } \\
\text { emergente }\end{array}$ & $\begin{array}{l}\text { Expansão das atividades na } \\
\text { área de atuação e início da } \\
\text { profissionalização } \\
\text { administrativa }\end{array}$ & $\begin{array}{l}\text { Clientes, } \\
\text { produto e } \\
\text { processo }\end{array}$ \\
\hline
\end{tabular}

Quadro 27 - Fases do processo de criação de estratégias da empresa C

\subsubsection{Especificidades de gestão}

\section{- Especificidades contextuais}

$\mathrm{O}$ ambiente da empresa $\mathrm{C}$ - heterogêneo, segmentado e em expansão na área de sua vocação - apresenta um alto grau de mudanças vinculadas ao desenvolvimento tecnológico e, por isso, proporciona muitas oportunidades de negócio. 
Os concorrentes da empresa são, em sua maioria, indústrias estrangeiras de grande e médio porte e de capital intensivo que, entretanto, devido à especificidade tecnológica, se apresentam em número restrito. Em época recente a empresa $\mathrm{C}$ deparou-se com a intensificação da concorrência das indústrias chinesas em um dos mercados em que atua, o de refletores, produto de grande representatividade em seu faturamento há alguns anos, cuja venda, porém, encontra-se estagnada. A concorrência é uma variável relevante, constituindo um dos parâmetros que utiliza para monitorar o seu desenvolvimento tecnológico.

Os clientes da empresa $\mathrm{C}$ têm características diversas em termos de porte, tecnologia e estrutura, conforme já se mencionou. A dificuldade inicial da empresa estava relacionada, de forma direta, à variável cliente que, em um primeiro momento, não absorvia a tecnologia oferecida. Hoje é grande sua importância e, devido à agilidade que os clientes requerem, o mercado de alguns produtos da empresa $\mathrm{C}$, como o de anti-reflexo, tem poucos concorrentes.

Os fornecedores da empresa $\mathrm{C}$, nacionais e estrangeiros, são considerados uma variável ambiental relevante, pois o custo de alguns componentes tem impacto significativo na composição de custo dos produtos.

Parcerias com a universidade, centros de pesquisa e outras organizações auxiliaram a empresa a manter o contínuo desenvolvimento tecnológico, sendo este o seu principal desafio. A fundação Parqtec, apesar do restrito apoio dispensado, foi fundamental para que a empresa conquistasse clientes e atuasse em novos mercados. A tecnologia é uma variável ambiental determinante no seu sucesso. No passado teve extrema importância, estando diretamente relacionada às primeiras dificuldades da empresa - a falta de sua aplicação, devido ao gap tecnológico que o país vivenciava. Porém, ressaltou o dirigente C: "como estamos com o foco definido, seu impacto diminuiu. Assim argumentando, chamava a atenção para o fato de que a empresa hoje domina a tecnologia aplicada aos equipamentos médicos e não mais a diversos mercados. "Somos mais competitivos quanto maior o valor tecnológico agregado ao produto", acrescentou o dirigente $\mathrm{C}$, ao ressaltar que uma das dificuldades relativas à questão ainda é a resistência à tecnologia brasileira ou o seu desconhecimento por parte de outros países. Concluindo, lamentou: "A imagem do Brasil é muito positiva no mercado, mas ainda é difícil vender tecnologia brasileira".

A economia influencia a gestão da empresa C. Comentou o dirigente $\mathrm{C}$ que inicialmente "foi pautada por certa ousadia até que o período se estabilizou, pois com a inflação estava em um mato sem cachorro. Com o anúncio de cada plano econômico as vendas caíam, chegando praticamente a zero". O câmbio também se apresenta como fator de influência, pois a empresa exporta grande parte de sua produção e importa componentes de 
alto valor e impacto nos custos dos produtos. A empresa mostra-se competitiva em produtos que incorporam alta tecnologia, porém perdeu competitividade, devido à queda do dólar, em alguns outros cuja tecnologia aplicada é menor.

Os financiamentos se destacam como determinantes para o sucesso da empresa que, inclusive, surgiu de um projeto financiado pelo Banco do Brasil. Também os recursos para a compra de equipamentos foram obtidos da FINEP.

Conclui-se, assim, que, entre as variáveis contextuais, as que exercem influência direta na definição do direcionamento futuro da empresa, no momento, são os clientes, a economia, os concorrentes e os fornecedores. Na criação de estratégias nas etapas evolutivas da empresa, influíram: a tecnologia, na fase de aprendizado; os financiamentos, os clientes, a tecnologia e a economia, nas fases de concepção do negócio e reestruturação; os clientes e os concorrentes nas fases de desenvolvimento e posterior foco, e, na fase de consolidação, a economia e a tecnologia (quadro 28).

\begin{tabular}{|c|c|}
\hline Fases & Especificidades \\
\hline Aprendizado & Tecnologia: aplicação para o desenvolvimento de um produto \\
\hline Concepção do negócio & $\begin{array}{l}\text { Clientes: não absorção da tecnologia; dificuldade de comercialização do } \\
\text { produto }\end{array}$ \\
\hline Reestruturação & $\begin{array}{l}\text { Tecnologia: detecção do gap tecnológico do país } \\
\text { Economia: alta taxa de inflação e recessão econômica com conseqüente } \\
\text { perda do controle das atividades e queda nas vendas }\end{array}$ \\
\hline $\begin{array}{l}\text { Desenvolvimento de } \\
\text { Mercado }\end{array}$ & Clientes: expansão das atividades em mercados de pouca concorrência \\
\hline Foco & $\begin{array}{l}\text { Clientes: concentração das atividades em um grupo de clientes (área } \\
\text { médica) } \\
\text { Concorrentes: aumento da concorrência da indústria chinesa }\end{array}$ \\
\hline Consolidação & $\begin{array}{l}\text { Tecnologia: domínio da tecnologia em equipamentos } \\
\text { médicos evidencia-se como diferencial da empresa } \\
\text { Economia: perda competitividade devido à taxa de câmbio }\end{array}$ \\
\hline
\end{tabular}

Quadro 28 - Especificidades contextuais de acordo com as fases evolutivas: empresa C

\section{- Especificidades de organização}

De forma geral, a organização da empresa $\mathrm{C}$ apresenta características flexíveis, mas registra tendência à incorporação de aspectos mecanicistas. Em diversos momentos, fica evidente a interação de níveis inferiores no desenvolvimento da tecnologia e do produto e nas 
decisões da empresa. "Um dos produtos em linha foi proposto por um vendedor que teve uma idéia ao visitar um cliente. Praticamente em todos os projetos há envolvimento de várias equipes com funcionários de diversos níveis", exemplificou o dirigente $\mathrm{C}$, informando como a interação resulta em novos projetos para a empresa. Na empresa há regras e procedimentos formais de comunicação, oriundos, em sua maioria, de processo de certificação. Por outro lado, a comunicação informal, também presente no seu dia-a-dia, é responsável pela agilidade e fluidez das informações nos diversos níveis hierárquicos. "O presidente da empresa, por exemplo, vai à produção verificar um processo ou uma informação. Isto está ficando cada vez mais raro, mas ainda acontece muito" - comentou o dirigente $\mathrm{C}$, ressaltando a presença da informalidade nas relações da empresa e a diminuição da influência dos níveis inferiores nas ações estratégicas. Ex-funcionários foram estimulados a aproveitar oportunidades para a criação de empresas próprias, que viriam a ser fornecedoras, clientes ou representantes atuais da empresa $\mathrm{C}$.

Há, na empresa, uma clara divisão de trabalho, executado por especialistas alocados em cargos, nas diversas áreas. As tarefas rotineiras são, muitas vezes, interrompidas por atividades variadas e flexíveis, demandadas por ações não previstas. As decisões estratégicas centralizam-se nos dirigentes e sócios, mas, com frequiência, funcionários de níveis inferiores são consultados e/ou participam da tomada de decisão. Atualmente, um conselho administrativo é responsável pela decisão estratégica na empresa $\mathrm{C}$.

A análise das especificidades de organização da empresa $C$ pode ser feita em duas etapas, considerando suas fases evolutivas: a primeira etapa compreende as fases de aprendizado, concepção do negócio e reestruturação; a segunda abrange as fases de desenvolvimento de mercado, foco na área médica e consolidação da empresa. Na primeira etapa, destacam-se os seguintes aspectos: Na segunda, apresentam-se:. Registre-se que, na segunda etapa, a empresa passou a apresentar uma estrutura funcional.

Atualmente, a empresa encontra-se em uma fase de reestruturação de sua organização, com clara tendência a mecanizar sua estrutura. Face ao seu crescimento, nos últimos anos, visa profissionalizar sua administração. "O modelo da empresa caminha para uma situação que logo não servirá mais. Precisamos caminhar para a profissionalização, ser mais racional e analítico. Precisamos de uma empresa que analisa mais e corre menos risco. Estamos procurando o equilíbrio entre ser flexível e burocrático" - comentou o dirigente C sobre o projeto de a empresa abrir o capital na Bolsa de Valores, a longo prazo.

A empresa utiliza sistemas de informações complexos e eficientes, mas que não abrangem toda a especificidade do negócio. "É muito difícil trabalhar com um sistema que 
exige alta previsibilidade" - disse o dirigente C, argumentando que, muitas vezes, falta informação para se realizar um planejamento mais eficiente e de longo prazo, devido a características tecnológicas ou a eventos não previstos. Um exemplo é o impacto sobre a gestão de materiais e produção de um determinado produto devido a evento recente, não previsto no plano anual da empresa.

Os planejamentos elaborados, na empresa C, são de longo, médio e curto prazo. O planejamento estratégico, de longo prazo, passou a ser feito recentemente, com o apoio de um consultor em gestão. Deste planejamento, que contém análises extensas sobre o ambiente e os pontos fortes e fracos da organização, derivam os projetos e investimentos a serem realizados. "Há algum tempo era tudo na loucura. Agora temos uma estrutura que nos permite realizar um planejamento baseado em análise de mercado. Fazemos estudos e definimos estratégias em um nível nunca feito anteriormente. Passamos por um amadurecimento administrativo" declarou o dirigente $\mathrm{C}$, analisando a evolução do processo de criação de estratégias na empresa. Apesar do amadurecimento administrativo ressaltado pelo dirigente e do esforço em elaborar estratégias deliberadamente, muitas ações são emergentes e proporcionam maior agilidade e flexibilidade à empresa. "A gente olha para o futuro, mas não muito distante. Muito pouco do que somos hoje foi planejado" - concluiu.

Apresentam-se a seguir as especificidades de organização da empresa C de acordo com as suas fases evolutivas (quadro 29).

\begin{tabular}{|l|l|}
\hline \multicolumn{1}{|c|}{ Fases } & \multicolumn{1}{c|}{ Especificidades } \\
\hline Aprendizado & $\begin{array}{l}\text { estrutura flexível } \\
\text { concentração das atividades nos dirigentes } \\
\text { informalidade nas relações } \\
\text { comunicação informal } \\
\text { pouca divisão do trabalho } \\
\text { tarefas não rotineiras }\end{array}$ \\
\hline Rencepção do negócio
\end{tabular}

Quadro 29 - Especificidades de organização de acordo com as fases evolutivas: empresa C 
- $\quad$ Especificidades do(s) dirigente(s)-estrategista(s)

Os dirigentes-estrategistas da empresa $\mathrm{C}$ buscavam, a princípio, criar uma empresa de tecnologia em ótica, pautada em suas competências e experiências. Entusiastas das possibilidades de aplicação da tecnologia, não possuíam, contudo, conhecimento administrativo e tomavam decisões a partir de percepções, intuição e análises vagas. Devido a um equívoco na mensuração do potencial de mercado - as indústrias brasileiras não absorveram os produtos iniciais - e a crescentes custos e despesas, a crise financeira se instaurou e quase levou a empresa $\mathrm{C}$ a falir.

A situação crítica foi contornada com a entrada de um sócio-investidor, que, sendo racional e detalhista e detentor de conhecimento administrativo, demandou controles, demonstrações financeiras e, com o auxílio de um funcionário de sua confiança, diretor de finanças, passou a apoiar toda a gestão da empresa. "No começo foi terrível. Todos nós (sócios-fundadores) viemos da universidade e não tínhamos noção do que é uma empresa. Ele (sócio-investidor) nos ensinou, nos educou administrativamente" - disse o dirigente C, justificando o apoio fundamental do sócio-investidor que, no início, não sabia da crise pela qual a empresa vinha passando. Então se dedicou a recuperar a empresa e fazê-la um sucesso. Observe-se que não atuou diretamente na gestão e não tinha nenhum vínculo com o desenvolvimento de tecnologia.

Um dos sócios-fundadores, professor universitário, destacou-se por sua ousadia, vontade de empreender e assumir riscos, porém não se adaptou ao cotidiano da empresa e, por motivos pessoais e financeiros, vendeu sua parte acionária. A participação desse sócio foi fundamental para a criação da empresa e para a entrada do sócio-investidor, que acreditou no potencial do negócio, em grande parte devido ao seu conhecimento e à sua reputação na área.

Outro sócio-fundador, também professor universitário, arrojado, visionário, empreendedor, intuitivo e com grande conhecimento na área de tecnologia ótica, foi responsável por inúmeras inovações realizadas na empresa C. Entusiasmado pelo negócio, dedicou-se a transformá-lo em uma empresa reconhecida internacionalmente. Em seu esforço foi apoiado pelos demais sócios, igualmente importantes no contorno das crises e dificuldades e nos sucessos alcançados. Destaque-se que características relativas ao estilo de gestão permitem classificar os sócios em categorias distintas: tecnocrata (eficiente, racional, determinando, aplicado, exigente), artesão (responsável, equilibrado, realista e previsível) e artista (ousado, emotivo, imaginativo, visionário, intuitivo). Conforme ressalta o dirigente, 
embora apresentando um perfil próprio, quase todos os sócios têm características mistas dos perfis citados. Somados os 23 anos de trabalho na empresa e mais alguns na oficina de ótica, constata-se que mantêm, há longo tempo, um relacionamento estável e respeito mútuo. " $A$ gente conversa muito para evitar desavenças. É muito franca a comunicação entre os diretores. Mantemos as amizades devido a nossas dívidas" - disse, brincando, o dirigente C.

Com o passar dos anos, os dirigentes-estrategistas adquiriram conhecimento administrativo especializado em suas áreas de atuação. Na gestão da empresa, estão presentes os seus valores, como valorização do conhecimento, estabelecimento da confiança nas relações com os stakeholders, honestidade e flexibilidade na resolução de problemas. A liderança exercida pelos dirigentes e a expansão do mercado para produtos de alta tecnologia incorporada sobressaem como um dos principais motivos para o sucesso da empresa.

A seguir encontram-se as especificidades do(s) dirigente(s)-estrategista(s) da empresa $\mathrm{C}$ de acordo com as suas fases evolutivas (quadro 30).

\begin{tabular}{|l|l|}
\hline \multicolumn{1}{|c|}{ Fases } & \multicolumn{1}{c|}{ Especificidades } \\
\hline Aprendizado & $\begin{array}{l}\text { Conhecimento técnico } \\
\text { Percepção do Mercado }\end{array}$ \\
\hline Concepção do negócio & $\begin{array}{l}\text { Empreendedorismo } \\
\text { Intuição } \\
\text { Dedicação ao negócio } \\
\text { pouca experiência administrativa }\end{array}$ \\
\hline Reestruturação & $\begin{array}{l}\text { Flexibilidade } \\
\text { Visão } \\
\text { Ousadia } \\
\text { Determinação } \\
\text { Rocenvolvimento de Mercadionalidade }\end{array}$ \\
\hline
\end{tabular}

Quadro 30 - Especificidades do dirigente estrategista de acordo com as fases evolutivas: empresa C 


\section{PROCESSO ESTRATÉGICO NA PEQUENA EMPRESA DE BASE TECNOLÓGICA}

Neste capítulo, a partir da apresentação e análise dos dados do trabalho de campo, busca-se fundamentar a proposição de um mapa estratégico para as pequenas empresas de base tecnológica de São Carlos/SP. A interpretação dos resultados, realizada para se chegar a uma visão geral do tema em destaque, contempla a triangulação dos métodos e dados e a comparação do resultado obtido com o referencial teórico. Com base nesta visão geral, propõe-se o mapa estratégico.

\subsection{INTERPRETAÇÃO DOS RESULTADOS}

A interpretação dos resultados sob a perspectiva do trabalho de campo e do referencial teórico, contempla os seguintes tópicos:
a) características das empresas de base tecnológica;
b) as especificidades de gestão da pequena empresa;
c) o processo de criação de estratégias.

8.1.1 As características das empresas de base tecnológica

Quanto às características das EBT, conclui-se que:

- São empresas criadas, em sua maioria, a partir de conhecimentos gerados por grupos de pesquisa e/ou de um estímulo ou da ação de uma empresa. No primeiro caso, os empreendedores podem ou não integrar o grupo de pesquisa, mas, reconhecendo que se pode aplicar uma tecnologia desenvolvida pelo grupo em um produto inovador, vislumbram a possibilidade de criar a empresa. Em algumas circunstâncias, o processo se 
concretiza quando uma organização demanda pelo fornecimento e, muitas vezes, também pelo desenvolvimento de um produto. Na segunda situação, geralmente as EBT surgem da demanda de uma empresa que, desejando desenvolver um novo fornecedor, identifica a aplicação de uma tecnologia e investe em pesquisa para aprimorar a sua aplicação. Observa-se, assim, que a EBT nasce de um produto e de um impulso do mercado.

- Particularidades estão presentes no contexto de criação das EBT, como, por exemplo, algumas situações relacionadas ao grupo de pesquisa que impulsionam a sua criação. De acordo com informações de dois dos professores entrevistados (1 e 3) e dados colhidos durante a observação feita, relacionam-se algumas destas particularidades.

- Cultura empreendedora do grupo de pesquisa: constatada, na investigação, pelo comportamento do líder, que orientava seus alunos, estimulando-os a criar empresas, por não haver, na universidade, oportunidades de atuação para todos os seus membros. Este fato indica a existência de uma cultura empreendedora no grupo de pesquisa, que possibilita transformar os projetos desenvolvidos em negócio. Sob este aspecto, a criação da empresa é uma forma de continuar o desenvolvimento de pesquisas. Tratase de uma particularidade dos grupos "maduros", como os que pertencem a alguns institutos que possibilitam a criação de dezenas de EBT.

- Conflitos internos nos grupos de pesquisa: conflitos entre o pesquisador e o orientador ou relacionados com a própria cultura do grupo. Algumas vezes o embate decorrente dos interesses acadêmicos do orientador/grupo e do investigador faz com que a sua característica empreendedora sobressaia como uma forma de comprovar a viabilidade da inovação resultante de sua pesquisa, ensejando a criação da empresa.

- Ausência da característica empreendedora: o pesquisador detém um conhecimento técnico inovador, mas, para introduzir o produto ou processo no mercado, muitas vezes se associa a um empreendedor para viabilizar o negócio.

○ Visão individual do empreendedor em relação ao grupo: alguns pesquisadores, que não se identificam com a dinâmica do ambiente acadêmico, mas pretendem desenvolver seus estudos, vêem a criação da empresa como uma possibilidade de conciliar a geração e aplicação de tecnologia resultante de pesquisa com o seu desejo de desenvolver produtos e mercados.

- Pesquisador empreendedor: tem a visão empreendedora e desenvolve seu trabalho para atender, simultaneamente, ao seu interesse de criar um negócio e às necessidades ou interesses do grupo de pesquisa. 
- Cultura do pólo que concentra empresas de tecnologia da cidade de São Carlos: os pesquisadores, para realizarem seus estudos, estabelecem contato com outras organizações e/ou colegas que criaram empresas resultantes de pesquisas. Estes contatos estimulam o desenvolvimento da cultura empreendedora em EBT da cidade.

- A vocação para pesquisa é outra característica relevante identificada nas EBT. Como a tecnologia é um dos fatores de competitividade, investe-se continuamente no desenvolvimento e na aplicação de tecnologia em sua gestão. Com departamentos de $\mathrm{P} \& \mathrm{D}$, em diferentes fases estruturais, é comum que se façam parcerias que complementem $\mathrm{o}$ processo. As parcerias com universidades, instituições de pesquisa, clientes e fornecedores apóiam o processo de P\&D interno, chegando, em alguns casos, a se estabelecer um relacionamento de cooperação.

As EBT, portanto, caracterizam-se pela inovação tecnológica aplicada ao desenvolvimento de produtos/processos únicos. Considerando a pesquisa como uma estratégia de capacitação tecnológica, investem em P\&D e em parceria e cooperação com universidades, centros de pesquisa, clientes e fornecedores. Destinam, conforme consta da literatura, altos volumes do que faturam a $\mathrm{P} \& \mathrm{D}$, que se realizam em departamentos próprios, independentemente do nível de estruturação que estes apresentem. A tecnologia, portanto, é um diferencial competitivo para as EBT que oferecem produtos e/ou processos com tecnologia inovadora e, às vezes, única, utilizada como um fator de diferenciação do produto e da empresa no mercado.

Não se constata que as EBT sejam relevantes porque provêem um número de empregos maior que o oferecido por pequenas empresas tradicionais, mas sim pela inovação, mediante a qual impulsionam o mercado e desenvolvem tecnologias, e pela absorção, no mercado nacional, de mão-de-obra especializada. São empresas dinâmicas, que crescem rapidamente, conforme assinalam Fontes e Coombs (2001), referindo-se à sua flexibilidade, ou seja, à capacidade para modificar a sua organização e desenvolver novas tecnologias. Por outro lado, porém, até sua consolidação, enfrentam problemas de natureza interna e externa.

Uma das dificuldades enfrentadas pelas EBT é a falta de experiência e conhecimento administrativo. "A empresa pode até nascer apenas com a visão do produto, mas quando cresce precisa ter a visão gerencial" - analisou o professor 1. Em relação à abertura, comentou que apenas a experiência e o conhecimento na área são suficientes, mas que "sem organização e recurso financeiro a empresa de tecnologia não sobrevive".

A gestão ineficiente, que decorre da falta de capacitação de seus administradores e da falta de habilidade para comercializar a sua tecnologia, representa um fator interno 
condicionante de dificuldades. Diferentemente do que autores da área afirmam, a escassez de recursos humanos não foi identificada como um problema, supondo-se que esta situação seja específica do pólo de São Carlos, que conta com mão-de-obra especializada e altamente qualificada. Por outro lado, um fator interno que condiciona dificuldades é a escala de produtos que, sendo pequena e apresentando baixo grau de automação, afeta, de modo direto, a competitividade, como esclarecem Pinho, Côrtes e Fernandes (2002), e configura uma condição em consonância com os problemas enfrentados pelas EBT, como a baixa produtividade e altos custos para competir em um mercado globalizado. Este fator põe em evidência a importância da incorporação de tecnologia como estratégia competitiva.

O empreendedor da EBT destaca-se pela capacidade de transformar-se, passando de tecnólogo a empresário, para suprir problemas internos de gestão, conforme destacam Becker e Lacombe (2003) e se constata nas três empresas investigadas. Esta transformação, porém, o afasta do desenvolvimento tecnológico - principal fator de competitividade da EBT. Percebese que, neste tipo de empresa, as atividades se concentram no dirigente, que acumula trabalhos funcionais e de direção, característica típica da pequena empresa, conforme descrito por Drucker (1981).

Como fator externo determinante de dificuldades destaca-se a limitada capacidade para absorver e comercializar produtos de alta tecnologia, em especial quando a empresa oferece uma tecnologia inovadora sem uma clara aplicação ou atua em mercados emergentes. Entre as condições ambientais das EBT, destaca-se também o desenvolvimento tecnológico que estabelece o seu nível de volatilidade, capacidade e complexidade - também considerado uma importante barreira à entrada de competidores.

O recurso financeiro desponta como outro fator relevante para a sobrevivência das EBT. Nos primeiros anos de vida das EBT, os empreendedores têm dificuldade em oferecer garantias reais para a obtenção de financiamento. Destacam-se, como alternativas para as pequenas empresas, os programas de financiamento a fundo perdido, como o Programa de Inovação Tecnológica em Pequenas Empresas (PIPE) da FAPESP.

A visão que o dirigente da EBT tem de seu contexto influencia a sua estratégia de capacitação tecnológica e define os seus esforços para promover a inovação nos produtos (atuais ou novos), nas práticas administrativas e/ou no desenvolvimento de tecnologias para novos mercados. Contudo, segundo ressaltam Lefebvre, Mason e Lefebvre (1997), a centralização das atividades dificulta a inovação nas EBT, fato comprovado na empresa A (fases de refinamento e desenvolvimento) e na empresa B (fase de crescimento). 
8.1.2 As especificidades de gestão da pequena empresa

A pequena empresa apresenta uma estrutura simples, que comporta relações informais e em cuja gestão refletem os valores e as ambições dos dirigentes. Mintzberg (2003), considerando a pequena empresa como uma estrutura simples, explicita e diferencia alguns aspectos que a caracterizam: por um lado, flexibilidade, pouca divisão do trabalho, comunicação informal e tarefas variadas, não rotineiras e flexíveis (características orgânicas); por outro, cargos ocupados por especialistas e decisões centralizadas, que se concentram na alta administração (características mecânicas). Estas características conferem à pequena empresa flexibilidade, rapidez nas mudanças e capacidade para atuar em nichos de mercado (DEAN-BROWN; BAMFORD, 1998). É importante ressaltar que as características mecânicas observadas se devem à peculiaridade tecnológica, que demanda conhecimento específico, ao pequeno porte e à gestão centralizada no dirigente.

Estão inseridas em um ambiente dinâmico, ou seja, em um ambiente cujas condições se alteram e passam a configurar novas circunstâncias, que devem ser consideradas continuamente para que se mantenham competitivas. A interação empresa e ambiente influi na criação de estratégias, conforme se constatou nas empresas investigadas e nas observações dos professores envolvidos na pesquisa. De acordo com Dodge, Fullerton e Robbins (1994) e McCarthy (2003), a interação com o ambiente e a reação às condições ambientais constituem fatores determinantes para sua sobrevivência e seu crescimento.

Como as mudanças ambientais são intensas e constantes e dificultam as previsões sobre o futuro, conforme destacam Mintzberg (1994) e Hough e White (2003), as análises realizadas resultam em planos mais detalhados, desenvolvidos em curto e médio prazo, ou genéricos, desenvolvidos em longo prazo. Ainda considerando a imprecisão do ambiente, registre-se que a dificuldade de previsão é visível em tecnologias com alto grau de inovação e sem uma aplicação específica e mercado definido.

A dificuldade de coletar informações e analisá-las é um dos entraves ao processo deliberado, como constatam Quezada et al. (1999), e enfatizam os dirigentes das empresas investigadas, justificando que, por falta de tempo e/ou de recursos, uma análise superficial e genérica serve de base para a definição de várias decisões relevantes ao futuro da empresa. McGee e Sawyer (2003) destacam que as pequenas empresas não possuem uma infraestrutura adequada à coleta de informações, devido ao dinamismo e alto grau de incerteza de seu ambiente. Porém, como Menezes e Almeida (1997) alertam, a pró-atividade é um comportamento necessário na busca de informações sobre o ambiente. A propósito, os 
dirigentes das empresas investigadas procuram obter informações - com fornecedores, clientes, funcionários e também pela internet - de maneira ágil, simples e acessível financeiramente. Esta pró-atividade evidencia-se no dirigente da empresa A, que demonstra a importância da análise para a definição dos investimentos e projetos futuros.

Segundo McCarthy (2003), os dirigentes das pequenas empresas agem de acordo com seus princípios, impulsos e intuição. Em sua maioria, consideram-se intuitivos na gestão. Alguns são realmente intuitivos, porém outros assim se julgam, porque não têm uma compreensão global das condições que as empresas enfrentam, situação que predomina pela falta de informação e reduzido interesse em analisar as circunstâncias.

A falta de uma compreensão mais abrangente das condições que influenciam a gestão da pequena empresas deve-se, em grande parte, a outra característica da pequena empresa, a centralização das atividades. O dirigente, por acumular funções, não dispõe do tempo necessário para tratar da estratégia. Esta situação, por um lado, o torna um dirigente flexível, versátil, conhecedor da rotina diária da empresa, na qual está envolvido, mas, por outro, conforme mencionado anteriormente, um dirigente com pouco tempo para tratar das questões estratégicas (DRUCKER, 1981; GOLDE, 1986). Assim sendo, diretamente engajado na resolução de problemas cotidianos, toma decisões com base em informações genéricas, obtidas por meio de sua rede pessoal de contatos e experiência, à procura de um curso de ação satisfatório para a empresa.

Diversamente do exposto, os dirigentes das empresas investigadas se classificam, de acordo com as categorias de Pitcher (1993; 1999), como tecnocratas, artesãos e artistas, respectivamente. Os que não se prendem a detalhes, seguem a sua intuição, são imaginativos e empreendedores enquadram-se na categoria de artistas, com a qual os dirigentes menos se identificam. Esta classificação possivelmente decorre de duas alternativas para se traçar o perfil: 1) há uma combinação de adjetivos que compõem o perfil do dirigente, ou seja, ele não é puramente um tecnocrata, artista ou artesão (alternativa também considerada pela autora) e/ou 2) o dirigente pertence a uma das categorias prioritariamente. Esta categorização dos dirigentes por meio de seus atributos corresponderia às características do "Sistema de Administração Estratégica”, propostas por Escrivão Filho (2006), voltadas à organização (tecnocrata), à liderança (artesão) ou ao ambiente (artista). 


\subsubsection{O processo de criação de estratégias}

Quanto ao processo de criação de estratégias, destaque-se que comporta características deliberadas e emergentes em diferentes níveis. As principais considerações sobre este processo são registradas a seguir.

- As características deliberadas e emergentes apresentam-se, simultaneamente, sendo complementares e interdependentes, conforme demonstrado na Análise dos Componentes Principais, realizada na fase 1 , e na análise de conteúdo, desenvolvida na fase 2.

- As estratégias emergentes são ações realizadas no cotidiano, que possibilitam solucionar problemas e aproveitar oportunidades. Implicam: criatividade, definição de objetivos gerais, sem o seu desdobramento em metas minuciosamente definidas, estabelecimento de prazos e delegação de responsabilidades. Portanto, o processo emergente é irregular, informal e não segue etapas previstas da ação para a reflexão, das operações para questões estratégicas.

- As estratégias deliberadas são estabelecidas pela alta administração, a partir da análise racional de informações relevantes (sobre os aspectos internos de gestão e o ambiente organizacional), para antecipar ações especificadas em um cronograma. O processo deliberado é regular, realizado em etapas, formal, da reflexão para a ação detalhada, da estratégia para as operações.

- A coexistência de aspectos deliberados e emergentes resulta em um processo que abrange: ações operacionais e intuitivas, análise de informações, uso da criatividade, para antecipar acontecimentos e tomar decisões em ocorrências cotidianas, objetivos claros e detalhados para algumas ações e gerais para outras. Trata-se, portanto, de um processo cujas características se apresentam mais deliberadas ou mais emergentes, em diferentes graus de intensidade.

- A interação e a intensidade dos aspectos deliberados e emergentes do processo de criação de estratégias dependem, diretamente, das fases evolutivas que a empresa vivencia.

- A relevância das ações na fase anterior à criação da empresa: em sua maioria, não são planejadas e, na fase que antecede a sua criação, conforme constatou o professor 3: "há apenas uma reflexão sobre a possibilidade de a empresa vir a ser um sucesso". Nesta etapa, as reflexões sobre o mercado e os clientes são superficiais e genéricas e as ações se voltam à aplicação da tecnologia - ao desenvolvimento do produto. A fase antecessora, cujo foco é o produto, tem forte impacto sobre o estágio de criação da empresa, no qual se enfrentam impasses mercadológicos. A identificação das necessidades dos clientes e do 
efetivo potencial de mercado realiza-se em um processo maturidade que ocorre mediante a interação da empresa com o mercado.

- As fases evolutivas apresentam especificidades de gestão que determinam a predominância de características deliberadas ou emergentes. Considera-se, portanto, que a dinâmica das variáveis organizacionais no processo de criação de estratégias está relacionada com as suas fases de evolução, cujas peculiaridades determinam a influência maior ou menor das especificidades de gestão.

A partir da análise integral dos resultados, pode-se inferir que:

- as estratégias pretendidas diferem das estratégias realizadas;

- as estratégias identificadas (realizadas) são pretendidas e emergentes;

- as características do dirigente influenciam o estabelecimento das estratégias pretendidas;

- determinadas características da organização e do contexto impedem que algumas estratégias pretendidas se transformem em estratégias realizadas - são abandonadas ou consideradas em uma análise futura, que poderá torná-las pretendidas novamente;

- características do contexto e da organização influenciam a emersão de estratégias.

A criação de estratégias ocorre a partir de um processo criativo e informal (processo emergente) e também de uma análise (processo deliberado), processos que podem se “entrelaçar" na formação de estratégias, conforme observa Mintzberg (1991), uma vez que entre eles não há uma situação dicotômica, mas de complementação.

O processo de criação de estratégia caracteriza-se por sua informalidade. Não constitui um processo totalmente deliberado, pois, embora apresente uma análise, esta não é sistematizada e se apresenta simultaneamente à utilização da intuição e da imaginação na compreensão das principais possibilidades para a tomada de decisões estratégicas (RICHERS, 1998).

A intuição é outra característica relevante ao processo de criação de estratégias das EBT. Como ressaltam Brouthers, Andriessen e Nicolaes (1998), em algumas circunstâncias as decisões não são racionais, baseando-se nas aspirações e experiência do dirigente. Por outro lado, contrariamente à situação identificada pelos autores, em algumas circunstâncias o processo demanda análise. Os dirigentes das EBT buscam, sem sistematização, coletar informações relevantes, com clientes ou em feiras e eventos. Assim, realizada com base em dados genéricos e superficiais, a análise, correspondendo à avaliação de Burke e Farrat (2004), não aborda as condições internas e externas em sua totalidade, e se desenvolve de forma dirigida, oportuna e instintiva. Conforme se discutiu anteriormente, os dirigentes não 
fazem análises completas e complexas antes de agir, com a ressalva de que estas se tornam mais elaboradas ao longo das fases evolutivas. Concluindo, reitere-se que fazem uma reflexão não-estruturada, que resulta em análise superficial e compreensão intuitiva da situação (LIMA, 1999).

A situação mencionada no parágrafo anterior leva a considerar o processo de criação de estratégias das EBT em conformidade com a proposta de Hambrick e Mason (1984), em especial quanto à característica "percepção administrativa", assim denominada pelos autores, que se refere à visão do dirigente-estrategista. O processo de criação de estratégias das pequenas empresas de base tecnológica estudadas assemelha-se de certo modo ao processo apresentado por Barros (2001), levando-se em conta diversos dos seus aspectos, tais como: a informalidade, a imprevisibilidade, o ajuste contínuo para se manter o alinhamento da organização com o ambiente e o estabelecimento de uma rede social, com todos os parceiros estratégicos, principalmente, clientes e fornecedores. Destaca-se que o processo não é estruturado e sistemático, implica ajuste contínuo, que demanda avaliações e revisões constantes e resulta em pequenas mudanças.

Destaque-se que o processo de criação de estratégias se modifica ao longo das fases evolutivas do ciclo de vida organizacional: inicia-se como emergente, depois assume características incrementais e, por fim, passa a apresentar aspectos deliberados. Estas características, genéricas e predominantes, coexistem, interagem e se integram de maneira dinâmica na criação de estratégias, carreando vantagens e limitações próprias de cada tipo de processo mencionado. Como explicitado por Day (2000) e Bhide (1994), trata-se de um processo dinâmico e evolutivo, que integra suposição, análise e ação simultâneas.

Concluindo, pode-se dizer que o processo de criação de estratégias apresenta características: do modo empreendedor, informais, criadas a partir da visão do líder. É, ao mesmo tempo, deliberado - concentra-se nas intenções do líder - e emergente, à medida que a visão do dirigente se altera com os detalhes surgidos durante o seu desenvolvimento, exigindo que se busque adaptação, inovação ou aprimoramento. 


\subsection{A CRIAÇÃO DE ESTRATÉGIAS E AS FASES EVOLUTIVAS}

Ao analisar o processo de criação de estratégias, as características das EBT e as especificidades de gestão das pequenas empresas de base tecnológica, destacam-se alguns aspectos:

1) A importância da fase anterior à criação das empresas - antecessora - na qual se definem ações determinantes para sua atuação ao longo de vários anos. Nas empresas investigadas, os empreendedores possuíam um conhecimento tecnológico específico que possibilitou desenvolver o produto inicial. Todas nasceram de um produto e o rumo que tomaram foi delimitado pela interação com o ambiente.

2) As empresas nasceram de uma demanda inicial para um produto. Aliado ao desenvolvimento do produto inicial na fase antecessora, a criação das três empresas foi a partir de um impulso do mercado, com uma demanda do produto por outras empresas e pela universidade.

3) A falta de conhecimento administrativo dos empreendedores culminou em dificuldades e crises que as empresas precisaram superar para crescer e se desenvolver.

4) Ausência de um processo formal de planejamento para a criação das empresas, como a elaboração de um plano de negócios ou mesmo reflexões sobre a viabilidade do empreendimento. A atenção dos empreendedores voltava-se à viabilidade de se produzir equipamentos/produtos. Em todos os casos, as empresas foram criadas simultaneamente ou em período anterior à criação do Parqtec, sendo que, na época, não se havia difundido a importância da análise inicial para a criação de uma empresa, conceito amplamente difundido pelo Sebrae e outros agentes na década de 90 . O foco inicial era o produto e não o mercado.

5) As variáveis contextuais relevantes no processo de criação de estratégias são os clientes, os concorrentes, a tecnologia e as condições econômicas. Entre as especificidades contextuais destacam-se: falta de informações e visão de mercado.

6) Registro da maturidade na organização das empresas investigadas, derivado da superação de crises e dificuldades. Apresentaram inicialmente uma organização flexível, informal, sem clara divisão do trabalho e delegação de responsabilidades. Em uma segunda fase, registraram-se os seguintes aspectos: clara divisão de tarefas, formalização das comunicações, regras e procedimentos, decisão baseada na alta administração e maior tendência à racionalidade na tomada de decisões. Assim, como especificidades de organização relevantes no processo de criação de estratégia evidenciam-se: falta de recursos e de pessoal qualificado, 
informalidade nas relações, administração não-profissional e não utilização de ferramentas administrativas.

7) As especificidades do dirigente-estrategista facilitam ou dificultam a criação de estratégias condizentes com a realidade da pequena empresa. São características que se relacionam diretamente com o perfil do(s) principal(is) dirigente(s) e refletem seus valores, suas ambições, sua visão do que é ou deveria ser o negócio e assim por diante. Os dirigentes das empresas investigadas apresentam características marcantes de um tecnocrata, de um artista e de um artesão, conforme os perfis de estrategistas propostos por Pitcher (1999). De acordo com as especificidades do dirigente-estrategista a gestão da empresa é mais conservadora, individualista, centralizada ou imediatista (com ações voltadas a resultados de curto prazo apenas) e o processo de criação de estratégias é mais ou menos deliberado ou emergente. De forma geral, os valores dos dirigentes evidenciam-se na gestão, chegando a se confundir com os valores organizacionais.

Constata-se que o "entrelaçamento" dos processos deliberado e emergente demanda um subprocesso formal que estabelece as estratégias intencionadas e define as condições estruturais, contextuais e de comportamento que possibilitam a emersão de estratégias, a partir da interação cotidiana da empresa com o seu ambiente. Mariotto (2003) denomina este processo formação contínua de estratégia, considerando-o próprio de organizações em fase avançada do seu ciclo de vida. Perussi Filho (2006) entende que o processo de criação de estratégias é quântico e segue um padrão associado às fases do ciclo de vida das empresas.

Verifica-se que os processos emergente e deliberado coexistem permanentemente, em maior ou menor grau, no processo de criação de estratégias. Além de coexistirem, estes processos interagem e se integram, ou seja, sua unicidade sobressai. O processo de criação de estratégias demanda características deliberadas e emergentes, como a intuição e a análise, a formalidade e a informalidade, o envolvimento da alta administração e dos níveis inferiores, conforme aspectos presentes no modelo de Mariotto (2003), com a ressalva de que a formação contínua de estratégia é uma característica não identificada em fases evolutivas iniciais. O que define o quanto são deliberados ou emergentes são alguns aspectos das fases evolutivas da EBT e a suas respectivas especificidades de gestão. Esta constatação ajusta-se às proposições de Perussi Filho (2006).

O processo de criação de estratégias das pequenas empresas de base tecnológica é emergente, nas primeiras fases evolutivas, passando a apresentar características deliberadas de acordo com a maturidade administrativa da empresa e a consolidação do negócio. Enfim, o foco das ações estratégicas muda de acordo com a maturidade e a consolidação da empresa no 
mercado. Compreende-se que as empresas passam por fases evolutivas com características semelhantes, assim denominadas: antecessora, criação, consolidação, crescimento e desenvolvimento. Em tais fases o processo de criação de estratégias caracteriza-se como emergente e deliberado em maior ou menor grau, conforme se destaca na figura 44. Percebese que, à medida que a empresa evolui, crescem, gradativamente, a formalização, a sistematização, a análise e a racionalidade na criação de estratégias, revelando um caráter cada vez mais deliberado.

A passagem de uma fase a outra implica a criação de estratégias com características diversas. Conforme a proposta de Perussi Filho (2006), o processo de criação de estratégias apresenta características deliberadas ou emergentes em cada uma das fases e a transição de um estágio a outro é impulsionada por um evento marcante revelado pelas especificidades de gestão.

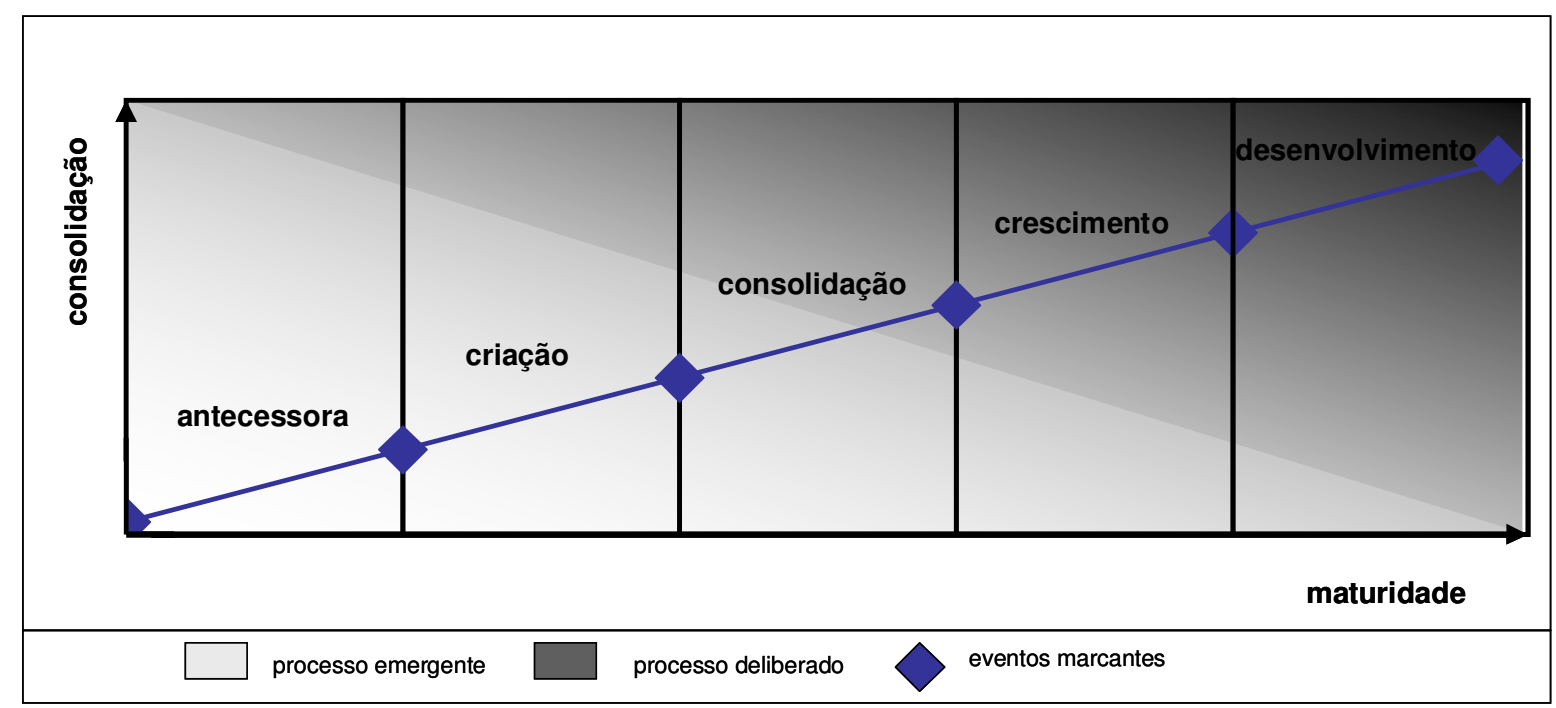

Figura 44 - Fases evolutivas e o processo de criação de estratégias

De maneira sucinta e simplificada, observa-se que, na fase antecessora, o dirigente se destaca como o empreendedor que detém o conhecimento tecnológico a ser incorporado no produto e visualiza, a partir de uma demanda, a possibilidade de criar a empresa. Com foco no produto, a partir da criação da empresa, as especificidades de organização passam a influenciar as estratégias da empresa e, com a falta de experiência administrativa e visão de mercado, a empresa enfrenta desafios para os quais não está preparada. A partir das dificuldades iniciais, o dirigente procura a consolidação da empresa, estabelecendo parcerias 
com universidades, clientes e fornecedores, para desenvolver tecnologia, ampliar a sua atuação no mercado e, conjuntamente, proceder à reestruturação administrativa. $\mathrm{O}$ crescimento se estabelece quando a visão do dirigente implica aproveitar oportunidades no ambiente. No desenvolvimento o dirigente busca a diversificação do negócio, com a expansão ou redefinição da linha de produtos e atuação em novos mercados.

Perussi Filho (2006) distingue quatro fases no ciclo de vida organizacional das pequenas empresas de base tecnológica, identificadas em uma pesquisa empírica. As fases evolutivas propostas neste trabalho se assemelham às fases do ciclo de vida apresentadas por Perussi Filho (2006), por alguns aspectos, tais como: o foco na aplicação de tecnologia e a sua viabilização em um produto que viabiliza a criação da empresa e o foco no mercado pela eficácia externa. As fases evolutivas identificadas também se assemelham, em muitos aspectos, ao modelo de ciclo de vida das pequenas empresas, proposto por Churchill e Lewis (1991). As variáveis utilizadas pelos autores - independência de ação, estrutura organizacional, sistemas formais, objetivos estratégicos, envolvimento do dirigente e estilo de gestão - podem ser sintetizadas nas variáveis contexto e dirigente. O contexto, porém, não foi identificado como uma variável relevante na proposição dos autores. No quadro 31, relacionam-se as fases do ciclo de vida apresentadas pelos autores com as fases evolutivas que despontam neste trabalho.

\begin{tabular}{|l|l|l|}
\hline \multicolumn{1}{|c|}{ Fases evolutivas } & \multicolumn{1}{c|}{ Persussi Filho (2006) } & \multicolumn{1}{c|}{ Churchill e Lewis (1991) } \\
\hline Antecessora & & \\
\hline Criação & Criação da empresa & Existência \\
\hline Consolidação & Eficácia externa & Sobrevivência \\
\hline Crescimento & Eficácia externa e interna & Sucesso \\
\hline Desenvolvimento & Maturidade & Decolagem \\
\hline & & Maturidade \\
\hline
\end{tabular}

Quadro 31 - Fases do ciclo de vida das pequenas empresas

Nas primeiras fases as empresas apresentam-se mais inovadoras e empreendem ações voltadas à eficácia, mas tendem a ser conservadoras nas fases de maior maturidade, quando as ações focam a eficiência organizacional (MILLER; FRIESEN, 1984). Apesar de existirem, nas propostas apresentadas no quadro 24, fases análogas às etapas de evolução das EBT, os eventos que condicionam o desenvolvimento de cada uma são exclusivos do grupo de 
empresas analisado, cujo ambiente, organização e dirigentes apresentam características específicas. Conforme enfatizam Dodge, Fullerton e Robbins (1994), não é possível determinar um modelo universal para todas as organizações, devido às suas especificidades.

Concluindo, constata-se que as fases de desenvolvimento estão diretamente relacionadas às especificidades de gestão da pequena empresa e não ao tamanho ou à idade cronológica, como sugerido por Greiner (1998), e que se registra, em cada uma, a existência de eventos marcantes relacionados ao crescimento e à crise, presentes no modelo do autor.

A influência das especificidades de gestão no processo de criação de estratégias é dinâmica: na primeira fase, destacam-se, em ordem de importância, o dirigente, o contexto e a organização; já na fase de criação, sobressaem o contexto, a organização e o dirigente; e assim, sucessivamente, conforme ilustrado na figura 45. Portanto, a influência não é exclusiva de uma ou outra categoria, como o contexto, o dirigente ou a organização.

Assim, considera-se que as especificidades apresentam uma influência primária, secundária ou terciária, em cada fase do processo de criação de estratégias, no qual essas especificidades desempenham uma alternância de influência no transcorrer do ciclo evolutivo, que caracteriza um movimento rotacional.

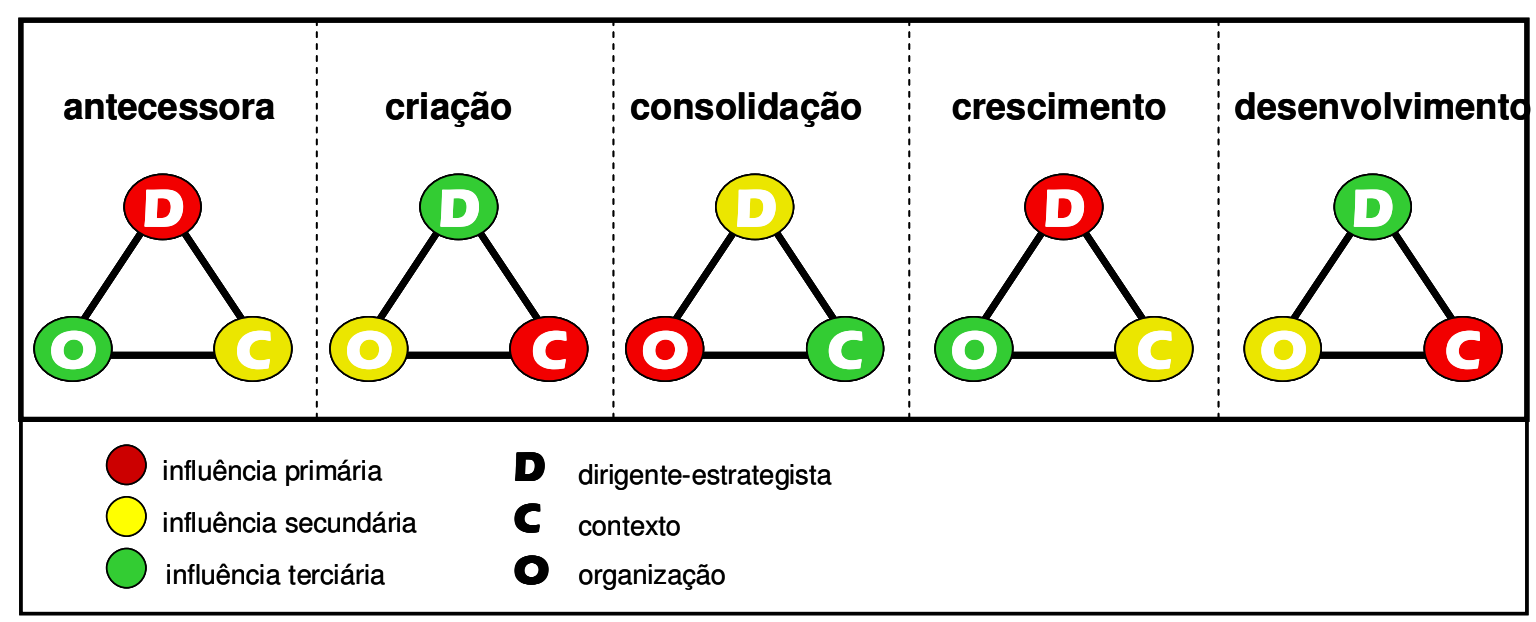

Figura 45 - Especificidades de gestão de acordo com as fases evolutivas

O quadro 32 apresenta uma síntese das especificidades de gestão das pequenas empresas de base tecnológica, discutidas no capítulo anterior, com destaque para as influências primária, secundária e terciária em cada fase evolutiva do processo de criação de estratégias. 


\begin{tabular}{|c|c|c|c|}
\hline Fases & Contexto & Organização & Dirigente \\
\hline antecessora & Tecnologia & $\begin{array}{c}\text { pouca divisão do trabalho } \\
\text { informalidade }\end{array}$ & conhecimento técnico \\
\hline criação & $\begin{array}{l}\text { clientes } \\
\text { tecnologia }\end{array}$ & $\begin{array}{l}\text { concentração de atividades } \\
\text { no dirigente } \\
\text { estrutura flexível } \\
\text { informalidade nas relações } \\
\text { tarefas não rotineiras }\end{array}$ & $\begin{array}{c}\text { intuição } \\
\text { empreendedorismo } \\
\text { dedicação ao negócio }\end{array}$ \\
\hline consolidação & economia & $\begin{array}{l}\text { divisão do trabalho } \\
\text { tarefas rotineiras } \\
\text { formalização dos } \\
\text { procedimentos }\end{array}$ & $\begin{array}{c}\text { intuição } \\
\text { criatividade }\end{array}$ \\
\hline crescimento & $\begin{array}{l}\text { economia } \\
\text { clientes } \\
\text { tecnologia }\end{array}$ & $\begin{array}{l}\text { centralização das decisões } \\
\text { divisão do trabalho } \\
\text { tarefas rotineiras } \\
\text { formalização dos } \\
\text { procedimentos } \\
\text { comunicação formal }\end{array}$ & $\begin{array}{c}\text { visão } \\
\text { racionalidade }\end{array}$ \\
\hline desenvolvimento & $\begin{array}{l}\text { clientes } \\
\text { tecnologia } \\
\text { economia }\end{array}$ & $\begin{array}{c}\text { profissionalização } \\
\text { administrativa } \\
\text { tarefas rotineiras } \\
\text { ocupação de cargos por } \\
\text { especialistas } \\
\text { comunicação formal } \\
\text { centralização das decisões }\end{array}$ & $\begin{array}{c}\text { visão } \\
\text { racionalidade } \\
\text { determinação }\end{array}$ \\
\hline
\end{tabular}

Quadro 32 - Influência primária, secundária e terciária das especificidades de gestão de acordo com as fases evolutivas das EBT

\subsection{PROPOSIÇÃO DO MAPA ESTRATÉGICO}

Para se elaborar o mapa estratégico, é necessário identificar os aspectos presente neste processo, fazendo-se a distinção entre os elementos estruturais e as forças de configuração. A partir do referencial teórico, em especial do estudo dos temas estratégia, processo estratégico 
e gestão de pequenas empresas, e da análise dos resultados obtido nas fases 1 e 2 do trabalho de campo, verifica-se que se manifestam os seguintes aspectos no processo de criação de estratégias:

- os elementos estruturais: a percepção estratégica, os processos deliberado e emergente, as fases evolutivas das empresas, as especificidades de gestão e as condições externas e internas,; a formação contínua e a criação quântica da estratégia. São aspectos constituintes.

- forças de configuração: posicionamento na representação, rotação as especificidades, dinâmica das variáveis, inter-relacionamento dos processos deliberado e emergente e ocorrência de eventos marcantes. São aspectos de formação.

Os apontamentos feitos na seção anterior evidenciam: a relevância das especificidades de gestão e o seu efeito rotacional no processo e criação de estratégia das pequenas empresas de base tecnológica, de acordo com as suas características (deliberadas e emergentes) em cada fase evolutiva, conforme a figura 46, como também a influência da visão do dirigente no processo.

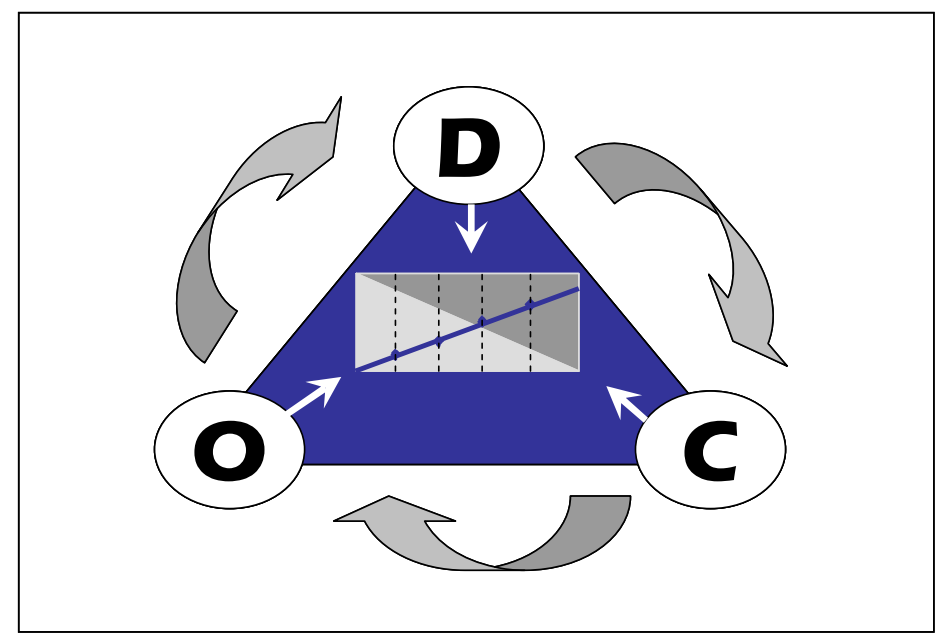

Figura 46 - Especificidades rotacionadas de gestão no processo de criação de estratégia

O mapa estratégico implica o pressuposto de que o dirigente, com base em sua visão, seleciona e interpreta os aspectos que possibilitariam criar a estratégia. Pode-se afirmar, portanto, que os fatores determinantes da estratégia são delimitados pelo dirigente, que utiliza sua percepção como um "filtro" na seleção e interpretação das condições do contexto e da 
organização. Acrescente-se que, sob este enfoque, as condições externas e internas são identificadas a partir da capacidade de interpretar do dirigente, determinada por sua cognição e intuição e de seus valores - que configuram a sua visão - denominada percepção estratégica, como consta no mapa. Complementando, em outras palavras, a percepção estratégica do dirigente desenha as possibilidades para a criação da estratégia. Considerada inicialmente, nesta pesquisa, uma das especificidades do dirigente, a percepção estratégica destacou-se no processo de criação de estratégia, passando a ser considerada como um dos elementos estruturais o mapa estratégico.

Após a delimitação promovida pela percepção estratégica, a criação da estratégia se dá em fases evolutivas, destacando-se que a passagem de uma a outra é marcada por um evento que dá origem a uma mudança estratégica. Em cada fase há uma formação contínua de estratégia, interrompida pela criação quântica que é impulsionada pelo evento marcante. As especificidades de gestão influenciam em diferentes níveis de intensidade - primária, secundária e terciária - o processo de criação de estratégias em suas fases evolutivas, sob um efeito de rotação, que alterna a intensidade da influência exercida por cada especificidade. Nas fases evolutivas pelas quais a empresa passa, não necessariamente de forma linear, os processos deliberado e emergente se integram, evidenciando-se o caráter emergente, nas fases iniciais, e o deliberado, nas fases de maior maturidade.

Ressalte-se que o mapa estratégico tem como arcabouço teórico o modelo proposto por Mariotto (2003), a formação quântica de estratégia constatada por Perussi Filho (2006) e o Sistema de Administração Estratégica destacado por Escrivão Filho (2006). O mapa estratégico, apresentado na figura 47, possui a peculiaridade que lhe deve ser atribuído - a orientação. Assim concebido, demanda interpretação, para se chegar a compreender o processo de criação de estratégias na pequena empresa de base tecnológica. Deve ser, entendido, por conseguinte, como uma representação que se aproxima da realidade de um grupo de empresas. E esta aproximação não o torna mais abrangente ou complexo que esta realidade. 



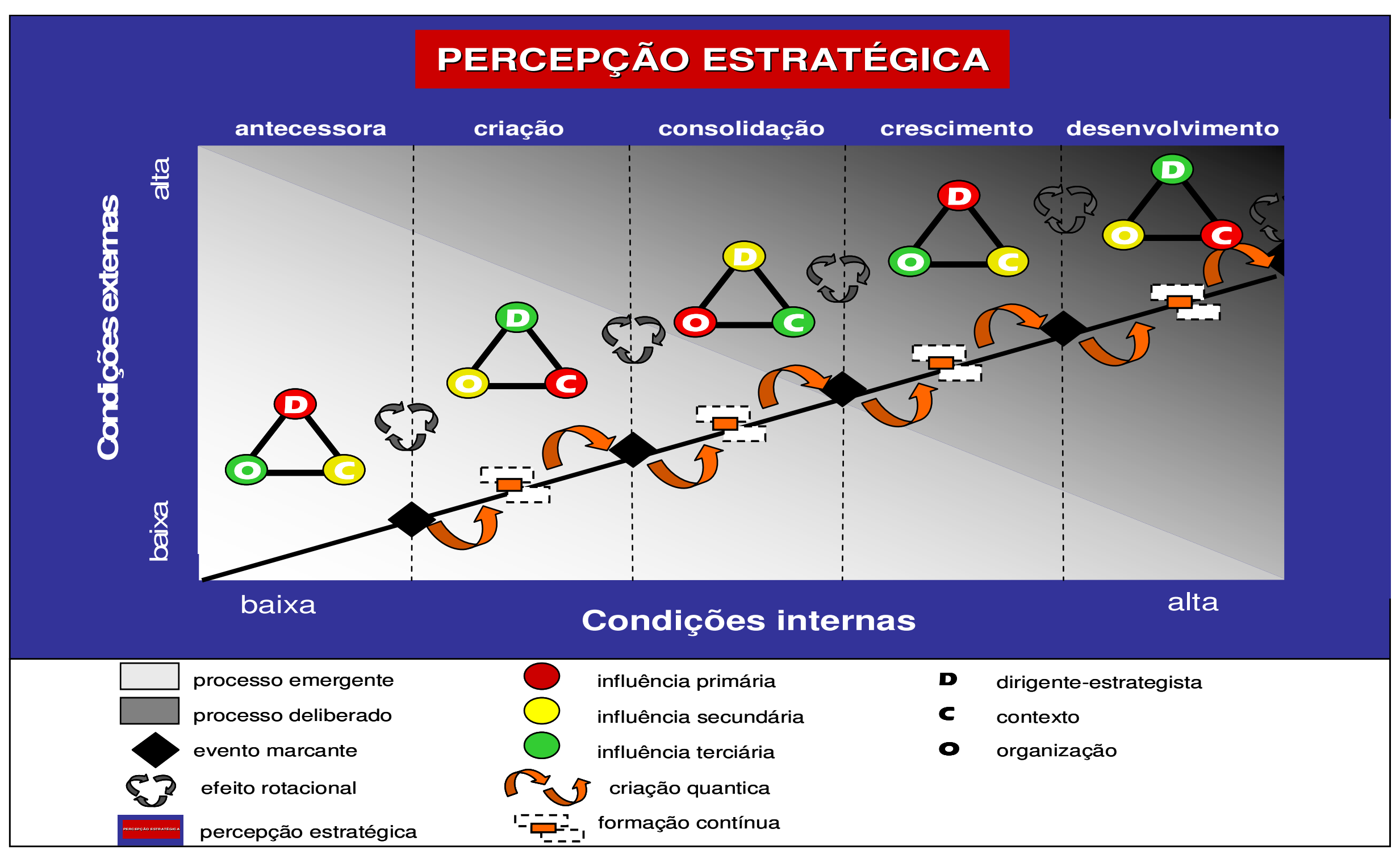

Figura 47 - Mapa estratégico 


\section{CONSIDERAÇÕES FINAIS}

Evidencia-se a representatividade das pequenas empresas no cenário mundial. Predominantes e responsáveis pela maioria dos estabelecimentos comerciais, industriais e de serviços, são consideradas propulsoras do desenvolvimento socioeconômico. Entretanto, na literatura sobre pequenas empresas, que se encontra em expansão, poucos estudos concentram-se em suas características de gestão, falta uma abordagem teórica específica do setor. Mais particularmente, o segmento das EBT, composto, sobretudo, por pequenas empresas, precisa de uma análise adequada.

É fundamental que sejam consideradas as peculiaridades das pequenas empresas e das EBT no processo de criação de estratégias. Na literatura, os estudos sobre estratégia empresarial fundamentam-se em propósitos voltados à realidade de grandes corporações, fazendo-se necessário, portanto, compreender o processo no contexto da pequena empresa de base tecnológica.

Neste trabalho, registram-se os resultados de uma pesquisa feita com o objetivo de conhecer melhor a realidade das pequenas empresas de base tecnológica. A elaboração do mapa estratégico, portanto, é o principal objetivo da pesquisa. A originalidade da delimitação do tema e do propósito da investigação está em conceber uma abordagem que não reduz a complexidade da criação de estratégias a um passo-a-passo didático, no entanto, abstrato e artificial. O mapa orienta a compreensão deste processo, que conta com um grande número de variáveis que, necessariamente, precisa ser interpretado pelo estrategista.

Em relação às fases de desenvolvimento da pesquisa, depois de formular o problema e definir os objetivos (introdução), procedeu-se à revisão da literatura, focalizando-se os seguintes temas: estratégia, processo estratégico e gestão de pequenas empresas, que inclui as empresas de base tecnológica. Destacam-se, a seguir, algumas contribuições da fundamentação teórica:

- a apresentação da relação estratégia e competitividade e a constatação de que as organizações adotam estratégias para orientar o seu desempenho e nas expectativas dos dirigentes para atingir seus objetivos (genéricos ou específicos). Assim, a capacitação 
acumulada é um fator restritivo em um processo evolutivo de criação de estratégias, pois a organização precisa reunir competência necessária à implantação da estratégia.

- o apontamento da visão de coexistência, interação e integração dos processos deliberado e emergente na criação de estratégias. Visão que demonstra o processo de criação de estratégia, base para a tomada de decisão estratégica, como um processo que relaciona as estratégias (deliberadas ou emergentes) com a tomada de decisão e sua operacionalização, a partir do envolvimento de atores organizacionais e do contexto.

- a organização dos modelos do processo de criação de estratégias, de acordo com suas compatibilidades, em quatro grupos que evidenciam aspectos diversos: modo racional que é um processo formal e analítico; modo empreendedor que enfatiza a visão do líder; modo adaptativo, que enfatiza a interação a organização ao ambiente em um processo de adaptação; modo emergente, com a interação social e aprendizado coletivo.

- a identificação de similaridade das categorias descritivas do perfil do dirigente às variáveis relacionadas às especificidades de gestão a pequena empresa sendo: o tecnocrata voltado à organização; o artista correspondente ao ambiente e; o artesão focado na liderança. Esta identificação resulta de uma aproximação das categorias de Pitcher (1993; 1999) ao Sistema de Administração Estratégica de Escrivão Filho (2006).

Ainda, em relação ao desenvolvimento da pesquisa, o trabalho de campo foi realizado em duas fases. A primeira foi realizada em trinta e três (33) empresas, com o objetivo de identificar as características gerais do processo de criação de estratégias, sendo classificada como survey. A segunda contempla um estudo de caso que foi realizado para descrever e analisar os elementos específicos e formadores do processo de criação de estratégias em três (03) empresas localizadas no pólo de São Carlos/SP.

$\mathrm{Na}$ primeira fase, os dados foram coletados com a utilização de um questionário estruturado e os resultados foram extraídos a partir de uma análise estatística descritiva de conteúdo e de uma análise exploratória multivariada denominada Análise dos Componentes Principais. Como resultados desta fase destacam-se:

- A identificação de uma relação positiva entre o tempo médio de vida e o porte da empresa. Esta relação, que diz respeito à sobrevivência, é uma das grandes questões discutidas no segmento das pequenas empresas, devido o alto índice de mortalidade a que estão sujeitas. O porte, estabelecido a partir do número de funcionários, representa maior apoio ao dirigente na execução das operações do negócio, possibilitando que se dedique a atividades estratégicas, o que resulta em maior competitividade e, consequientemente, 
maior chance de sobrevivência. Destaque-se que não se considera, como único fator determinante da alta taxa de mortalidade das pequenas empresas, os seus problemas de cunho administrativo, pois esta seria uma visão simplificada e limitada de tão complexo segmento, que necessita de uma análise integral de suas características específicas, exigência que se levou em conta na pesquisa feita.

- A heterogeneidade das EBT. Embora agrupadas em um único setor, as EBT apresentam características diversas que influenciam, entre outros aspectos, o seu faturamento, o número de funcionários empregados e a tecnologia que utiliza. É oportuno assinalar que o segmento comporta empresas com capacidades competitivas superiores, como as de novos materiais, eletrônicas e de telecomunicações; empresas com deficiências competitivas, como as de software, sistemas de informação e fabricação de computadores, e empresas difusoras de desenvolvimento tecnológico, como as de biotecnologia, robótica, materiais especiais, entre outras.

- A expansão das atividades das EBT. Registra-se um crescimento de $42 \%$ no faturamento destas empresas no triênio 2004/2006, enquanto o PIB acumulado do país para o período foi de $12 \%$. A expansão das atividades das EBT, geradoras de inovação, contribui com desenvolvimento tecnológico significativo na comercialização de novos produtos e processos da indústria nacional.

- A influência do desenvolvimento tecnológico no contexto das EBT. Com o desenvolvimento tecnológico, diminuem a capacidade competitiva e as pressões externas. Este fato alicerça a relevância da visão dos dirigentes das pequenas empresas que, com características de organização típicas de seu segmento, visualizam a intensidade e agilidade do desenvolvimento tecnológico como uma maior incerteza ambiental.

- Os dirigentes das EBT se identificam como determinados e aplicados, em virtude de sua dedicação ao negócio, porém, no processo de criação de estratégias, destacam-se os visionários e imaginativos. Constata-se, assim, que é legítimo considerar a percepção estratégica do dirigente como um elemento básico neste processo. Reiterando, a estratégia reflete a visão que o dirigente tem de sua organização e de seu ambiente (HAMBRICK; MASON, 1984).

- A presença de características emergentes e deliberadas em um processo único de criação de estratégias. Esta constatação, que a bibliografia consultada também aponta, delineia-se, inicialmente, com a análise das variáveis que intervêm no processo estratégico, depois se confirma com a identificação do grupo deliberado e emergente, subdividido em 
deliberado, emergente e misto, que, posteriormente, configura a composição do conglomerado de empresas. Este conglomerado representa, portanto, a visão que implica a coexistência, interação e integração dos processos deliberado e emergente na criação de estratégias.

- O levantamento de algumas características determinantes do processo de criação de estratégias deliberado ou emergente: a racionalidade, a previsibilidade, a lógica e a análise ou a intuição, a conciliação do pensamento e da ação, a imaginação e a visão, respectivamente.

Na segunda fase da investigação, coletaram-se os dados por meio de entrevistas com proprietários, funcionários e professores universitários e descreveram-se os resultados mediante análise categorial dos dados, realizada indutivamente. Como contribuições expressivas desta etapa, destacam-se:

- A constatação de que o processo de crescimento das EBT - desde a criação até os dias atuais - ocorre em fases evolutivas com características compatíveis com seu processo de criação de estratégias. A passagem de uma etapa a outra implica a criação de estratégias com características diversas. Conforme a proposta de Perussi Filho (2006), o processo de criação de estratégias apresenta características deliberadas ou emergentes em cada uma das fases e a transição de um estágio a outro demanda uma mudança estratégica. De acordo com a proposta de Mariotto (2003), há uma criação contínua de estratégia ao longo do tempo.

- A relevância da fase antecessora no ciclo de vida organizacional das EBT. Esta fase antecede a criação das empresas, porém as influencia. Os modelos de ciclo de vida organizacional, comumente abordam os seus estágios, considerando problemas e características típicos de cada um, a partir da formalização das atividades da empresa, ou seja, de sua efetiva criação. Porém, no caso das EBT, ações anteriores à formalização do negócio afetam diretamente suas atividades, sendo este o principal motivo que levou a incluir a fase antecessora em sua evolução.

- O reconhecimento da dinâmica das especificidades da pequena empresa de base tecnológica presentes em cada fase evolutiva, estabelecida em um movimento rotacional, cujo nível de influência se altera, passando pelo dirigente, contexto e organização.

A concepção da pesquisa pauta-se no modelo de criação de estratégias, proposto por Mintzberg (1978; 2004), à medida que possibilita identificar e sistematizar as variáveis e examinar o seu nível de influência no processo, destacando-se as seguintes: o dirigente, o 
contexto e a organização. Considerando que as estratégias realizadas se originam da elaboração de estratégias pretendidas, algumas das quais não se realizam, ao mesmo tempo em que outras emergem, constata-se que as variáveis influenciam em maior ou menor grau o processo, conforme a representação apresentada no capítulo 1 (figura 2).

$\mathrm{Na}$ proposta da pesquisa, presume-se haver maior influência do dirigente nas estratégias pretendidas; da organização na não realização de estratégias e do contexto nas estratégias emergentes. Feita a pesquisa, identificou-se um conjunto de variáveis com diversos graus de influência - primário, secundário e terciário - sobre os seguintes tipos de estratégias, respectivamente: pretendidas, o dirigente, o contexto e a organização; nãorealizadas, a organização, o contexto e o dirigente, e emergentes, a organização, o contexto e o dirigente. Explicam-se, assim, alguns dos elementos presentes na concepção da estratégia e os seus graus de influência.

Como resultado da análise de todos os dados obtidos no trabalho de campo, sob a perspectiva teórica adotada, a percepção estratégica desponta como um elemento que impulsiona a criação de estratégias, enfatizando a importância do dirigente no processo. A partir da visão do dirigente, delimitada por sua cognição e percepção das condições internas e externas da empresa, as estratégias são criadas, incorporando a influência de suas características de liderança, do nível de incerteza do ambiente e das condições de organização. A percepção estratégica, embora a literatura consultada não a ressalte isoladamente, é um elemento que afeta todo o processo de criação de estratégias e, conseqüentemente, toda a gestão da EBT.

O mapa estratégico destaca os seguintes aspectos do processo de criação de estratégias nas pequenas empresas de base tecnológica, denominados elementos estruturais: a percepção estratégica do dirigente; a sua própria composição, que reúne características deliberadas e emergentes de forma simultânea e integrada; o seu desenvolvimento, relacionado com as fases evolutivas do processo de criação de estratégias, a formação contínua de estratégia, a criação quântica da estratégia e a influência das especificidades de gestão das pequenas empresas. A tais aspectos, acrescentem-se, como forças de configuração para a representação do processo de criação de estratégias das EBT: o posicionamento, a rotação das especificidades, os eventos marcantes, a dinâmica do processo e as inter-relações das variáveis. A partir da visão do dirigente, o processo se desenvolve em fases nas quais a influência das especificidades do dirigente, do contexto e da organização manifesta-se em diferentes intensidades, contemplando características emergentes e deliberadas em um processo evolucionário. 
A análise do processo de criação de estratégias por meio de um mapa, não de um modelo, atende ao propósito de oferecer um esquema de orientação, que precisa ser interpretado, para se chegar à compreensão desejada. Ressalta, portanto, que o mapa orienta a compreensão de como as estratégias são criadas nas EBT, pela identificação e interrelacionamento dos processos deliberado e emergente e pela dinâmica das variáveis de gestão da empresa: dirigente, contexto e organização.

A consideração das especificidades da pequena empresa em seus processos de gestão, incluindo o de criação de estratégias, é um esforço conjunto dos membros do Grupo de Estudos Organizacionais da Pequena Empresa (GEOPE) que, ao realizar diversas pesquisas, procura compreender o universo deste segmento, auxiliar na gestão das pequenas organizações, adequando os instrumentos administrativos, e contribuir para o desenvolvimento de uma "teoria administrativa" específica do setor. Os membros do grupo consideram que temas relevantes da administração, como estratégia, estrutura, tecnologia, comportamento e tomada de decisão, extraídos da Teoria Administrativa, não se revelam com as mesmas características e intensidade nas pequenas empresas, ressaltando a necessidade de abordá-los, contemplando as especificidades de gestão do segmento. No GEOPE, os estudos se voltam a características do dirigente, do contexto e da organização, contempladas na pesquisa em destaque.

Algumas limitações se apresentaram no desenvolvimento da pesquisa. O reduzido número de estudos que enfoca a complexidade das pequenas empresas, associado à abordagem que as considera "pequenas grandes empresas", foi um aspecto limitador.

No trabalho de campo, para a definição da amostra, alguns problemas foram enfrentados, como a resistência de alguns dirigentes em participar da pesquisa, por falta de tempo, receio da eventual exposição ou desinteresse. Estas dificuldades levaram à composição de uma amostra pequena - um reduzido número de casos em relação ao grande número de variáveis, apesar de todo o esforço empreendido na coleta dos dados. O tamanho da amostra constituiu um fator que limitou a análise multivariada, que demanda um número maior de casos para identificar as possíveis correlações das variáveis. Porém, apesar desta limitação, optou-se por realizar a ACP, considerando-se as inferências com a devida precaução, para se ter uma visão global do processo mediante análise da influência de determinadas variáveis. Esta abordagem consolidou alguns apontamentos realizados anteriormente e apoiou a análise de conteúdo categorial.

Limitou-se o estudo de caso a três empresas, em virtude do tempo de dedicação exigido tanto da pesquisadora, para a realização das entrevistas e análise dos dados, como do 
dirigente. Considera-se, portanto, que os resultados, refletindo o ponto de vista de alguns dirigentes de um número restrito de empresas, não podem ser generalizados para todo o universo das pequenas empresas de base tecnológica.

Outra limitação merece destaque, a definição das EBT como foco da pesquisa. O objetivo que se propunha alcançar era identificar e analisar as características próprias do segmento, porém se constatou a sua heterogeneidade quanto a: estrutura administrativa, nível de tecnologia, perfil do empresário, nível de competitividade, entre outras características.

Para estudar a questão da heterogeneidade das EBT, sugere-se considerá-la, em pesquisas futuras, não apenas em sua abrangência, mas também em sua diversidade. A escolha de empresas de pequeno porte de um determinado ramo de atuação parece relevante, porque poderia minimizar as diferenças substanciais existentes entre as EBT.

Recomenda-se, para trabalhos posteriores, a análise da percepção estratégica, por seu importante papel na criação de estratégias. Destacam-se, portanto, investigações que abordem a visão e o comportamento do dirigente-estrategista no processo de criação de estratégias.

Uma outra possibilidade de estudo seria analisar o processo de criação de estratégias em um número maior de empresas, como, por exemplo, nas EBT situadas nos pólos tecnológicos do estado de São Paulo, para minimizar a limitação identificada na fase 1 do trabalho de campo, favorecendo o uso de outras técnicas multivariadas para eventuais constatações não realizadas. Também se poderia investigar o processo de criação de estratégias por meio de uma pesquisa-ação, que permitiria o acompanhamento do processo, a identificação de dificuldades ou mesmo a reprodução de uma nova dinâmica das variáveis.

Como observação final, destaca-se a importância das EBT para o desenvolvimento tecnológico que reverte em benefícios sociais e econômicos ao país. As contribuições decorrentes de inovação permitem incorporar valor tecnológico aos produtos nacionais, eventualmente substituir componentes e produtos finais importados, aumentar a exportação de produtos com maior valor agregado, entre outras possibilidades. Sua relevância também pode ser percebida pelo papel exercido na transferência da tecnologia desenvolvida na universidade e nos centros de pesquisa e na formação de pesquisadores.

Concluindo, assinala-se que a reprodução do processo de criação de estratégia, destacando seus elementos, suas delimitações e sua dinâmica, tem, como propósito, contribuir para o desenvolvimento do conhecimento científico sobre gestão de empresas de pequeno porte de base tecnológica, especificamente sobre a criação de suas estratégias. 


\section{REFERÊNCIAS}

ACKOFF, R. L. (1981). Creating the corporate future. New York: John Wiley.

ADIZES, I. Os ciclos de vida das organizações. São Paulo: Pioneira, 1996.

ALBUQUERQUE, A. F. (2004). Gestão estratégica das informações internas na pequena empresa: estudo multicasos em empresas do setor de serviços (hoteleiro) da região de BrotasSP. Dissertação (Mestrado) - Escola de Engenharia de São Carlos, Universidade de São Paulo.

ALMEIDA, M. I. R. (1994). Desenvolvimento de um modelo de planejamento estratégico para grupos de pequenas empresas. Tese (Doutorado) - Faculdade de Economia, Administração e Contabilidade, Universidade de São Paulo.

ALVES, A. J. (1991) O planejamento de pesquisas qualitativas em educação. Cadernos de Pesquisa, São Paulo, v. 77, p. 53-61, mai.

ALVES-MAZZOTTI, A. J.; GEWANDSZNAJDER, F. (2004). O método nas ciências naturais e sociais: pesquisa quantitativa e qualitativa. São Paulo: Pioneira Thomson Learning.

ANDERSEN, T. J. (2004). Integrating decentralized strategy making and strategic planning process in dynamic environments. Journal of Management Studies, v. 41, n. 8, p. 12711299 , dec.

ANDERSON, C. R.; ZEITHAML, C. P. (1984). Stage of the product life cycle, business strategy, and business performance. Academy of Management Journal, v. 27, n. 1, p. 5-24, mar.

ANDREWS, K. (1971) The concept of strategy. Homewood, Illinois: Irwin.

. (1987) The concept of corporate strategy. Homewood, Illinois: Irwin.

ANPROTEC (2002). Glossário dinâmico de termos na área de tecnópolis, parques tecnológicos e incubadoras de empresas. Brasília: Anprotec; Sebrae.

ANSOFF, I. (1965). Corporate strategy. New York: McGrall-Hill. Wiley.

(1976) From strategic planning to strategic management. London; New York : (1977). Estratégia empresarial. São Paulo: Atlas. 
(1984). Implanting strategic management. Englewood Cliffs : Prentice-Hall (1990). A nova estratégia empresarial. São Paulo: Atlas.

(1991). Critique of Henry Mintzberg's The design school: Reconsidering the basic premises of strategic management. Strategic Management Journal, v. 12, p. 449-461.

ARAGÓN-SÁNCHEZ, A.; SÁNCHEZ-MARÍN, G. (2005). Strategic orientation, management characteristics, and performance: a study of Spanish SMEs. Journal of Small Business Management, v. 43, n. 3, p. 287-308.

ARMSTRONG, J. S. (1982). The value of formal planning for strategic decisions: Review of empirical research. Strategic Management Journal, v.3, p. 197-211.

AUTIO, E.; YLI-RENKO, H. (1998). New, technology-based firms in small open economiesan analysis based on the Finnish experience. Research Policy, v. 26, p. 973-987.

BABBIE, E. R. (2003). Métodos de pesquisa de survey. Belo Horizonte: editora da UFMG.

BALKIN, D.B.; GOMEZ-MEJIA, L. R. (1987). Toward a contingency theory of compensation strategy. Strategic Management Journal, v. 8, n. 2, 169-182, mar./apr.

BAMBERGER, I. (1983). Value systems, strategy and performance of small and medium sized firms. International Small Business Journal, v. 1, p. 25-39.

BARAÑANO, A. M. (1998). A relação entre a inovação e a dimensão de empresas. In: SIMPÓSIO DE GESTÃO DA INOVAÇÃO TECNOLÓGICA, 20, 1998, São Paulo/SP, Anais..., São Paulo, FEA/USP, 1998 /cd rom/

BARBOSA, R. R. (1997). Monitoração ambiental: uma visão interdisciplinar. Revista de Administração, São Paulo, v. 32, n.4, p. 42-53, out/dez.

BARNEY, J. B. (1986). Types of competition and the theory of strategy: toward an integrative framework. Academy of Management Review, v. 11, n. 4, p. 791-800.

BARQUETTE, S. (2002). Fatores de localização de incubadoras e empreendimentos de alta tecnologia. Revista de Administração de Empresas, São Paulo, v. 42, n. 3, p. 101-113, jul./set..

BARROS, F. R. (1978). Pequena e média empresa e política econômica. Rio de Janeiro: Apec.

BARROS, M. A. (2001). Estratégia nas empresas de internet: lições da informalidade. Revista de Administração de Empresas, São Paulo, v. 41, n. 4, p. 32-43.

BARTUNEK, J. M.; SEO, M. (2002). Qualitative research can add new meanings to quantitative research. Journal of Organizational Behavior, v. 23, n.2, p. 237-242, mar.

BAUM, R.; WALLY, S. (2003). Strategic decision speed and firm performance. Strategic Management Journal, v. 24, p. 1107-1129, aug. 
BECKER, G.V.; LACOMBE, B. M. B. (2003). Colocando luz em quem tem "idéias luminosas": competências do empreendedor de base tecnológica. In: ENCONTRO DA ASSOCIAÇÃO NACIONAL DE PÓS-GRADUAÇÃO E PESQUISA EM ADMINISTRRAÇÃO, 27, 2003, Atibaia, SP, Anais... Rio de Janeiro: Anpad, 2003.

BERTERO, C. O. (1995). Rumos da estratégia empresarial. Revista de Administração de Empresas, RAE Light, p. 20-25, mar./abr.

BERTERO, C. O.; VASCONCELOS, F. C.; BINDER, M. P. (2003). Estratégia empresarial: a produção científica brasileira entre 1991 e 2002. Revista de Administração de Empresas, São Paulo, v. 43, n.4, p.48-62, out/dez.

BETHLEM, A. (1981). Os conceitos de política e estratégia. Revista de Administração de Empresas, Rio de Janeiro, v. 21, n. 1, p. 7-15, jan./mar.

BEVERLAND, M.; LOCKSHIN, L. (2001). Organizational life cycle in small New Zealand wineries. Journal of Small Business Management, v. 39, n. 4, p. 354-362.

BHASKARAN, S. (2006) Incremental innovation and business performance: small and medium-sized enterprises in a concentrated industry environment. Journal of Small Business Management, v.4, n.1, p. 64-80.

BHIDE, A. (1994). How entrepreneurs craft strategies that work. Harvard Business Review, p. 150-161, mar./apr.

BIGATON, A. L. W. (2005). Gestão estratégica da informação nas pequenas empresas: estudo comparativo de casos em empresas do setor industrial de São José do Rio Preto - SP. Dissertação (Mestrado) - Escola de Engenharia de São Carlos, Universidade de São Paulo.

BIRLEY, S.; WESTHEAD, P. (1990). Growth and performance contrasts between "types" of small firms. Strategic Management Journal, v. 11, n. 7, p. 535-557, nov./dec.

BOAVENTURA, J. M. G.; COSTA, B. K.; FISCHMANN, A. A. (2005). Cenários: metodologias e métodos de construção. In: COSTA, B. K.; ALMEIDA, M. I. R. Estratégia: direcionando negócios e organizações. São Paulo: Atlas.

BODGAN, R. C.; BIKLEN S. K. (1982). Qualtitative research for education: an introduction to theory and methods. Boston: Allyn and Bacon.

BORTOLI NETO, A. (1980) Tipologia de problemas das pequenas e médias empresas. Dissertação (Mestrado) - Faculdade de Economia, Administração e Contabilidade, Universidade de São Paulo.

(2005). Elas não sabem ganhar a guerra. HSM Management, v. 9, n. 50, mai./jun..

BRACKER, J. (1980). The historical development of the strategic management concept. Academy of Management Review, v. 5, n. 2, p. 219-224

BRACKER, J. S.; PEARSON, J. N. (1986). Planning and financial performance of small, mature firms. Strategic Management Journal, v. 7, n. 6p. 503-522, nov./dec. 
BROUTHERS, K. D.; ANDRIESSEN, F.; NICOLAES, I. (1998). Driving blind: strategic decision-making in small companies. Long Range Planning, Great Britain, v. 31, n. 1, p. 130-238, feb.

BROWN, S. L.; EISENHARDT, K. M. (1997). The art $\mathrm{f}$ continuous change: linking complexity theory and time-paced evolution in relentlessly shifting organizations. Administrative Science Quarterly, v. 42, p. 1-34.

BULMER, M. (1977). Sociological research methods: an introduction. London: Macmillan.

BURKE, G. I.; JARRAT, D. G. (2004). The influence of information and advine on competitive strategy definition in small and médium sized enterprises. Qualitative Market Research, v. 7, n. 2, p. 126-138.

CÂMARA, S. F.; FREITAS, A. A. F.; TIMBÓ, D. B. P.; RODRIGUES, P. M.; ALBUQUERQUE, M. M. B.; OLIVEIRA JÚNIOR, J. B. A. C. (2005). Os empreendedores e as atividades organizacionais: analisando o processo cognitivo e as práticas administrativas em pequenos negócios. In: ENCONTRO DA ASSOCIAÇÃO NACIONAL DE PÓSGRADUAÇÃO E PESQUISA EM ADMINISTRAÇÃO, 29, 2005, BRASÍlLIA, DF, Anais... Rio de Janeiro: Anpad, 2005.

CAMARGOS, M. A.; DIAS, A. T. (2003). Estratégia, administração estratégica e estratégia corporativa: uma síntese teórica. Caderno de Pesquisas em Administração, São Paulo, v. 10, n. 1, jan./mar.

CAMPBELL, A.; ALEXANDER, M. (1997). What's wrong with strategy? Harvard Business Review, p. 42-51, nov./dec..

CANCELLIER, E. L. P. L. (2004). Sistema de monitoramento ambiental para pequena empresa: um estudo em empresa de base tecnológica. 181 p. Tese (Doutorado) Faculdade de Economia, Administração e Contabilidade, Universidade de São Paulo.

CARDOSO, J. E.S. (1982). Pequenas e médias empresas: um modelo opcional para países em desenvolvimento. Revista de Administração de Empresas, Rio de Janeiro, v. 22, n. 4, p. 4657, out./dez.

CARVALHO, K., C. (2004). Gestão da informação sobre o ambiente externo da pequena empresa. Dissertação (Mestrado) - Escola de Engenharia de São Carlos, Universidade de São Paulo.

CARVALHO, M. M.; MACHADO, S.; PISYSIEZNIG FILHO, J.; RABECHINI JR, R. Empresa de Base Tecnológica Brasileira: características distintivas. In: SIMPÓSIO DE GESTÃO DA INOVAÇÃO TECNOLÓGICA, 20., 1998, São Paulo/SP, Anais..., São Paulo, FEA/USP, 1998 /cd rom/

CHAFFEE, E. E. (1985). Three models of strategy. Academy of Management Review, v. 10, n. 1, p. 89-98, jan.

CHAGANTI, R. (1987). Small business strategies in different industry growth environments. Journal of Small Business Management, v. 25, n. 3, p. 61-68, jul. 
CHAN, S. Y.; FOSTER, M. J. (2001). Strategy formulation in small business: the Hong Kong experience. International Small Business Journal, v. 19, n. 3, p. 56-71, apr./jun.

CHANDLER, A. D. (1990). Strategy and structure: chapters in the history of the industrial enterprise. Cambridge, Massachusetts: MIT Press.

CHER, R. (1990) A gerência da pequena e média empresa. São Paulo: Maltese.

CHILD, J. (1972). Organizational structure, environment, and performance: the role of strategic choice. Sociology, v. 6, p. 1-22.

(1997). Strategic choice in the analysis of action structure, organizations and environment: retrospect and prospect. Organization Studies, v. 18, n. 1, p. 43-76.

CHILD, J.; SMITH, C (1987). The context and process of organizational transformation. Journal of Management Studies, v. 24, n. 6, p.555-593, nov.

CHIZZOTTI, A. (1995) Pesquisa em ciências humanas e sociais. São Paulo: Cortez, 1995

CHURCHILL, N.; LEWIS, V. (1983). The five stages of small business growth. Harvard Business Review, v. 61, n.3, 30-50.

CLAUSEWITZ, C. Von. (2003). Da guerra. São Paulo: Martins fontes, 2003.

COSTA, B. K.; ALMEIDA, M. I. R. (2005). Estratégia: direcionando negócios e organizações. São Paulo: Atlas

COSTA, L. S. V.; SILVA, J. F. (2002). As tipologias estratégicas "realmente existem"? In: ENCONTRO DA ASSOCIAÇÃO NACIONAL DE PÓS-GRADUAÇÃO E PESQUISA EM ADMINISTRAÇÃO, 26, 2002, Salvador, Anais..., Salvador: Anpad, 2002. /cd rom/

COURTLET, C. (1993). Novas dinâmicas de desenvolvimento e sistemas industriais localizados (SIL). Ensaios FEE - Fundação de Economia e Estatística, Porto Alegre, v.14, n. 1, p. 9-25.

COUTINHO, L.; FERRAZ, J. C. (1995). Estudo da competitividade da indústria brasileira. Campinas: Papirus, 1995.

CYERT, MARCH (1963). A Behavioral Theory of the Firm, Englewood Cliffs, Prentice Hall

CYPRIANO, C. A. C (2004). Pequena empresa, desenvolvimento social e a ação institucionalizadora do SEBRAE. 335 p. Tese (Doutorado) - Escola de Administração, Universidade Federal da Bahia.

D'AMBOISE, G.; MULDOWNEY, M (1988). Management theory for small business: attempts and requirements. Academy of Management Review, v. 13, n. 2, p. 236-240.

DAMANPOUR, F. (1996). Organizational complexity and innovation: developing and testing multiple contingency models. Management Science, v 42, n. 5, 693-716. 
DANDRIGE, T. C. (1979). Children are not "little grown-ups": small business needs its own organizational theory. Journal of small business management. v.17, n.2, p. 53-53, apr.

DANE, F. C. (1990). Research methods. Belmont, CA: Brooks/Cole.

DAVIES, H.; WALTERS, P. (2004). Emergent patterns of strategy, environment and performance in a transition economy. Strategic Management Journal, v. 25, n. 4, p. 347364, apr.

DAY, J. (2000). The value and importance of the small firm to the world economy. European Journal of Marketing, Bradford, v. 34, n.9/10, p. 1033.

DEAN, T. J.; BROWN, R. L.; BAMFORD, C. E. (1998). Differences in large and small firm responses to environmental context: strategic implications from a comparative analysis of business formations. Strategic Management Journal, v. 19, n. 8, p. 709-728, aug.

DELAPIERRE, M.; MADEUF, B.; SAVOY, A. (1998). NTBFs - the French case. Research Policy, v. 26, p. 989-1003.

DELMAR, F.; SHANE, S. (2003). Does business planning facilitate development of new ventures? Strategic Management Journal, v. 24, n. 12, p. 1165-1185, dec.

DENZIN, N. K; LINCOLN, Y. S. (2005) Handbook of Qualitative Research. Thousand Oaks: Sage.

DESARBO, W. S.; DI BENEDETTO, C. A.; SONG, M.; SINHA, I. (2005). Revisiting Miles and Snow strategic framework: uncovering interrelationships between strategic types, capabilities, environmental uncertainty, and firm performance. Strategic Management Journal, v. 26, p. 47-74, oct.

DODGE, H. R.; FULLERTON, S.; ROBBINS, J. E. (1994). Stage of the organizational life cycle and competition as mediators of problem perception for small business. Strategic Management Journal, v. 15, n. 2, feb., p. 121-134.

DRUCKER, P.F. (1981). Práticas de administração de empresas. São Paulo: Pioneira.

EDEN, C.; HUXHAM, C. (2001). Pesquisa-ação no estudo das organizações. In: CALDAS, M.; FACHIN, R. FISCHER, T. (Org.). Handbook de estudos organizacionais. São Paulo: Atlas.

EISENHARDT, K. M. (1989). Making fast strategic decision in high-velocity environments. Academy of Management Journal, v. 27, p. 299-343

3 , p. $65-72$

(1999). Strategy as strategic decision making. Sloan Management Review, v. 40, n.

EL-NAMAKI, M. S. S. (1990). Small Business: the myths and the reality. Long Range Planning, Great Britain, v.23, n.4, p.78-87.

ESCRIVÃO FILHO, E.; CARVALHO, K. C; BENZE, R. P.; ALBUQUERQUE, A. F (2005). Compreendendo a dinâmica das pequenas empresas: mapa organizacional como ferramenta da ação administrativa. Revista Matiz, Matão, v. 1, n. 1, p. 20-40. 
ESCRIVÃO FILHO, E. (2006). Pequena empresa e administração estratégica: reconhecendo especificidades, restrições e facilitadores com o mapa organizacional. Tese (Livre-Docência). Escola de Engenharia de São Carlos-USP, São Carlos, 2006.

ESCRIVÃO FILHO, E.; PERUSSI FILHO, S.; TERENCE, A. C. F. Restrições e facilitadores à Administração Estratégica: uma proposta baseada nas escolas de Mintzberg e Associados. In: ENCONTRO DE ESTUDOS EM ESTRATÉGIA, 3 E's, 3, Anais..., São Paulo/SP, 2007.

EVERED, R. (1983). So what is strategy? Long Range Planning, v. 16, n. 3, P. 57-72

FARINA, E. M. M. Q. (1997). Regulamentação, política antitruste e política industrial. In: FARJOUN, M. (2002). Towards an organic perspective on strategy. Strategic Management Journal, v. 23, n. 7, p. 561-594, jul.

FEIGENBAUM, A. V.; FEIGENBAUM, D. S. (2005). What quality means today. MIT Sloan Management Review, Massachusetts, n. 2, v. 46, winter.

FERRAUDO, A. S. Técnicas de Análise Multivariada. 2.ed. São Caetano do Sul: StatSoft South América, 2006.

FERNANDES, A. C. ; CÔRTES, M. R. (1998) Caracterização do perfil da pequena empresa de base tecnológica no estado de São Paulo: uma análise preliminar. In: SCIENCE AND TECHNOLOGY RESEARCH SEMINAR, 1998, Campinas. Anais...Campinas: Unicamp Instituto de Geociências, 1998.

FERNANDES, A. C.; CÔRTES, M. R.; OISHI, J. (2000). Innovation characteristics of small and médium sized technology-based firms in São Paulo, Brazil: a preliminary analysis. INTERNATIONAL CONFERENCE ON TECHNOLOGY POLICY AND INNOVATION, 4, Curitiba, Anais..., Curitiba, Brazil.

FERNANDES, A. C.; CORTÊS, M. R.; PINHO, M. (2004). Caracterização das pequenas e médias empresas de base tecnológica em São Paulo: uma análise preliminar. Economia e Sociedade, Campinas, v. 13, n.1, p. 151-173, jan./jun.

FERNANDES, B. H. R.; BERTON, L. H. (2005). Administração estratégica: da competência empreendedora à avaliação de desempenho. São Paulo: Saraiva.

FERRO, J. R.; TORKOMIAN A. L. (1988). A criação de pequenas empresas de alta tecnologia. Revista Administração de Empresas. São Paulo, v. 28, n. 2, p. 43-50.

FILLION, L. J. (1991) O planejamento do seu sistema de aprendizagem empresarial: identifique uma visão e avalie o seu sistema de relações. Revista de Administração de Empresas, São Paulo, v. 31, n. 3, p. 63-71, jul./set.

L. J. (1999). Diferenças entre sistemas gerenciais de empreendedores e operadores de pequenos negócios. Revista de Administração de Empresas, São Paulo, v. 39, n. 4, p. 6-20, out./dez.

FLETCHER, M.; HARRIS, S. (2002). Seven aspects of strategy formation. International Small Business Journal, v. 20, n. 3, p. 297-314. 
FONSECA, V. S.; MACHADO-DA-SILVA, C. L. (2002) Conversação entre abordagens da estratégia em organizações: escolha estratégica, cognição e instituição. Organizações \& Sociedade, v. 9, n. 25, p. 93-109.

FONTES, M.; COOMBS, R. (2001). Contribution of new technology-based firms to the strengthening of technological capabilities in intermediate economies. Research Policy, v. 30, p. 79-97.

FREDRICKSON, J.; MITCHELL, T. (1984). Strategic decision processes: Comprehensiveness and performance in an industry with an unstable environment. Academy of Management Journal, v. 27, p. 399-423.

FREEMAN, R. E., REED, D. L. (1983). Stockholders and stakeholders: a new perspective on corporate governance. California Management Review, p. 88-103, spring

FREITAS, H ; OLIVEIRA, M.; SACCOL, A. Z.; MOSCAROLA, J. (2000). O método de pesquisa survey. Revista de Administração, São Paulo,v.35, n.3, P. 105-112, jul./set.

GALBRAITH, J. R.; LAWLER III, E. E. (1995). Organizando para competir no futuro. São Paulo: Makron Books.

GAY,L; DIEHL,P. (1992). Research methods for business and management. New York:Maxwell Macmilan.

GHEMAWAT, P. A estratégia e o cenário dos negócios: texto e caso. Porto Alegre: Bookman, 2000.

GIBBONS, P.; O'CONNOR, T. (2005) Influences on strategic planning process among Irish SMEs. Journal of Small Business Management, v. 43, n. 2, p. 170-186.

GIL, A. C. (1996). Como elaborar projetos de pesquisa. São Paulo, Atlas.

GIMENEZ, F. A. P. (1998). Comportamento estratégico dos dirigentes de pequenas empresas moveleiras de Londrina-PR. Dissertação (Mestrado) - Faculdade de Economia, Administração e Contabilidade, Universidade de São Paulo.

. (2000) O estrategista na pequena empresa. Maringá, 2000

GLUCK, F; KAUFMAN, S; WALLECK, A. S. (1982). The four phases of strategic management. Journal of Business Strategy, v.2, n.3. winter, p. 9-21.

GODOY, A. S. (1995a). Introdução à pesquisa qualitativa e suas possibilidades. Revista de Administração de Empresas, São Paulo, v. 35, n. 2, p. 57-63, mar./abr.

(1995b) Pesquisa qualitativa: tipos fundamentais. Revista de Administração de Empresas, São Paulo, v. 35, n. 3, p. 20-29, mai./jun.

(2005). Refletindo sobre critérios de qualidade da pesquisa qualitativa. Revista Eletrônica de Gestão Organizacional-Gestão.org, v. 3, n.1, p. 85-94, jan./abr.

GOLDE, R. A. (1986). Planejamento prático para pequenas empresas. In: Coleção Harvard de Administração. São Paulo, Nova Cultural, v. 9, p.7-34. 
GOLDENBERG, M. (1999) A arte de pesquisar: como fazer pesquisa qualitativa em Ciências Sociais. Rio de Janeiro: Record.

GONÇALVES, A.; KOPROWSKI, S. O. (1995). A pequena empresa no Brasil. São Paulo: EDUSP.

GONÇALVES, C. A.; PAIVA JÚNIOR, F. G. (2005). Competitividade e inovação influenciando o crescimento empresarial: a perspectiva dos empreendedores de empresas de base tecnológica. In: ENCONTRO DA ASSOCIAÇÃO NACIONAL DE PÓSGRADUAÇÃO E PESQUISA EM ADMINISTRAÇÃO, 29, 2005, BRASÍlLIA, DF, Anais... Rio de Janeiro: Anpad, 2005.

GREINER, L. E. (1998). Evolution and revolution as organizations grow. Harvard Business Review, HBR Classic, May-Jun, p. 55-67, 1998.

GUTIERREZ, G. L. (1986). A metodologia científica e o estudo das organizações. Revista de Administração de Empresas, Rio de Janeiro, v. 26, n.1, p. 91-96, jan./mar.

HAGUENAUER, L. (1989). Competitividade: conceitos e medidas: uma resenha da bibliografia recente com ênfase no caso brasileiro. Universidade Federal do Rio de Janeiro, Instituto de Economia Industrial /texto para discussão, n. 211/

HAGUETE, T. M. F. (1999). Metodologias qualitativas na sociologia. 6. ed. Petrópolis: Vozes.

HAIR, J. F.; ANDERSON, R. E.; TATHAM. R. L.; BLACK, W. C. (2006). Análise multivariada de dados. 5. ed. Porto Alegre: Bookman.

HAMBRICK, D. C. (1980). Operationalizing the concept of business-level strategy in research. Academy of Management Review, v. 4, n. 4, p. 567-575, oct.

(1983). Some tests of the effectiveness and functional attributes of Miles and Snow's strategic types. Academy of Management Journal, v. 26, n. 1, p. 5-26, mar.

HAMBRICK, D. C.; MASON, P. A. (1984). Upper echelons: the organization as a reflection of its top managers. Academy of Management Review, v. 9, n. 2, p. 193-206, apr.

HAMEL, G. (1996). Strategy as revolution. Harvard Business Review. v. 74, n. 4, p. 69-76.

HART, S. L. (1992). An integrative framework for strategy-making processes. Academy of Management Review, v. 17, n. 2, p. 327-351. apr.

HAX, A.; MAJLUF, N. (1988). The concept of strategy and the strategy formation process. Interfaces, v. 18, n. 3, p.99-109, may/jun.

HAYATI, D; KARAMI, E.; SLEE, B. (2006). Combining qualitative and quantitative methods in the measurement of rural poverty. Social Indicators Research, v.75, p.361-394, springer.

HENDERSON, R.M.; CLARK, K.B. Architectural innovation: the reconfiguration of existing product technologies and the failure of established firms. Administrative Science Quarterly, v. 35, p. 9-30, 1990. 
HERACLEOUS, L. (1998). Strategic thinking or strategic planning? Long Range Planning, v. 31, n. 3, p. 481-487, jun.

HEYINK, J.W.; TYMSTRA, T. J. (1993). The function of qualitative research. Social Indicators Research, $v$. 29, 291-305.

HITT, M. A.; IRELAND, R. D. (1985). Corporate distinctive competence, strategy, industry and performance. Strategic Management Journal, v. 6, n. 3, p. 273-293, jul/sep.

HITT, M. A.; IRELAND, R. D.; HOSKISSON, R. E. (2005). Administração estratégica. São Paulo: Pioneira Thomson.

HOUGH, J. R.; WHITE, M. A. (2003). Environmental dynamism and strategic decisionmaking rationality: an examination at the decision level. Strategic Management Journal, v. 24 , n. 5, p. 481-489, may.

IDENBURG, P.J. (1993). Four styles of strategy development. Long Range Planning, v. 26, n. 5, p.132-137.

JEMINSON, D. B. (1987). Risk and the relationship among strategy, organizational process and performance. Management Science, v. 33, n. 9, p. 1087-1101, sep.

JOHANNESSEN, J. A., OLSEN, B.; LUMPKIN, G. T. (2001). Innovation as newness: what is new, how new, and new to whom? European Journal of Innovation Management, $v .4$, n. 1, p. 20-31.

JONES, G. R. (1995). Organizational theory: text and cases. Reading: Addison-Wesley.

JULIEN, P. A. (1998) The state of the art in small business and entrepreneurship. Aldershot, England: Ashgate, 1998.

KAMPAS, P. J. (2003). Shifiting cultural gears in technology-driven industries. MIT Sloan Management Review, v. 44, n. 2, p. 41-48, winter.

KAPLAN, S.; BEINHOCKER, E. D. (2003). The real value of strategic planning. MIT Sloan Management Review, v. 44, n. 2, winter.

KAZANJIAN, R. K. (1988). Relation of dominant problems to stages of growth in technology-based new ventures. Academy of Management Journal, v. 31, n. 2, jun. , p. 257279.

KRAJEWSKI, L. J.; RITZMAN, L. P. (2000). Operations Management: strategy and analysis. 5. ed. Adison Wesley.

KRUGLIANSKAS, I. (1996). Tornando a pequena e média empresa competitiva. São Paulo: Instituto de Estudos Gerenciais e Editora.

KRUGMAN, P. R. (1994). Competitiveness: a dangerous obsession. In: KRUGMAN, P. R. Competitiveness: an international economics reader. New York: Council on Foreign Relations. 
KUPFER, D. (1992). Padrões de concorrência e competitividade. In: Encontro Nacional de Economia, 20, Anais..., 1992. Campos de Jordão, São Paulo.

(1998). Trajetórias de reestruturação da indústria brasileira após a abertura e a estabilização. 185 p. Tese (Doutorado) - Instituto de Economia, Universidade Federal do Rio de Janeiro.

LANDIM, P. M. B. (2000) Análise estatística de dados geológicos multivariados. Rio Claro: UNESP, Departamento de Geologia Aplicada /texto didático 03/

LEFEBVRE, L. A.; MASON, R.; LEFEBVRE, E. (1997). The influence prism in SMEs: the power of CEO's perceptions on technology policy and organizational impacts. Management Science, v. 43, n. 6, jum., p. 856-878.

LEONE, N.M.C.P.G. (1991). A dimensão física das pequenas e médias empresas: a procura de um critério homogeneizador. Revista de Administração de Empresas. São Paulo, v. 31, n.2, p. 53-59, abr./jun.

. (1999). As especificidades das pequenas e médias empresas. Revista de Administração, São Paulo, v.34, n.2, p.91-94, abr./jun..

LIMA, E. O. (1999). A estratégia emergente na pequena empresa e sua complementaridade à visão estratégia. In: ENCONTRO NACIONAL DOS PROGRAMAS DE PÓSGRADUAÇÃO EM ADMINISTRAÇÃO, 19, 1999, Foz do Iguaçu, Anais... Rio de Janeiro: ANPAD.

LIMA, M. C. (2005). Pesquisa-ação nas organizações: do horizonte político à dimensão formal. Gestão.Org, v. 3, n. 2, mai./ago.

LONGENECKER, J. G.; MOORE, C. W.; PETTY, J. W. (1997). Administração de Pequenas Empresas: ênfase na gerência empresarial. . São Paulo: Makron Books.

LÖWY, M. (1985). Ideologias e ciência social: elementos para uma análise marxista. São Paulo, Cortez, 1985

MacCRIMMON, K. R. (1993). Do firm strategies exist? Strategic Management Journal, v. 14, p. 113-13-, winter.

MALHOTRA, N. K.; ROCHA, I.; LAUDiSiO, M. C.; ALTHEMAN, É.; BORGES, F. M. (2005). Introdução à pesquisa de marketing. São Paulo: Prentice Hall.

MANDERSCHEID, S. KUSY, M. (2005). How to design strategy with no dust - just results. Organizational Development Journal, v. 23, n. 2, p. 62-70, summer

MANLY, B. J. F. (2008). Métodos estatísticos multivariados: uma introdução. 3. ed. Porto Alegre: Bookman.

MARCIAL, E. C.; COSTA, A. J. L. (2001). O uso de cenários prospectivos na estratégia empresarial: vidência especulativa ou inteligência competitiva? In: ENCONTRO DA ASSOCIAÇÃO NACIONAL DE PÓS-GRADUAÇÃO E PESQUISA EM ADMINISTRAÇÃO, 25, 2001, Campinas, SP, Anais... Rio de Janeiro: ANPAD /cd rom/ 
MARCOVITCH, J,; SANTOS, S. A.; DUTRA, I. (1986). Criação de empresas com tecnologia avançada. Revista de Administração, São Paulo, v. 21, n.2, abr./jun.

MARIOTTO, F. L. (2003). Mobilizando estratégias emergentes. Revista de Administração de Empresas, Rio de Janeiro, v. 43, n. 2, p. 78-93.

MARTINS, G. A. (1994). Metodologias convencionais e não convencionais e a pesquisa em Administração. Cadernos de Pesquisas em Administração, São Paulo, v. 0, n. 0, $2^{\circ}$ sem.

McCARTHY, B. (2003). Strategy is personality-driven, strategy is crisis-driven: insights form entrepreneurial firms. Management Decision, v. 41, n. 4, p. 327-339.

McGEE, J. E.; SAWYER, O. (2003). Uncertainty and information search activities: a study of owner-managers of small high-technology manufacturing firms. Journal of Small Business Management, v. 41, n. 4, p. 385-401.

MCT. Ministério da Ciência e Tecnologia, 2005. Disponível em <www.mct.gov.br> Acesso em 20/12/2005

MEDEIROS, J. A. (1990) As novas tecnologias e a formação de pólos tecnológicos brasileiros. São Paulo: Instituto de Estudos Avançados.

MENEZES, E. J. C.; ALMEIDA, M. I. R. (1997). Será possível as pequenas e médias empresas crescerem sem informações do ambiente? In: ENCONTRO NACIONAL DE ENGENHARIA DE PRODUÇÃO, 17, 1997, Gramado/Canela, Anais..., Rio Grande do Sul/RS: Anpad.

MEREDITH, J. (1987). The strategic advantages of new manufacturing technologies for small firms. Strategic Management Journal, v. 8, n.3, p. 249-258, may/jun.

MigliatO, A. L. T. (2004). Planejamento estratégico situacional aplicado à pequena empresa. Dissertação (Mestrado) - Escola de Engenharia de São Carlos, Universidade de São Paulo.

MILES, R.; SNOW, C. C. (1978) Organizational strategy, structure and process. London: McGraw-Hill.

MILES, R.E.; SNOW, C.C.; MEYER, A.D.; COLEMAN Jr., H.J. Organizational Strategy, Structure, and Process. Academy of Management Review, v. 3, n.3, p. 546-562, jul.

MILLER, C. C.; CARDINAL, L. B. (1994). Strategic planning and firm performance: a synthesis or more than two decades of research. Academy of Management Review, v. 37, n. 6, p. 1649-1665, dec.

MILLER, D.; FRIESEN, P. H. (1983). Strategy-making and the environment: the third link. Strategic Management Journal, v. 4, p. 221-235.

(1984). A longitudinal analysis of the corporate life cycle. Management Science, v. 30. n. 10, p. 1161-1183.

MINTZBERG, H. (1973). Strategy-making in three modes. California Management Review, Berkeley, v.16, n.2, p.44-53, winter. 
(1978). Patterns in strategy formation. Management Science, v.29, n. 9, p. 934-48.

(1987a). Five Ps for strategy. California Management Review, Berkeley, v. 30, n.

1, p. 11-24, fall.

(1987b). Another look at why organizations need strategies. California

Management Review, v. 30, n.1, p. 25-32.

(1987c). Crafting strategy. Harvard Business Review, p. 66-75, jul/aug.

(1991). Learning 1, planning 0: reply to Igor Ansoff. Research Notes and

Communications. Strategic Management Journal, v. 12, n. 6, p. 463-466, sep.

114, jan-fev.

(1994). The fall and rise of strategic planning. Harvard Business Review, p. 107-

(2003). Criando organizações eficazes. São Paulo: Atlas.

(2004). Ascensão e queda do planejamento estratégico. Porto Alegre: Bookman.

MINTZBERG, H.; AHLSTRAND, B.; LAMPEL, J. (2000) Safári de estratégia: um roteiro pela selva do planejamento estratégico. Porto Alegre: Bookman.

MINTZBERG, H.; LAMPEL, J. (1999). Reflecting on the strategy process. Sloan Management Review, v. 40, n. 3, p. 21-30, spring.

MINTZBERG, H.; LAMPEL, J.; QUINN, J. B; GHOSHAL. (2006). O processo da estratégia. 4.ed. Porto Alegre: Bookman.

MINTZBERG, H.; WESTLEY, F. (2001). It's not what you think. Sloan Management Review, v. 42, n. 3, p. 89-93, spring

MINTZBERG, H.;WATERS, J. A. (1985). Of strategies, deliberate and emergent. Strategic Management Journal, v. 6, n. 3, p.257-272, jul.-sep.

MORAES, G. D. A. (2005). Tecnologia da informação na pequena empresa: uma investigação sobre sua contribuição à gestão estratégica da informação nos empreendimentos de São José do Rio Preto-SP. Dissertação (Mestrado) - Escola de Engenharia de São Carlos, Universidade de São Paulo.

MORAIS, E. F. C. (1999). Inteligência competitiva: estratégias para pequenas empresas. Brasília: GH Comunicação Gráfica Ltda.

MOTTA, F. G. (2000). Fatores condicionantes na adoção de métodos de custeio em pequenas empresas: estudo multicasos em empresas do setor metal-mecânico de São Carlos/SP. Dissertação (Mestrado) - Escola de Engenharia de São Carlos, Universidade de São Paulo, São Carlos.

MOTTA, P. R. (1991). Gestão contemporânea: a ciência e a arte de ser dirigente. São Paulo: Record. 
NAKAMURA, M. M. (2000). Estratégia empresarial para as pequenas e médias empresas: recomendações práticas para empresas industriais do setor metal-mecânico de São Carlos-SP. Dissertação (Mestrado) - Escola de Engenharia de São Carlos, Universidade de São Paulo, São Carlos.

NEVES, J. L. (1996). Pesquisa qualitativa: características, usos e possibilidades. Cadernos de Pesquisas em Administração, v. 1, n.3, $2^{\circ}$ sem.

O'FARRELL, P. N.; HITCHENS, D. (1988). Alternative theories of small firm growth: a critical review. Environment and Planning, v. 20, n. 2, p. 1365-1383.

O'REGAN, N.; SIMS, M.; GHOBADIAN, A. (2004). The impact of management techniques on performances in technology-based firms. Technovation, v. 24, p. 265-273.

OHMAE, K. (1982). The mind of strategist. New York: McGraw-Hill.

OLAVE, M. E. L.; AMATO NETO, J. (2005). A formação de redes de cooperação e clusters em países emergentes: uma alternativa para as PMEs no Brasil. In: AMATO NETO, J. (org.) Redes entre organizações: domínio do conhecimento e da eficácia operacional. São Paulo: Atlas.

OLIVA, F. L.; SOBRAL, M. C.; SANTOS, S. A. (2005) Como aferir a probabilidade de inovação nas empresas de base tecnológica. In: ENCONTRO DA ASSOCIAÇÃO NACIONAL DE PÓS-GRADUAÇÃO E PESQUISA EM ADMINISTRAÇÃO, 29, 2005, BRASÍLIA, DF, Anais... Rio de Janeiro: Anpad, 2005.

OSBORN, C. (1998). Systems for sustainable organizations: emergent strategies, interactive controls and semi-formal information. Journal of Management Studies, v. 35, n. 4, p. 481483.

PANKAJ, G. A (2000) Estratégia e o Cenário dos Negócios. Porto Alegre: Bookman.

PARNELL, J. A. (2003) Five critical challenges in strategy making. Advanced Management Journal, v. 68, n. 2, p. 15- 22, spring.

PARNELL, J. A.; LESTER, D. L. (2003). Towards a philosophy of strategy: reassessing five critical dilemmas in strategy formulation and change. Strategic Change, v. 12, n. 6, p. 291303 , sep./oct.

PARQTEC (2006). Conheça São Carlos, a capital da tecnologia, 2006. Disponível em $<$ www.parqtec.com.br> Acesso em 02/03/2006.

PATTON, M. (2002). Qualitative research and evaluation methods. Londres, Thousand Oaks : Sage Publications.

PAUlinO, A. D.; BARBIERI, J. C.; ABREU, M. C. A.; FREITAS, J.; MORAIS, M. R. (2001). Organização e estratégia: tendências de estudos no cenário nacional. In: ENCONTRO DA ASSOCIAÇÃO NACIONAL DE PÓS-GRADUAÇÃO E PESQUISA EM ADMINISTRAÇÃ̃O, 25., 2001, Campinas, SP, Anais... Rio de Janeiro: ANPAD /cd rom/ 
PEARCE,, J. A.; FREEMAN, E. B.; ROBINSON, R. B. (1987). The tenuous link between formal strategic planning and financial performance. Academy of Management Review, v. 12 , p. 658-675.

PERUSSI FILHO, S. (2006). Processo de criação de estratégias em pequenas empresas de base tecnológica: proposta de modelo contemplando as fases de desenvolvimento de empresas do setor de fabricação de equipamentos médico-odontológicos. 163p. Tese (Doutorado) - Escola de Engenharia de São Carlos, Universidade de São Paulo, São Carlos. 2006.

PERUSSI FILHO, S.; ESCRIVÃO FILHO, E. (2007). A formação quântica de estratégia em pequenas empresas de base tecnológica: uma proposta inicial. In: ENCONTRO DE ESTUDOS EM ESTRATÉGIA, 3 E's, 3, Anais..., São Paulo/SP, 2007.

PERRY, S. C. (2001). The relationship between written business plans and the failure of small businesses in the U.S. Journal of Small Business Management, v. 39, n. 3, p. 201208.

PINHEIRO, M (1996). Gestão e desempenho das empresas de pequeno porte. Tese (Doutorado). São Paulo: Faculdade de Economia, Administração e Contabilidade da Universidade de São Paulo - FEA/USP.

PINHO, M. (coord.); FERNANES, A. C.; CÔRTES, M. R.; PEREIRA, R. C.; SMOLKA, R. B.; CALligARIS, A. B.; DEUS, A. S.; BARRETO, A. L. C. M. (2005). Empresa de Base Tecnológica. Universidade Federal de São Carlos, São Carlos, 2005. /relatório de pesquisa/

PINHO, M., CÔRTES, M. R.; FERNANDES, A. C. (2002) A fragilidade das empresas de base tecnológica em economias periféricas: um interpretação baseada na experiência brasileira. Ensaios FEE. Porto Alegre, v. 23, n. 1, p.135-162.

PITCHER, P. (1993). Balancing personality types at the top. Business Quarterly, v. 58, p. 46-50, winter. 30-33, july.

(1999). Artists, craftsmen \& technocrats. Training \& Development, v. 53, v. 7, p.

PORTER, M. E. (1985). Competitive advantage: creating and sustaining superior performance. New York: Free Press.

(1991). Estratégia competitiva: técnicas para análise de indústrias e das concorrência. 7. ed. Rio de Janeiro: Campus.

(1996). What is strategy? Harvard Business Review, p. 61-78, nov-dec. (1997). Os caminhos da lucratividade. HSM Management, v. 1, n. 1, mar/abr.

POWEL, T. C. (1982). Strategic planning as competitive advantage. Strategic Management Journal, v. 13, n. 7, p. 551-558, oct. 
PRADO JÚNIOR, S. T. (2003). Estratégias emergentes: uma proposta de síntese conceitual. In: ENCONTRO DE ESTUDOS EM ESTRATÉGIA, 1, 2003, Curitiba/PR, Anais... Rio de Janeiro: Anpad.

PRAHALAD, C. K.; HAMEL, G. (1990). The core competente of the corporation. Harvard Business Review, v. 63, n.3, p. 79-91, may-jun.

QIAN, G.; LI, L. (2003). Profitability on small-and medium-sized enterprises in high-tech industries: the case of the biotechnology industry. Strategic Management Journal, v. 24, n. 9, p. 881-887, sep.

QUEZADA, L. E.; CÓRDOVA, F. M.; WIDER, S.; O’BRIEN, P. (1999). A methodology for formulating a business strategy in manufacturing firms. International Journal of Production Economics. v. 60-61, p. 87-94, abr.

QUINN, J. B. (1978). Strategic change: "logical incrementalim", Sloan Management Review, v. 20, n. 1, p. 7-21, fall.

. (1980). Strategies for change: logical incrementalism. Homewood, Irwin.

. (1989). Strategic change: "logical incrementalim", Sloan Management Review SMR Classic Reprint, v. 30, n. 4, p. 45-60, summer /retrospective commentary/ n. 4, summer.

(2002). Strategy, science and management. MIT Sloan Management Review, v. 43, . (2006). Estratégias para mudança. In: MINTZBERG, H.; LAMPEL, J.; QUINN, J. B.; GOSHAL, S. O processo da estratégia: conceitos, contextos e casos. Porto Alegre: Bookman.

QUINN, R. E.; CAMERON, K. (1983). Organizational life cycles and shifiting criteria of effectiveness: some preliminary evidence. Management Science, v. 29, n. 1, p. 33-51.

RAMOS, S. C.; GIMENEZ, F. A.; FERREIRA, J. M. (2005). Cognição, instituições e a estratégia em pequenas empresas. In: ENCONTRO DA ASSOCIAÇÃ̃O NACIONAL DE PÓS-GRADUAÇÃO E PESQUISA EM ADMINISTRAÇÃO, 29, 2005, BRASÍLIA, DF, Anais... Rio de Janeiro: Anpad, 2005.

REGNÉR, P. (2003). Strategy creation in the periphery: inductive versus deductive strategy making. Journal of Management Studies. v. 40, n. 1, p. 57-82, jan.

RICHERS, R. (1988). O planejamento estratégico no contexto brasileiro. Relatório da Estratégia Empresarial, Divisão de Consultoria Estratégica e Organizacional, Price Waterhouse.

RIEG, D. C. (2004) Estratégia tecnológica e desempenho inovador. Tese (Doutorado) Departamento de Engenharia de Produção, Universidade Federal de São Carlos, 2004.

ROBINSON, JR. R. B.; PEARCE II, J. A. (1984). The impact of formalized strategic planning on financial performance in small organizations. Strategic Management Journal, v. 4, n. 3, p. 197-207, jul./sep. 
RODRIGUES, L. C.; RISCAROLLI, V.; ALMEIDA, M. I. R. (2004). Maturação Tecnológica e Estratégia de Inovação. In: SIMPÓSIO DE GESTÃO DA INOVAÇÃ̃O TECNOLÓGICA, 23, 2004, Curitiba, Anais..., Curitiba, v. 1, p. 2270-2286.

SANTOS, A. R. (2000). Metodologia científica a construção do conhecimento. Rio de Janeiro: DP\&A.

SCHEIN, E. H. (1982). Psicologia organizacional. Rio de Janeiro: Prentice-Hall.

SCHUMPETER, J. A. (1954) Capitalism Socialism and Democracy. New York, Harper \& Row.

SEBRAE (2001) MPEs de base tecnológica: conceituação, formas de financiamento e análise de casos brasileiros, 2001. /relatório de pesquisa/

(2004a). Fatores condicionantes e a taxa de mortalidade de empresa no Brasil, 2004. /relatório de pesquisa/

(2004b). Legislação básica da micro e pequena empresa. Disponível em: $<$ http://www.sebrae.com.br/br/aprendasebrae/mpeemnumeros.asp >. Acesso em: 17/09/2005.

(2005). Sobrevivência e mortalidade das empresas paulistas de 1 a 5 anos. /relatório de pesquisa/ Disponível em <www.sebraesp.com.br> Acesso em 14/02/2006.

(2006). Indicadores Sebrae-SP: pesquisa de conjuntura, 2006. Disponível em $<$ www.sebraesp.com.br $>$ Acesso em 23/02/06.

SEGENBERGER, W.; LOVERMAN, G. W.; PIORE, M. J. The reemergence of small enterprises: industrial restructuring in industrialized countries. Genebra, International Labour Organization, 1991.

SEGEV, E. (1987). Strategy, strategy making and performance an empirical investigation. Management Science, v. 33, n. 2, p. 258-269, feb.

SHRADER, C. B.; MULFORD, C. L.; BLACKBURN, V. L. (1989). Strategic and operational planning, uncertainty, and performance in small firms. Journal of Small Business Mangement, v. 27, n. 4, oct., p. 45-60.

SHUMAN, J. C.; SEEGER, J. A. (1986). The theory and practice of strategic management in smaller rapid growth firms. American Journal of Small Business. summer

SILVA, E. L.; MENEZES, E. M. (2005). Metodologia da pesquisa e elaboração de dissertação. 4. ed. Florianópolis: UFSC.

SILVA, S. J. T. (2005). Planejamento estratégico e operacional na pequena empresa: um estudo sobre sua influência no desempenho dos empreendimentos de base tecnológica industrial e de serviços de São Carlos/SP. Projeto (Iniciação Científica) - Escola de Engenharia de São Carlos, Universidade de São Paulo.

SILVEIRA, M. A. (2003). Método para avaliação de estratégias organizacionais: aplicação ao estudo comparativo de estratégias em indústrias In: ENCONTRO DE ESTUDOS EM ESTRATÉGIA, 1, 2003, Curitiba/PR, Anais... Rio de Janeiro: Anpad. 
SMITH, J. A. (1998). Strategies for start-ups. Long Range Planning, v.31, n.6, p.857-872, Dec.

SMITH, N. R.; MINER, J. B. (1983). Type of entrepreneur, type of firm, and managerial motivation: implications for organizational life cycle theory. Strategic Management Journal, v. 4, n. 4, oct./dec., p. 325-340.

SNOW, C. C.; HAMBRICK, D. C. (1980). Measuring organizational strategies: some theoretical and methodological problems. Academy of Management Review, v. 5, n. 4, p. 527-538, oct.

SOLOMON, S. (1986). A grande importância da pequena empresa: a pequena empresa nos Estados Unidos no Brasil e no mundo. Rio de Janeiro: Nórdica.

SOUZA, M. C. A. F. (1995). Pequenas e médias empresas na reestruturação industrial. Brasília: Sebrae.

TAVARES, M. C.; AMARAL. L. A. S.; GONÇALVES, C. A. (2003). Construção do conhecimento em estratégia e competitividade: uma síntese. In: ENCONTRO DE ESTUDOS EM ESTRATÉGIA, 1, 2003, Curitiba/PR, Anais... Rio de Janeiro: Anpad.

TEIXEIRA, H. J. (1981). O trabalho de dirigentes de pequenas e médias empresas. Revista de Administração, São Paulo, v.16, n.3, p76-94, jul/set.

(1982). Comparação entre o trabalho de dirigentes de pequenas e médias empresas e o trabalho de dirigentes de grandes empresas a través da observação estuturada. Revista de Administração de Empresas, Rio de Janeiro, v. 22, n. 1, p. 48-51, jan./mar.

TERENCE, A. C. F. (2002). Planejamento estratégico na pequena empresa como ferramenta de competitividade: desenvolvimento e avaliação de um roteiro prático para o processo de elaboração do planejamento. Dissertação (Mestrado). Escola de Engenharia de São Carlos, Universidade de São Paulo, São Carlos.

TERENCE, A. C. F.; BENZE, R.; ESCRIVÃO FILHO, E. (2004). A influência das características estruturais na gestão estratégica da pequena empresa. In: ASAMBLEA ANUAL DEL CONSEJO LATINOAMERICANO DE ESCUELAS DE ADMINISTRACIÓN - CLADEA, 39, 2004, Puerto Plata. Anais... Puerto Plata, República Dominicana: Pontifícia Universidad Católica Madre y Maestra, 20-24 octubre 2004, 1 CDROM.

TERENCE, A. C. F.; ESCRIVÃO FILHO, E. (2001). Planejamento estratégico na pequena empresa: as particularidades das pequenas empresas no processo estratégico. In: ENCONTRO NACIONAL DE ENGENHARIA DE PRODUÇÃO, 21, 2001, Salvador/BA, Anais... Rio de Janeiro: ABEPRO, FTC, UFRGS, UFSC, 17 a 19 de outubro/2001. CD-ROM. 8p.

THONG, J.Y.L. (2001). Resource constraints and infomation systems implementation in Syngapoean small businesses. Omega, v, 29, p.143-156.

TIDD, J. B. J.; PAVITT, K.; BESSANT, J. R. (2001). Managing innovation: integrating technological, market and organisational Change. London: Wiley. 
VAN CAUWENBERGH; COOL, K. (1982). Strategic management in a new framework. Strategic Management Journal, v. 3, p. 245-265.

VAN HOORN, T. P. (1979). Strategic planning in small and medium-sized companies. Long Range Planning,v.12, n.2, p.84-91.

VASCONCELOS, F. (2001). Safári de estratégia, questões bizantinas e a síndrome do ornitorrinco: uma análise empírica dos impactos da diversidade teórica em estratégia empresarial sobre a prática dos processos de tomada de decisão estratégica. In: ENCONTRO DA ASSOCIAÇÃO NACIONAL DE PÓS-GRADUAÇÃO E PESQUISA EM ADMINISTRAÇÃ̃O, 25, 2001, Campinas/SP, Anais..., Rio de Janeiro: Anpad, 2001. /cd rom/

VASCONCELOS, F. C.; CYRINO, A. B. (2000). Vantagem competitiva: os modelos teóricos atuais e a convergência entre a estratégia e a teoria organizacional. Revista de Administração de Empresas, Rio de Janeiro, v. 40, n. 4, p. 20-37, out./dez.

VENKATRAMAN, N.; RAMANUJAM, V. (1986). Measuring of business performance in strategy research: a comparison approaches. Academy of Management Review, v. 11, n.4, p. 801-814.

VERGARA, S. C. (2005). Métodos de pesquisa em administração. São Paulo: Atlas.

WELSH, J. A.; WHITE, J. F. (1981). A small business is not a big business. Harvard Business Review, p. 18-32, jul/aug.

WHEELEN, T. L.; HUNGER, J. H. (1993). Strategic issues in entrepreneurial ventures and small business. In: WHEELEN, T. L.; HUNGER, J. H. Cases in strategic management. Reading, Mass: Addison Wesley.

WOOD JR., Thomaz (2001). Organizações cinematográficas. 264p. Tese (Doutorado) Escola de Administração de Empresas de São Paulo, Fundação Getúlio Vargas, São Paulo.

WOODS, A; JOYCE, P. (2003). Owner-managers and the practice of strategic management. International Small Business Journal, v.21, n.2, p.181-195.

YIN, R. K (2001). Estudo de caso: planejamento e métodos. 3. ed. Porto Alegre: Bookman.

ZANNI, P. P. (2003). A historical perspective of the concept of emergent strategy. Iberoamerican Academy of management, 3, 2003, Anais... São Paulo. Iberoamerican Academy of Management, 2003.

ZILBER, M. A.; FISCHMANN, A. A. (2002). Competitividade e a importância de indicadores de desempenho: utilização de um modelo de tendência. In: ENCONTRO DA ASSOCIAÇÃO NACIONAL DE PÓS-GRADUAÇÃO E PESQUISA EM ADMINISTRAÇÃO, 26, 2002, Salvador, BA, Anais..., Rio de Janeiro: Anpad, 2002. /cd rom/ 


\section{APÊNDICE A}

\section{PROTOCOLO DO TRABALHO DE CAMPO: FASE 1 E FASE 2}

Objetivo identificar as características gerais do processo de criação de estratégias e as especificidades do dirigente, do contexto e da organização a pequena empresa de base tecnológica

\begin{tabular}{|c|c|c|c|c|c|c|}
\hline Fases & $\begin{array}{c}\text { Unidade de } \\
\text { Análise }\end{array}$ & $\begin{array}{c}\text { Objetivos } \\
\text { específicos }\end{array}$ & Coleta de Dados & $\begin{array}{c}\text { Técnica de Análise } \\
\text { dos Dados }\end{array}$ & Respondentes & $\begin{array}{c}\text { Esforço empreendido e } \\
\text { resultados }\end{array}$ \\
\hline $\begin{array}{l}\text { Fase } 1 \\
\text { (quantitativa) }\end{array}$ & $\begin{array}{l}\text { Grupo e empresas } \\
\text { industriais de base } \\
\text { tecnológica }\end{array}$ & $\begin{array}{l}\text { Identificar o processo } \\
\text { de criação de } \\
\text { estratégias no grupo } \\
\text { de pequenas } \\
\text { empresas de base } \\
\text { tecnológica }\end{array}$ & $\begin{array}{c}\text { Aplicação de } \\
\text { questionário } \\
\text { estruturado em } \\
\text { blocos temáticos }\end{array}$ & $\begin{array}{c}\text { Parte 1 } \\
\text { Análise descritiva } \\
\text { dos conteúdos } \\
\text { (análise das variáveis } \\
\text { isoladas) } \\
\\
\text { Parte 2 } \\
\text { Análise dos } \\
\text { Componentes } \\
\text { Principais } \\
\text { (visão geral do } \\
\text { grupo) }\end{array}$ & Dirigentes & $\begin{array}{l}\text { Coleta de dados realizada em } \\
6 \text { meses } \\
\text { Identificação de } 99 \text { empresas } \\
\text { Estabelecimento de contato } \\
\text { com } 79 \text { empresas } \\
\text { Identificação de } 67 \text { pequenas } \\
\text { empresas de base tecnológica } \\
\text { Coleta de dados em } 33 \\
\text { empresas }\end{array}$ \\
\hline $\begin{array}{l}\text { Fase } 2 \\
\text { (qualitativa) }\end{array}$ & $\begin{array}{l}\text { Duas empresas } \\
\text { industriais de base } \\
\text { tecnológica de } \\
\text { pequeno porte }\end{array}$ & $\begin{array}{l}\text { Identificar as } \\
\text { especificidades do o } \\
\text { dirigente, do contexto } \\
\text { e da organização das } \\
\text { EBT }\end{array}$ & $\begin{array}{c}\text { Realização de } \\
\text { entrevistas e } \\
\text { observação }\end{array}$ & $\begin{array}{l}\text { Análise de conteúdo } \\
\text { categorial }\end{array}$ & $\begin{array}{l}\text { Dirigentes } \\
\text { (especificidades de } \\
\text { gestão e evolução da } \\
\text { empresa) }\end{array}$ & $\begin{array}{l}\text { Coleta de dados realizada em } \\
4 \text { meses } \\
\text { Realização de } 8 \text { entrevistas, } \\
\text { com duração média de } 3 \\
\text { horas }\end{array}$ \\
\hline
\end{tabular}




\section{APÊNDICE B}

\section{PARTE A - DADOS GERAIS E CARACTERIZAÇÃO DA EMPRESA DE BASE TECNOLÓGICA}

1. Nome da empresa:

2. Ano de fundação:

3. Ramo de atividade:

$\square$ informática/software $\square$ eletrônica/telecomunicações $\square$ mecânica de precisão/automação

$\square$ química fina $\square$ biotecnologia $\square$ novos materiais

$\square$ outro. Especificar:

4. Número de sócios $\square 1 \square 2 \square 3 \square 4 \square 5 \square 6$ ou +

5. Especificar a escolaridade dos sócios da empresa:
Sócio Escolaridade
4 especificar
5 especificar
6 especificar
Sócio Escolaridade
1 especificar
2 especificar
3 especificar

6. Indique o faturamento da empresa no ano de 2006:
$\square$ até RS 240 mil
de $\mathrm{R} \$ 241$ mil a $\mathrm{R} \$ 2.400$ milhões
acima de $\mathrm{R} \$ 2.400$ milhões

7. Indique o número de funcionários da empresa

Total

Alocados em Pesquisa e Desenvolvimento (P\&D)

Autônomos (bolsistas ou profissionais liberais alocados em projetos)

$\%$ de funcionários com formação superior

8. A empresa possui departamento de P\&D?

$\square$ não $\square$ sim.

Se sim, qual é o estágio de desenvolvimento?

$\square$ em fase de estruturação $\square$ semi-estruturado $\square$ estruturado

9. Qual é o investimento anual realizado em P\&D ( $\%$ do faturamento)?
$\square 1 \%$
$\% \square 2 \%$
$3 \%$
$4 \%$
$\square$ 5\% $\square+5 \%$ Especificar
$\%$

10. A empresa foi criada

$\square$ a partir de uma empresa e de uma tecnologia já existente

$\square$ a partir de um estímulo ou da ação de uma empresa, com o intuito de desenvolver um novo fornecedor ou criar uma nova empresa sob seu controle acionário e estrutura

$\square$ a partir de grupos de pesquisa e conhecimentos gerados de universidades ou instituições de pesquisa $\square$ outra forma. Especificar

11. Indique as características a seguir de acordo com a situação da sua empresa

1 muito baixa 2 baixa 3 média 4 alta 5 muito alta NI não identificada 
$\square$ fabrica produtos ou serviços que demandam alto recurso tecnológico

$\square$ possui tecnologia única

utiliza de tecnologia desenvolvida por centros de pesquisa ou universidade

$\square$ a inovação é um diferencial da empresa

$\square$ aprimora constantemente os processos de produção

$\square$ realiza alianças para desenvolver novos produtos ou processos ou incrementar os atuais

As alianças são realizadas com:

$\square$ universidades ou centros de pesquisa

$\square$ fornecedores

$\square$ clientes

$\square$ outras empresas

\section{PARTE B - PROCESSO DE CRIAÇÃO DE ESTRATÉGIAS}

Assinale (x) o ponto que melhor descreve as características da organização quanto ao processo de criação de estratégia.

1. A orientação principal (direcionamento) da organização é criada com base:

\begin{tabular}{|c|c|c|}
\hline Razão & $\square \square \square \square \square \square \square$ & Intuição \\
\hline Experiência & $\square \square \square \square \square \square \square$ & Informação \\
\hline Análise de informações & $\square \square \square \square \square \square \square$ & Utilização da criatividade \\
\hline Antecipação dos acontecimentos & $\square \square \square \square \square \square \square$ & Ocorrências do dia-a-dia \\
\hline $\begin{array}{r}\text { Definida e alterada de acordo com } \\
\text { acontecimentos cotidianos }\end{array}$ & $\square \square \square \square \square \square \square$ & Definida de acordo com o cronograma \\
\hline $\begin{array}{r}\text { Interação entre a alta direção e níveis } \\
\text { inferiores }\end{array}$ & $\square \square \square \square \square \square \square$ & Decisões da alta direção \\
\hline Objetivos claramente definidos e detalhados & $\square \square \square \square \square \square \square$ & Definição de objetivos gerais \\
\hline
\end{tabular}

2. Pode-se dizer que o processo de definição da orientação principal (direcionamento) quanto ao futuro da organização é:

Processo regular $\square \square \square \square \square \square \square \quad$ Processo irregular

Realizado em etapas $\square \square \square \square \square \square \square \quad$ Não segue etapas previstas

Baseado em ações inesperadas $\square \square \square \square \square \square \square \quad$ Baseado em ações previstas

Formal $\square \square \square \square \square \square \square \quad$ Informal

Flexível $\square \square \square \square \square \square \square \quad$ Rígido

3. A empresa realiza um processo de planejamento formal?

$\square \operatorname{sim} \square$ não

3. 1. Se sim, indique o grau de concordância com os tipos de planejamento apresentados abaixo: Realiza o planejamento de longo prazo (estratégico). O planejamento é realizado a partir da identificação de oportunidades e ameaças de negócio, definição de objetivos e projetos (período médio de 3 anos), análise dos fatores externos (concorrentes, clientes, tecnologia, economia etc).

$\square$ concordo totalmente $\square$ concordo $\square$ neutro $\square$ discordo $\square$ discordo totalmente

Realiza o planejamento de curto prazo (operacional). O planejamento apresenta um plano de ação (anual, mensal ou semanal) voltado a ações específicas de produção, finanças, mercadologia entre outras.

concordo totalmente $\square$ concordo $\square$ neutro $\square$ discordo $\square$ discordo totalmente

3.2. Se não, indique o grau de concordância com as afirmações abaixo. 
É desenvolvido com base na intuição e experiência do dirigente. Não é escrito, encontra-se na mente dos dirigentes e é de curto prazo. Está relacionado às condições atuais da empresa e do seu ambiente e aos objetivos dos seus dirigentes.

$\square$ concordo totalmente $\square$ concordo $\square$ neutro $\square$ discordo $\square$ discordo totalmente

Não há planejamento mensurável na empresa.

$\square$ concordo totalmente $\square$ concordo $\square$ neutro $\square$ discordo $\square$ discordo totalmente

\section{PARTE C - ESPECIFICIDADES DE GESTÃO E MEDIDAS DE DESEMPENHO}

\begin{tabular}{|c|c|c|}
\hline Muito segmentado & $\square \square \square \square \square \square \square$ & Pouco segmentado \\
\hline $\begin{array}{r}\text { Clientes com características } \\
\text { semelhantes }(*)\end{array}$ & $\square \square \square \square \square \square \square$ & Clientes com características diversas $(*)$ \\
\hline $\begin{array}{r}\text { Concorrentes com características } \\
\text { semelhantes }(*)\end{array}$ & $\square \square \square \square \square \square \square$ & Concorrentes com características diversas $(*)$ \\
\hline Com mudanças rápidas e imprevisíveis & $\square \square \square \square \square \square \square$ & Com mudanças lentas e previsíveis \\
\hline Estável & $\square \square \square \square \square \square \square$ & Dinâmico \\
\hline Muitas oportunidades & $\square \square \square \square \square \square \square$ & Poucas oportunidades \\
\hline
\end{tabular}

(*) Porte, tecnologia, perfil etc.

2. Assinale (x) o ponto que melhor caracterize a sua organização.

Rígida com ampla divisão do trabalho

Os cargos são ocupados por especialistas

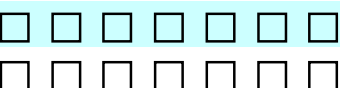

Flexível com pouca divisão do trabalho

Os cargos são continuamente redefinidos por meio da interação com outras pessoas que participam da tarefa

As decisões são descentralizadas e delegadas a níveis inferiores

Ênfase nas regras e procedimentos formais

Apresenta tarefas variadas, não rotineiras e flexíveis

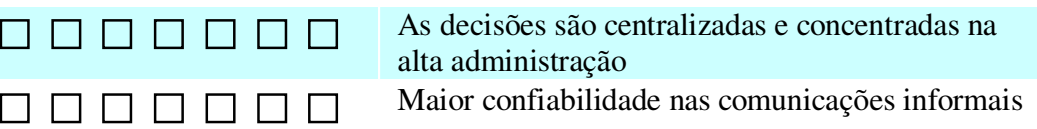
alta administração

Maior confiabilidade nas comunicações informais

Apresenta tarefas rotineiras e rigidamente estabelecidas

3. Indique o nível de influência que as variáveis abaixo exercem na definição do direcionamento futuro da empresa (orientação e tomada de decisão de ações futuras).

1 muito baixa 2 baixa 3 média 4 alta 5 muito alta NI não identificada

$\square$ Desenvolvimento tecnológico

Condições políticas

Condições econômicas

Condições do meio-ambiente

Condições sócio-culturais da população

Ações dos concorrentes

Características dos fornecedores

Características dos clientes

Atuação de órgãos reguladores

4. As características abaixo descrevem a personalidade e a postura do dirigente estrategista (pessoa responsável por definir a orientação principal quanto ao futuro da organização). Indique o grau de precisão que estas características se aplicam ao dirigente. Quanto mais precisa for a característica, mais alto o número a ser escolhido.

1 não identificada 2 baixa 3 média 4 alta 5 muito alta 


\begin{tabular}{|c|c|c|}
\hline Emotivo & Estável & Determinado \\
\hline Imaginativo & Previsível & Eficiente \\
\hline Visionário & Equilibrado & Cerebral (racional) \\
\hline Empreendedor & Realista & Exigente \\
\hline Intuitivo & Justo & Detalhista \\
\hline Engraçado & Sensível & Descomprometido \\
\hline Inspirador & Confiável & Intenso \\
\hline
\end{tabular}

5. Indique o \% de oscilação (positivo ou negativo) das taxas de crescimento em vendas nos últimos 3 anos:

2006 em relação a $2005 \quad \%$

2005 em relação a $2004 \quad \%$

2004 em relação a $2003 \quad \%$

6. Indique o número de lançamento de novos produtos ou aperfeiçoamento dos atuais nos últimos três anos:

$$
\square 1 \square 2 \square 3 \square 4 \square 5 \square 6 \text { ou +. Especificar }
$$

Obrigado pela colaboração.

\section{GEOPE}

EESC/USP 


\section{APÊNDICE C}

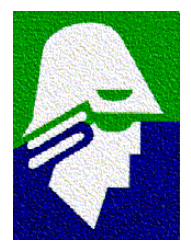

\section{UNIVERSIDADE DE SÃO PAULO ESCOLA DE ENGENHARIA DE SÃO CARLOS DEPARTAMENTO DE ENGENHARIA DE PRODUÇÃO}

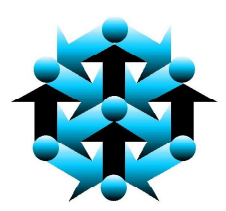

São Carlos, 28 de março de 2007

Prezado(a) Senhor(a),

Estamos realizando uma pesquisa com o objetivo de caracterizar o processo estratégico nas empresas industriais de base tecnológica situadas no pólo de São Carlos-SP. Para atingirmos nosso objetivo estaremos enviando nos próximos dias, por e-mail, um questionário para coleta dos dados necessários.

O preenchimento do questionário é rápido e solicitamos que seja respondido pelo dirigente responsável por tomar decisões sobre os futuros direcionamentos da empresa, ressaltando que a sua participação é fundamental para o sucesso da pesquisa.

Não é solicitada informação sigilosa, ainda assim garantimos que a tabulação dos dados será feita por meio de uma análise quantitativa, de sorte que, para sua apresentação e análise, serão agrupados, nunca utilizados isoladamente. Portanto, as informações fornecidas serão tratadas com o sigilo necessário e utilizadas de maneira agregada, pois temos o intuito de compreender o processo estratégico no segmento como um todo.

Por fim, assumimos o compromisso de lhes enviar um relatório com os resultados e de fazer uma apresentação oral das atividades desenvolvidas, oportunamente, na Escola de Engenharia de São Carlos-USP.

Certos de que em breve estaremos juntos para discutirmos os resultados de nossa pesquisa, aproveitamos o ensejo para antecipar os agradecimentos por sua valiosa colaboração.

Edmundo Escrivão Filho Professor Associado do Departamento de Engenharia de Produção - EESC/USP

Ana Cláudia Fernandes Terence Professora do Departamento de Economia Rural - UNESP

Stéfano Junqueira Silva Graduando em Engenharia de Produção - Bolsista FAPESP - EESC-USP 


\section{APÊNDICE D}

Caro(a) Dirigente,

Conforme correspondência enviada, convido-o(a) a acessar a nossa página do Grupo de Pesquisa (www.prod.eesc.usp.br/geope), para participar da caracterização do processo estratégico nas empresas industriais de base tecnológica de São Carlos-SP. Para tanto, basta clicar no endereço abaixo e inserir o seguinte usuário e senha:

\section{http://www.prod.eesc.usp.br/geope/questionario/questionario.php}

\section{Usuário: empresa}

Senha: geope07

O questionário deve ser respondido pelo dirigente responsável pela definição do direcionamento futuro da empresa. O tempo estimado para responder todo o questionário é de aproximadamente 10 minutos.

Ressalto que as informações fornecidas serão tratadas com o sigilo necessário e utilizadas de maneira agregada, pois o objetivo é compreender o processo estratégico no segmento como um todo.

Assim que finalizar as análises dos dados, entrarei em contato para o envio do relatório e o agendamento da apresentação e discussão dos resultados com os participantes.

Coloco-me à disposição para esclarecer eventuais dúvidas. Grata pela colaboração e atenção.

Até breve.

Ana Cláudia 


\section{APÊNDICE E}

\section{DADOS GERAIS E CARACTERIZAÇÃO DA EMPRESA}

Nome da empresa:

entrevistado:

Ano de fundação

Ramo de atividade:

Área fabril (m2):

Proprietários $\left(\mathrm{n}^{0}\right)$ Participação (\%)

Faturamento da empresa no ano de 2006 e 2007

Número de funcionários da empresa

$\%$ administração

$\% \mathrm{P} \& \mathrm{D}$

\% produção

\section{Histórico da empresa}

Como a empresa foi concebida? Qual foi o objetivo?

Hoje, como a empresa está? O enfoque mudou?

Houve algum processo sucessório na empresa?

\section{Organização da empresa}

Como a empresa está organizada? Estrutura - organograma

Como se dá a comunicação, de maneira formal ou informal? Como é realizada a divisão de tarefas?

\section{Produtos}

Quais são os produtos fabricados pela empresa?

Os produtos são produzidos sob encomenda ou em linha para estoque?

Qual o tipo de organização do trabalho?

\section{Posição da empresa na cadeia produtiva:}

Quais são seus fornecedores? Onde estão localizados? Qual é o porte destes?

Quais são seus clientes? Onde estão localizados? Qual é o porte dos principais clientes?

A carteira de clientes é diversificada ou concentrada? (clientes $\mathrm{x}$ faturamento)

\section{Mercado de atuação:}

Qual é o nível de competição do mercado de atuação?

Quais são seus principais competidores? Onde estão localizados? Qual é o porte destes competidores?

Qual é a posição da empresa no mercado em que atua (market-share)?

Qual é a atuação da empresa com relação ao mercado geográfico? (local, regional, nacional ou internacional) 
PROCESSO DE CRIAÇÃO DE ESTRATÉGIAS

\section{Contexto}

Como é realizada análise do ambiente? Como são coletadas as informações do ambiente da empresa?

São realizadas análises para identificar possíveis oportunidades e/ou ameaças futuras de negócio

A falta de tempo e recurso limita a análise do ambiente? De que maneira?

Como é realizado o monitoramento da concorrência?

As informações do ambiente são obtidas casualmente? São obtidas por meio de um sistema de informações?

As oportunidades exploradas pela empresa surgem a partir de pesquisas internas e/ou a partir de contato com fornecedores e/ou clientes e/ou a partir de ações desenvolvidas pelos concorrentes?

Como são definidas as ações futuras da empresa? Como são definidos os novos investimentos?

A empresa preocupa-se em identificar antecipadamente o desenvolvimento de novas tecnologias e/ou de produtos substitutos?

Como você percebe a influência das forças econômicas, sociais, legais, políticas, ecológicas e tecnológicas sobre o desempenho da empresa? Como essa influência se manifesta?

Como você percebe a influência das forças econômicas, sociais, legais, políticas, ecológicas e tecnológicas sobre o desempenho da empresa? Como essa influência se manifesta? Quais características do ambiente influenciam a criação da estratégia?

\section{Organização}

Como é realizada a análise das condições internas de gestão? Como são coletadas as informações internas da empresa? São realizadas análises para identificar as dificuldades de gestão e/ou diferenciais da empresa (identificação dos pontos fracos e fortes)

As condições internas influenciam a não realização de estratégias definidas?

Como são tomadas as ações? São tomadas com base em acontecimentos inesperados ou cotidianos?

Algumas ações derivam da interação social (dirigente x empregados x membros do ambiente)?

Quem lidera as decisões estratégicas? Como é o processo de tomada de decisão estratégica? As estratégias são criadas_pelos dirigentes ou tem contribuição e participação de outros membros (níveis inferiores)? 
Quais características da organização influenciam a criação da estratégia?

\section{Dirigente}

Quais características do ambiente influenciam a criação de estratégia

As decisões são tomadas de maneira coletiva? Quais são os mecanismos de envolvimento dos funcionários utilizados?

O dirigente é o responsável por delinear estratégias intencionadas?

A criação de estratégia depende da dedicação e participação direta dos dirigentes principais?

As atitudes e iniciativas dos funcionários de níveis inferiores são incentivadas e recompensadas? Os funcionários de níveis inferiores participam do processo de formação de estratégia?

Você considera que as estratégias são baseadas em sua percepção quanto a condições internas e externas?

As estratégias surgem por meio de um processo de suposição, análise e ação, sem a realização de análises extensas?

As decisões estratégicas são realizadas de maneira incremental sem uma análise detalhada das condições ambientais? 


\section{APÊNDICE F}

A ACP foi processada inicialmente com as variáveis do contexto, da organização, do dirigente e do processo estratégico para as 33 empresas (quadro 33), originando um conjunto de menor dimensão contendo aquelas variáveis consideradas mais importantes em cada categoria (correlação superior a 0,7 ou -0,7). A partir desse conjunto a ACP foi processada novamente, o que permitiu caracterizar e discriminar as variáveis em cada categoria.

\begin{tabular}{|c|c|c|c|c|c|c|c|c|c|c|}
\hline \multicolumn{5}{|c|}{ Contexto } & \multicolumn{6}{|c|}{ Organização } \\
\hline & CP1 & \begin{tabular}{|l|} 
CP2 \\
\end{tabular} & CP3 & CP4 & & CP1 & $\begin{array}{l}\mathbf{C P 2} 2 \\
\end{array}$ & CP3 & CP4 & \\
\hline \begin{tabular}{l|l|l}
$\mathbf{A 1}$ & -0 \\
\end{tabular} & $-0,6734$ & $-0,3287[$ & 0,3922 & 0,1750 & $\mathbf{0 1}$ & $-0,7256$ & 0,2699 & 0,1212 & 0,4911 & \\
\hline \begin{tabular}{l|l|l} 
A2 & -0 \\
\end{tabular} & $-0,6141]$ & 0,4352 & $-0,2522$ & 0,4708 & O2 & $-0,4140$ & \begin{tabular}{|l|}
0,6383 \\
\end{tabular} & 0,5129 & $-0,2994$ & \\
\hline \begin{tabular}{l|l}
$\mathbf{A 3}$ & 0, \\
\end{tabular} & 0,0056 & 0,9181 & 0,1127 & 0,0760 & $\mathbf{0 3}$ & $-0,2835$ & $-0,7238$ & 0,5207 & $-0,261$ & \\
\hline $\begin{array}{lll}\mathbf{A 4} & 0, \\
\end{array}$ & 0,7341 & 0,2397 & 0,1755 & $\mid-0,0306$ & O4 & $-0,6631$ & 0,0690 & $-0,5$ & $445 \quad-0,4$ & \\
\hline \begin{tabular}{l|l}
$\mathbf{A 5}$ & 0, \\
\end{tabular} & ר,4041 & -0,2628 & \begin{tabular}{c|c}
$-0,5894$ & 0,
\end{tabular} & $\overline{\overline{0,5959}}$ & & & & & & \\
\hline $\begin{array}{lll}\mathbf{A 6} & -0 \\
\end{array}$ & \begin{tabular}{l|l}
0,3206 & 0 \\
\end{tabular} & 0,0906 & $-0,6785-0$ & $-0,5871$ & & & & & & \\
\hline & & irigente & & & & & ocesso e & strat & égico & \\
\hline & CP1 & CP2 & CP3 & CP4 & & $\overline{\mathrm{CP1}}$ & $\mathrm{CI}$ & 22 & CP3 & CP4 \\
\hline Dou & $-0,3366$ & 6 & 90,1284 & 0,3160 & $\mathbf{X 1}$ & $-0,7724$ & 0,268 & & $-0,0909$ & 0,2529 \\
\hline Dem & -0,2163 & 3 & \begin{tabular}{l|l|}
8 & 0,5467
\end{tabular} & $\mid-0,3799$ & $\overline{\overline{\mathrm{X2}}}$ & $\mid-0,3977$ & 0,459 & & 0,5761 & -0,0484 \\
\hline "Dim & $-0,2950$ & 0 & \begin{tabular}{|l|l|}
0 & $-0,1834$ \\
\end{tabular} & \begin{tabular}{|l|l|}
0,0127 \\
\end{tabular} & 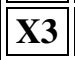 & $-0,6056$ & 0,275 & & $-0,0545$ & $-0,6602$ \\
\hline Dvis & $-0,4086$ & $6-0,7696$ & \begin{tabular}{|l|l|} 
& $-0,0965$ \\
\end{tabular} & 5 & $\overline{\mathrm{X4}}$ & $-0,7189$ & $-0,07$ & & $-0,1109$ & 0,4278 \\
\hline Demp & $-0,4182$ & \begin{tabular}{|l|l}
$-0,3717$ \\
\end{tabular} & \begin{tabular}{|l|l|}
7 & 0,3861 \\
\end{tabular} & 0,1842 & $\overline{\mathrm{X5}}$ & $-0,6507$ & $-0,22$ & & 0,0110 & $-0,0387$ \\
\hline Dint & $-0,2937$ & $7 \longdiv { - 0 , 4 6 7 4 }$ & 勾 0,0907 & $-0,5654$ & $\overline{\overline{X 6}}$ & 0,3520 & $-0,21$ & & 0,8073 & 0,2617 \\
\hline Dres & $-0,4186$ & $6 \longdiv { 0 , 0 0 5 7 }$ & $7-0,3659$ & \begin{tabular}{|l|l|} 
& $-0,4540$ \\
\end{tabular} & $\overline{\mathrm{X} 7}$ & $-0,7817$ & 0,195 & & 0,0908 & $-0,0970$ \\
\hline Dest & $-0,4649$ & \begin{tabular}{|l|l}
$-0,1095$ \\
\end{tabular} & \begin{tabular}{|l|l|}
5 & $-0,5473$ \\
\end{tabular} & \begin{tabular}{|l|l|} 
& $-0,0963$ \\
\end{tabular} & $\overline{\mathrm{X8}}$ & $-0,7855$ & $-0,38$ & & $-0,0970$ & 0,2209 \\
\hline Dpre & $-0,5032$ & $2 \longdiv { 0 , 5 0 2 2 }$ & $\begin{array}{lll} & -0,1875 \\
\end{array}$ & \begin{tabular}{|l|l|}
$-0,2073$ \\
\end{tabular} & $\overline{\mathrm{X9}}$ & $-0,6961$ & $-0,39$ & & $-0,0973$ & 0,0186 \\
\hline Dequi & $\begin{array}{ll}\mathbf{i}-0,2776 \\
\end{array}$ & $6 \longdiv { 0 , 0 1 9 6 }$ & \begin{tabular}{|l|l|} 
& $-0,6031$ \\
\end{tabular} & 10,4579 & $\mathbf{x 1 0}$ & $-0,7154$ & $-0,10$ & & 0,2045 & $-0,0729$ \\
\hline Dreal & \begin{tabular}{|l|l|}
$-0,3980$ \\
\end{tabular} & \begin{tabular}{l|l}
0,4644 \\
0,4
\end{tabular} & \begin{tabular}{l|l|}
7 & 0,0971 \\
\end{tabular} & $-0,2990$ & $\mathbf{x 1 1}$ & $-0,7422$ & $-0,13$ & & 0,2578 & $-0,1744$ \\
\hline Djus & \begin{tabular}{|l|}
$-0,3990$ \\
\end{tabular} & $0 \longdiv { 0 , 3 0 3 7 }$ & $7-0,2040$ & \begin{tabular}{|l|l|}
$-0,3715$ \\
\end{tabular} & $\mathbf{x 1 2}$ & 0,2505 & $-0,70$ & & 0,1356 & $-0,4171$ \\
\hline Dapl & $-0,6772$ & 20,2148 & 0,1393 & 0,2997 & & & & & & \\
\hline Ddet & 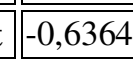 & \begin{tabular}{|l|l}
$-0,5067$ \\
\end{tabular} & \begin{tabular}{|l|l|}
7 & $-0,1163$ \\
\end{tabular} & 0,1317 & & & & & & \\
\hline Defi & $-0,7109$ & $\begin{array}{l}9 \longdiv { 0 , 1 1 7 0 } \\
\end{array}$ & - & $-0,0894$ & & & & & & \\
\hline Drac & $-0,6074$ & $4 \longdiv { 0 , 3 0 7 3 }$ & $3-0,0877$ & 0,1987 & & & & & & \\
\hline Dexi & $-0,6484$ & $4 \longdiv { 0 , 3 4 6 2 }$ & 0,4708 & 0,1153 & & & & & & \\
\hline Ddeta & \begin{tabular}{|l|l|}
$-0,7671$ \\
\end{tabular} & $\begin{array}{l}0,3480 \\
\end{array}$ & 0,2659 & 0,1883 & & & & & & \\
\hline
\end{tabular}

Quadro 33 - Correlação das variáveis X Componentes Principais 
Foram considerados os seis maiores autovalores que conseguiram reter aproximadamente $76 \%$ da variância original (Tabela 14). Os dois primeiros componentes principais originam a maior concentração da variabilidade original quando comparado a quaisquer outros dois componentes $(40,36 \%)$.

Tabela 14 - Autovalores e variância dos componentes principais

\begin{tabular}{ccccc}
\hline Componentes & Autovalores & $\begin{array}{c}\text { \% total de } \\
\text { variância }\end{array}$ & $\begin{array}{c}\text { Autovalores } \\
\text { acumulados }\end{array}$ & $\begin{array}{c}\text { \% } \\
\text { Variância } \\
\text { acumulada }\end{array}$ \\
\hline 1 & 4.150335 & 25.93960 & 4.15034 & 25.9396 \\
2 & 2.306995 & 14.41872 & 6.45733 & 40.3583 \\
3 & 2.015310 & 12.59569 & 8.47264 & 52.9540 \\
4 & 1.485441 & 9.28401 & 9.95808 & 62.2380 \\
5 & 1.223675 & 7.64797 & 11.18176 & 69.8860 \\
6 & 1.035598 & 6.47249 & 12.21736 & 76.3585 \\
\hline
\end{tabular}

A tabela 15 apresenta as correlações entre variável e componente principal destacando aquelas variáveis que mais se correlacionam em cada componente.

Tabela 15 - Matriz dos componentes principais

\begin{tabular}{lcccccc}
\hline & CP1 & CP2 & CP3 & CP4 & CP5 & CP6 \\
\hline $\mathrm{X}_{1}$ & -0.803120 & 0.012997 & 0.295203 & 0.065210 & -0.135456 & 0.114329 \\
$\mathrm{X}_{4}$ & -0.746768 & 0.390574 & 0.345301 & -0.026416 & 0.039143 & 0.027447 \\
$\mathrm{X}_{6}$ & 0.376513 & 0.435327 & -0.269269 & -0.087352 & -0.466794 & -0.096601 \\
$\mathrm{X}_{7}$ & -0.787765 & -0.145414 & -0.115324 & -0.028451 & -0.196610 & 0.053059 \\
$\mathrm{X}_{8}$ & -0.802290 & 0.108920 & -0.101828 & -0.121702 & 0.102431 & 0.209812 \\
$\mathrm{X}_{10}$ & -0.686429 & 0.259335 & -0.121993 & -0.161222 & -0.246019 & -0.240297 \\
$\mathrm{X}_{11}$ & -0.718036 & 0.048524 & -0.398426 & 0.064344 & -0.116179 & -0.209876 \\
$\mathrm{X}_{12}$ & 0.266437 & 0.333284 & -0.579390 & -0.267240 & 0.276845 & 0.233687 \\
$\mathrm{~A}_{3}$ & 0.132044 & -0.184619 & 0.110545 & 0.305687 & -0.531587 & 0.707910 \\
$\mathrm{~A}_{4}$ & 0.288281 & -0.349373 & 0.375521 & 0.599866 & -0.066426 & -0.297673 \\
$\mathrm{O}_{1}$ & -0.141239 & -0.193941 & -0.602615 & 0.345986 & -0.351563 & -0.123198 \\
$\mathrm{O}_{3}$ & $\mathbf{0 . 4 9 2 7 3 7}$ & 0.312398 & -0.409933 & -0.160649 & -0.167243 & 0.041391 \\
$\mathrm{D}_{\text {im }}$ & -0.249494 & -0.751551 & -0.262819 & -0.091383 & 0.363298 & 0.008065 \\
$\mathrm{D}_{\text {vis }}$ & -0.107843 & -0.810869 & -0.385215 & -0.205705 & -0.048461 & 0.188831 \\
$\mathrm{D}_{\text {efi }}$ & 0.169113 & -0.472042 & 0.140036 & -0.538896 & -0.431823 & -0.376193 \\
$\mathrm{D}_{\text {deta }}$ & 0.134765 & -0.120665 & $\mathbf{0 . 5 3 0 9 8 1}$ & -0.644840 & -0.163447 & 0.159139 \\
\hline
\end{tabular}


A seguir estão descritos os seis autovetores ${ }^{15}$ extraídos da matriz de covariância:

$$
\begin{aligned}
& C P 1=-0,39 X_{1}-0,37 X_{4}+0,18 X_{6}-0,39 X_{7}-0,39 X_{8}-0,34 X_{10}-0,35 X_{11}+0,13 X_{12}+0,06 A_{3}+ \\
& 0,14 A_{4}-0,07 O_{1}+0,24 O_{3}-0,12 D_{\text {im }}-0,05 D_{\text {vis }}+0,08 D_{\text {efi }}+0,07 D_{\text {deta }} \\
& \text { CP2 }=0,01 X_{1}+0,26 X_{4}+0,29 X_{6}-0,10 X_{7}+0,07 X_{8}+0,17 X_{10}+0,03 X_{11}+0,22 X_{12}-0,12 A_{3}- \\
& 0,23 A_{4}-0,13 O_{1}+0,21 O_{3}-0,49 D_{\text {im }}-0,53 D_{\text {vis }}-0,31 D_{\text {efi }}-0,08 D_{\text {deta }} \\
& \text { CP3 }=0,21 X_{1}+0,24 X_{4}-0,19 X_{6}-0,08 X_{7}-0,07 X_{8}-0,09 X_{10}-0,28 X_{11}-0,41 X_{12}+0,08 A_{3}+0,26 \\
& A_{4}-0,42 O_{1}-0,29 O_{3}-0,49 D_{\text {im }}-0,27 D_{\text {vis }}+0,10 D_{\text {efi }}+0,37 D_{\text {deta }} \\
& \text { CP4 }=0,05 X_{1}-0,02 X_{4}-0,07 X_{6}-0,02 X_{7}-0,10 X_{8}-0,13 X_{10}+0,05 X_{11}-0,22 X_{12}+0,25 A_{3}+ \\
& 0,49 A_{4}+0,28 O_{1}-0,13 O_{3}-0,07 D_{\text {im }}-0,17 D_{\text {vis }}-0,44 D_{\text {efi }}-0,53 D_{\text {deta }} \\
& \text { CP53=-0,12 } X_{1}+0,04 X_{4}-0,42 X_{6}-0,18 X_{7}+0,09 X_{8}-0,22 X_{10}-0,11 X_{11}+0,25 X_{12}-0,48 A_{3}- \\
& 0,06 A_{4}-0,32 O_{1}-0,15 O_{3}+0,33 D_{\text {im }}-0,04 D_{\text {vis }}-0,39 D_{\text {efi }}-0,15 D_{\text {deta }} \\
& \text { CP6 }=0,11 X_{1}+0,03 X_{4}-0,09 X_{6}+0,05 X_{7}+0,21 X_{8}-0,24 X_{10}-0,21 X_{11}+0,23 X_{12}+0,70 A_{3}- \\
& 0,29 A_{4}-0,12 O_{1}+0,04 O_{3}+0,01 D_{\text {im }}+0,19 D_{\text {vis }}-0,37 D_{\text {efi }}+0,16 D_{\text {deta }}
\end{aligned}
$$

As cargas dos autovetores identificam as variáveis mais importantes em cada componente. Assim, destacam-se: em CP1, $\mathrm{X}_{1}, \mathrm{X}_{4}, \mathrm{X}_{7}, \mathrm{X}_{8}, \mathrm{X}_{10}$ e $\mathrm{X}_{11}$; em CP2 C $\mathrm{im}_{\mathrm{im}}$; $\mathrm{D}_{\text {vis }}, \mathrm{D}_{\text {efi }}$; em CP3, O1, $\mathrm{X}_{12}, \mathrm{D}_{\text {im }}$ e $\mathrm{D}_{\text {deta }}$; em CP4, A4, $\mathrm{D}_{\text {efi }}$ e $\mathrm{D}_{\text {deta }}$; em CP5, $\mathrm{X}_{6}, \mathrm{~A}_{3}$ e $\mathrm{D}_{\text {efi }}$; em CP6, $\mathrm{A}_{3}$ e $\mathrm{D}_{\text {efi. }}$ Os autovetores podem ser utilizados como indicadores da influência e inter-relacção das variáveis no processo de criação de estratégias nas pequenas empresas de base tecnológica investigadas.

\footnotetext{
${ }^{15} \mathrm{O}$ autovetor corresponde ao resultado do carregamento das variáveis originais em cada componente principal. É uma medida da relativa importância de cada variável em relação aos componentes principais e, os respectivos sinais, indicam relações direta ou inversamente proporcionais (LANDIN, 2000).
} 